\title{
ALTERNATIVE REFRIGERANTS AND REFRIGERATION CYCLES FOR DOMESTIC REFRIGERATORS
}

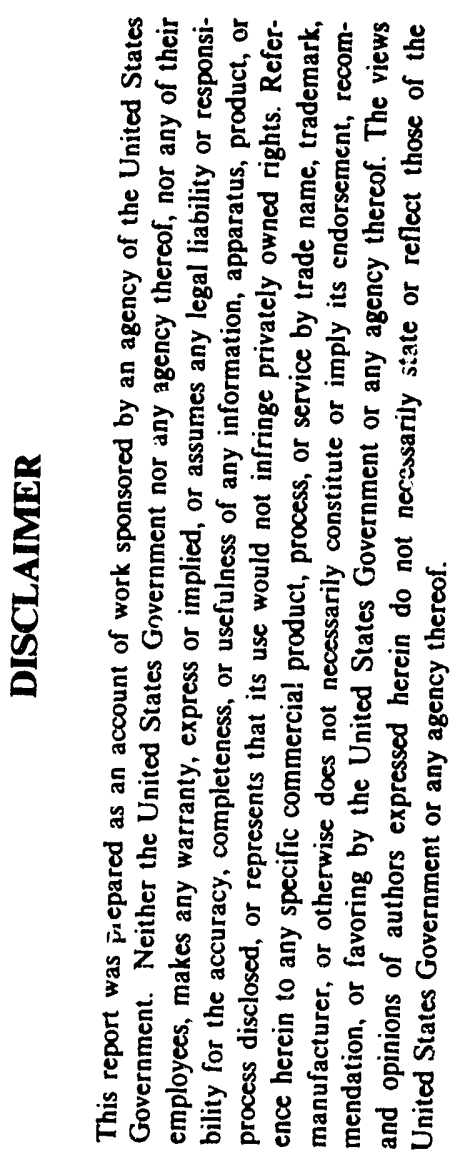

\author{
J. R. Sand \\ C. K. Rice \\ E. A. Vineyard
}

December 1992

Prepared for the U.S.

Environmental Protection Agency and

the U.S. Department of Energy,

Office of Building Technologies

Prepared by the

OAK RIDGE NATIONAL LABORATORY

Oak. Ridge, Tennessee 37831

managed by

MARTIN MARIETTA ENERGY SYSTEMS, INC.

for the

U.S. Department of Energy

under Contract DE-AC05-\$4OR21400 


\section{CONTENTS}

LIST OF FIGURES $\ldots \ldots \ldots \ldots \ldots \ldots \ldots \ldots \ldots \ldots \ldots$

LIST OF TABLES $\ldots \ldots \ldots \ldots \ldots \ldots \ldots \ldots \ldots \ldots \ldots \ldots$

LIST OF ACRONYMS $\ldots \ldots \ldots \ldots \ldots \ldots \ldots \ldots \ldots \ldots \ldots$

EXECUTIVE SUMMARY $\ldots \ldots \ldots \ldots \ldots \ldots \ldots \ldots \ldots \ldots \ldots \ldots$

ACKNOWLEDGMENTS $\ldots \ldots \ldots \ldots \ldots \ldots \ldots \ldots \ldots \ldots \ldots$

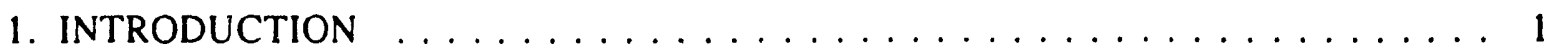

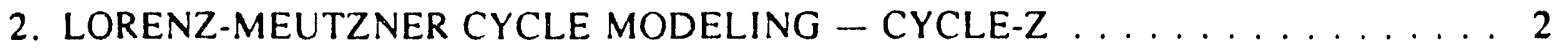

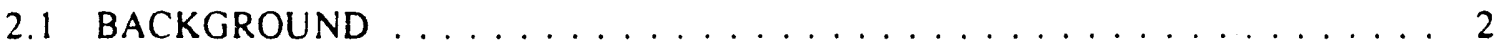

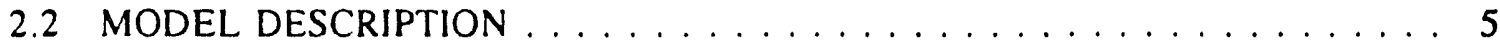

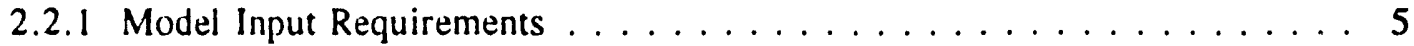

2.2 .2 Cycle Assumptions . . . . . . . . . . . . . . . . . 7

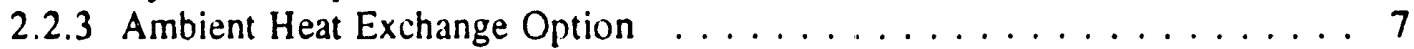

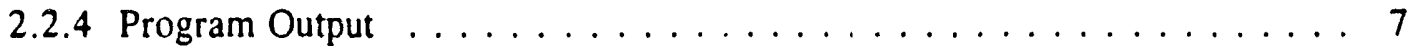

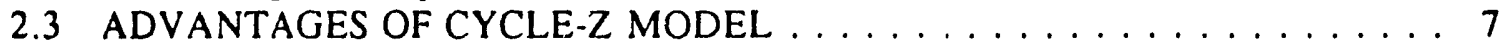

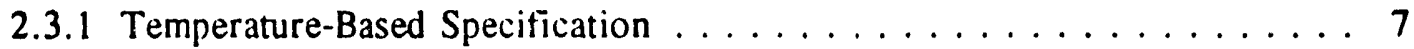

2.3.2 Constant Heat Exchange Loading . . . . . . . . . . . . . . 8

2.3.3 Fast Program Execution .................. 8

2.3.4 Design Rather Than Simulation Model . . . . . . . . . . . . . 8

2.3.5 Comparative Refrigerant Screening . . . . . . . . . . . . . . 8

2.4 INITIAL PARAMETRIC INVESTIGATIONS AND RESULTS . . . . . . . . . 9

2.4.1 Relative Heat Exchanger Area Distribution . . . . . . . . . . . . . . 9

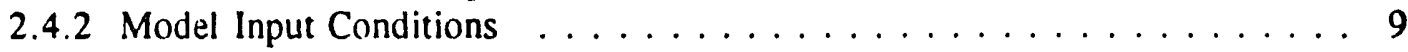

2.4 .3 NARM Concentration Variation ................. 11

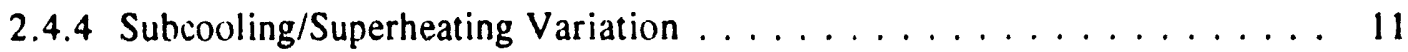

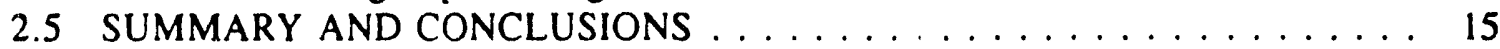

3. CALORIMETER TESTING WITH NARMS $\ldots \ldots \ldots \ldots \ldots \ldots \ldots$

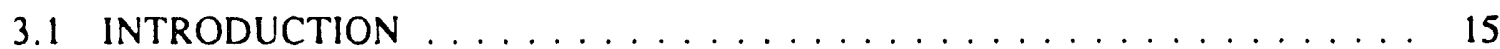

3.2 CALORIMETER SET-UP AND TEST PROCEDURE $\ldots \ldots \ldots \ldots \ldots \ldots$

3.3 CALORIMETER TEST RESULTS $\ldots \ldots \ldots \ldots \ldots \ldots \ldots \ldots \ldots \ldots$

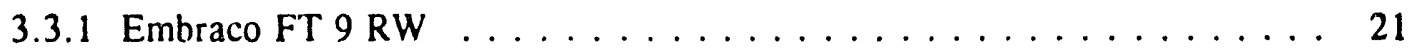

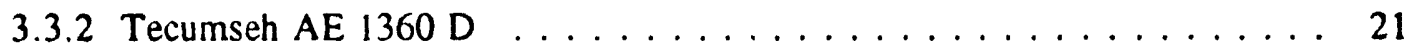

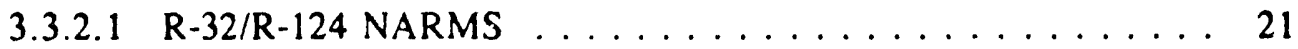

3.3 .2 .2 R-22/R-14lb NARM $\ldots \ldots \ldots \ldots \ldots \ldots \ldots \ldots \ldots$

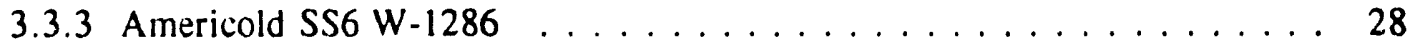

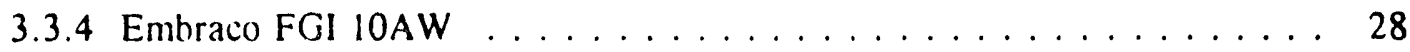

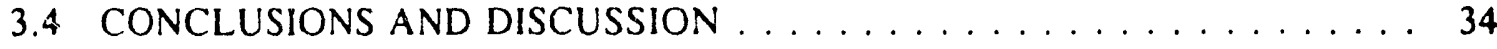


4.1 BACKGROUND ........................ 34

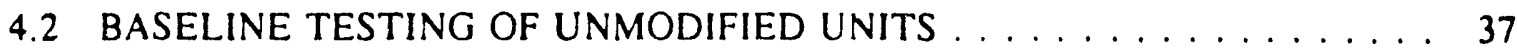

4.3 LORENZ-MEUTZNER CONSTRUCTION $\ldots \ldots \ldots \ldots \ldots \ldots \ldots \ldots 41$

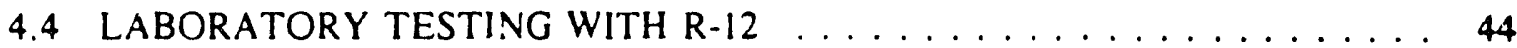

4.5 LORENZ-MEUTZNER TESTING WITH AN R-32/R-124 NARM . . . . . . 45

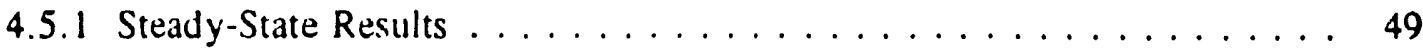

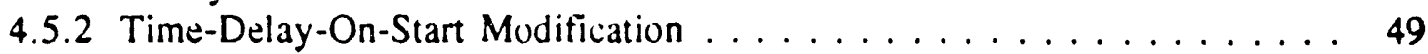

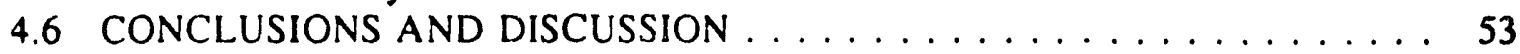

5. DUAL-LOOF REFRIGERATOR-FREEZER TESTING $\ldots \ldots \ldots \ldots \ldots \ldots 53$

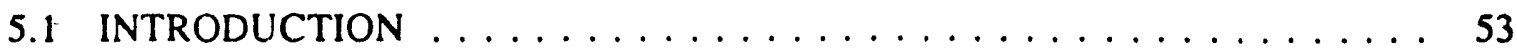

5.2 DUAL-CIRCUIT, DUAL-LOOP DESIGN AND TESTING $\ldots \ldots \ldots \ldots .54$

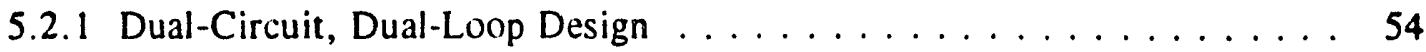

5.2 .2 Dual-Circuit Dual-Loop Modeling $\ldots \ldots \ldots \ldots \ldots \ldots \ldots \ldots 55$

5.2 .3 Initial Modifications $\ldots \ldots \ldots \ldots \ldots \ldots \ldots \ldots \ldots \ldots \ldots$

5.2.4 Testing and Performance Rating $\ldots \ldots \ldots \ldots \ldots \ldots \ldots \ldots$

5.2 .5 Second Phase of Moditications $\ldots \ldots \ldots \ldots \ldots \ldots \ldots \ldots \ldots$

5.2.6 Energy Consumption Analysis $\ldots \ldots \ldots \ldots \ldots \ldots \ldots \ldots 606$

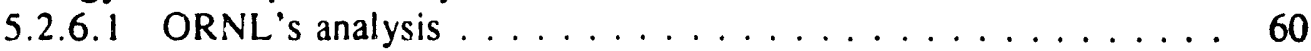

5.2.6.2 Amana's analysis . . . . . . . . . . . . . . 63

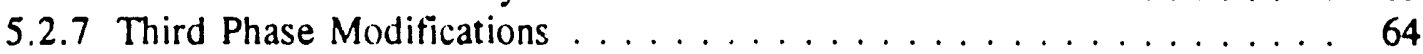

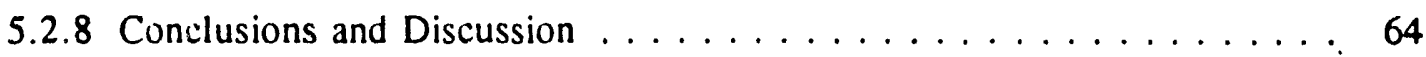

5.3 REFRIGERANT-SWITCHING, DUAL-LOOP REFRIGERATOR

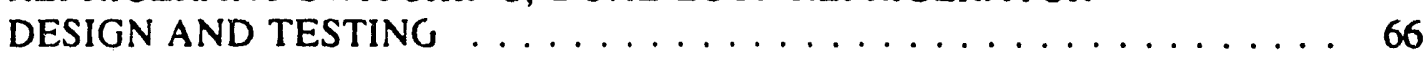

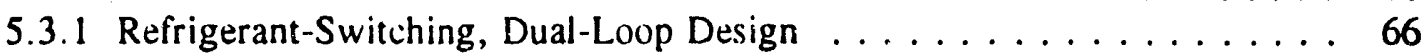

5.3.2 Air-or Refrigerant-Switching Dual-Loop Modeling Analysis $\ldots \ldots .68$

5.3.3 Refrigerant-Switching Construction $\ldots \ldots \ldots \ldots \ldots \ldots \ldots 69$

5.3.4 Initial Test Results With $\mathrm{R}-12 \ldots \ldots \ldots \ldots \ldots \ldots \ldots \ldots$

5.3.5 Refrigerant-Switching Dual-Loop RF Performance

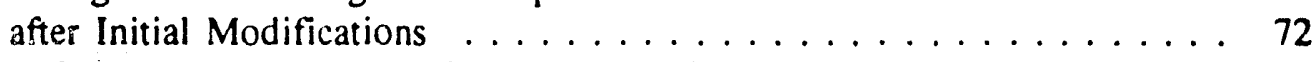

5.3.6 Refrigerant-Switching Dual-Loop RF Performance

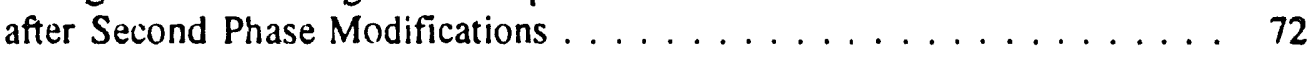

5.3.7 Final Laboratory Tests on Refrigerant-Switching

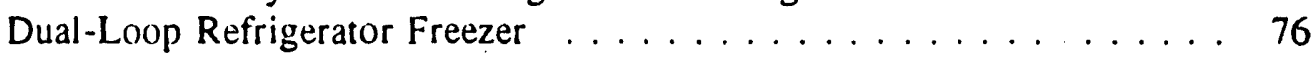

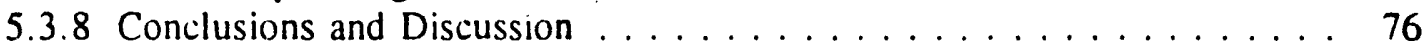

6. CLOSING OBSERVATIONS $\ldots \ldots \ldots \ldots \ldots \ldots \ldots \ldots \ldots \ldots$

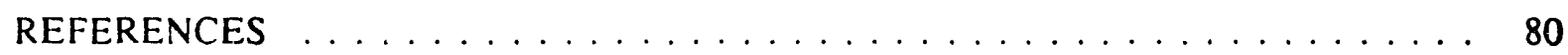

APPENDIX A: ADL's Dual-Loop Modeling and Design Work $\ldots \ldots \ldots \ldots$ A-1

APPENDIX B: ADL's Dual-Loop Design Specifications $\ldots \ldots \ldots \ldots \ldots \ldots$ B-1

APPENDIX C: Refrigerant-Switching Dual-Loop Design $\ldots \ldots \ldots \ldots \ldots \ldots$ C-1 


\section{LIST OF FIGURES}

2.1 Schematic diagram of Lorenz-Meutzner refrigerator-freezer cycle $\ldots \ldots \ldots \ldots$

2.2 Refrigerant circuit state-points for the Lorenz-Meutzner,

refrigerator-freezer cycle corresponding to the CYCLE-Z model . . . . . . . . 4

2.3 Variation in Lorenz-Meutzner, refrigerator-freezer coefficients of

performance with changes in the area ratio of evaporator to

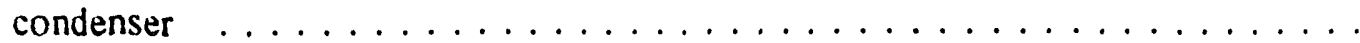

2.4 Nonazeotropic refrigerant mixture (NARM) composition effects for an

R-32/R-124 NARM ......................

2.5 Topographical plots of system coefficient of performance of a

Lorenz-Meutzner refrigerator-freezer circuit as a function of

suhcooling accomplished in the high-temperature and

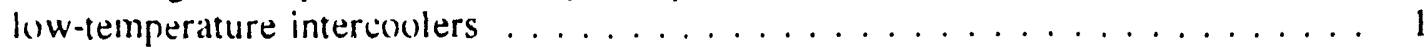

2.6 Effects of subcooling in the low temperature intercouler $\ldots \ldots \ldots \ldots \ldots \ldots$

3.1 Four cases of specified refrigerant heat exchanger comparisons $\ldots \ldots \ldots \ldots$

3.2 Performance for $R-22 / R-1 / 4$ mixtures as a function of composition

calculated for the four cases of specified refrigerant temperature

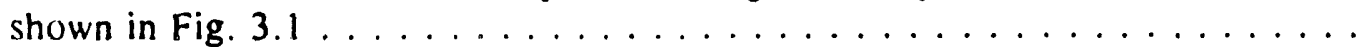

3.3 Compressor capacity and energy efficiency ratio of $R-12$ to

$15 \%$ R-32/85\% R-124 and $80 \%$ R-22/20\% R-14lb Lorenz-Meutzner nonazeotropic refrigerant mixtures for a Tecumseh AE $140 \mathrm{CT}$ compressor . . . . . . . . .

3.4 Comparable compressor capacities and energy efficiency ratios for $R-12$

and a $15 \%$ by mass R-32/85\% R-124 nonazeotropic refrigerant mirture in an Americold SS6 W-1286 compressor at the $120^{\circ} \mathrm{F}$ condensing

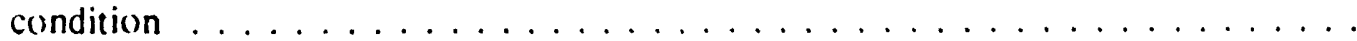

3.5 Comparable compressor capacities and energy efficiency ratios for R-12 and a $15 \%$ by mass R-32/85\% R-124 nonazeotropic refrigerant mixture in an Americold SS6 W-1286 compressur at the $130^{\circ} \mathrm{F}$ condensing condition

4.1 Compressor and defrost cycling data from unmodified Amana

ESTR 18D refrigerator-freezers

4.2 Freezer and fresh food temperatures in closed-door tests of Amana refrigerator-freezers showing transition from $\mathrm{mid} / \mathrm{mid}$ to warm/warm

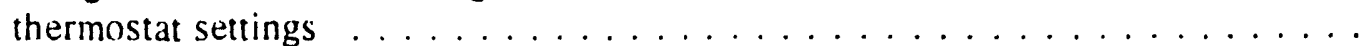




\section{LIST OF FIGURES (continued)}

4.3 Instrumentation for Lorenz-Meutzner refrigeration circuit. . . . . . . . . . 42

4.4 Sketch of static fresh food evaporator huilt for Lorenz-Meutzner refrigerator-freezer design. . . . . . . . . . . . . . . . . .

4.5 Comparison of freezer "pull down" and "heat gain" of Amana 18 ESTR at $90^{\circ} \mathrm{F}$ before and after modification to the L-M RF design.

4.6 Refrigerant and air temperatures for two compressor "on" cycles of a Lorenz-Meutzner refrigerator operating with a $15 \%$ by mass $\mathrm{R}-32 / 85 \%$ by mass $\mathrm{R}-124$ nonazeotropic refrigerant mixture before time-out-delay relay installed on the freezer fan $\ldots \ldots \ldots \ldots \ldots$

4.7 System pressures for two compressor cycles of a Lorenz-Meutzner refrigerator freezer operating with an R-32/R-124 nonazeotropic refrigerant mixture.

4.8 Nonazeotropic refrigerant inixture refrigerant and air temperatures in the Lorenz-Meutzner freezer evaporator through two compressor cycles.

5.1 Thermocouple (TC) and pressure transducer (PT) locations on the dual-circuit dual-lonp refrigerator-freezer. . . . . . . . . . . . . . 56

5.2 Schematics of single-compressor dual-loop refrigerator-freezers $\ldots \ldots \ldots 7$

5.3 Refrigeration system schematic for refrigerant-switching, dual-loop refrigerator-freezer system. 


\section{LIST OF TABLES}

2.1 Input parameters for the CYCLE-Z refrigerator-freezer and

CYCLE 7 heat pump model programs $\ldots \ldots \ldots \ldots \ldots$

2.2 Coefticient of performance and capacity data from CYCLE-Z model $\ldots \ldots \ldots 12$

3.1 Calorimeter evaporator and condenser pressures for nonazeotropic refrigerant mixtures corresponding to mean glide temperatures in the heat exchangers $\ldots \ldots \ldots \ldots \ldots \ldots \ldots \ldots \ldots$

3.2 Oak Ridge National Laboratory small compresser calorimeter test data

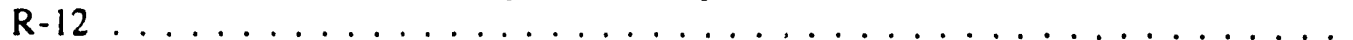

3.3 Oak Ridge National Lahoratory small compressor calorimeter test data

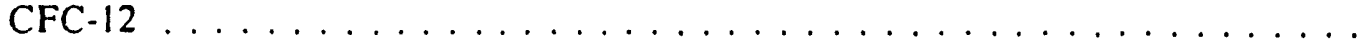

3.4 Oak Ridge National Laboratory small compressor calorimeter test data

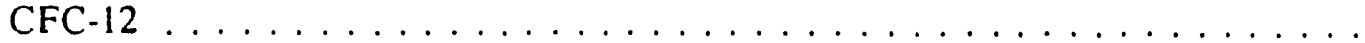

3.5 Oak Ridge National Laboratory small compressor calorimeter test

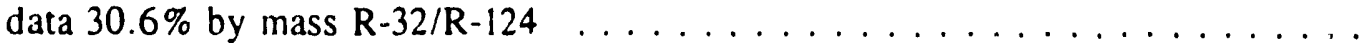

3.6 Oak Ridge National Laboratory small compressor calorimeter test data $15 \%$ by mass $R-32 / 85 \%$ by mass $R-124 \ldots \ldots \ldots \ldots \ldots$

3.7 Oak Ridge National Laboratory small compressor calorimeter test data $80 \%$ by mass $R-22 / 20 \%$ by mass $R-141 b \ldots \ldots \ldots \ldots$

3.8 Oak Ridge National Laboratory small compressor calorimeter test data

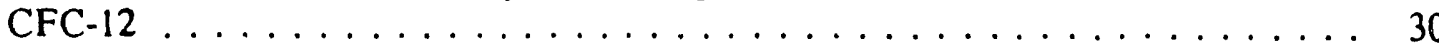

3.9 Oak Ridge National Laboratory small compressor calorimeter test data $15 \%$ by mass $\mathrm{R}-32 / 85 \%$ by mass $\mathrm{R}-124 \ldots \ldots \ldots \ldots \ldots \ldots$

3.10 Oak Ridge National Laboratory small compressor calorimeter test data CFC-152a

3.11 Oak Ridge National Lahoratory small compressor calorimeter test data CFC-12

4.1 Amana ESTR 18D unit 1 baseline R-12 testing-Anerican Home Appliance Manufacturers four point, $90^{\circ} \mathrm{F}$, closed-door test procedure . . . . . . . . .

4.2 Amana ESTR 18D unit 2 baseline R-12 testing-American Home Appliance Manufacturers four point $90^{\circ} \mathrm{F}$, closed-door test procedure . . . . . . . . . 


\section{LIST OF TABLES (continued)}

4.3 Amana ESTR 18D unit 3 baseline R-12 testing-American Home Appliance Manuficturers four point, $90^{\circ} \mathrm{F}$, closed-door test procedure . . . . . . . . . . 40

4.4 Lorenz-Meutzner refrigerator-freezer testing with 15\% R-32/R-124

American Home Appliance Manufacturers four-point, $90^{\circ} \mathrm{F}$, closed-door test procedure before time-delay-on-start relay installation . . . . . . . . . . . . 46

4.5 Refrigerator-freezer steady state energy use $\ldots \ldots \ldots \ldots \ldots \ldots \ldots$. . . . . 5 I

4.6 Lorenz-Meutzner refrigerator-freezer testing with $15 \%$ R-32/R-124 American Home Appliance Manufacturers four-point, $90^{\circ} \mathrm{F}$, closed-door test procedure after time-delay-on-start relay installation . . . . . . . . . . 51

5.1 Amana dual-loup. two-circuit haseline R-12 texting-Americian Home Appliance Manufacturers four-point, $90^{\circ} \mathrm{F}$. closed-door test procedure (unmoditied refrigerator-freezer as received from supplier) $\ldots \ldots \ldots \ldots \ldots$. . . 58

5.2 Amana dual-loop, two-circuit, baseline R-12 testing-American Home Appliance Manufacturers four-point, $90^{\circ} \mathrm{F}$, closed-door test procedure (after energy-saving modifications) $\ldots \ldots \ldots \ldots \ldots \ldots$

5.3 Oak Ridge National Laboratory small compressor calorimeter test data

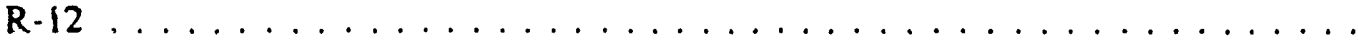

5.4 Oak Ridge National Laboratory small compressor calorimeter test data

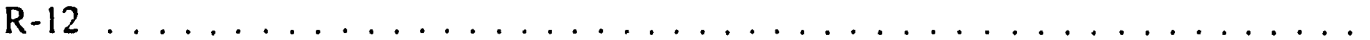

5.5 Amana dual-loop, two circuit, baseline R-12 testing-American Home Appliance Manufacturers four-point, $90^{\circ} \mathrm{F}$ closed-door procedure after energy-saving modifications (after compressor substitution and detailed charging) $\ldots \ldots \ldots \ldots$

5.6 Modeled dual-loop performance spreadsheet - air- and refrigerantswitching dual-loop cycle $\ldots \ldots \ldots \ldots \ldots \ldots \ldots$

5.7 Refrigerant-switching Jual-loop haseline testing. $90^{\circ} \mathrm{F}$ ambient closed-door procedure-refrigerator-freezer as received from Tillery Mechanical . . . . . . . 73

5.8 Refrigerant switching dual-loop R-12 baseline data-hefore modification . . . . 73

5.9 Refrigerant-switching dual-loop R-12 baseline data after freezer fan and check valve modifications-longer fresh food capillary . . . . . . . . . 


\section{LIST OF TABLES (continued)}

5.10 Refrigerant-switching dual-loop R-12 baseline data after fresh food evaporatur enlargement-longer tresh food capillary $\ldots \ldots \ldots \ldots$

5.11 Refrigerant-switching dual-loop R-152a data after fresh food enlargement-longer fresh food capillary

5.12 Refrigerant-switching dual-loop R-12 data after fresh food evaporator enlargement-longer fresh food capillary, better air distribution in freezer evaporator $\ldots \ldots \ldots \ldots \ldots \ldots \ldots$

5.13 Refrigerant-switching dual-loop R-152a data after fresh food enlargementlonger fresh food capillary, better air distrioution in freezer evaporator . . . . . . . . 


\section{LIST OF ACRONYMS}

$\begin{array}{ll}\text { AHAM } & \text { American Home Appliance Manufacturers } \\ \text { COP } & \text { coefficient of pertiomance } \\ \text { CFC } & \text { chlorofluorocarbon } \\ \triangle T & \text { changes in temperature } \\ \text { DOE } & \text { Department of Energy } \\ \text { EER } & \text { energy efficiency ratio } \\ \text { EPA } & \text { United States Environmental Protection Agency } \\ \text { GWP } & \text { greenhouse warming potential } \\ \text { Hx } & \text { heat exchanger } \\ \text { IC } & \text { interaction coefficient } \\ \text { kWh/d } & \text { kilowatt hours per day } \\ \text { L-M } & \text { Lorenz-Meutzner } \\ \text { LMTD } & \text { log mean-temperature difference } \\ \text { NARM } & \text { Nonazeotropic refrigerant mixture } \\ \text { ODP } & \text { ozone depletion potential } \\ \text { ORNL } & \text { Oak Ridge National Laboratory } \\ \text { RF } & \text { refrigerator-freezer }\end{array}$




\section{EXECUTIVE SUMMARY}

This project initially ficused on using nonazeotropic i efrigerant mixtures (NARMs) in a two-evaporator refrigerator-freezer design using two stages of liquid refirigerant subcooling. This concept was proposed and tested by A. Lorenz and K. Meutzner in 1975.' Their work suggested that the concept was $20 \%$ more efficient than the conventional one-evaporator refrigerator-freezer (RF) design. After considerable planning and system modeling based on using a NARM in a Lorenz-Meutzner (L-M) RF, the program scope was broadened to include investigation of a "dual-loop" concept where energy savings result from exploiting the less stringent operating conditions needed to satisfy cooling of the fresh fond section.

A steady-state computer model (CYCLE-Z) capable of simulating conventional, dual loop, and L-M refrigeration cycles was developed. This model was used to rank the performance 0 : 20 ozone-safe NARMs in the L-M refrigeration cycle while key system parameters were systematically varied. The results indicated that the steady-state efticiency of the L-M design was up to $25 \%$ greater than that of a conventional cycle. This model was also used to calculate the performance of other pure refrigerants relative to that of dichlorodifluoromethane, $\mathrm{R}-12$, in conventional and dual-loop RF designs. Projected efticiency gains for these cycles vere more modest, ranging from 0 to $10 \%$.

Individual compressor calorimeter tests of nine combinations of evaporator and condenser temperatures usually used to map RF compressor performance were carried out with $R-12$ and two candidate L-M NARMs in several compressurs. A testing protocol was set up to select evaporating and condensing pressures for the NARMs that corresponded to the normal saturated evaporator and condenser temperatures used for pure refrigerants. The protocol was based on the average mean of the NARM temperature glide. which compensates for any nonlinearity in their temperature-enthalpy profiles. Efficiency and capacity comparisons made between R-12 and R-32/R-124 in the same compressors showed 4 to $6 \%$ greater efficiency for the NARM at approximately the same capacity as the $R-12$. The other NARM tested $(R-22 / R-141 \mathrm{~b})$ generally had poorer performance than $R-12$ at the same refrigeration capacity.

Several models of a commercially produced two-evaporator RF were obtained as test units. Typical energy consumption as measured by the $90^{\circ} \mathrm{F}$, closed-door test procedure of the Association of Home Appliance Manufacturers (AHAM) was evaluated. Based on results from the computer modeling work. one of these field units was modified to simulate the two-evaporator, dual-intercooler design suggested hy A. Lorenz and K. Meutzner.' Energy consumption measurements were then made on this unit with an R-32/R-124 NARM. Test results indicated that steady-state efficiency was about $20 \%$ better than the original unmodified $R F$, closely matching CYCLE-Z predictions for this NARM. Cyclic performance failed to show an efficiency gain over that of traditional RFs because of inefficiencies in the design and function of the RF heat exchangers.

Two dual-loop RF designs were built and tested as part of this project. Amana was commissioned to build a dual-circuit, dual-loop RF that had two completely separate vapor compression circuits and compressurs for the freezer and fresh food sections. Results of closeddoor $90^{\circ} \mathrm{F}$ tests were used to compare this unit's performance to its energy consumption before it was moditied and to its predicted performance hased on modeling studies. Modeled performance projections using actual measured compressor efficiencies and cabinet loadings indicated that the unit should use 1.72 kilowatt hours per day $(\mathrm{kWh} / \mathrm{d})$. This is about a $25 \%$ energy savings over conventional RF designs. The unit actually consumed $3.00 \mathrm{kWh} / \mathrm{d}$, but excessive run time for the freezer circuit was the main reason for the added consumption. 
Another dual-forp RF design was huilt around a three-way valve that directed liquid refrigerant flow (1) a freezer or a fresh food evaporator through a capillary tube and heat exchanger appropriate for the cemperatures needed in these compartments. This refrigerant-switching, dual lowp design was tested with R-12 and R-152a. After several design iterations the laboratory test unit was able of achieve a daily energy consumption comparable to its unmoditied (conventional design) performance with $R-12$ refrigerant. The refrigerantswitching, dual-loup RF design showed a 6-7\% improvement over baseline R-12 performance when $R-152$ a was used for the refrigerant. 


\section{ACKNOWLEDGMENTS}

The authurs wish to acknowledge the contributions of the following people to completion of this proi. ct. Dr. Horst Kruse and Mike Kauftield graciously hosted a visit to their laboratory at the University of Hannover, provided copies of their Lorenz-Meutzner (L-M) refrigerator-freezer (RF) computer model, and aided in the design of the L-M RF at Oak Ridge National Laboratory (ORNL). Drs. Reinhard Radermacher and Dung $S(x)$ Jung at the University of Maryland provided helpful discussions on RF designs, advice on hardware modifications, and copies of their RF models for comparisun.

Mike Adams and Brad Hein at Brazeway Corporation in Adrian. Michigan, helped design and fabricate RF heat exchangers used in the project. Dick Merriam from Arthur D. Little, Inc., produced the hasic design and collected components for the dual-circuit, dual-loop RF. Refrigerant samples used for some of the testing were ohtained from Don Bivens at DuPont and Dick Crooker at ATOCHEM. Sample RF compressors were provided by Laercio Hart. Bruce Kopf and Eivind Sallo at Amana were the primary contacts during the construction and testing of the dual-circuit, dual-foup RF. Raymond Bohman was responsible for the refrigerant-switching, dual-loup design and had very helpfui advice on the performance of othc prototype units. Lennis Thumas at Tillery Mechanical in Knoxville. Tennessee, built and performed preliminary test runs on the L-M and refrigerant-switching. dual-loop RFs in his shop.

At ORNL. Bill Miller set up and. with the help of John Owens from Tennessee State University, conducted shake-down tests on the STARCO calorimeter used for the compressor calorimetry testing portion of this report. Bill Levins of the Existing Buildings Research Group wrote the PC computer program to accept and organize data from the laboratory data logger. Steve Fischer contributed many important routines and algorithms to the data reduction programs. As laboratory technicians for the project. Charles Hardin and Randy Linkous set up and performed most of the laboratory tests and helped reduce and organize the raw research data. Finally, it is our pleasure to acknowledge the advice and assistance of $V$ an Baxter who provided many helptul ideas for the laboratory research work and was instrumental in the organization and content of this report.

This work was sponsored by the United States Envirunmental Protection Agency (EPA) under interagency agreement DOE No. 1824-C019-AI and by the U.S. DOE Office of Building Technologies, managed by Martin Marietta Energy Systems, Inc., under contract No. DE-AC05-84OR21400. 


\section{INTRODUCTION}

With the realization of the Montreal Protocol and its recent revisions, it has become apparent that the world community will no longer permit the use of fully halogenated. chlorine-containing tluids as vapor compression retrigerants and foam blowing agents. ${ }^{2}$ The signing of this intemational treaty and the subsequent conferences and govermmental actions have sought to limit the effects of chemicals produced by man on the global environment.

For the refrigeration industry, this legislation and heightened environmental concem has resulted in restricted production and salss of blowing agents and refrigerants such as trichlorofluoromethane (R-11), dichlorodifluoromethane (R-12), and chloropentafluoroethane (R-115). Because energy efficient ctorage and distribution of refrigerated food is essential for the existence of industrialized society, subsiitute fluids or refrigeration cycles must be developed to replace those in the processes or products being phased out.

Approximately 115 million domestic refrigerator-freezers (RFs) that utilize $R-11$ as the blowing agent for wall insulation and R-12 as the circulated refrigerant are used in the United States loday. These account for abeut $20 \%$ of the household electrical energy load, or about 1.4 quads a year, so the efficiency of domestic refigerator-freezers represents a significant facto. in nationil and world-wide energy use."

The singie-component refrigerant ( $R-134 \mathrm{a}$ ) and the nearly azeotropic mixture (the DuPont tenary blend) altematives to $R-12$ have shown roughly equivalent energy use in laboratory tests perfonned thus tar. ${ }^{4}$ If tluid or cycle changes could be implemented that would significantly improve the efficiency of household RFs, it would be advantageous to introduce these changes in this period of transition away from environmentally damaging chenicals.

Nonazeoiropic refrigerant mixtures (NARMs) have been proposed as altemative refrigerants that can provide more acceptable environmental consequences and, potentially, decreased energy consumption in RFs. During evaporation or condensation of a NARM at constant pressure. the saturation temperature changes due to differences in the volatility of the component fluids. The temperature difference between the "dew point" and the "bubble point" of a NARM at any specified pressure is referred to as the refrigerant's "temperature glide." For domestic refrigeration, it is conceivable that a mixture can be chosen with a glide that will accommodate the temperature requirements for both the freezer and the fresh food compartments in a typical RF.

Conventional RFs maintain approximately $5^{\circ} \mathrm{F}$ in the freezer compartment and $38^{\circ} \mathrm{F}$ in the fresh food section by using the refrigeration cycle to maintain the colder freezer temperature. At rating conditions in a conventional top-mount RF, about $50 \%$ of the cooling load is due to the fresh food compartment. Colder freezer air is allowed to flow into the refrigerator section to maintain the $38^{\circ} \mathrm{F}$ temperature needed for fresh food preservation. Thermodynamically, it would be more efficient 10 satisfy the cooling load in the refrigerator compantment by cycling the refrigerant between the wanmer refrigerator temperature and ambient temperature, thereby taking advantage of the smaller temperature lift between the refrigerator and roon temperatures. Several RF designs that incorporate separate freezer and fresh food circuits and which. theoretically, would save energy by working against this smaller fresh food/ambient lift for at least part of the cooling cycle, have been proposed.

One goal for this research project was to design, build, and demonstrate through laboratory testing a number of domestic RF designs operating with ozone-safe refrigerants that would show improved energy efficiency over conventional RFs operating with R-12. 


\section{LORENZ-MEUTZNER CYCLE MODELING-CYCLE-Z}

The applicaltion of NARMs in domestic refrigerator-freezers (RFS) has been suggested and experimenlally investigilled will mixed results." A RF circuil described and lested initially by A. Lorenz and K. Meut/ner in 1975 and by H. Kruse in 1981 has shown promise as the means to realize the encrgy saving potential of NARM refrigerants. ${ }^{1 .}$ CYCLE-Z is an RF model developed al ORNL 10 allow analytical simulation of the L-M circuit with newer. environmentally-acceptable NARM refrigerints.

\subsection{BACKGROUND}

A fundamental paper on methods for the analytical comparison of pure and mixed refrigerants in vapor compression cycles was published in 1985 by McLinden and Radermacher. ${ }^{8}$ They conclude that meaningful comparisons between pure and mixed refn arants should include the absolute application temperatures and the required temperature chan ${ }_{5} \ldots$ of the external heat transfer streams. In addition, the repon recommends a constant total heat exchanger surface area per unit of outpur capacity for pure and mixed refrigerants for the evaluation of comparative cycle perfominance.

McLinden notes that modeling heat exchangers with equal log mean temperature differences (LMTDs) for a simple heat pump cycle with equal glides gives results nearly equivalent to the more rigorous requirements set forth in ref. 8. This was the basis of the CYCLE 7 heat pump model that has been widely used for screcning candidate refrigerant mixtures for different applications. ${ }^{y}$.1n Recently, however. McLinden has noted some of the limitations of the CYCLE 7 model when used for refrigerant perfonmance screening in refrigerator cycles. ${ }^{11.12}$

A number of models specifically iniended for the L-M cycle have also been developed at the University of Hannover, the University of Maryland. the University of Illinois at Champaign-Urbana. Purdue University. NIST, and Arthur D. Little. Inc. These models use a mix of heat exchanger approaches and with differing levels of complexity-ranging from assumptions of infinite heat exchanger area to UA-specified/LMTD-calculated, and heat exchange effectiveness/NTU-based melhods.

The approach taken in the present work was to adapt the CYCLE 7 model to the L-M RF cycle (shown schematically in Fig. 2.1 and on a temperature-enthalpy diagram in Fig. 2.2) while preserving and enhancing the unique advantages of the original LMTD-based formulation. The resulting model was designated CYCLE-Z and is described fully in ref. 13. We developed consistent definitions for overall evaporator and condenser LMTDs and a means to maintain constant total heat exchanger area per unit of refrigeration capacity. The sequential solution technique used in CYCLE 7 was extended to incorporate the two high-to-low-side intercoolers and the split evaporator.

This repon tirst describes the program input requirements, model assumptions, and program output. as well as a summary of the perceived advantages of the resultant model. This description is followed by a review of initial parametric investigations using CYCLE-Z; effects of the distribution of total heat exchanger area, relative RF loading, refrigerant composition, and extent and distribution of intercooler/subcooling/superheat are considered. 


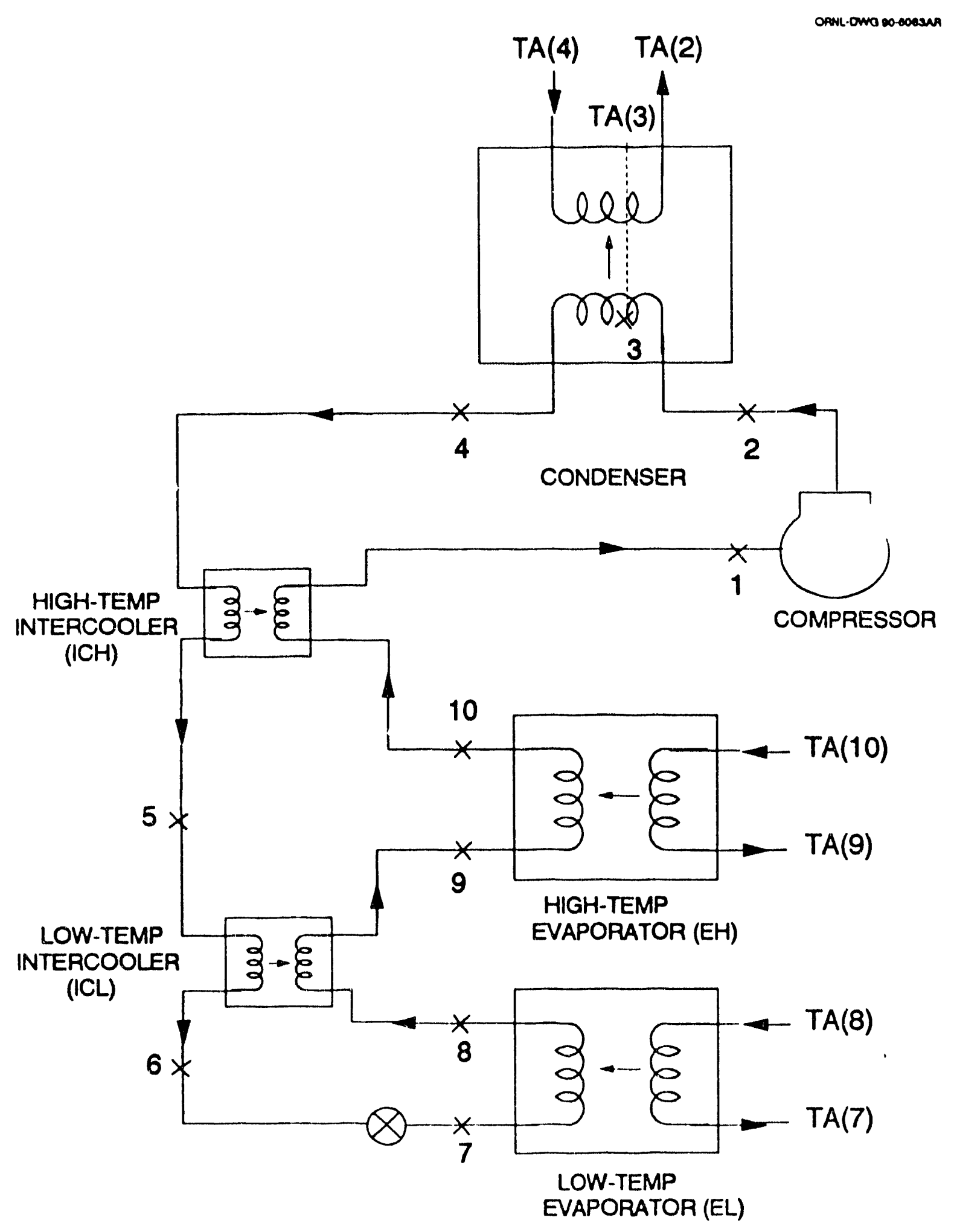

Fig. 2.1. Schematic diagram of Lorenz-Meutzner refrigerator-f-cezer cycle. 


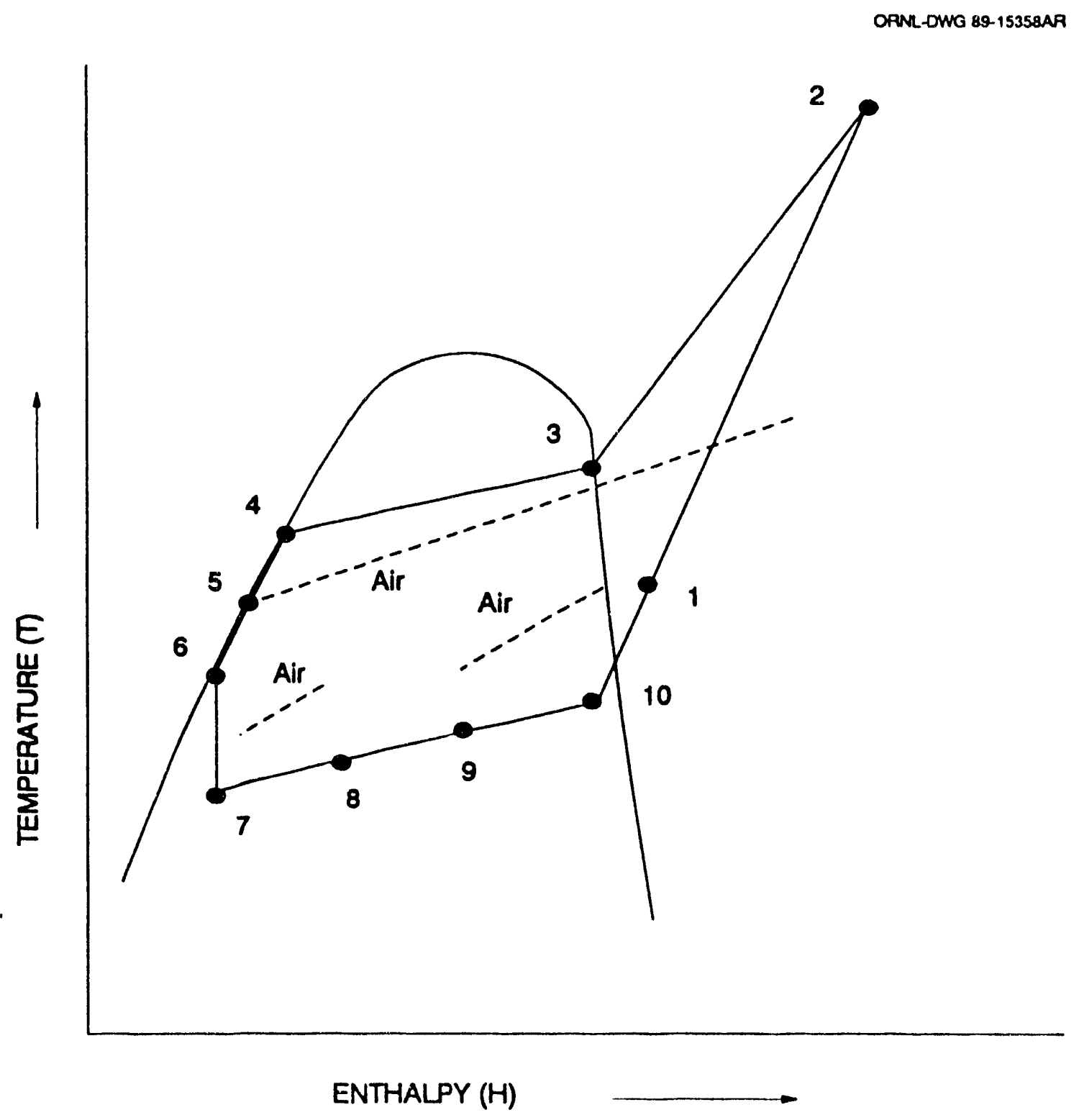

Fig. 22 Refrigerant circuit state-points for the Lorenz-Mcutzner, refrigerator-freczer cycle corresponding to the CYCLE-Z model. Superimposed condenser, freezer, and fresh food compartment temperatures. 


\subsection{MODEL DESCRIPTION}

\subsubsection{Model Input Requirements}

The user-required input to the CYCLE-Z program was kept similar in form to that of CYCLE $77^{8} \quad$ Both programs require selection of one or two refrigerants, a mass fraction concentration, inlet and exit temperatures of the extemal heat transfer streams, condenser and evaporator LMTDs and total pressure drops, and a compressor isentropic efficiency. The additional input for the CYCLE-Z program provides for specification of separate evaporators for the freezer (EL) and fresh-food (EH) compartments, and low (ICL) and high (ICH) temperature intercoolers (see Fig. 2.1 and Table 2.1).

For the two evaporators, the individual source stream inlet and exit temperatures are required as well as the fresh-food to freczer load ratio. The program still requires that only one evaporator LMTD be input; however, in CYCLE-Z this input now refers to an overall or combined LMTD of the two evaporators. This specification of the overall evaporator LMTD rather than an individual heat exchanger LMTD allows the degree of freedom needed for each evaporator LMTD to adjust for different refrigerant glides while the combined value is held constant. This combined value is inversely proportional to the overall evaporator area per unit of refrigeration capacity.

The high- and low-temperature intercoolers are specified simply by providing the desired individual subcooling $\Delta T$ 's. An ambient heat exchange option is also included to allow the user to specify, in place of the high-temperature intercooler subcooling $\Delta T$, an ambient temperature that both high-intercooler fluid streams will approach. This option is a somewhat passive high-intercooler heat exchange assumption (with no high- to low-temperature refrigerant heat exchange), whereas the specified subcooling choice is the active heat interchanger approach. The low-temperature intercooler is defined the same way in either case.

For the condenser, the specified LMTD differs from that in CYCLE 7 in two ways. First, the equation used in CYCLE 7 to determine an overall condenser LMTD across superheated and two phase refrigerant regions has been modified as described in ref. 13. In CYCLE-Z, condenser LMTDs are weighted by area rather than heat transfer fractions. Second, the LMTD is redefined relative to the total refrigeration output rather than the condenser heat load.

The user-specified total high-side and low-side refrigerant pressure drops are apportioned across the appropriate heat exchangers in relation to their relative refrigerant-side areas.

The CYCLE-Z program also allows the user to speciiy compressor shell heat loss as a fraction of the computed compressor input power. Laboratory and calorimeter testing has indicated this can be an appreciable portion of the electrical power supplied to the compressor, and this capability provides for more reasonable estimates of compressor discharge temperature.

Temperalures and pressures are expressed in either cgs or mks units in Sect. 2 of this report to be consistent with the required input and output units used in the CYCLE-Z model. Experimental results presented in the subsequent sections are in inch-pound (IP) units commonly used in American industry. 


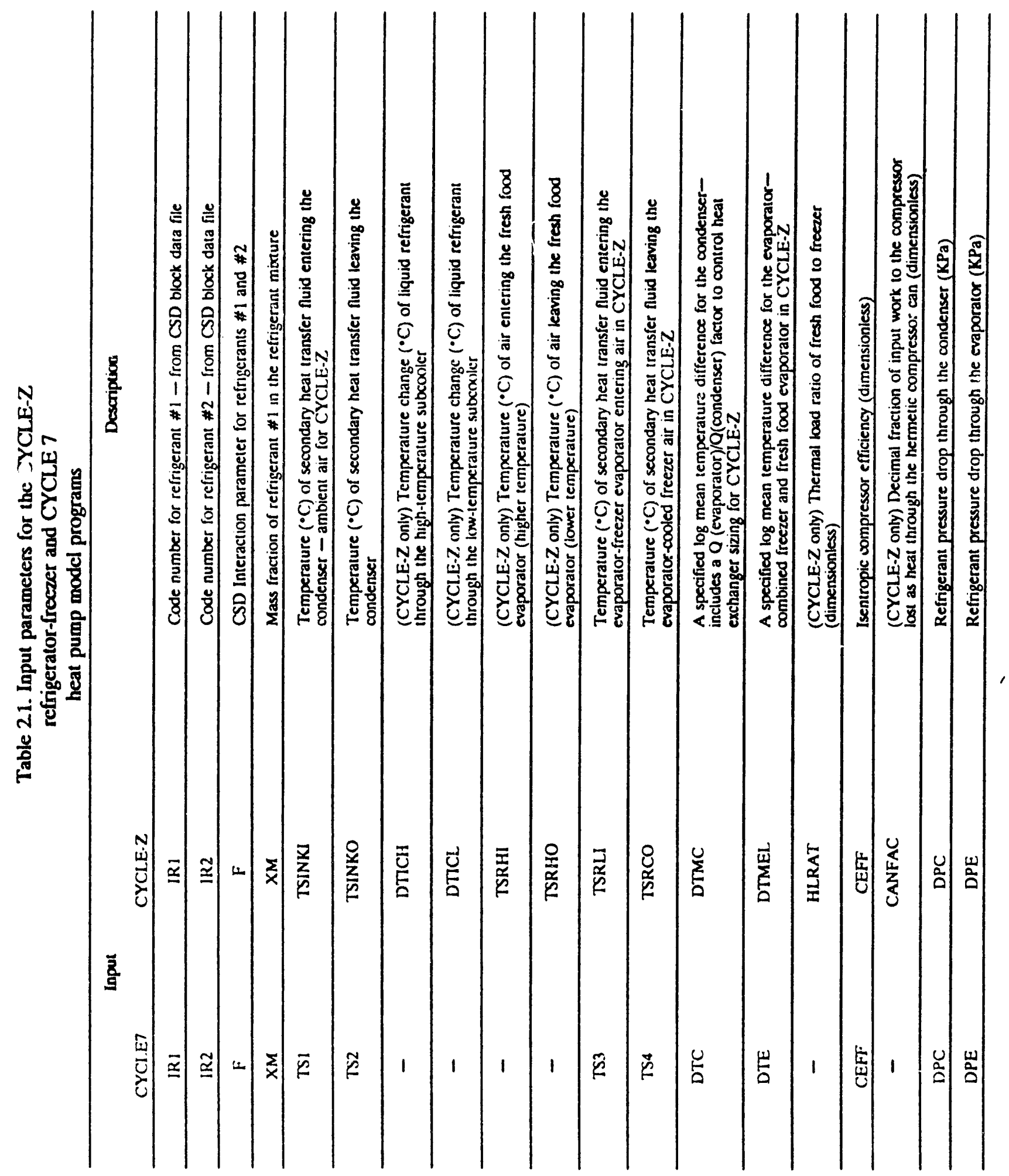




\subsubsection{Cycle Assumptions}

As in the case of the CYCLE 7 model, assumptions are made of saturated liquid at the condenser exit and saturated vapor at the high-temperature evaporator exit. These assumptions are consistent with the evaluation of optimal pertionance configurations for the L-M cycle. because optimal levels of condenser subcooling and compressor inlet superheat can be achieved with the two intercoolers. Use of the condenser and high-temperature evaporator for any additional subcooling or superheating, respectively, serves only to unnecessarily raise the condenser pressure or lower the evaporator pressure for a given LMTD. While prediction of these situations is necessary in a simulation model capable of predicting the full range of operating conditions that an actual installation may encounter, the present model is better suited as an initial design model to define the hardware performance requirements of an optimal configuration.

\subsubsection{Ambient Heat Exchange Option}

For the option of ambient heat exchange in lieu of the high-temperature intercooler, the basic program solution logic remains unchanged. In this case, points 1 and 5 in Fig 2.2 are set at the user-specified ambient temperature (which must be less than the condenser inlet :sink temperature), and the required heat transfers to the respective saturation points are computed. With this option, the temperature of refrigerant entering the freezer evaporator, $T(6)$ in Figure 2.1, is fixed by the user-specified subcooling in the low-temperature intercooler, and the evaporator inlet enthalpy is constant for all values of the refrigerant temperature leaving the condenser, $T(4)$. The evaporator pressure is thus totally independent of the condenser conditions. As such the program runs more quickly than in the general case with two true intercoolers.

\subsubsection{Prograin Output}

Once convergence on overall evaporator and condenser LMTDs has been obtained, a cycle summary is printed. The CYCLE-Z program output follows the basic format of the CYCLE 7 program with a number of additions, including:

- $\quad$ individual and overall Hx LMTDs;

- $\quad$ individual and overall $\mathrm{Hx}$ loadings (both conventional and per unit refrigeration load);

- relative $\mathrm{Hx}$ area and UA ratios:

- thermodynamic state conditions at the 10 cycle points:

- refrigerant glides:

- $\quad$ estinated maximum plausible low- and high-temperature subcooling;

- compressor pressure ratio, work, shell heat loss, and exit superheat; and

- refrigeration COP and enthalpic and volumetric capacities.

\subsection{ADVANTAGES OF CYCLE-Z MODEL}

\subsubsection{Temperature-Based Specification}

The C'CLE-Z approach gives an entirely temperalure-based cycle specification through the use of overall LMTDs and intercooler subcooling $\Delta T$ 's. Specification of the cycle configuration in this manner is more intuitive because it is easier to relate the basic task of 
refrigerant-glide matching to the application at hand. A temperature-based specification is also more straightforward for making comparisons with experimental results.

\subsubsection{Constant Heat Exchange Loading}

The ovcrall heal exchanger loading of the major heat transfer surfaces is specified in a general fashion per unil of refrigeration capacity. This specification is fluid and hardware independent. No UAs ir external fluid flow rates are required. The heat exchangers are essentially specified on a perfonmance basis and in a manner that allows the total available heat transfer area of the condenser and the two evaporators to be held constant for a required unit capacity.

\subsubsection{Fast Program Execution}

The icmpcrature-based approach as applied to the L-M cycle intercoolers also results in relatively quick cycle convergence (about 10-15 s on a 386-based IBM-compatible). The convergence is speedy because the intercoolers ' high-10-low-side heat transfers are uncoupled from the low-side iterations by use of performance rather than hardware specifications. In the optional case employing ambient heat exchange in place of an active high-side intercooler, the solution time is even faster.

\subsubsection{Design Rather Than Simulation Model}

CYCLE-Z has advantages for the evaluation of optimal thermal cycle configurations for two reasons. First, the assumptions built into the solution logic maintain optimum cycle conditions at the condenser and fresh-food evaporator outlets (zero subcooling and superheat, respectively). Simulation models with fixed hardware are more difficult to constrain to follow a particular optimal themodynamic design path. Second, use of thermal performance specifications as opposed to hardware specifications allows more of the general cycle parameters to be controlled directly (e.g., intercooler subcooling and total heat exchanger loading) while automatically adjusting the hardware requirements internally as needed with different fluids.

\subsubsection{Comparative Refrigerant Screening}

Because of the characteristics discussed in the preceding sections, CYCLE-Z is well-suited for comparative screening of refrigerant mixtures for application to the L-M cycle. The capability to maintain constant heat exchanger loading per unit refrigeration capacity and optimal condenser and evaporator exit conditions simplifies the determination of optimum cycle requirements for a particular refrigerant mixture. These requirements include distribution of heat exchanger area, optimal intercooler subcooling, and most advantageous mixture composition. Once optimal configurations have been determined for all candidate pairs in a consistent manner, fair performance rankings can be made. Because the CYCLE- $Z$ model allows the user to more easily determine optimum cycle configurations given consistent heat exchanger assumptions, the program is most appropriate for use in such performance ranking and in defining the optimal hardware requirements. 


\subsection{INITIAL PARAMETRIC INVESTIGATIONS AND RESULTS}

The implied reason for developing CYCLE-Z was that the effects of parameter variations could be analytically detemined rather than experimentally measured in the laboratory. The L-M cycle is sufficiently different from the conventional, pure-refrigerant RF configuration that many new system variables must be investigated.

Before outliring results from the parametric investigation of the L-M cycle, it is important to specify where NARMs provide an advantage over pure refrigerants for the domestic RF application. With mixed refrigerants, some of the themodynamic irreversibility of heat exchange can be decreased by matching the evaporating and condensing temperatures of the refrigerant with the temperature glide requirements of the secondary fluid (RF air temperatures). Also, liquid line subcooling of a mixed refrigerant produces a given evaporator temperature at a higher suction pressure, thereby decreasing the pressure ratio across the compressor. ${ }^{14}$ Several chemical compounds with less severe ozone-depletion potentials (ODPs) and greenhouse-warming potentials (GWPs) than the currently used chlorofluorocarbon (CFC) refrigerants have been identified as potential NARM components. ${ }^{10}$

\subsubsection{Relative Heat Exchanger Area Distribution}

The relative distribution of heat exchanger area between evaporating and condensing functions was varied by changing the overall LMTD values while maintaining a constant $\mathrm{UA}_{\text {tod }} / \mathrm{Q}_{\text {evap }}$ value of $0.2^{\circ} \mathrm{C}^{-1}$, which is equivalent to a $\mathrm{LMTD}$ of $10^{\circ} \mathrm{F}$ for the combined evaporator and the condenser. Figure 2.3 shows the system COP for NARM pairs with small, medium, and large temperature glides (R-22/R-152a, $R-32 / R-124$, and $R-22 / R-123$, respectively) and nominal values of intercooler subcooling $\left(20^{\circ} \mathrm{C}\right.$ of subcooling in both the high and low temperature intercoolers). These results indicate that a $U A_{\text {evap }}\left(U A_{t o r}\right.$ ratio of approximately 0.5 gave optimal performance for these three NARMs. so this relative area distribution was used for all subsequent calculations.

\subsubsection{Model Input Conditions}

We assumed a fresh-food-to-freezer loading ratio of $1 / 1$ for the parametric investigations, based on recommendations in the ASHRAE Equipment Handbook. ${ }^{15}$ Analytical runs with changing relative RF loadings showed that larger relative fresh-food loadings gave better system performance, primarily due to the smaller temperature lift required for these conditions.

CYCLE-Z calculates the required distribution of evaporator area between the freezer and fresh-food compartments. This is a strong function of the refrigerator/freezer load distribution and a lesser function of the component refrigerants and composition of the NARM pair. NARMs with larger temperature glides (larger normal boiling-point differences) and those that benefit most from larger amounts of subcooling require larger fresh-food comparument evaporators.

Other conditions that we held constant for virtually all of the CYCLE-Z runs were:

- low-temp evaporator air inlet and outlet temperatures $\left(-15^{\circ} \mathrm{C}\right.$ and $\left.-20^{\circ} \mathrm{C}\right)$,

- high-temp evaporator air inlet and outlet temperatures $\left(-3^{\circ} \mathrm{C}\right.$ and $\left.-2^{\circ} \mathrm{C}\right)$,

- condenser air inlet and outlet temperatures $\left(32^{\circ} \mathrm{C}\right.$ and $\left.40^{\circ} \mathrm{C}\right)$,

- overall evaporator LMTD $\left(10^{\circ} \mathrm{C}\right)$.

- overall condenser LMTD $\left(10^{\circ} \mathrm{C}\right)$.

- evaporator superheat and condenser subcooling $\left(0^{\circ} \mathrm{C}\right)$,

- evaporator and condenser pressure drop $(\mathrm{kPa})(0.0)$. 


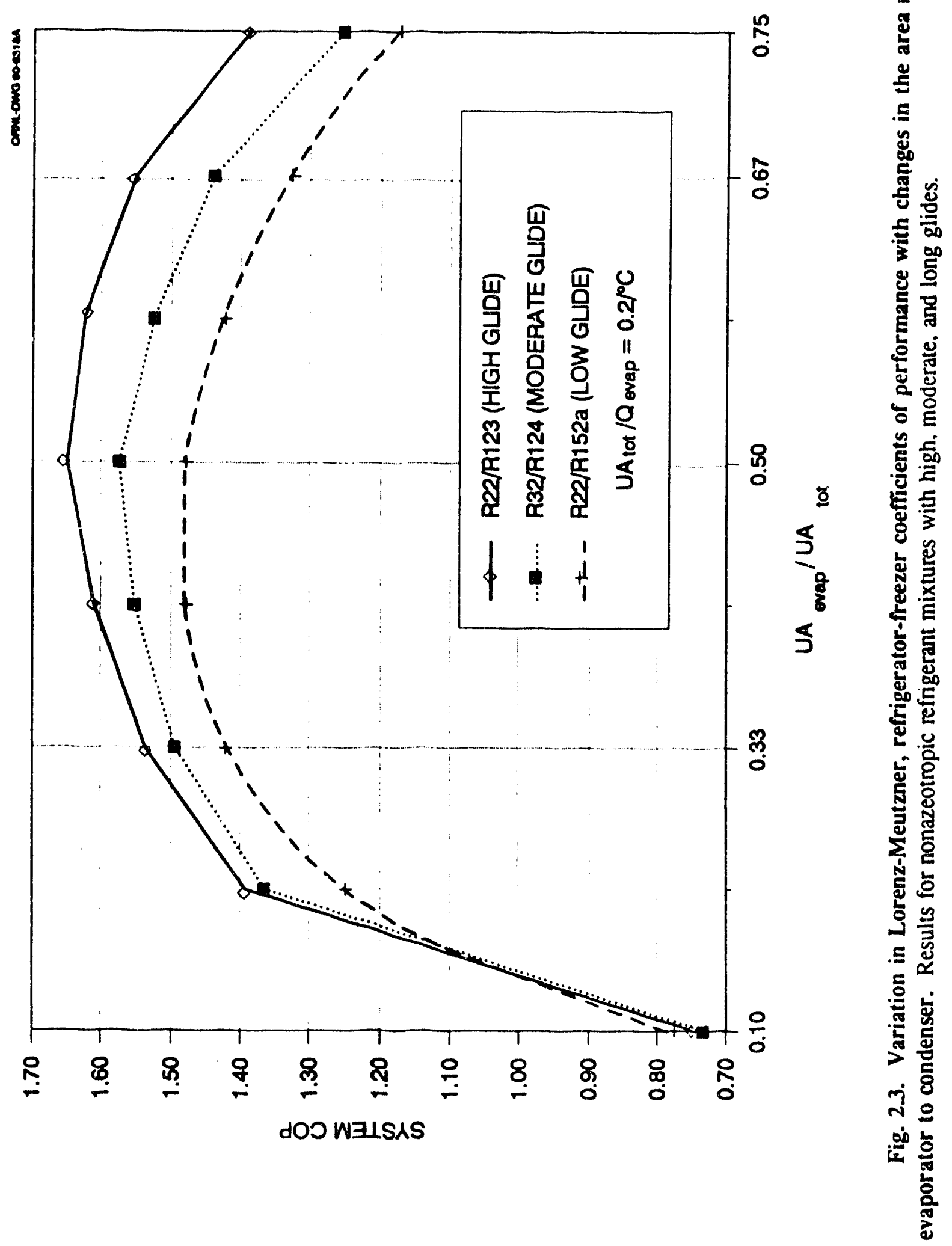


- compressor efficiency (0.55), and

- fraction of input work lost through compressor can (0.10).

Where experimentally measured interaction coctficients were not available for the CSD refrigerant property routines, we used a value of 0.01 . We determined variations of system COP, refrigerant volumetric capacities, evaporator and condenser glides, and compressor pressure ratios for 20 refrigerant mixtures at concentrations, ranging from 0 to 1.0 mass fraction of the lower boiling component. Table 2.2 presents optimal COP results from these calculations. In this table, comparisons are referenced to the performance of $\mathrm{R}-12$ in a conventional, single-evaporator refrigerator-freezer.

\subsubsection{NARM Concentration Variation}

The concentration of components in a NARM controls the resulting refrigerant temperature glide as the NARM evaporates or condenses, and matching specified tctal air-side glide with the refrigerant is an important aspect of NARM efficiency in this application. It follows, then, that the composition of the refrigerant mixture has a significant effect on system performance. Figure 2.4 shows typical plots of the variation in modeled $R F$ performance and refrigerant-side glides with the composition of an R-32/R-124 NARM. Also plotted in part (a) are the volumetric capacity of the refrigerant mixture and the "bascline" performance and volumetric capacity of R-12 in a single-evaporator RF. Similar results for the other NARM combinations were used to select the data for Table 2.1 .

Part (b) of Fig. 2.4 shows the evaporator and condenser refrigerant-side glides in relation to the air-side glides as a function of concentration in these two heat exchangers. It is quite apparent that the model is predicting optimal system periormance at a NARM concentration where the best correspondence occurs between refrigerant and air-side glides, especially on the evaporator side where the larger glide occurs. Naturally, heat exchanger pressure drops and other aberrations that result from actual running conditions will modify these considerations.

\subsubsection{Subcooling/Superheating Variation}

CYCLE-Z includes an option for setting the suction line superheat and first stage of liquid subcooling to ambient tempcrature (a condition sought in most conventional single-evaporator designs). This mode of operating puts a rather severe constraint on the extent of high-temperature intercooling in the system, and model runs using this option did not produce system COPs as high as those in which both high- and low-temperature subcooling/superheating were individually specificd and controlled.

Clearly, the extent and division of the subcooling and superheating accomplished with the intercooler stages on the L-M design are important parameters for controlling system performance. An automated series of model runs, for each of the NARM combinations listed in Table 2.1, provided data on how COPs changed as a result of the subcooling and subcooling/superheating obtained in these intercooler heat exchangers.

Figure 2.5 shows topographical plots of COP versus intercooler subcooling for high glide (R-22/R-123), low glide (R-22/R-152a), and moderate glide (R-32/R-124) NARMs in an L-M RF [parts (a). (b), and (c), respectively]. From the slopes of the contour lines for constant COP, it is apparent that high-temperature subcooling/superheating is more effective than low-temperature subcooling for improving system COP. Subcooling accomplished in the lower-temperature intercooler is much more effective at improving system efficiency for NARM pairs with a higher- 


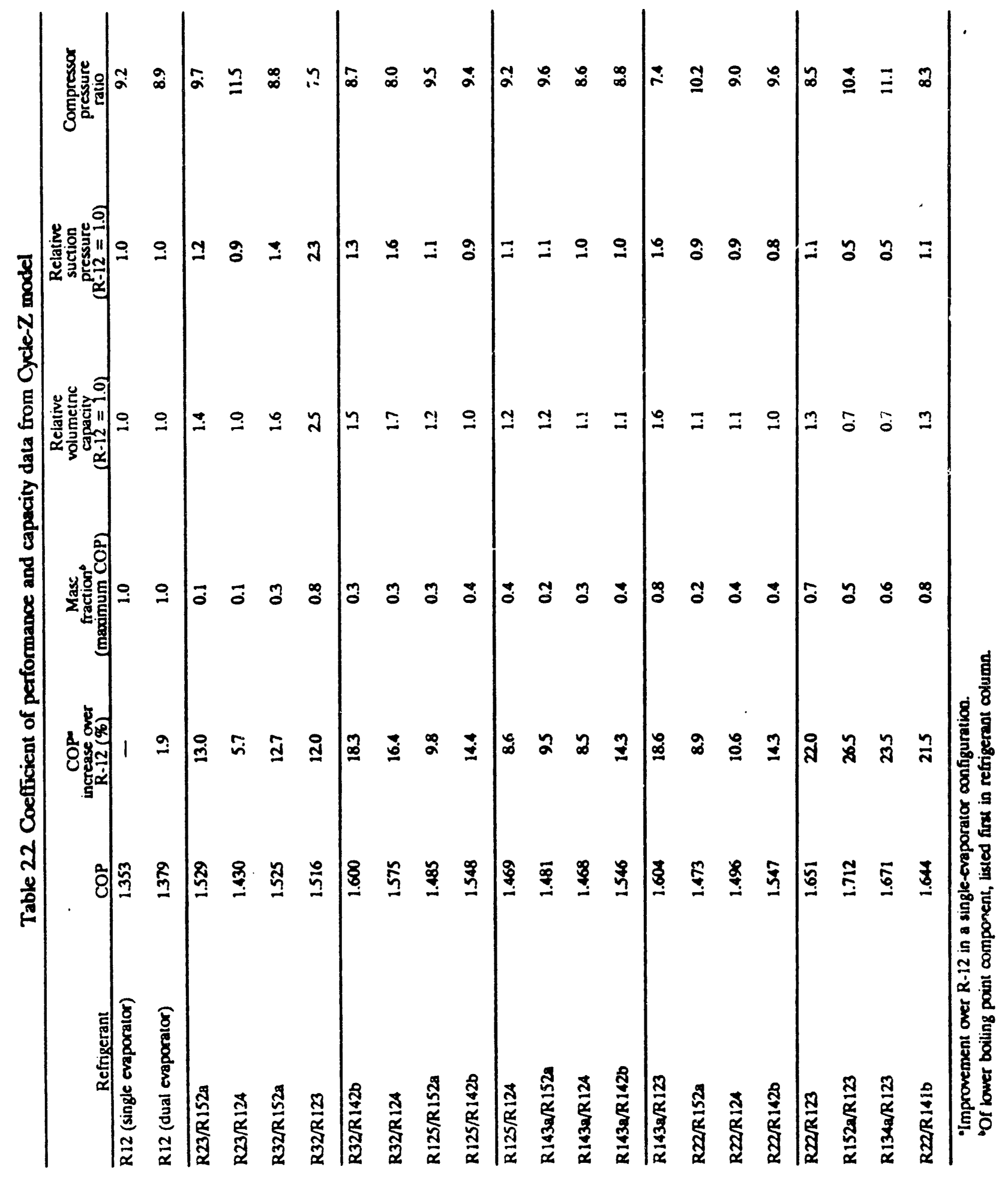




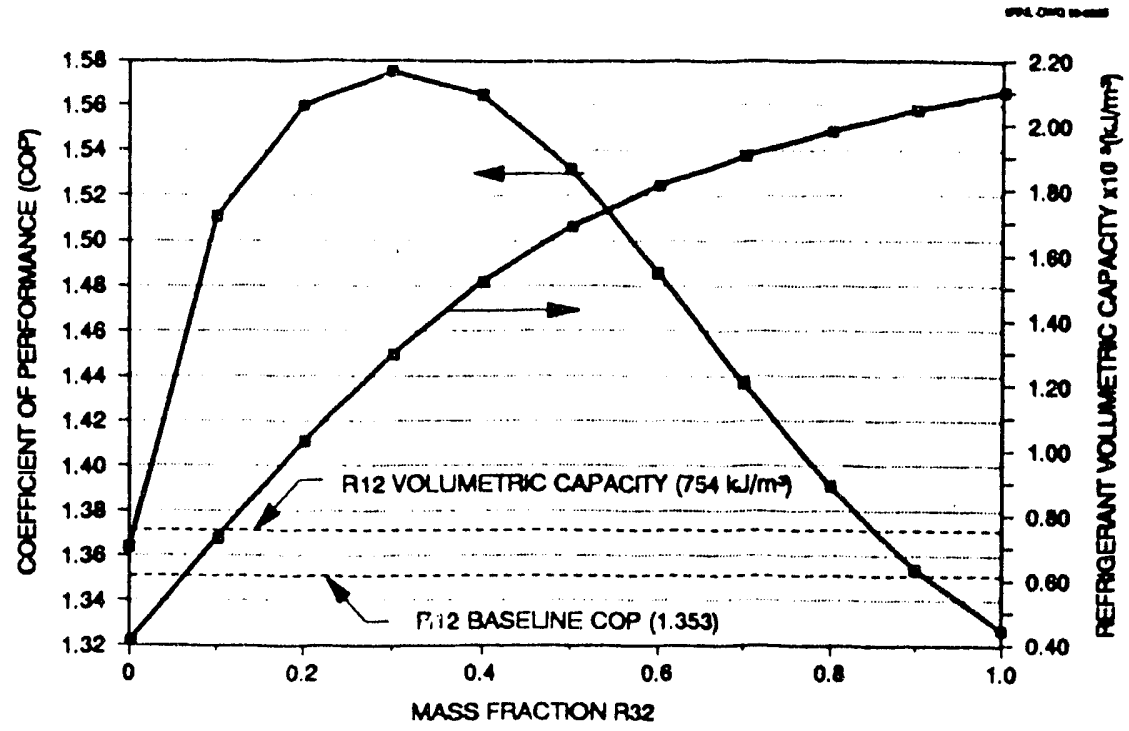

(a)

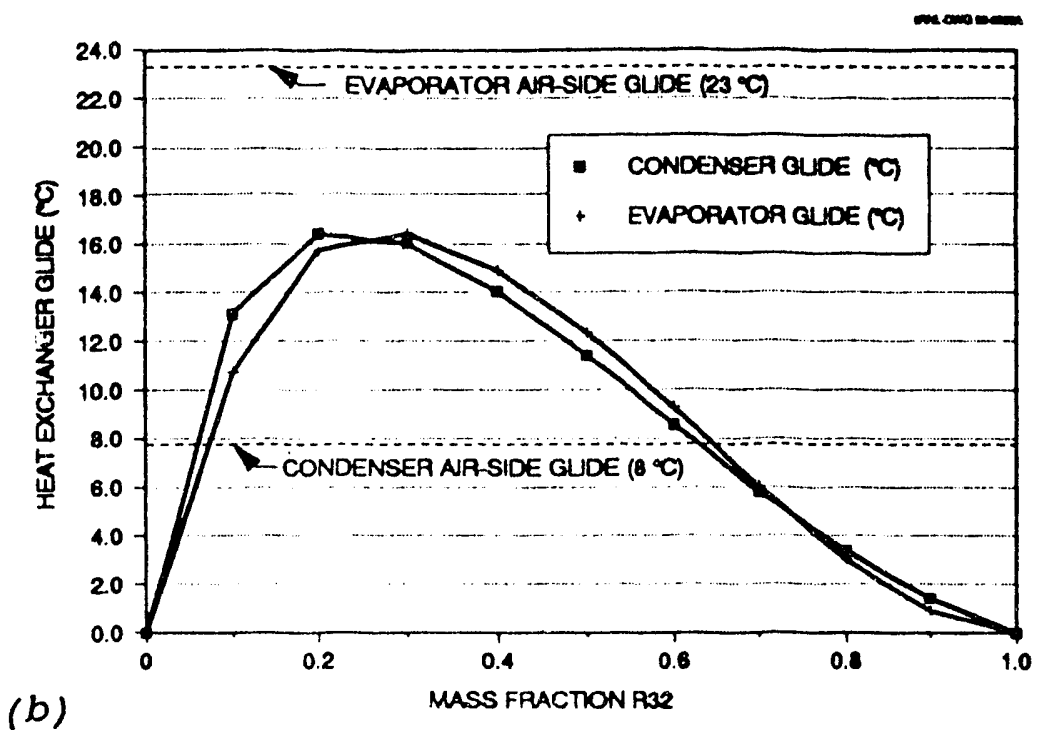

Fig. 2.4. Nonazeotropic refrigerant mixture (NARM) composition effects for an R-32/R-124 NARM. (a) Lorenz-Meutzner refrigerator-freezer cocfficient of performance and refrigcrant volumetric capacity as a function of NARM composition for an R-32/R-124 NARM, (b) NARM tempcrature glides in the evaporator and condenser of a Lorenz-Meutzner refrigeratorfreczer as a function of composition for an R-32/R-124 NARM. 
A.22/R.123-70 MASS\% R.22

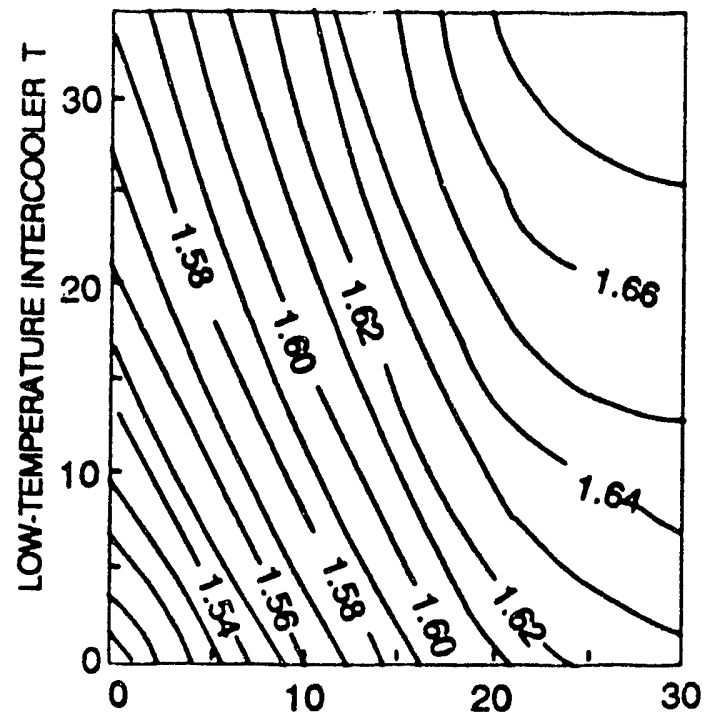

(a)

HIGH-TEMPERATURE INTERCOOLER AT

R-32/R-124-30 MASS\% R-32

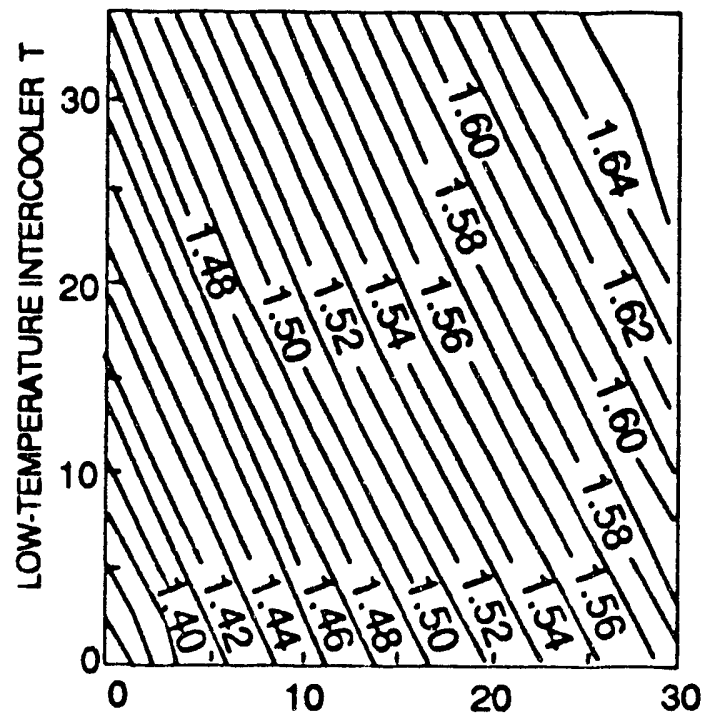

(c)

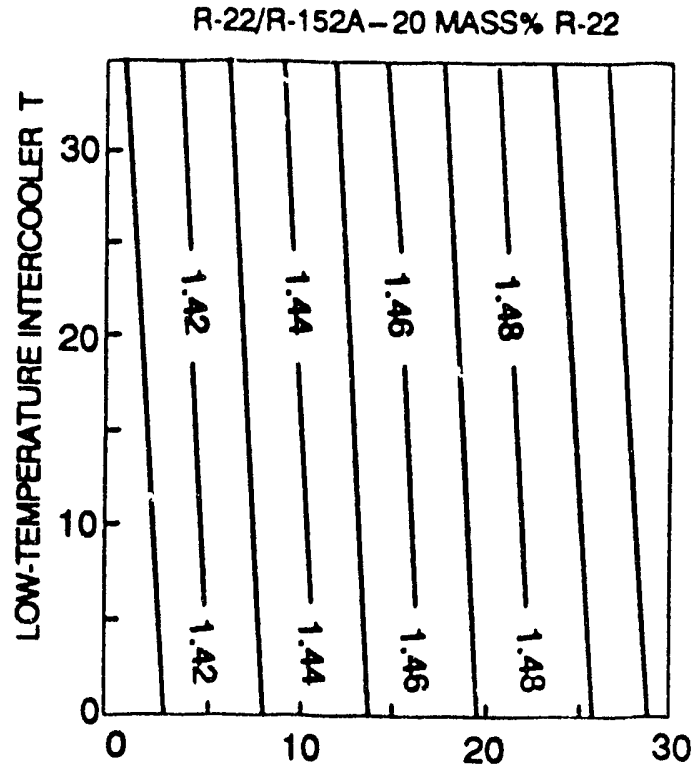

(b)
R-12 REFRIGERANT - LOAENZ CYCLE

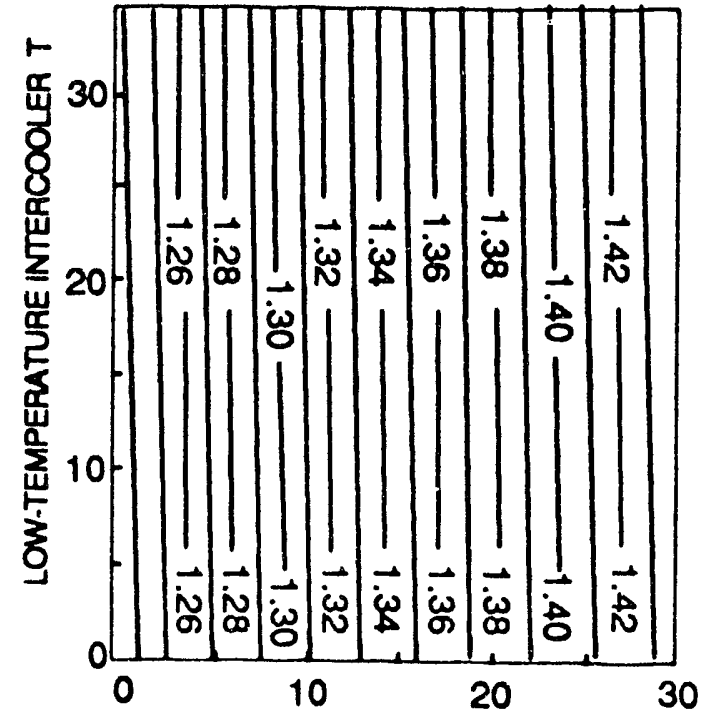

(d)

HIGH-TEMPERATURE INTERCOOLER $\triangle T$

Fig. 2.5. Topographical plots of system coefficient of performance of a LorenzMeutzher refrigerator-freezer circuit as a function of subcooling accomplished in the hightemperature and low-temperature intercoolers. (a) high glide; $(b)$ low glide; $(c)$ moderate glide; (d) zcro glide. 
temperature glide, which is consistent with the previously stated advantages of NARMs over pure refrigerants. This low-temperature subcooling effectively decreases the compressor pressure ratio at the same evaporator temperature and causes the two-phase refrigerant temperature to better match the corresponding evaporatc ${ }^{-}$air temperatures. Part (d) of Fig. 2.5 is included to show that the low-tempcrature intercooler does nothing to improve the efficiency of a pure refrigerant in this circuit. $^{14}$

Another advantage of adding liquid-line subcooling via the low temperature intercooler is that this internal heat exchange need not contribute directly to higher compressor discharge temperatures.

Figure 2.6 further illustrates that subcooling with the low-temperature intercooler facilitated temperature-giide matching in the RF evaporators. The two-level temperature changes for air in the evaporator remain constant, whereas increased subcooling by the low-teinperature intcricoler serves to decrease the LMTD of the high-temperature (fresh-food) evaporator and promote more efficient heat transfer at the expense of a slightly larger LMTD of the low-temperature (freezer) evaporator.

\subsection{SUMMARY AND CONCLUSIONS}

CYCLE-Z extends the advantages of the CYCLE 7 model to the L-M P.F cycle. ${ }^{8}$ It has the added capability of maintaining a constant total heat exchanger area per unit of refrigeration capacity over the primary heat exchangers (the condenser and the two evaporators) for different refrigerants and refrigerant mixtures. As such, CYCLE-Z is well suited for performance ranking of different fluid combinations under optimum cycle conditions without the need for and possible limitations of hardware characteristics.

NARMs offer performance advantages over pure refrigerants in an RF application through more efficient heat transfer and effective use of liquid subcooling. COP gains of 6 to 26\% over R-12 are predicted for NARMs operating in a modified RF circuit with separate fresh-food and freezer ivaporators and two stages of refrigerant intercooling.

We cietermined an uptimum distribution of heat exchanger area between the evaporator and the condenser for an L-M RF by a sensitivity analysis using the CYCLE-Z model. The same ratio worked well for NARM pairs with low, moderate, and large temperature glides. This optimum ratio was used for all of the NARM comparisons.

With NARMs, subcooling with suction gas and two-phase refrigerant between the lowand high-temperature evaporators is a very effective method to improve refrigerating performance. The extent of subcooling and the location at which the subcooling is performed are functions of the components and composition of the NARM pair. Allowing the suction line and condenser liquid line to come to ambient temperature as the first stage of subcooling/superheating appears to iimit the performance potential of the L-M cycle.

Modeling calculations have shown that optimization of heat exchanger distribution among the intercooling functions, fresh-food refrigeration, freezer operation, and NARM condensation are critical parameters in designing and demonstrating this L-M refrigeration circuit.

\section{CALCRIMETER TESTING WITH NARMS}

\subsection{INTRODUCTION}

The compressor is the most active part of any vap -compression refrigeration system. Knowing the performance characteristics of a compressoi with a given refrigerant at a specified 


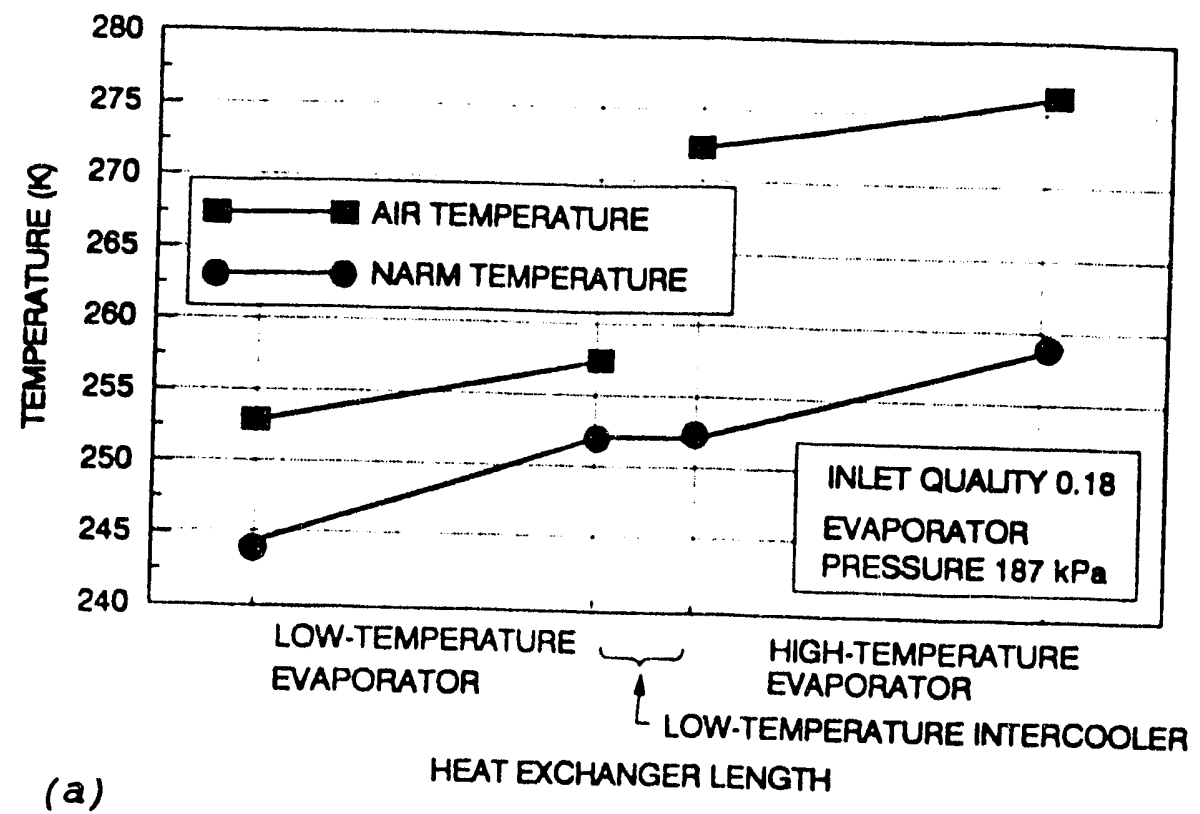

OANR-DWO 80-6062A

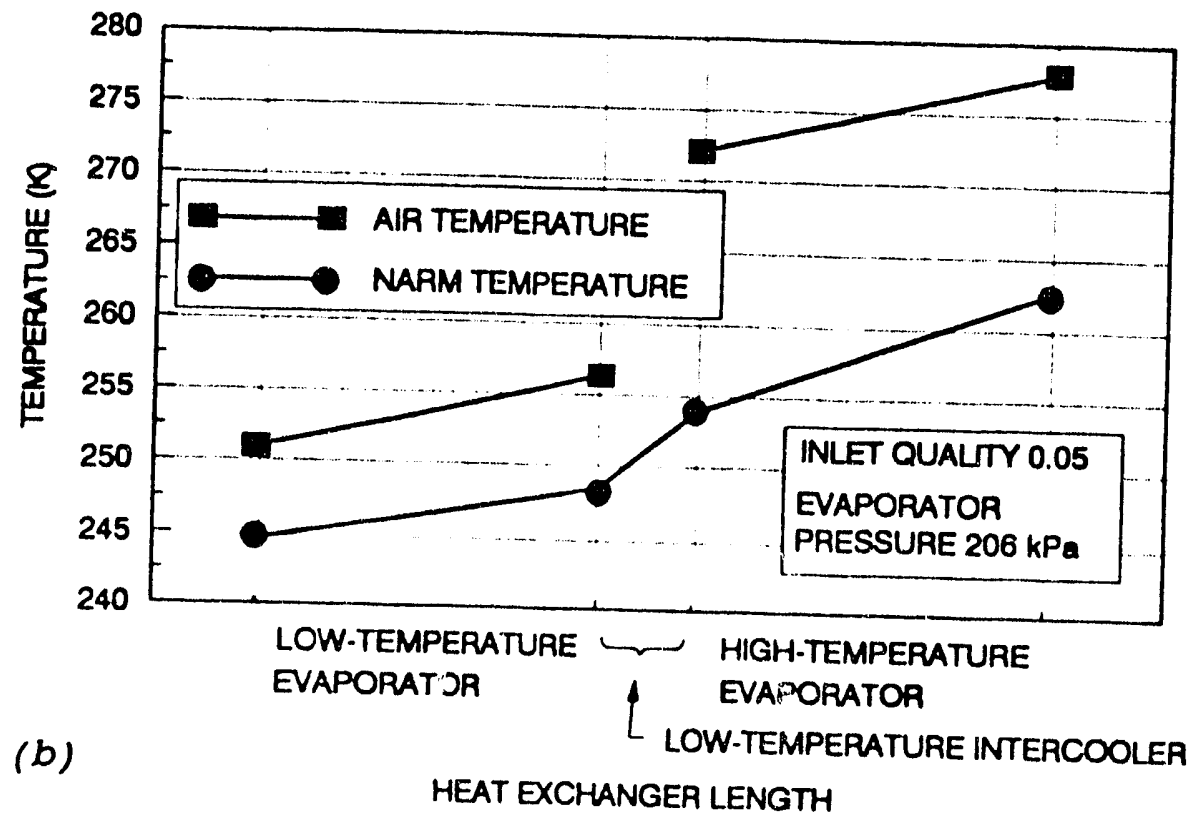

Fig. 2.6. Effects of subcooling in the low temperature intercooler. Matching refrigerant-side and air-side glides and elevated suction pressure resulting from additional liquidline subcooling. $(a) 0^{\circ} \mathrm{C}$ low-temperature subcooling for 0.30 mass percent R32/R 124 nonazcotropic refrigerant mixture (NARM); (b) $30^{\circ} \mathrm{C}$ low-temperature subcooling for 0.30 mass
percent R32/R 124 NARM 
set of operating conditions is typically the prerequisite for sizing and designing all the other components needed for a refrigeration circuit to handle a certain application.

Standard 23-78 of the American Society of Heating. Refrigerating, and Air Conditioning Engincers (ASHRAE), Standard Methods of Testing for Rating Positive Displacement Refrigeration Compressors, was written to provide engineers with an objective, uniform, industry-wide basis for rating and comparing the capacity and efficiency of compressors. ${ }^{16}$ This purpose can be expanded to establishing and comparing the performances of new refrigerants with a given compressor.

In addition to researching other refrigeration cycles, finding refrigerant fluids that do not have as many environmental liabilities as R-12 was also part of this RF work. The L-M cycle obviously requires NARMs that can be blended from a varicty of fluids with lower ODPs and smaller GWPs than the CFC refrigerants.

Out of necessity, most of the experimental work on prototype RF systems has required the use of compressors that were originally designed and optimized for R-12. A central question about the system performance data resulting from testing these prototypes will be how well the new refrigerants perform in a compressor designed to work with another fluid.

The testing and results presented in this section show the relative performance characteristics of NAKM and other non-CFC refrigerants that are being considered for domestic refrigeration in R-12 compressors. This compressor calorimeter data is needed to help select the best fluids for additional testing and to ascertain if changes in RF prototype performance are attributable to the thermodynamics of the cycle, or if they are partially due to changes in the efficiency of the refrigerant/compressor combinations used in the test setup.

\subsection{CALORIMETER SET-UP AND TEST PROCEDURE}

We used a $\operatorname{Starco}^{\circ} 100-3000 \mathrm{Btu} / \mathrm{h}$ calorimeter for this work. The suction and discharge lines between the calorimeter and an environmental chamber containing the compressor were insulated to improve the compressor rating precision. A factory calibrated wattmeter and a watt-hour totalizer working off the same switches that control the electrical-heater and refrigerant-flow totalizers were installed on the calorimeter to measure and integrate electrical power input to the compressor motor.

For RF applications, compressor capacities and energy efficiency ratios (EERs) are usually measured at all nine operating conditions corresponding to $110^{\circ}, 120^{\circ}$, and $130^{\circ} \mathrm{F}$ condenser temperatures and $-20^{\circ},-10^{\circ}$, and $0^{\circ} \mathrm{F}$ evaporator temperatures. Also specified in the test procedure are a $90^{\circ} \mathrm{F}$ ambient temperature for the compressor, superheating of the suction gas to $90^{\circ} \mathrm{F}$, and subcooling of the liquid line to $90^{\circ} \mathrm{F}$. In addition, a uniform horizontal air flow of 3.5 $\mathrm{ft} / \mathrm{s}$ across the top of the compressor is stipulated.

A consistent procedure was established for comparing the performances of pure refrigerants and NARMs. Radermacher and McLinden had shown that NARM performance comparisons are totally dependent on the pressures chosen to correspond to NARM evaporator and condenser temperatures. ${ }^{8}$ Some recommend that NARMs be rated at the bubble point for the condenser temperature and at the dew point for the evaporator temperature. ${ }^{17}$ Figures 3.1 and 3.2 from the Radermacher/McLinden paper classify this method of rating as "Case B" and illustrate that it is the most conservative (pessimistic) way to rate the cycle performance of NARMs. Using the midpoint of the NARM glide, "Case C" in Figs. 3.1 and 3.2, is more widely accepted, but this approach can lead to a crossover of the refrigerant temperatures and sink or source temperatures for NARMs with high glides, which would be a violation of the second law of thermodynamics. Results reponed by Boot support this glide midpoint or averaged temperature approach. ${ }^{18}$ 


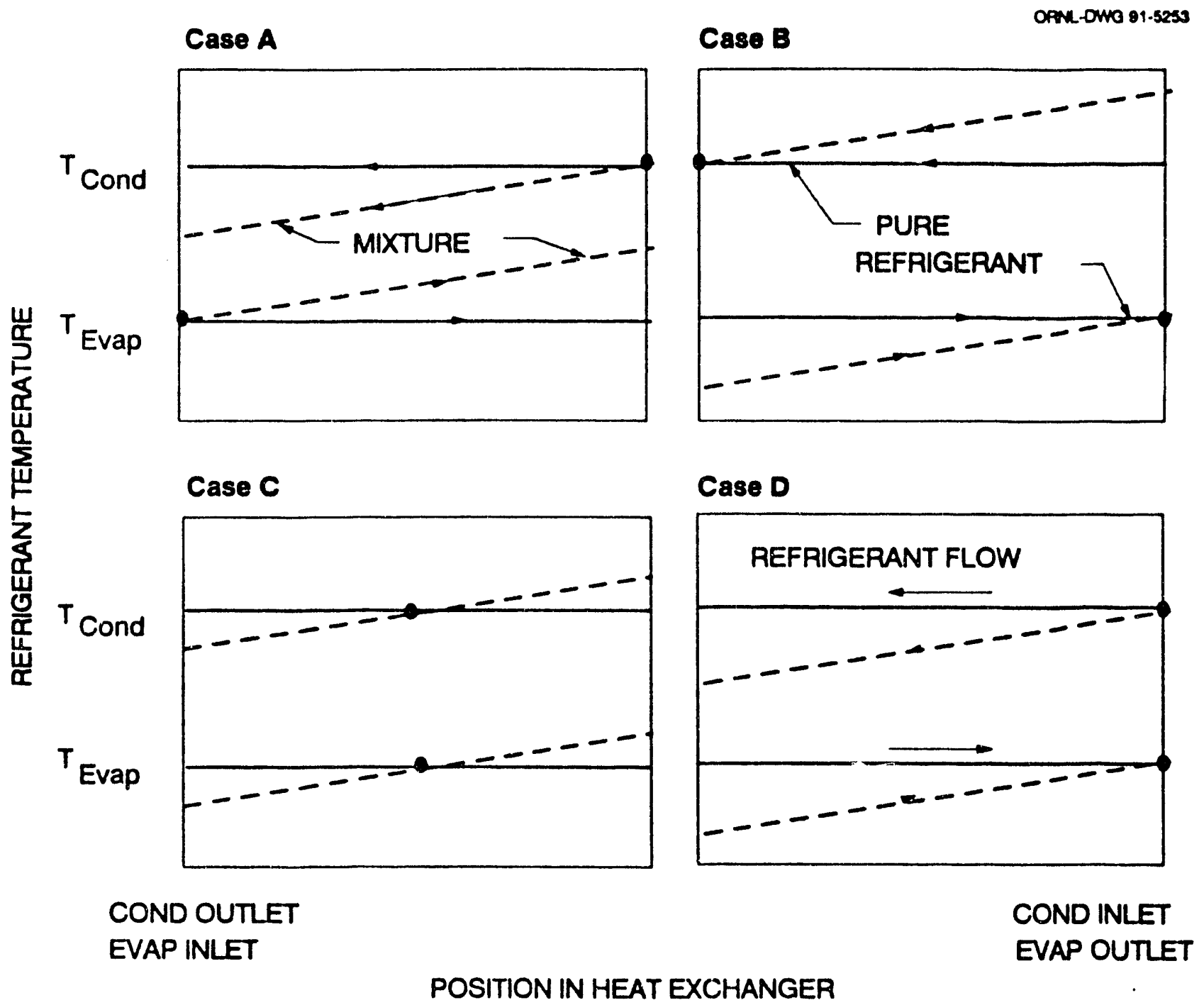

Fig. 3.1. Four cases of specified refrigerant heat exchanger comparisons. Refrigerant mixtures (--) to pure refrigerants (- - at characteristic evaporator or condenser temperatures. 


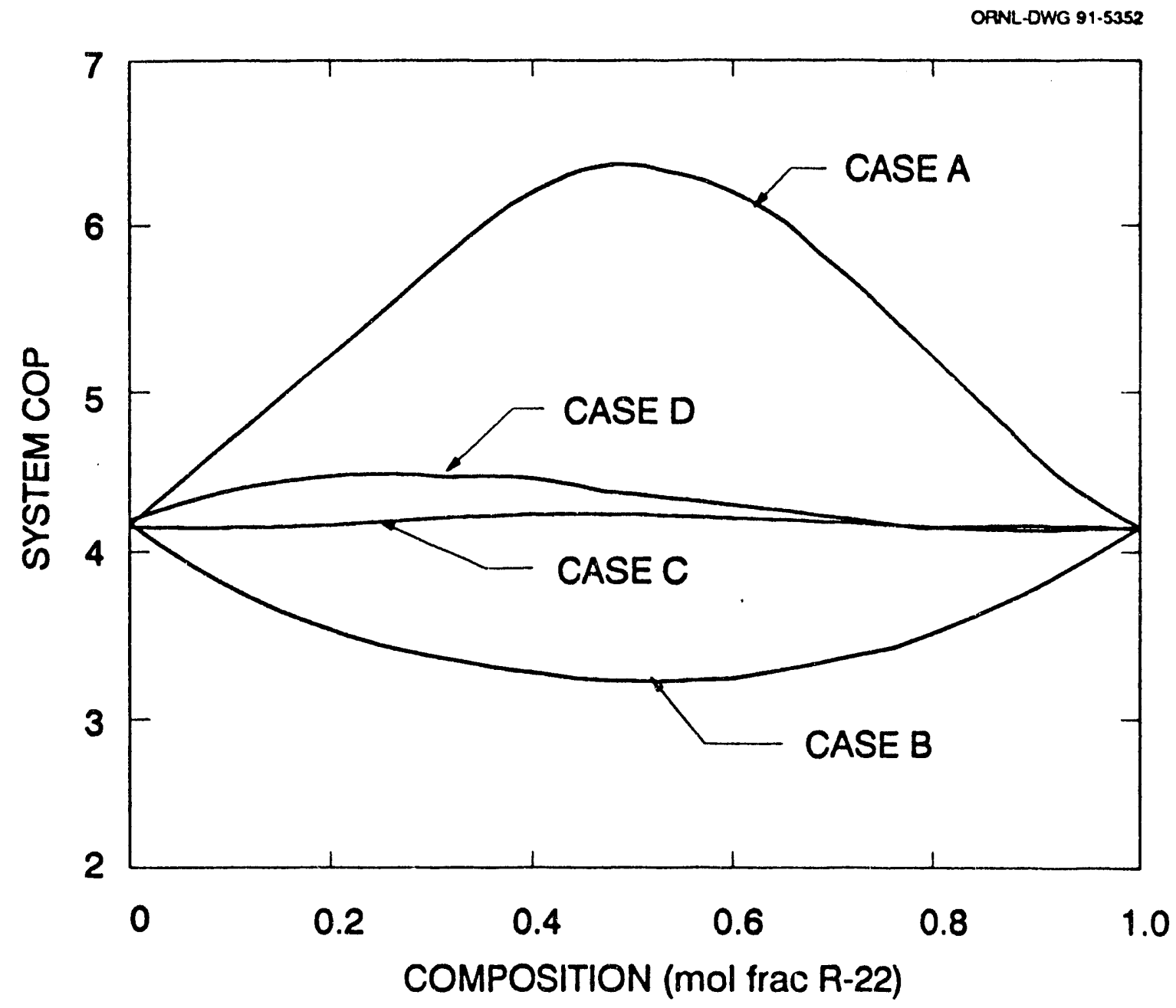

Fig. 3.2. Performance for R-22/R-114 mixtures as a function of composition calculated for the four cases of specified refrigerant temperature shown in Fig. 3.1. 
In preparation for this NARM calorimetry work, we developed a methodology to calculate the equilibrium vapor pressure corresponding to the midpoint of the NARM temperature glide in an evaporator or condenser. The method was later modified to compensate for nonlinearity in the NARM temperature/enthalpy profile (glide). This was accomplished by dividing the evaporator or condenser into ien equal changes in enthalpy and computing the pressure that corresponds to the mean temperature of these steps in the two-phase region. This additional computation is required for NARMs, because the suction and discharge pressures are set and controlled on the calorimeter to give operating conditions simulating different evaporator and condenser temperatures.

We calculated evaporator and condenser pressures (based on nonlinear glide means) corresponding to the nine-point $R F$ compressor rating conditions for $R-32 / R-124, R-22 / R-123, R-$ 22/R-14lb, and R-22/R-142b NARMs at concentrations simulating the volumetric capacity of $R-12$, as Table 3.1 shows. Condensing pressures for the R-32/R-124 NARM go as high as 220 psig at the higher condenser temperature, but these pressures are well within the safety margins for R-12 hemelic compressor cans and the components of the small Starco calorimeter. Evaporator pressures for R-22/R-123, R-22,R-14 lb, and R-22/R-142b NARMs, which are all good candidates mixtures for an L-M RF. drop below atmospheric pressure at the lower evaporator temperature rating points. Sub-atmospheric suction pressures are not desirable because they could result in atmospheric contaminants leaking into the refrigcration circuit.

We developed a computcrized data reduction program for the compressor calorimeter that incorporated the Lee Kessler Plöcker (LKP) refrigerant property routines for this work. We used LKP refrigerant property routines for this program because they contained a built-in algorithm for estimating the interaction coefficient (IC) of refrigerant mixtures, and because the calorimeter program was being developed by a student who needed to use the LKP routines for subsequent work. Good agreement had been demonstrated between CSD and LKP based calculations. The program computes compressor capacities. EERs, and COPs from raw calorimeter data. It uses the refrigerant property routines with refrigerant mass tlow rates to provide a refrigerant-side check against compressor capacities calculated from energy supplied to the electrical heaters in the secondary evaporator. Refrigerant-side capacitics were consistently within 1-2\% of those calculated from electric heater measurements. We saw small discrepancies $(0.5-0.6 \%)$ in the refrigerant-side capacities calculated with the LKP and Martin-Hou refrigerant property subroutines.

Table 3.1. Calorimeter evaporator and condenser pressures for nonazeotropic refrigerant mixtures corresponding to mean glide temperatures in the heat exchangers (Glide non-linearities used in calculation)

\begin{tabular}{lccccccc}
\hline $\begin{array}{c}\text { NARM } \\
\text { combination }\end{array}$ & $\begin{array}{c}\text { Mass } / \\
\text { composition }\end{array}$ & $\begin{array}{c}-20.0 \\
\text { (psig) }\end{array}$ & $\begin{array}{c}-10.0 \\
(\text { psig) }\end{array}$ & $\begin{array}{c}0.0 \\
\text { (psig) }\end{array}$ & $\begin{array}{l}110.0 \\
\text { (psig) }\end{array}$ & $\begin{array}{c}120.0 \\
(\text { psig) }\end{array}$ & $\begin{array}{c}130.0 \\
\text { (psig) }\end{array}$ \\
\hline R-32/RI24 & $0.15 / 0.85$ & -0.82 & 2.87 & 7.30 & 135.21 & 157.36 & 181.91 \\
R-32/RI24 & $0.30 / 0.70$ & 5.56 & 10.75 & 16.96 & 189.299 & 218.79 & 251.41 \\
R-22/RI23 & $0.70 / 0.30$ & -1.61 & 2.02 & 6.40 & 137.10 & 159.88 & 185.10 \\
R-22/R141b & $0.80 / 0.20$ & -0.70 & 3.31 & 7.75 & 143.46 & 166.89 & 192.92 \\
R-22/RI42b & $0.40 / 0.60$ & -3.23 & -0.13 & 3.60 & 115.65 & 135.45 & 157.46 \\
\hline
\end{tabular}

Pressures calculated using the Camahan Starling DeSantis (CSD) refngeraill propeny subroutines and estimated interaction coefficients were required.

Tabulaled pressures calculated 10 correypond to "saluration pressure" values used for pure refrigerants. 


\subsection{CALORIMETER TEST RESULTS}

\subsubsection{Embraco FT 9 RW}

Calorimeter results with R-12 in an Embraco ${ }^{\circ} \mathrm{FT} 9 \mathrm{RW}$ compressor are summarized in Table 3.2. These tests were conducted with a compressor power line voltage of $130 \mathrm{~V}$ higher than the $115 \mathrm{~V}$ specified in the test procedure. Repeated runs at $115 \mathrm{~V}$ for the $130^{\circ} / 0^{\circ}$ and $110^{\circ} /-10^{\circ} \mathrm{F}$ conditions are shown in Table 3.3. We measured a slightly improved EER $(0.5-2.7 \%)$ at the controlled voltage. We performed subsequent tests with electrical power to the compressor controlled at 115 volts.

\subsubsection{Tecumseh AE $1360 \mathrm{D}$}

We rated a Tecumseh ${ }^{\circ}$ AE 1360 D compressor identical to that used in the L-M RF test unit (see Sect. 3.3.2.1) on the small calorimeter with $R-12$ and both $R-32 / R-124$ and $R-22 / R-141 b$ NARM refrigerants to support work being performed on the L-M RF design. Baseline calorimeter tests with $R-12$ are shown in Table 3.4.

We prepared the R-32/R-124 and R-22/R-14lb NARMs used for calorimeter testing by weighing appropriate amounts of pure components into a gas cylinder cooled in dry ice. A gas manifold that permits convenient addition and removal of this NARM from the liquid phase of the sample cylinder was added to the calorimeter. We installed a sampling port at the condenser inlet of the calorimeter, but difficulties in obtaining representative, single-phase samples for NARMs precluded its use. The following tables present results for NARM concentrations as prepared in the sampling cylinder and charged into the calorimeter from the liquid phase. Known flammability limits of R-32 in air were used to estimate the nonflammable and flammable concentrations of R-32 in R-124.

\subsubsection{R-32/R-124 NARMS}

Table 3.5 summarizes the standard nine-point test on the Tecumseh AE 1360 D compressor operating with a $30 \%$ by mass R-32/R-124 NARM. These results indicate a drastic improvement in the EER of this compressor at operating points comparable to the R-12 compressor map. This improvement is due almost entirely to a substantial increase in refrigeration capacity with a small increase in compressor power consumption. Unfortunately, this compressor did not have enough starting torque to cycle on and off with the $30 \%$ R-32/R-124 mixture. A $15 \%$ mixture of R-32 in R-124 was prepared by diluting the $30 \%$ mixture with additional R-124.

The simulated effects of decreasing the R-32 concentration in this NARM from $30 \%$ by mass to $15 \%$ by mass can be estimated from the results presented in Fig. 2.4. The CYCLE-Z L$M$ RF model predicts a decrease in system COP from approximately 1.575 to about 1.540 , but the volumetric capacity of the mixture with less R-32 more closely approximates R-12, the refrigerant for which this compressor was designed.

Table 3.6 shows test results for a $15 \%$ by mass mixture of R-32 in R-124. This NARM has a refrigeration capacity very similar to that of $R-12$ in this compressor, but it showed a significantly higher EER than R-12 at similar operating conditions, as Fig. 3.3 shows. 


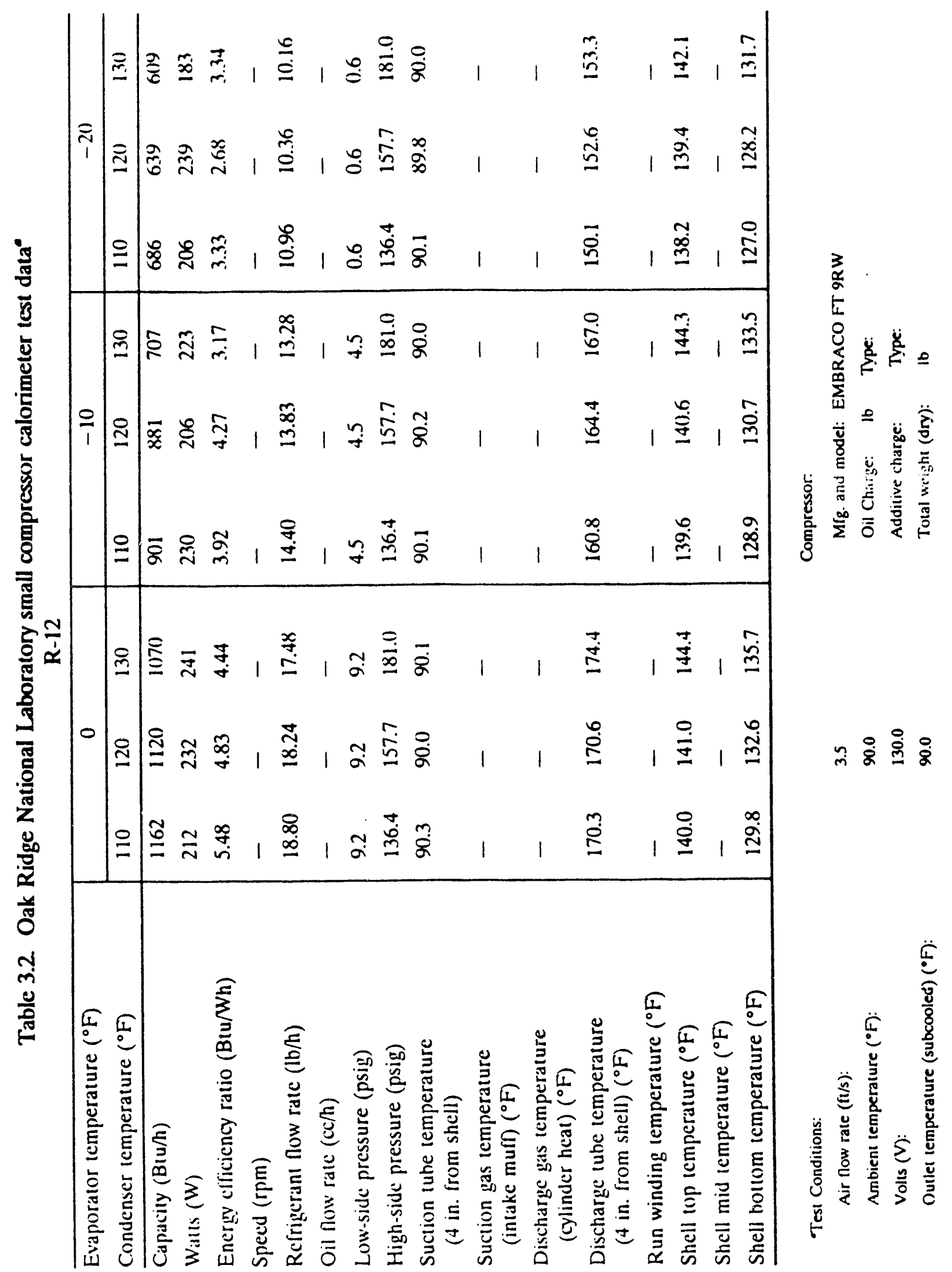




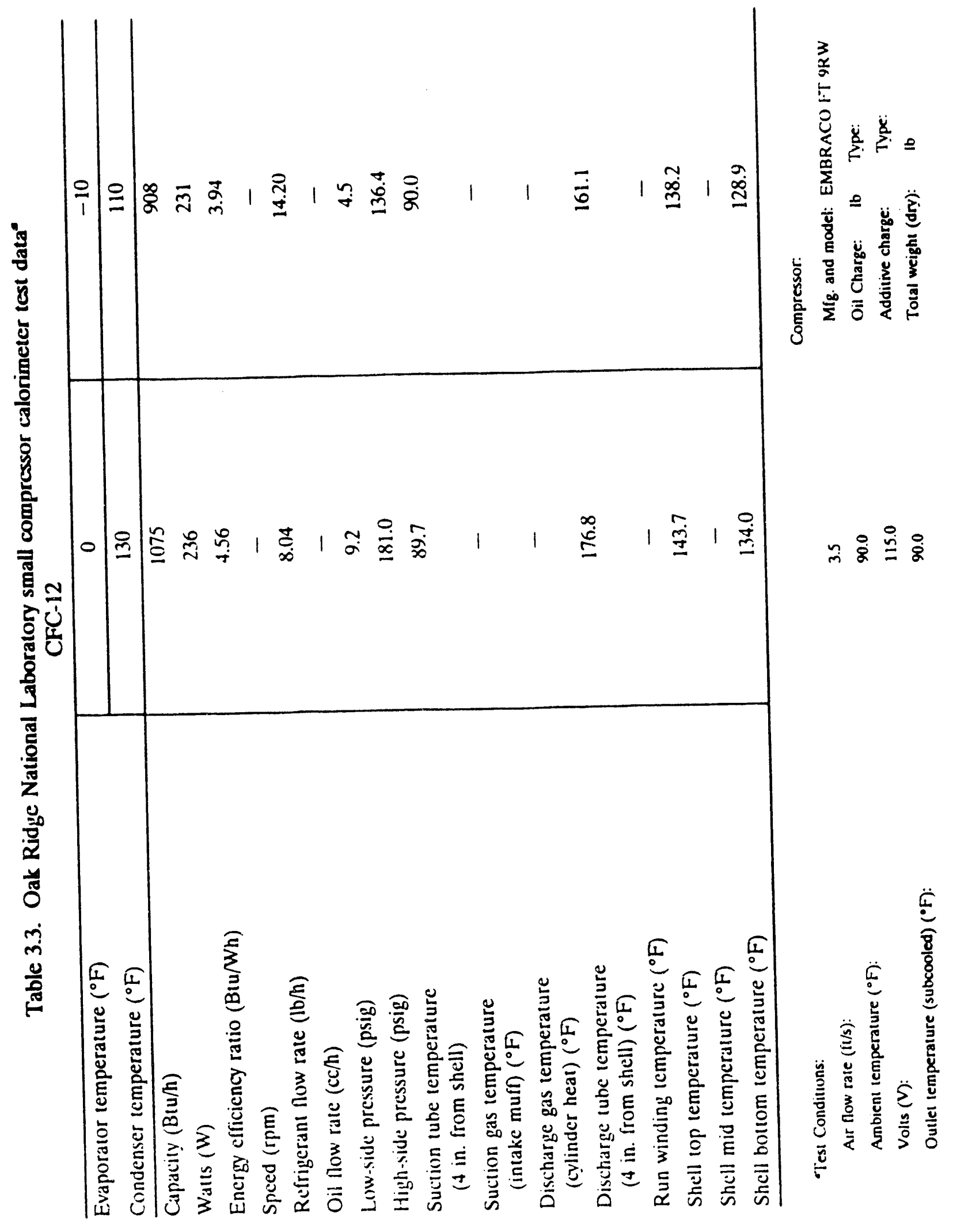




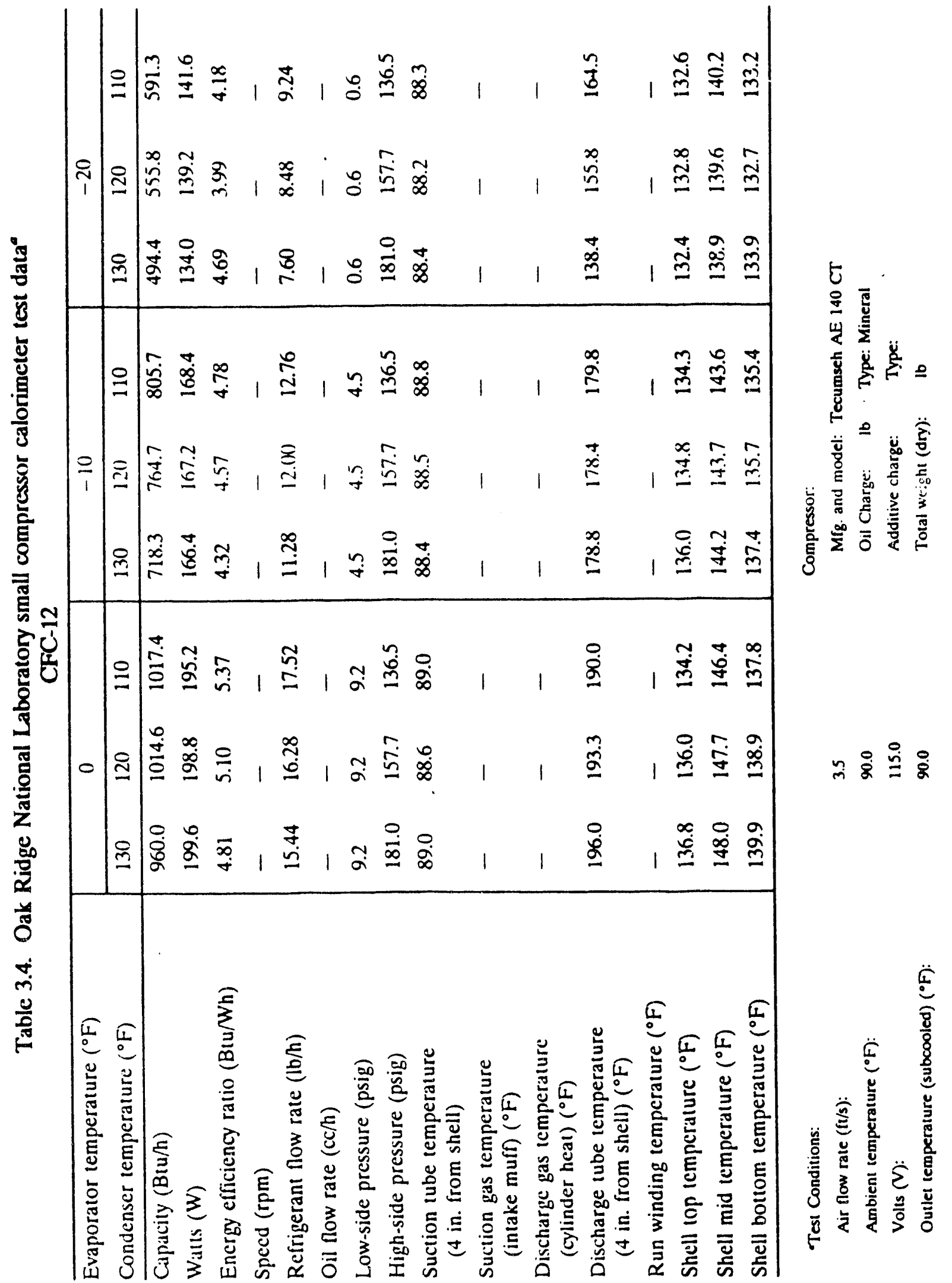




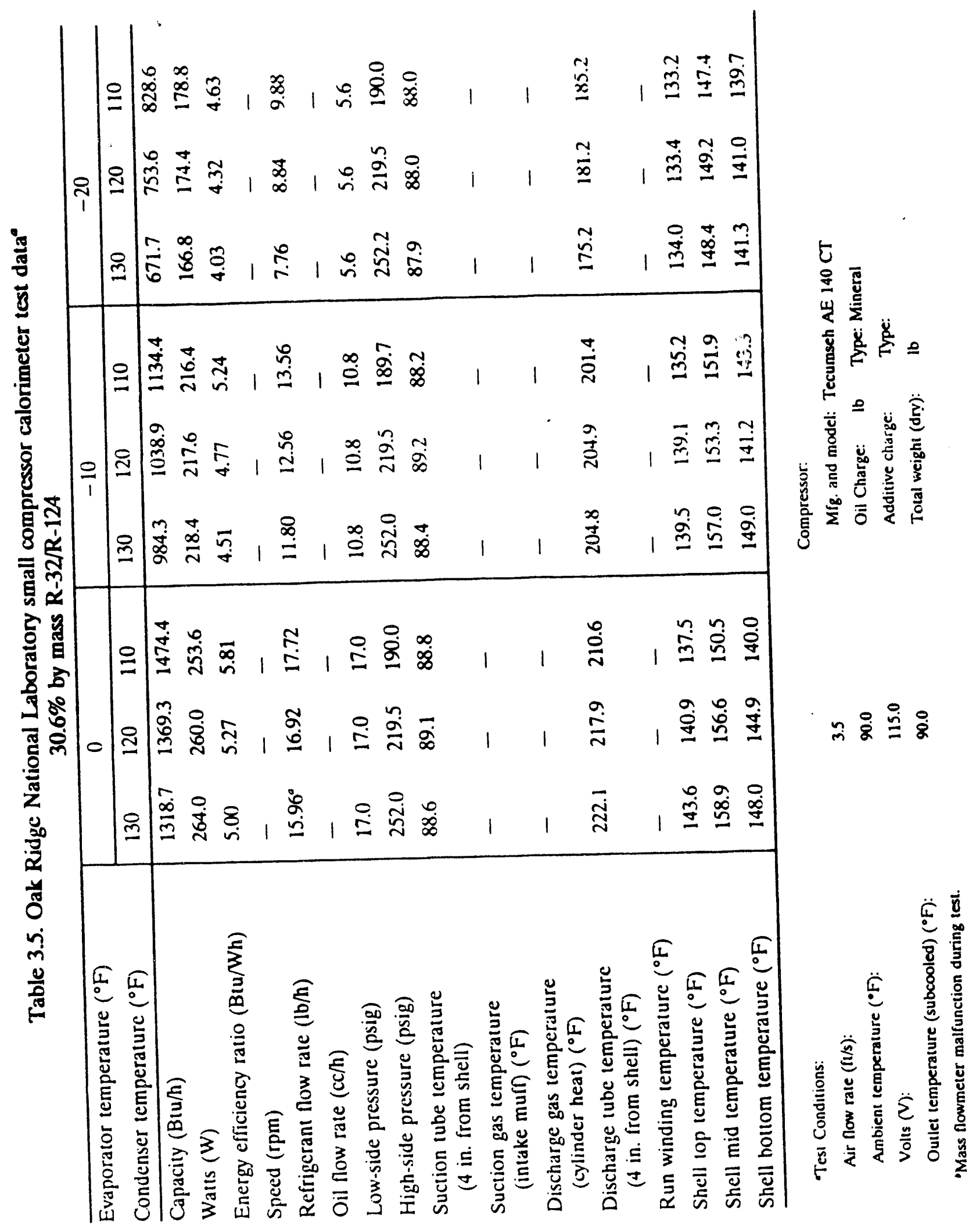




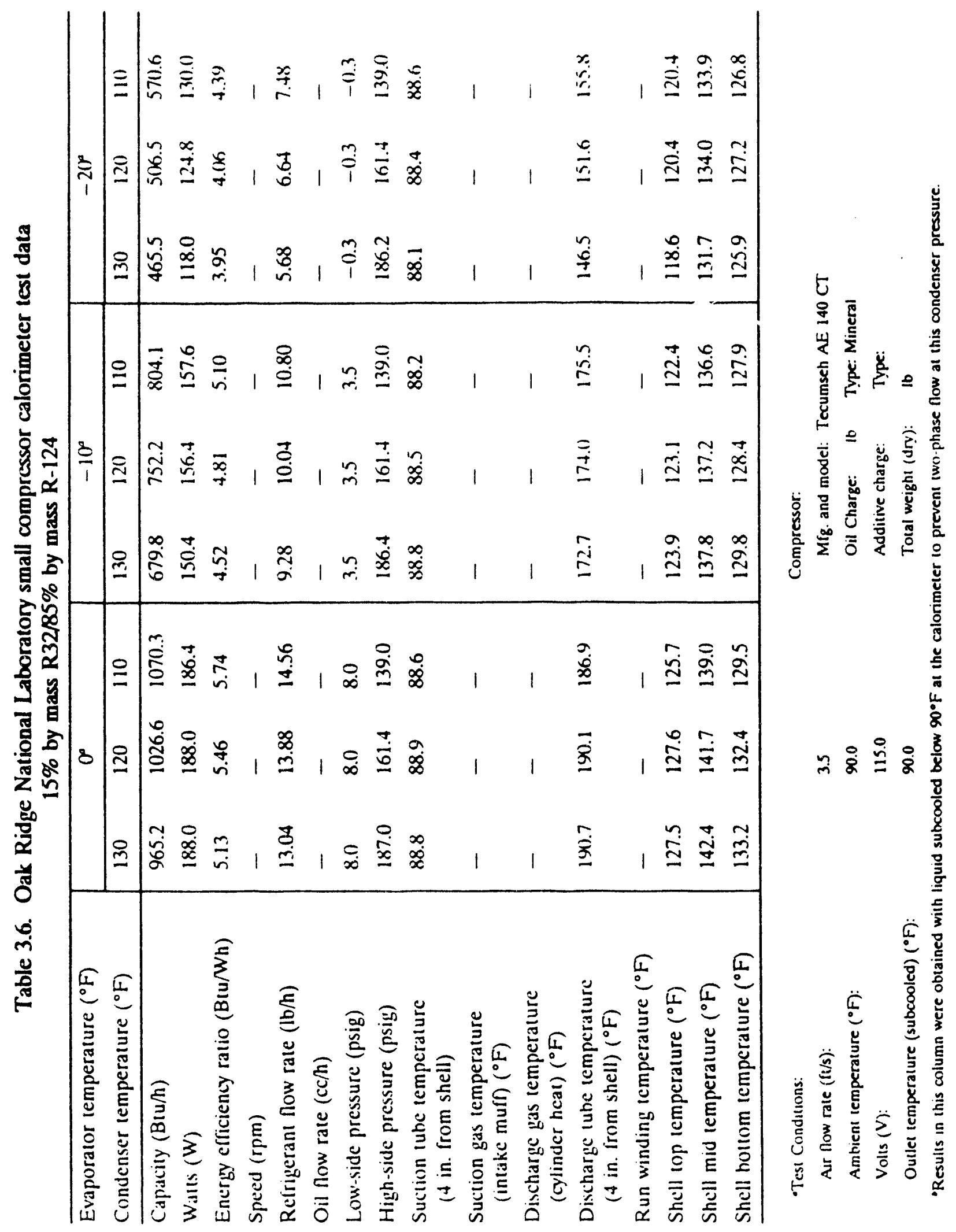






Fig. 3.3. Compressor capacity and energy efficiency ratio comparison of $R \cdot 12$ to $15 \% \quad \mathrm{R}-32 / 85 \% \quad \mathrm{R}-124$ and $80 \% \quad \mathrm{R}-22 / 20 \%$ R-141b Lorenz-Meutzner nonazeotropic refrigerant mixtures for a Tecumseh $\mathrm{AE} 140 \mathrm{CT}$ compressor. 


\subsubsection{R-22/R-14lb NARM}

At the requests of EPA and the University of Maryland, ORNL also rated this Tecurnseh compressor with an $80 \%$ by mass R-22/R-14lb NARM on the calorimeter. The University of Maryland requested the compressor run with this sample at a 9.3 psig saturated evaporator and 189.3 psig saturated condenser condition (which roughly corresponds to a $0^{\circ} \mathrm{F}$ evaporator and $110-120^{\circ} \mathrm{F}$ condenser condition according to our program) to calculate the NARM equivalents of saturated evaporator and condenser temperature measurements, as Table 3.1 shows.

The R-14lb needed to prepare this mixture was obtained from Dick Crooker at ATOCHEM ${ }^{\circ}$. It was specially dried to bring it up to refrigerant-grade specifications. $R-141 \mathrm{~b}$ is one of the NARM mixtures being used for L-M RF work at the University of Maryland. We performed the standard nine-point calorimeter test for RF compressors at a $90^{\circ} \mathrm{F}$ ambient on the R-22/R-14 lb NARM in a Tecumsch AE 1360 D compressor, as Table 3.7 shows.

Figure 2.3 indicates that the EER of the R-32/R-124 NARM is consistently better than those of R-12 and the R-22/R-14lb NARM ai operating conditions used for the calorimetry testing. The capacity of the NARM containing R-32 ranges from values less than $R-12$ at the lower cvaporator temperatures to slightly greater than $R-12$ at the $0^{\circ} \mathrm{F}$ evaporator condition. The results indicate that the R-32/R-124 NARM should perform better than R-22/R-14/b for this application in this compressor.

\subsubsection{Americold SS6 W-1286}

We also completed compressor calorimeter tests on an Americold SS6 W-1286. 1000 Btu/h compressor operated with R-12 and the $15 \%$ by mass R-32/R-124 NARM as part of this program. This compressor was being considered for use in the L-M RF test unit if more capacity was needed. Tables 3.8 and 3.9 summarize results from these calorimeter tests. A polyol ester was used as the lubricant in the Americold SS6 W-1286 compressor at the suggestion of the manufacturers. Differences in the viscosity index (temperature variation of oil viscosity) of mineral oils and polyester synthetic oils made it appropriate to use the less viscous polyester oil in this RF application. Because R-12 and the NARM were tested with the same oil, the results should be comparable. Figures 3.4 and 3.5 show refrigeration capacities and EERs measured for this compressor operated with R-12 and the R-32/R-124 NARM at the $120^{\circ} \mathrm{F}$ and $130^{\circ} \mathrm{F}$ condensing conditions, respectively. A trend similar to that seen in previous tests with the R-32/R-124 NARM in R-12 compressors is indicated: at similar refrigeration capacities and operating conditions, the R-32 NARM provides substantially better compressor efficiency.

However, testing described in Sect. 4 indicates that the dynamics of the heat exchange process in the actual application will dictate whether or not this NARM refrigeration capacity is fully utilized. The method of comparing calorimeter results for compressors operaled with single component or azeotropic and NARM refrigerants is one that requires more analysis and research.

\subsubsection{Embraco FGI 10A W}

As part of this program. EPA and the University of Maryland asked ORNL to rate an Embraco FGI $10 \mathrm{AW}$ compressor operated with refrigerant R-152a on the calorimeter at a designated operating condition. We also ran four standard evaporator and condenser temperature conditions that bracket the operating condition. $R-152 \mathrm{a}$ is a flammable refrigerant that has been proposed as a desirable altemative for $R-12$ in RF applications because it has a very short atmospheric lifetime (1.7 years) and low halocarbon GWP (0.03 relative to $R-11)$. We also measured R-12 performance results in this compressor at some of the same operating points and 


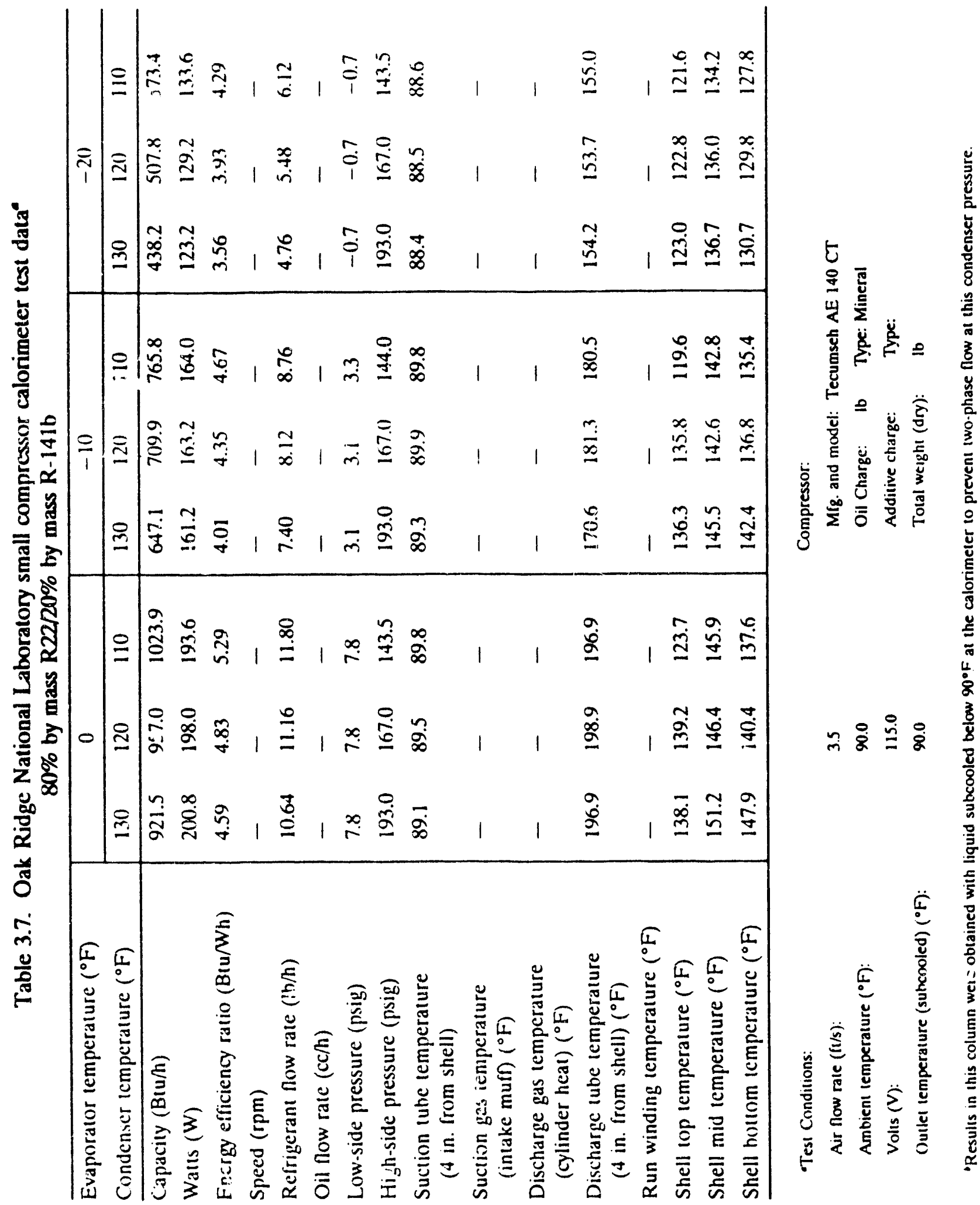




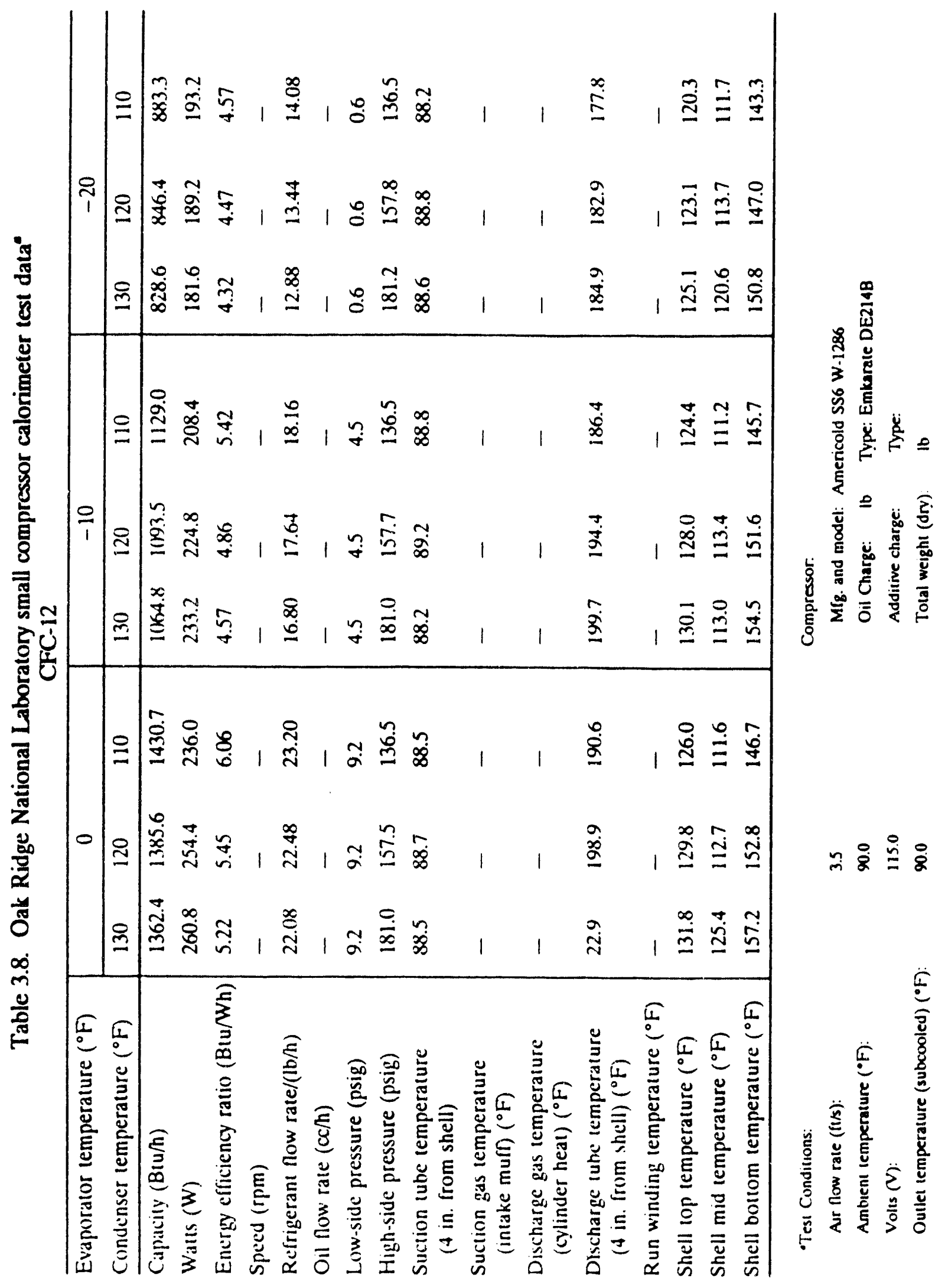




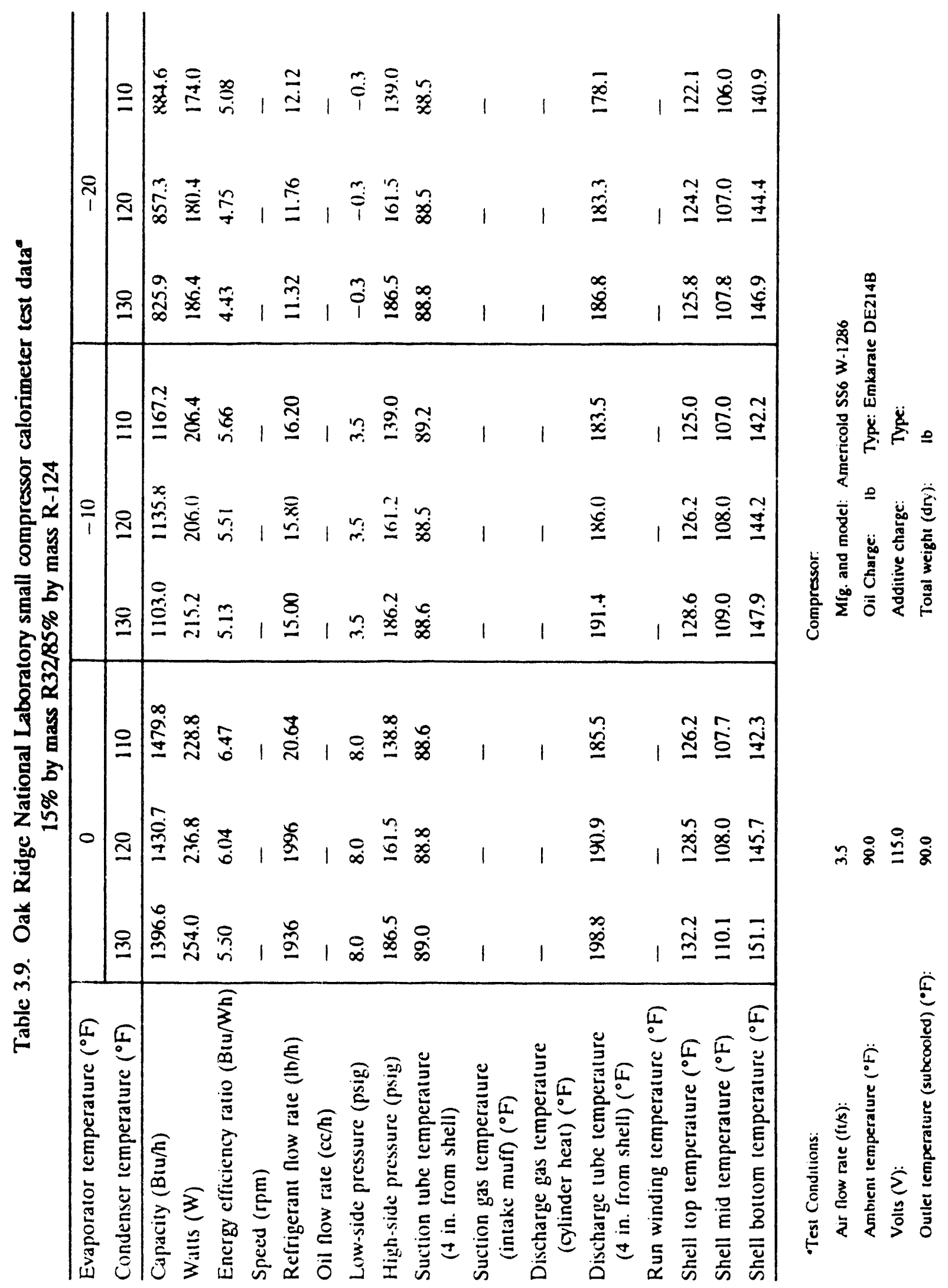




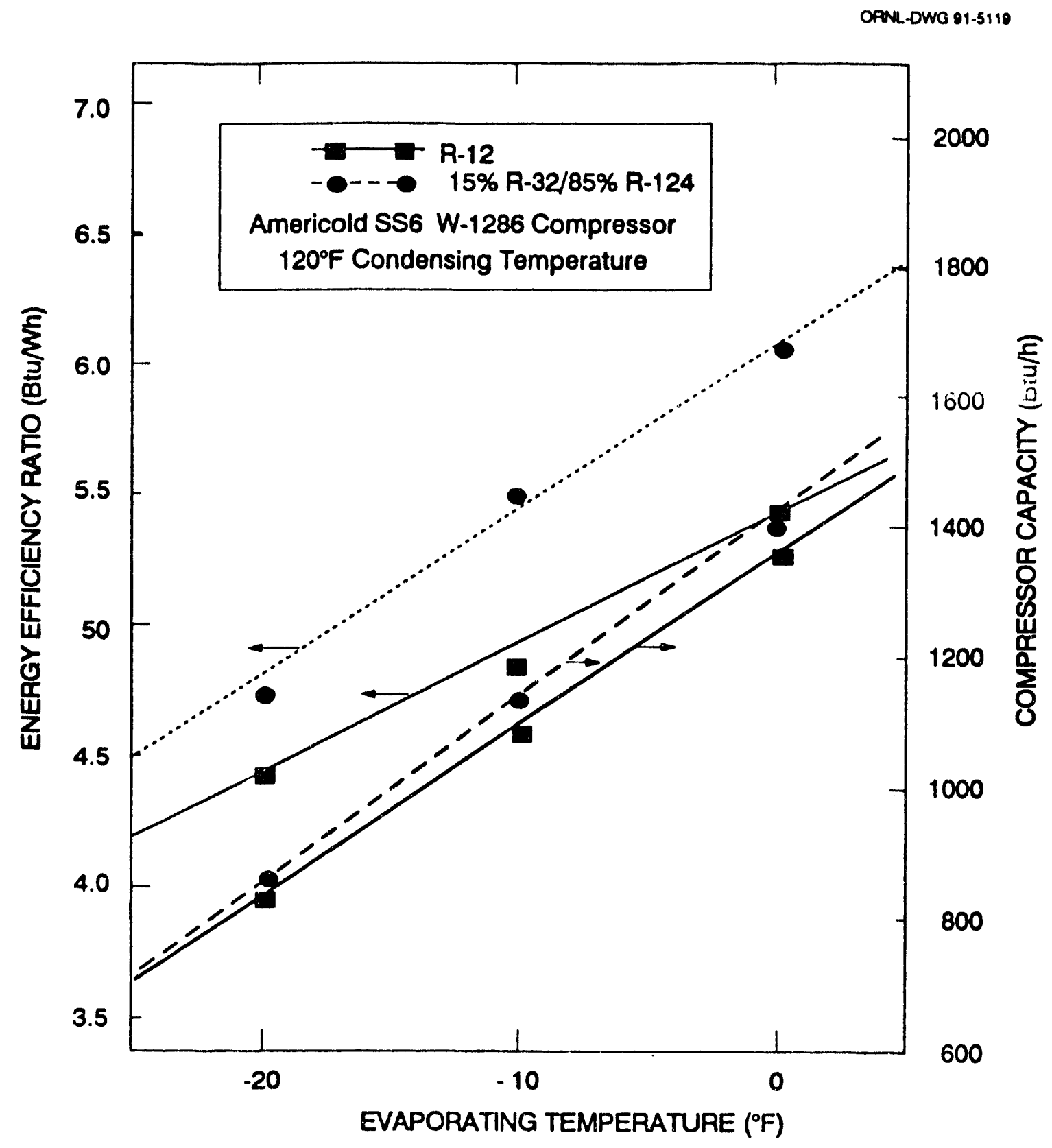

Fig. 3.4. Comparable compressor capacities and energy efficiency ratios for $R-12$ and a $15 \%$ by mass R-32/85\% R-124 nonazeotropic refrigerant mixture in an Americold SS6 W1286 compressor at the $120^{\circ} \mathrm{F}$ condensing condition. 


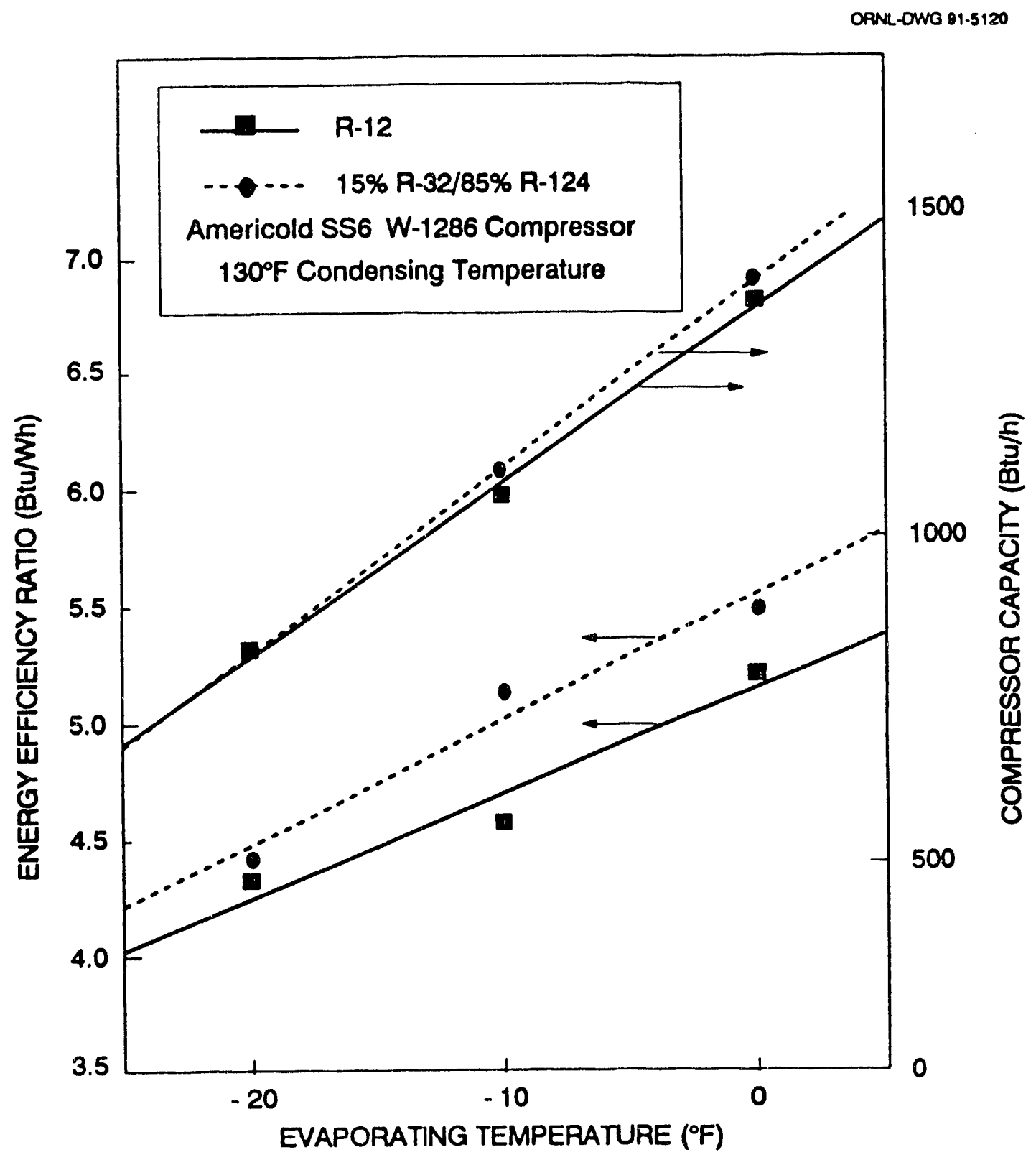

Fig. 3.5. Comparable compressor capacities and energy efficiency ratios for $\mathbf{R}-12$ and a $15 \%$ by mass R32/85\% hR-124 nonazcotropic refrigerant mixture in an Americold SS6 $\mathrm{W}-1286$ compressor at the $130^{\circ} \mathrm{F}$ condensing condition. 
at the $130 \%-10^{\circ} \mathrm{F}$ standard rating condition to provide comparable $\mathrm{R}-152 \mathrm{a}$ and $\mathrm{R}-12$ results and to verify their accuracy. Tables 3.10 and 3.11 of this report, which summarize the data obtained from these calorimeter tests, indicate that $R-12$ has a larger volumetric capacity than $R-152 a$, but that the compressor operates more efficiently with $R-152 a$. $R-12$ results of the $130^{\circ} \mathrm{F}$ condensing/$10^{\circ} \mathrm{F}$ evaporating condition support the manufacturer's rating.

\subsection{CONCLUSIONS AND DISCUSSION}

We developed a protocol to define calorimeter operating pressures for NARMs that correspond to saturated evaporator and condenser temperatures commonly used with pure refrigerants. We used a calorimeter pressure matching the mean glide temperature of the NARM (accounting for any nonlinearities in the temperature/enthalpy profile).

Using a calorimeter testing procedure based on the mean glide temperature, we obtained comparable compressor performance results for pure refrigerants and NARMs in the same compressor operating under the "same" conditions.

Calorimeter tests of several NARM candidates indicated that compressors designed for use with R-12 could efficiently handle certain NARMs.

Compressor can heat loss measurements, while not tabulated with the regular calorimeter data, ranged from 70 to $80 \%$ of the compressor input power. This was much larger than the $10 \%$ used for CYCLE-Z modeling (Sect. 2). Additional can heat loss has the effect of reducing refrigerant discharge temperatures from the compressor.

\section{EXPERIMENTAL TESTING OF LORENZ-MEUTZNER DESIGN}

\subsection{BACKGROUND}

Based on Dr. Horst Kruse's 1989 ASHRAE presentation' describing the experimental performance of an R-22/R-142b NARM in an L-M RF design, we initiated work to build and demonstrate the performance of a prototype, two-evaporator RF operating with NARMs. Researchers from ORNL and EPA visited Dr. Kruse at his laboratory in Hannover, Germany, to review the work he had already done on the L-M cycle, to obtain the code for his RF simulation model, and to work out a protocol for instrumenting and monitoring the performance of L-M RFs designed to satisfy the American market.

As a result of our discussions in Hannover, we decided to obtain Amana ESTR 18D RFs as the base models for this study because they were 18- $\mathrm{ft}^{3}$, top-mount RFs typical of the most common U.S. model and were designed with separate freezer and fresh food eyaporators. These Amana RFs also incorporatcd such energy saving features as additional wall-insulation and longer defrost cycle times that would enhance their efficiency. EPA, through ICF corporation in Virginia, located and arranged the purchase of three used Amana ESTR 18D RFs from private owners. 


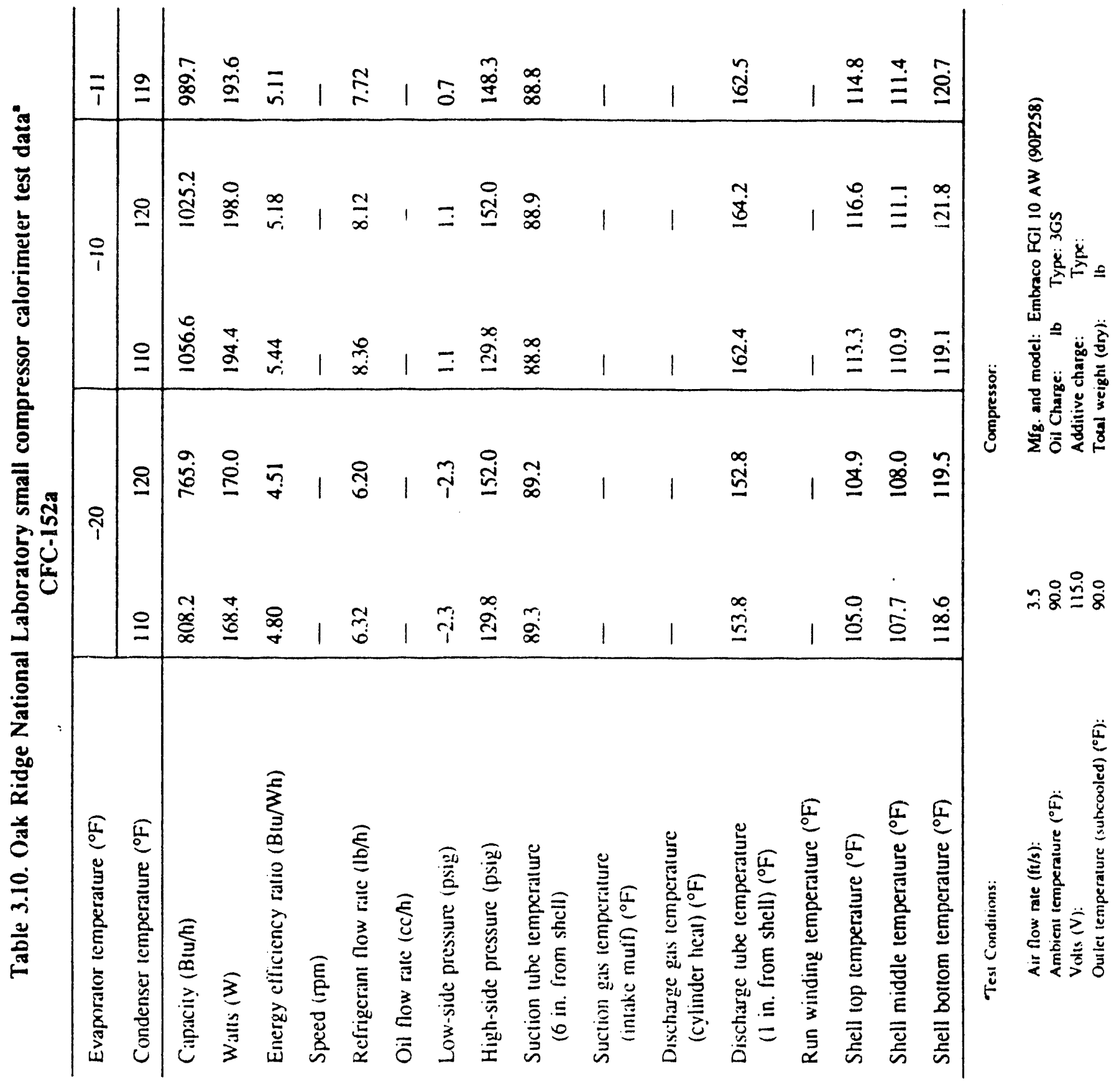




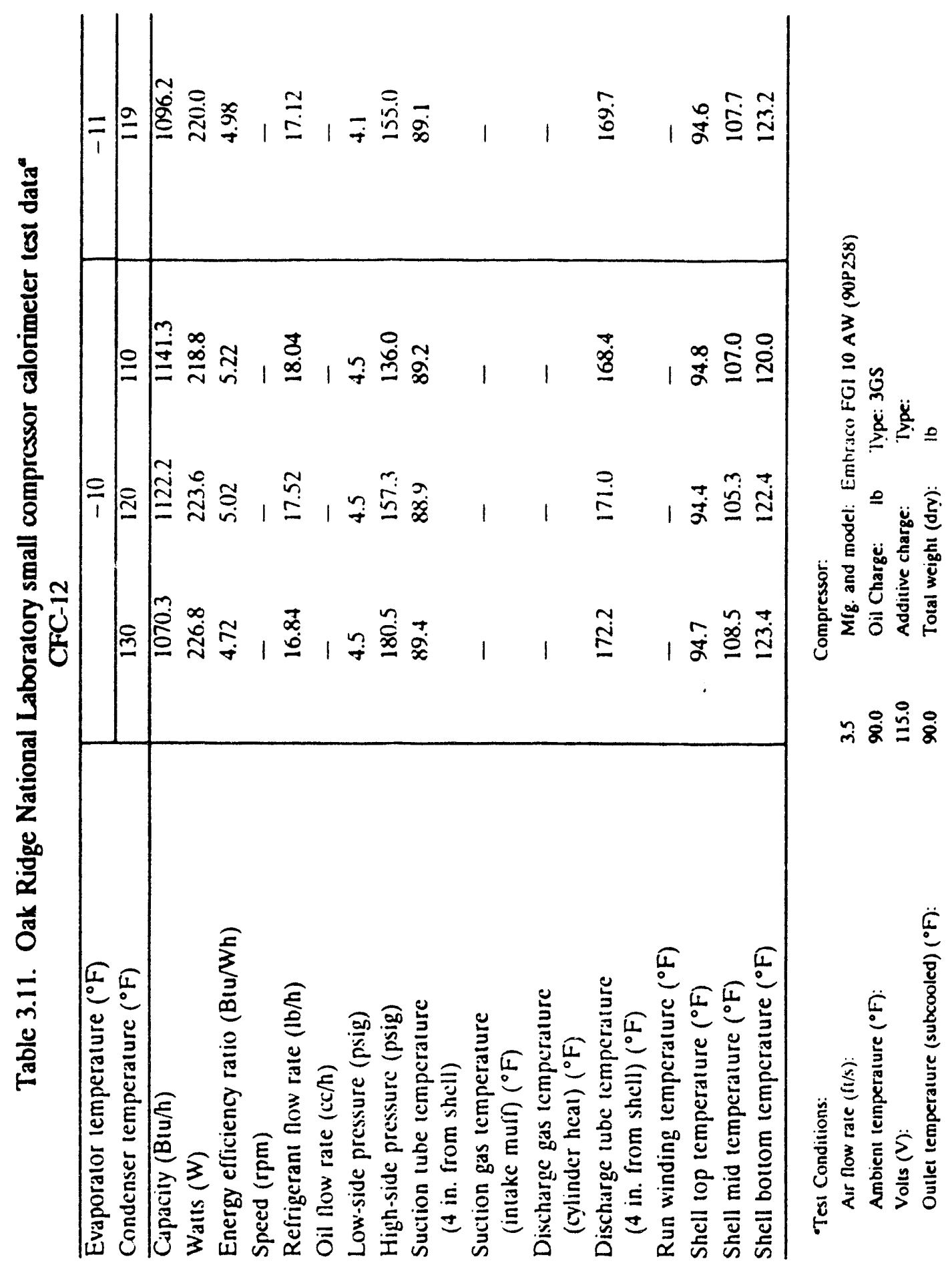




\subsection{BASELINE TESTING OF UNMODIFIED UNITS}

All three of the unmodified Amana two-evaporator RFs were instrumented with intemaland extemal-ambient thermocouples to make air-side measurements according to the AHAM procedure. Their daily energy consumption was monitored in a small environmental chamber at the $90^{\circ} \mathrm{F}$ closed-door condition. In addition, we installed relative humidity sensors in the fresh food compartment of these test units and monitored them during the test procedure to verify that the two-evaporator approach inherent in this design would result in higher refrigerator humidity levels and less dehydration of the fresh foods stored in this section.

The defrost cycle on this two-evaporator, energy-saving design was complicated by a longer-than-nomal interval (48-h compressor run time) between major freezer defrosts with minor, fresh-food evaporator defrosts occurring every $10 \mathrm{~h}$, as Fig. 4.1 shows. We determined kWh/d energy use measurements over the cycle between freezer defrosts. To help simplify the data reduction and analysis, simple contact relays were added to the RFs that give a " 1 " or " 0 " response when the compressor is on or off, respectively, or when a system defrost is occurring.

Some modification of the small environmental chamber was required in order to adequatcly control ambient temperatures during RF compressor "on" cycles when two or more RF units were being tested simultaneously. The extemal thermocouple on the "windward" side of these forced-condenser RFs showed a three- or four-degree temperature swing between on and off cycles. Small fans were eventually used inside the chamber to keep ambient temperature variations within the limits prescribed by the AHAM $90^{\circ}$ closed-door test procedure.

We built a computerized data acquisition system around an ACUREX ${ }^{\circ}$ data logger, an ACUREX ${ }^{\circ}$ Netpac module, and a small, portable, laptop computer. In-house programs were written for the computer that captured data scans every $15 \mathrm{~s}$ and organized the data into $4-5 \mathrm{~min}$ averages that were written to a disk file for subsequent off-line data reduction. Using this scheme together with the " 0 " for "off" and " 1 " for "on" response mentioned previously, it was possible to time transient events within $15 \mathrm{~s}$ and save several days of operating data on a floppy disk. Figure 4.2 illustrates the capabilities and resolution of this data-gathering equipment during the $90^{\circ} \mathrm{F}$, closed-door tests on one of the unmodified RFs.

Tables 4.1-4.3 summarizes the results of this R-12, baseline testing on all three Amana RFs obtained from the field. It is interesting to note that these Amana RFs were the result of a DOE-sponsored development project in the late 70s-early 80 s and they demonstrated $60 \%$ better energy efficiencies than conventional RFs of that period. ${ }^{19}$ The efficiencies of the units as measured here are, however, poorer in energy efficiency than the currently mandated DOE standard for $18 \mathrm{ft}^{3}$ top-mounts $(2.45 \mathrm{kWh} / \mathrm{d}){ }^{20}$ 


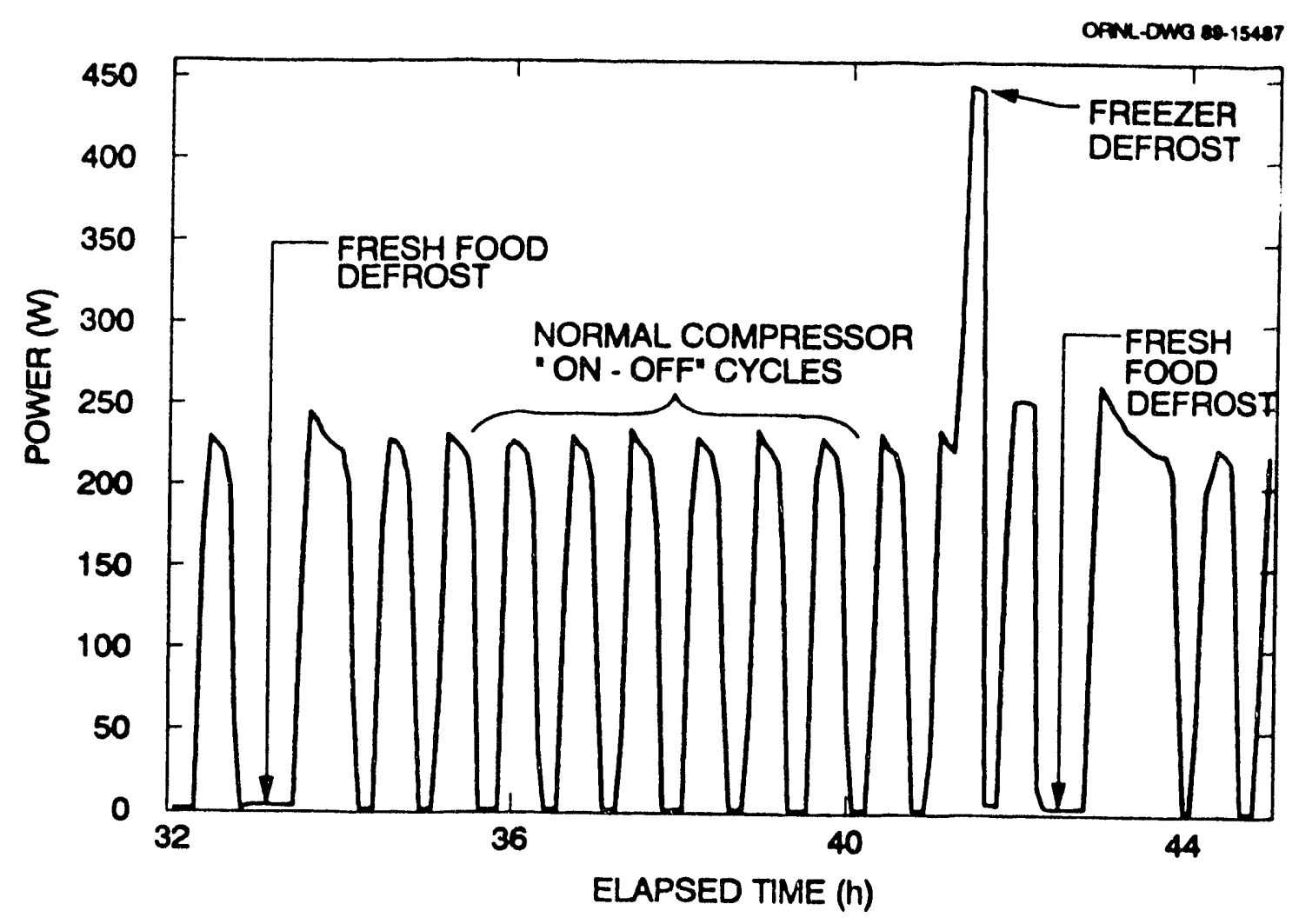

Fig. 4.1. Compressor and defrost cycling data from unmodified Amana ESTR 18D refrigerator-freezers. Illustration of the timing of fresh food and freezer defrosts. 

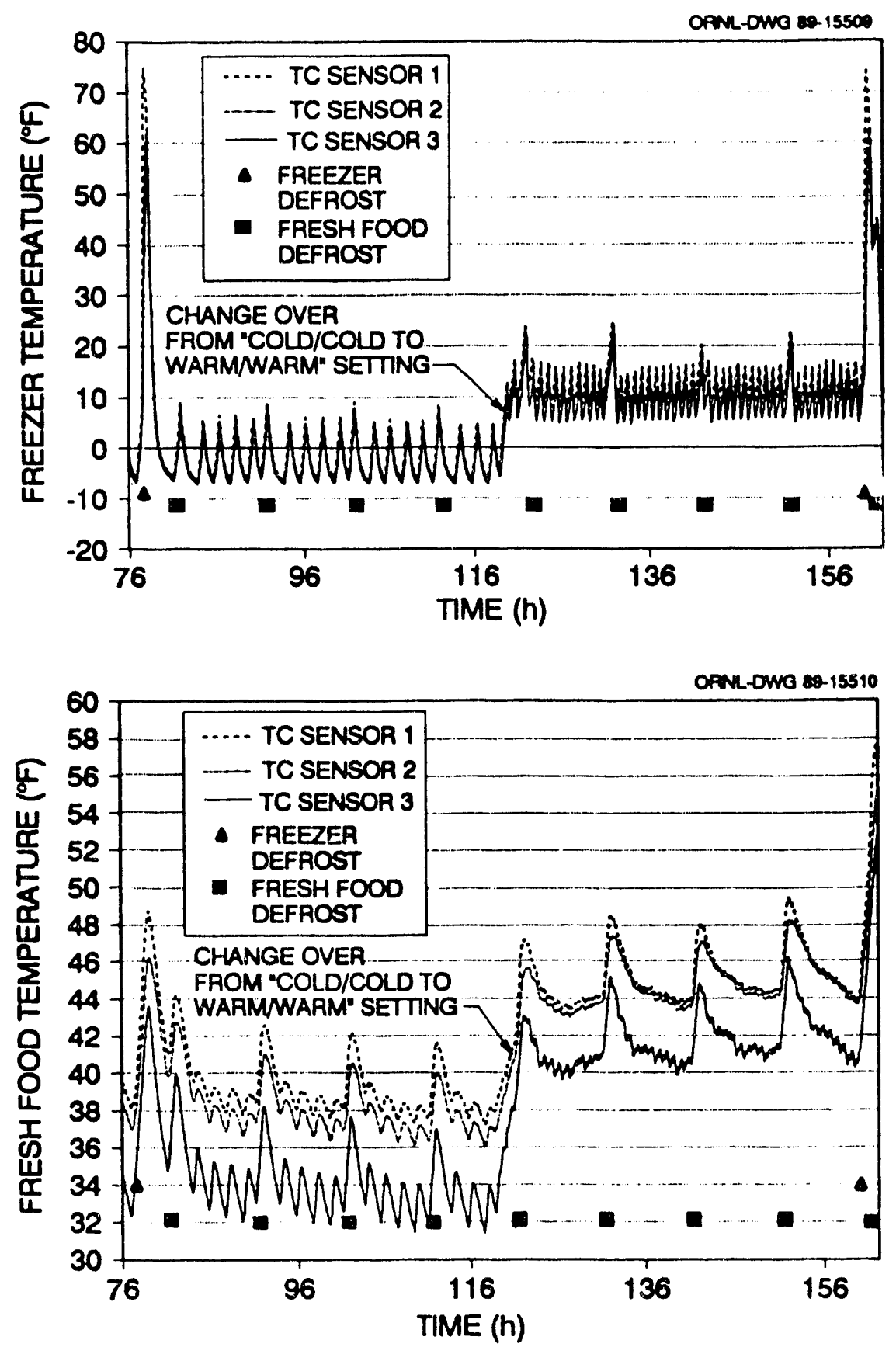

Fig. 4.2. Freezer and fresh food temperatures in closed-door tests of Amana refrigerator-freezers showing transition from $\mathrm{mid} / \mathrm{mid}$ to $\mathrm{warm} / \mathrm{warm}$ thermostat settings. 
Table 4.1. Amana ESTR 18D unit 1-baseline R-12 testing American Home Appliance Manufacturers four point, $90^{\circ} \mathrm{F}$, closed-door test procedure

\begin{tabular}{lcccccc}
\hline $\begin{array}{c}\text { Teinperature } \\
\text { control } \\
\text { selting }\end{array}$ & $\begin{array}{c}\text { Power } \\
\text { consumption } \\
(\mathrm{kWh} / \mathrm{d})\end{array}$ & $\begin{array}{c}\text { Compressor } \\
\text { run time } \\
(\%)\end{array}$ & $\begin{array}{c}\text { Average } \\
\text { freezer } \\
\text { temperature } \\
\left({ }^{\circ} \mathrm{F}\right)\end{array}$ & $\begin{array}{c}\text { Relative } \\
\text { humidity } \\
(\%)\end{array}$ & $\begin{array}{c}\text { Average } \\
\text { fresh food } \\
\text { temperature } \\
\left({ }^{\circ} \mathrm{F}\right)\end{array}$ & $\begin{array}{c}\text { Freczer defrost } \\
\text { cycle time } \\
(\mathrm{h})\end{array}$ \\
\hline Mid/mid/off & 2.857 & 52.3 & 2.77 & - & 37.44 & 88.975 \\
Mid/mid/on & 3.606 & 60.2 & 2.12 & - & 38.11 & 78.683 \\
Warm/warm/off & 2.433 & 43.4 & 12.74 & 20.6 & 43.43 & 109.163 \\
Warm/warm/on & 2.998 & 47.7 & 12.78 & 18.0 & 44.09 & 99.558 \\
\hline
\end{tabular}

Overall power consumption rating: $3.10 \mathrm{kWh} / \mathrm{d}$.

Table 4.2. Amana ESTR 18D unit $2^{\circ}$-baseline R-12 testing American Home Appliance Manufacturers four point, $90^{\circ} \mathrm{F}$, closed-door test procedure

\begin{tabular}{lcccccc}
\hline $\begin{array}{c}\text { Temperature } \\
\text { control } \\
\text { setting }\end{array}$ & $\begin{array}{c}\text { Power } \\
\text { consuinption } \\
(\mathrm{kWh} / \mathrm{d})\end{array}$ & $\begin{array}{c}\text { Compressor } \\
\text { run time } \\
(\%)\end{array}$ & $\begin{array}{c}\text { Average } \\
\text { freezer } \\
\text { temperature } \\
\left({ }^{\circ} \mathrm{F}\right)\end{array}$ & $\begin{array}{c}\text { Relative } \\
\text { humidity } \\
(\%)\end{array}$ & $\begin{array}{c}\text { Average } \\
\text { fresh food } \\
\text { temperature } \\
\left({ }^{\circ} \mathrm{F}\right)\end{array}$ & $\begin{array}{c}\text { Freezer defrost } \\
\text { cycle time } \\
(\mathrm{h})\end{array}$ \\
\hline Mid/mid/off & 2.895 & 55.2 & 1.87 & 23.0 & 37.89 & 85.671 \\
Mid/mid/on & 4.018 & 70.2 & -1.90 & - & 36.79 & 67.409 \\
Warm/warm/off & 2.340 & 41.2 & 10.93 & - & 47.74 & 110.430 \\
Warm/warm/on & 2.954 & 48.7 & 10.55 & 24.0 & 44.28 & 96.870 \\
\hline
\end{tabular}

Overall power consumption rating: $3.07 \mathrm{kWh} / \mathrm{d}$.

-This R/F had a new food defrost kit installed before tests were initiated, and it drew 30-31 W during fresh food defrosts. Units 1 and 3 did not draw any additional power during fresh food defrost cycles.

Table 4.3. Amana ESTR 18D unit 3-baseline R-12 testing American Home Appliance Manufacturers four point, $90^{\circ} \mathrm{F}$, closed-door test procedure

\begin{tabular}{lcccccc}
\hline $\begin{array}{c}\text { Teinperature } \\
\text { control } \\
\text { selting }\end{array}$ & $\begin{array}{c}\text { Power } \\
\text { consumption } \\
(\mathrm{kWh} / \mathrm{d})\end{array}$ & $\begin{array}{c}\text { Compressor } \\
\text { run time } \\
(\%)\end{array}$ & $\begin{array}{c}\text { Average } \\
\text { freezer } \\
\text { temperature } \\
\left({ }^{\circ} \mathrm{F}\right)\end{array}$ & $\begin{array}{c}\text { Relative } \\
\text { humidity } \\
(\%)\end{array}$ & $\begin{array}{c}\text { Average } \\
\text { fresh food } \\
\text { temperature } \\
\left({ }^{\circ} \mathrm{F}\right)\end{array}$ & $\begin{array}{c}\text { Freezer defrost } \\
\text { cycle time } \\
(\mathrm{h})\end{array}$ \\
\hline $\mathrm{Mid} / \mathrm{mid} / \mathrm{off}$ & 2.882 & 55.6 & -0.81 & - & 35.80 & 85.130 \\
$\mathrm{Mid} / \mathrm{mid} / \mathrm{un}$ & 3.715 & 63.9 & -2.06 & - & 36.09 & 73.837 \\
Warm/warm/off & 2.413 & 43.7 & 7.28 & 31.8 & 41.45 & 108.008 \\
Warm/warm/on & 2.992 & 48.5 & 6.48 & 28.9 & 42.09 & 97.454 \\
\hline
\end{tabular}

Overall power consumption rating: $2.83 \mathrm{kWh} / \mathrm{d}$. 


\subsection{LORENZ-MEUTZNER CONSTRUCTION}

We hired Tillery Mechanical, a Knoxville refrigeration service and repair contractor, to modify one of the tested Amana RFs to incorporate the L-M cycle. Only one of the three refrigerators was sent to the subcontractor for modification. because a major share of ORNL's work was directed at an investigation of "dual-loop" RF concepts. Tillery Mechanical was provided with the No. 3 ESTR unit, which showed a $2.83-\mathrm{kWh} / \mathrm{d}$ power consumption in the $\mathrm{R}-12$ baseline testing. We also provided:

- a sketch indicating the sequential arrangement of intercoolers and heat exchangers in addition to thermocouple and pressure transducer locations (Fig. 4.3),

- pressure transducers and thermocouples necessary for instrumentation of the refrigeration loop.

- a larger static evaporator fabricated at ORNL that was to be used in the fresh food compartment (Fig. 4.4),

- several commercial suction-to-liquid-line heat exchangers that were to be used for the two liquid-line subcoolers on the Lorenz circuit, and

- a variety of fine metering valves that were to be used as expansion valves after the last liquid-line subcooler instead of capillary tubes.

The circuit shown in Fig. 4.3 is virtually identical to the design Dr. Kruse and his students used for the operating model seen in Germany. We had originally planned to install a Coriolis mass flowmeter after the condenser outlet to monitor refrigerant flow during testing, but the large internal volume of the measuring cell of this meter would have seriously disrupted the operating efficiency of the prototype unit. The smallest commercially available suction-to-liquid-line heat exchangers were used for cycle intercoolers, pattemed after a similar arrangement seen on the Hannover test unit.

Discussions with Dr Kruse and with Mike Kauffeld and results from the CYCLE-Z and University of Maryland L-M cycle models indicated that a larger fresh-food evaporator was needed in this test unit. Using estimates from Hannover for the air-side, overall heat-transfer values and using model results for the R-32/R-124 NARM to be tested by ORNL, we calculated the size of the fresh food evaporator needed for optimum performance to be about $4-6 \mathrm{ft}^{2}$. The overall, air-side heat transfer values $\left(U_{\text {ur }}\right)$ used for these calculations were 26.2 watts per kelvin per square meter $\left(\mathrm{W} / \mathrm{K} \cdot \mathrm{m}^{2}\right)$ fivir the fan-forced freezer and $17.0 \mathrm{~W} / \mathrm{K} \cdot \mathrm{m}^{2}$ for the static fresh-food evaporator.

The University of Hannover recommended installing an oversized fresh-food evaporator and then insulating sections to adjust its size to fit the fluid pair and conditions being tested. The tube-and-wire heat exchanger sketched in Fig. 4.4 was designed to provide approximately $8 \mathrm{ft}^{2}$ of air-side surface area with a minimum internal volume.

The subcontractor completed modification of the Amana RF in July 1990. Testing performed with R-12 showed that a "hard start" kit was needed to ensure that the compressor would cycle on and off in response to the thermostat. This testing also indicated that the large thermal mass of the static evaporator required an excessively long pull-down time and contributed so much superheat to the suction gas that the compressor often cut out on high head pressure before compartment temperatures could be pulled down to the normal operating range. 


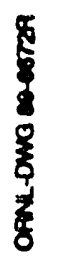
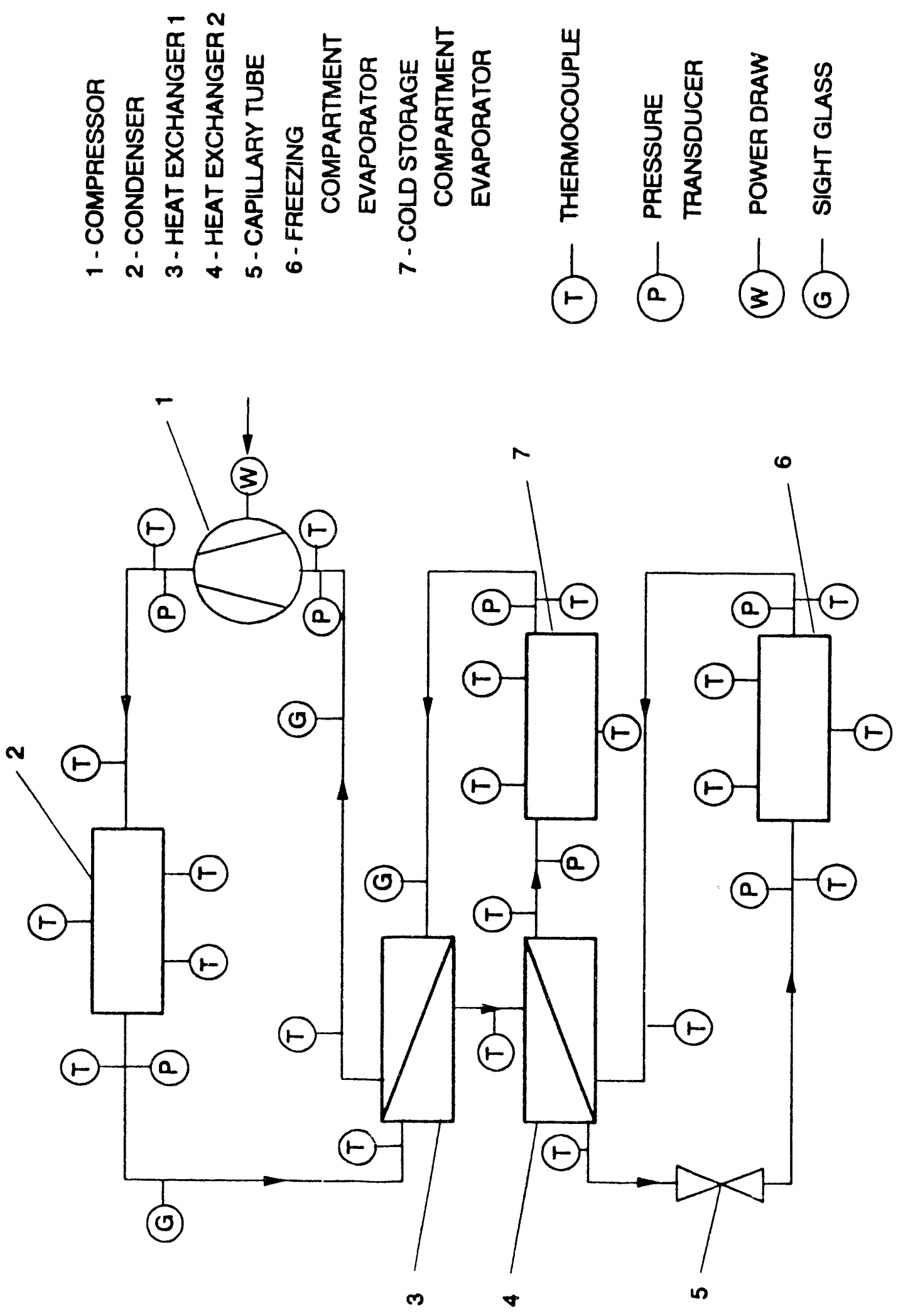

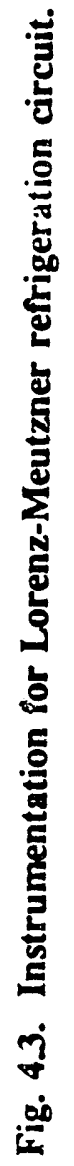




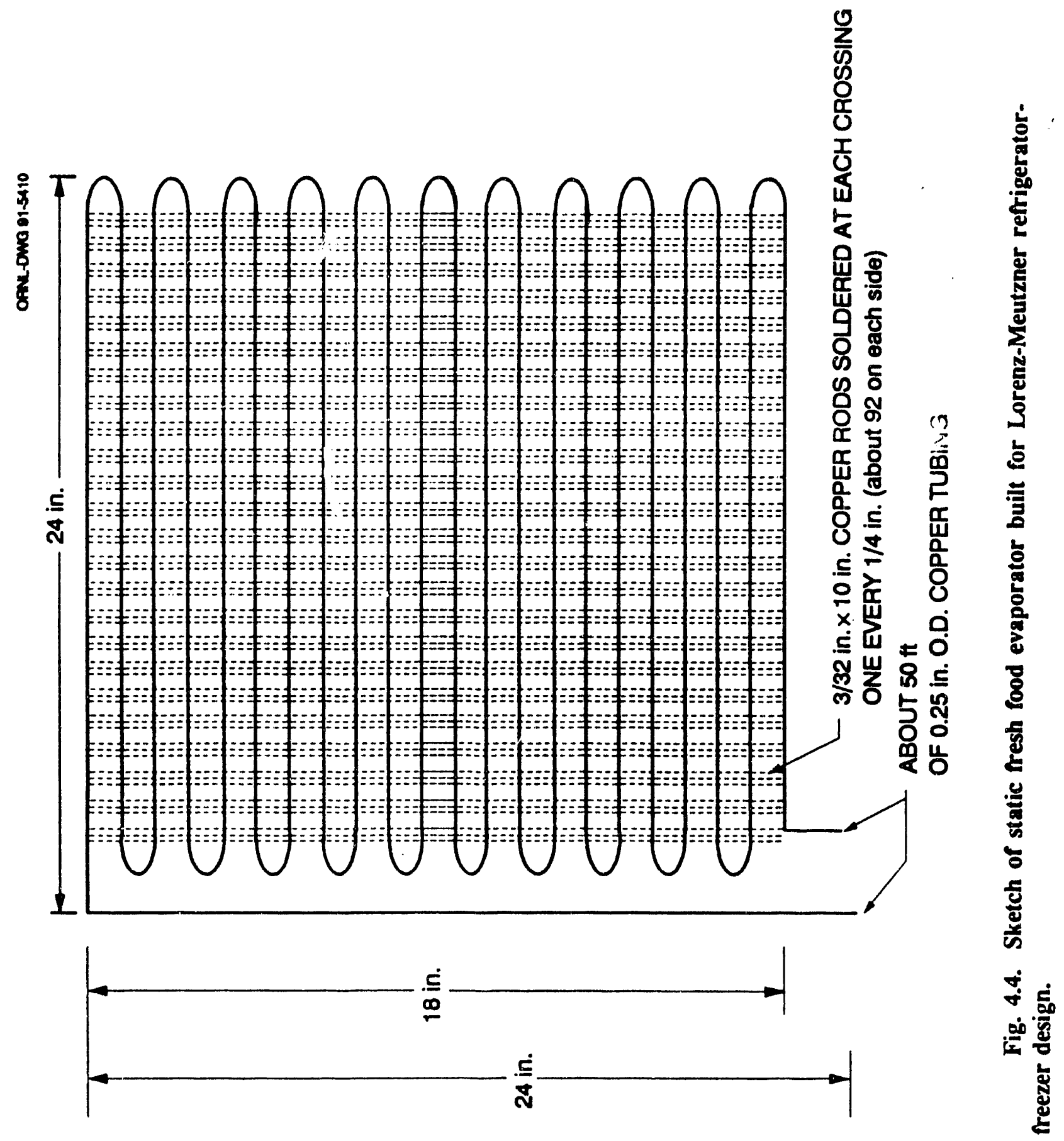




\subsection{LABORATORY TESTING WITH R-12}

The modified Amana RF was delivered 10 the laboratory in August. Betler cycling response to thermostat demand was achieved by replacing the original Amana thermostat with one having a narrower dead band range, laken from an upright freezer.

We performed laboratory runs with $R-12$ in this RF primarily to verify proper thermocouple and pressure transducer operation. Data obtained from these runs, however, indicated that the refrigerant pressure drep through the fresh food evaporator was too large for efficient operation. This large pressure drop resulted in very low suction pressures.

To correct this problem, we divided the large fresh food evaporator on the L-M RF into two parallel circuits. Tests performed with R-12 after this mudification indicated that the refrigerant-side pressure drop had decreased from 7-9 psi for the single circuit to about 1-3 psi with the parallel circuit design.

Data obtained from two days of testing with $R-12$ indicated additional problems with the $\mathrm{RF}$ as it was received from Tillery Mechanical. The fine metering valve that was to be used as a throttling device did not work reliably. The micrometer metering valve could be adjusted to give the desired suction pressure once the compressor was nunning. However, when the compressor cycled "off" and "on" again in response to the themostat, a latger pressure drop was usually established over the metcring valve, constricling refrigerant flow to the point where there was insufficient capacity to satisfy the cooling load and shutting off the compressor again. This situation could be cleared by slightly opening and immediately closing the valve, but this action was required for every on-off cycle. These results suggest that a valve with a "feed back" mechanism that causes it to open and close whilc sccking an ideal output condition (like a conventional themal expansion valve) might work in this application. The valve must be able to control the 6-12-lb/h refrigerant flow rates typical in an RF. however.

We replaced the metering valve with capillary tubes. Because sizing of capillary tubes for RFs tends to be a discontinuous, trial-and-error process, a manifold containing three different tubes was prepared. Initial estimates for the capillaries used on this manifold were calculated from data presented in the ASHRAE Equipment Handbook and were based on the assumption that a $30 \%$ by mass mixture of R-32 in R-124 would be used for the NARM refrigerant. ${ }^{15}$ The results of these calculations were discussed and verified with Dung Soo Jung at the University of Maryland and a representative from Whirlpool.

Calorimeter tests with the Tecumseh AE 1360 D compressor used in this refrigerator and the $30 \%$ R-32/R-124 NARM that ORNL planned to use for these studies showed that this compressor did not have e. jugh torque to s'art against the saturated vapor pressure of this refrigerant. It was necessary to decrease the R-32 content of the NARM $1015 \%$ by mass to accommodate the RF compressor. This change eventually affected the choice of capillaries used in the manifold.

The R-12 testing showed that when the compressor shut off in the L-M design. relatively hot refrigerant on the high-pressure side of the low-temperature intercooler heated up the gaseous refrigerant on the other side of the heat exchanger. This +50 to $+60^{\circ} \mathrm{F}$ low-pressure refrigerant was pushed into the outlet side oi the freczer evaportior and the inlet side of the fresh food evaporator, causing these compartments to wann up. To help limit this problem, we moved the low-temperature intercooler inside the fresh food companment. This was an attempt to minimize the temperature difference between the high-pressure liquid side and the low-pressure gas side of this heat exchanger. A Superior Valve HXSV-1/2,1/2-hp subcooler was installed in place of the Superior Valve 1677, 1/4-1/3-hp high-temperature intercooler to lower the liquid refrigerant temperáute more before it entered intercooler No. 4 (Fig. 4.3). 
This off-cycle backup of hot refrigerant caused additional problems with the unit's themostat. The thennostal heing used in the fresh food section to control compressor operation called for a compressor stin al approximalcly $35^{\circ} \mathrm{F}$ and for compressor shul-down at temperatures ranging from $0^{\circ} \mathrm{F} 10-30^{\circ} \mathrm{F}$. depending on the dial selling. When the sensing element for this thermostill was clipped to the fresh food cvaporator inlet, it was not effective in controlling unifom cycling of compressor run times. Hot refrigerant backup into the fresh food evaporator caused shor cycling of the compressor and did not allow adequate time for pressure equalization between runs.

We eventually used relay control cards and logic algorithms on the data logger instead of a thermostat to control the compressor cycling based on air temperatures in the fresh food or freezer compartments. Initially, air temperatures in the fresh food chamber were used. An upper limit/compressor-on temperature of $38^{\circ} \mathrm{F}$ with a dead band of $1.5^{\circ} \mathrm{F}$ was used as the RF low-temperature (mid/mid) lest, and $42^{\circ} \mathrm{F}$ with a dead band of $0.5^{\circ} \mathrm{F}$ was used for the hightemperature (wamiwarm) test condition. Later, a themos:at centrol scheme was worked out that cycled on the basis of the averaged freezer temperatures rather than fresh food temperatures. For the freczer, a compressor-on limit of $5^{\circ} \mathrm{F}$ and a $6^{\circ} \mathrm{F}$ dead band was used for the mid/mid senting. and an $8^{\circ} \mathrm{F}$ limil with a $6^{\circ} \mathrm{F}$ dead band was used 10 obtain the wamm/wam condition. This freezcr-based algorithm gave more precise control of the freezer temperature and permitted the use of charge size to control the fresh food temperature, so it was used for the bulk of the L-M RF prototype tests.

These control temperatures and operating dead bands were selected to correspond with previously obtained R-12 baseline rating data from the unmodified Amana units. Any combination of starting temperatures and dead band can be implemented through use of the data logger to achieve prescribed comparment lemperalures or allow pressure equalization across the compressor before restar.

Another problem indicated in the initial tests with R-12 was that the static evaporator mounted on top of the fresh food section did not promote adequate air circulation for uniformly cooling the fresh food compartment. The thermocouple right under the evaporator (top of the compartment) hovered near freezing while the two lower thermocouples were in the $40^{\circ} \mathrm{F}$ to $50^{\circ} \mathrm{F}$ temperature range. The solid glass shelves used in this RF design contributed to air stratification. We subsequently used open shelves to oblain a more uniform temperature distribution.

\subsection{LORENZ-MEUTZNER TESTING WITH AN R-32/R-124 NARM}

The L-M RF capillary manifold was fitted with 14-. 12-. and 10-ft lengths of 0.026-in. internal dianeter capillary lubing. These shon lengths of narrow-bore tubing helped minimize heat exchange with the $90^{\circ}$ ambient chamber. Naturally, all of the cold refrigerant lines on the back of the RF were insulated as well as possible with foam rubber insulation to increase efficiency.

We used the $15 \%$ by mass R-32/R-124 NARM sample prepared for the calorimetry work to charge this RF. We made charge size and capillary selection by choosing a capillary that gave frcezer inlet temperatures in the $-15^{\circ} \mathrm{F} 10-20^{\circ} \mathrm{F}$ range with enough charge to keep the fresh food near $38^{\circ} \mathrm{F}$ over the $\mathrm{mid} / \mathrm{mid}$ and warm/wam thermostat settings.

We nuted during testing that the L-M design was very sensitive to ambient temperatures. Capillaries and refrigerant charges appropriate for operaling the RF in the laboratory (approximatcly $70^{\circ} \mathrm{F}$ ) did not work well when the RF was moved into the $90^{\circ} \mathrm{F}$ chamber. 
Generally, more restrictive capillaries and less relrigerant charge were needed at higher operating ambient lemperalures.

A full, 4-point, AHAM. $90^{\circ} \mathrm{F}$. closed-door rating test was performed with the L-M RF. The results for R-12 in the unmodified RF and the 15\% R-32/R-124 NARM in the L-M prototype are shown in Tables 4.3 and 4.4. respectively. The $3.41-\mathrm{kWh} / \mathrm{d}$ rating with the NARM is roughly $20.5 \%$ worse than the unmodified RF's performance with R-12.

Table 4.4. Lorenz-Meutzner refrigerator-freezer testing with $15 \%$ R-32/R-124

American Home Appliance Manufacturers four-point, $90^{\circ} \mathrm{F}$, closed-door test procedure before time-delay-on-start relay installation

\begin{tabular}{lccccc}
\hline $\begin{array}{c}\text { Teinperalure } \\
\text { control } \\
\text { selting }\end{array}$ & $\begin{array}{c}\text { Power } \\
\text { consuinption } \\
(\mathrm{kWh} / \mathrm{d})\end{array}$ & $\begin{array}{c}\text { Compressor } \\
\text { run time } \\
(\%)\end{array}$ & $\begin{array}{c}\text { Average freezer } \\
\text { temperalure } \\
\left({ }^{\circ} \mathrm{F}\right)\end{array}$ & $\begin{array}{c}\text { Average } \\
\text { fresh food } \\
\text { temperature } \\
\left({ }^{\circ} \mathrm{F}\right)\end{array}$ & $\begin{array}{c}\text { Freezer defrost } \\
\text { cycle time } \\
(\mathrm{h})\end{array}$ \\
\hline Mid/Inid/off & 3.038 & 73.86 & 4.89 & 37.87 & 62.57 \\
Mid/Inid/on & 3.797 & 83.07 & 4.94 & 38.20 & 56.91 \\
Warm/warm/off & 2.618 & 57.14 & 10.95 & 42.19 & 82.30 \\
Warm/warm/on & 3.107 & 71.29 & 8.93 & 42.84 & 67.54 \\
\hline
\end{tabular}

Overnll power consumprion rating: 3.4 ! kWh/d.

Data obtained from this testing indicaled some of the reasons the system was not perforning as well as modeling had predicted. Figure 4.5 contains temperature versus time plots for refrigerant and air in the freezer and fresh food compantments over two compressor cycles at the warm/warm setting. Figure 4.6 is a comparison of freezer "pull down" and "warm up" data for this RF operating with R-12 in the unmodified configuration and with the R-32/R-124 in the L-M configuration. These data indicate:

1. The large refrigerant charge size (approx. $20 \mathrm{oz}$ ) being used for this test unit contributed to cycling losses by requiring significant compressor run time to cool down the large mass of refrigerant.

2. The intercooler design (using commercial subcooler/superheaters from Superior Valve) contributed to the large refrigerant inventory because of their large intemal volumes. During the compressor off cycles. the intercoolers also trapped hot high-pressure refrigerant in close proximity to the low-pressure gas going through the evaporators. This heated up the low-pressure gas, backing it up into the freezer and fresh food evaporators and driving their temperatures up to 30 to $50^{\circ} \mathrm{F}$. as Fig. 4.6 shows.

3. At the next compressor stan. the freezer fan pulled air over these wamed coils, causing a sharp rise in the freezer air temperature, which in tum caused longer compressor run times. 


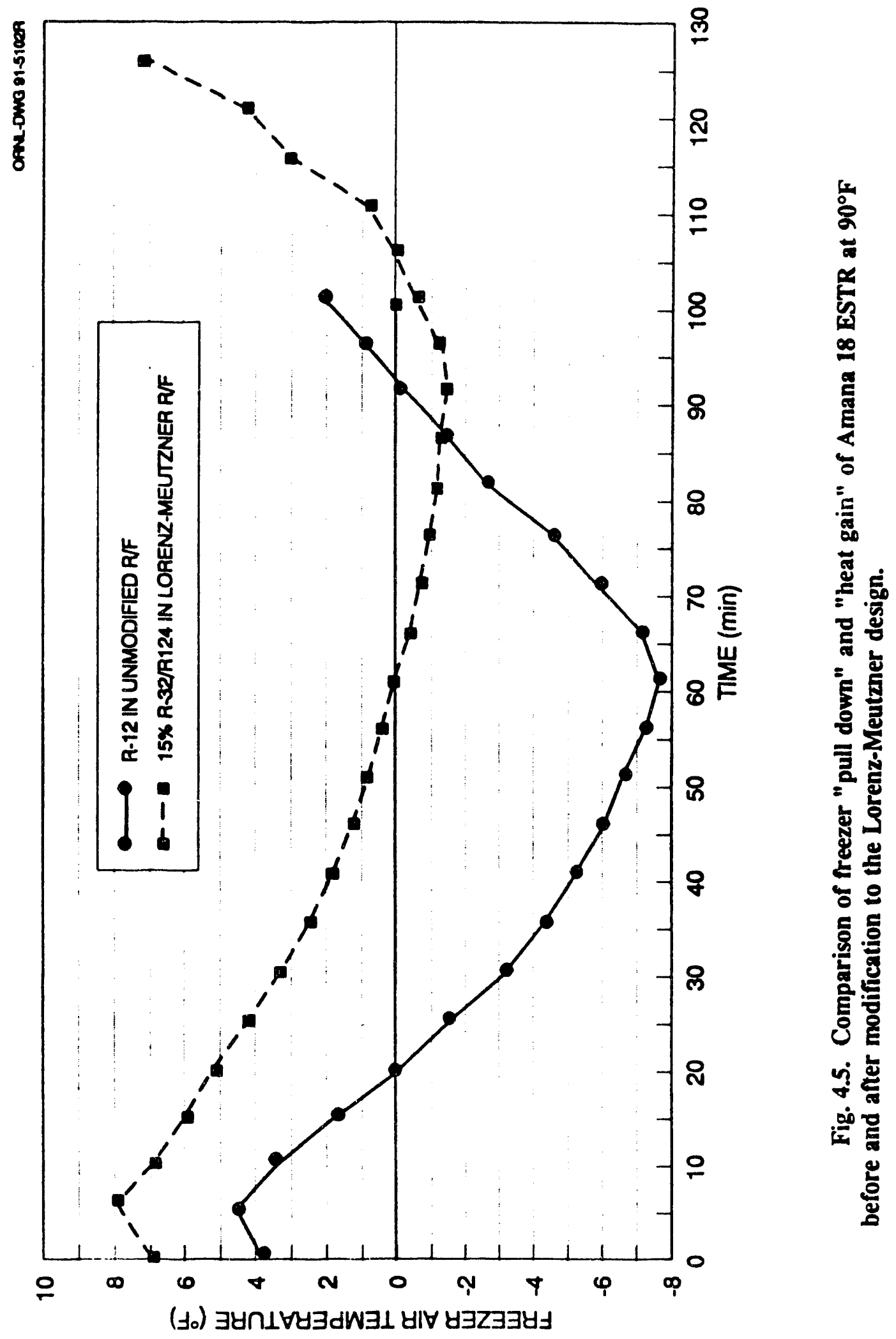



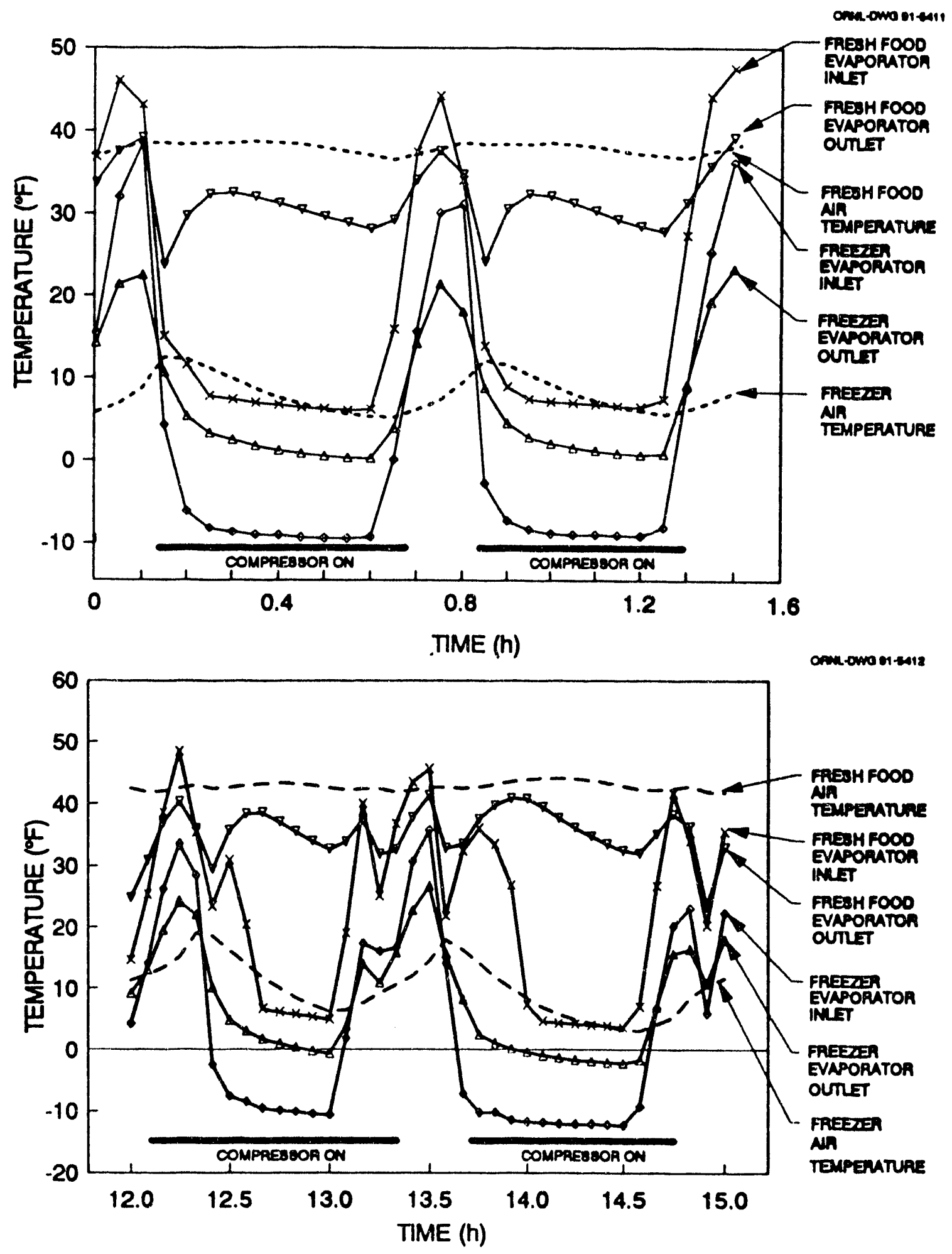

Fig. 4.6. Refrigerant and air temperatures for two compressor "on" cycles of a Lorenz-Meutzner refrigerator operating with a $15 \%$ by mass $R-32 / 85 \%$ by mass $R-124$ nonazeotropic refrigerant mixture before time-out-delay relay installed on the freezer fan. 
Figure 4.7, which is a plot of typical system pressures over two compressor on cycles, shows excess pressure drop in the large, static fresh-food evaporator on the L-M unit. This pressure drop in the fresh food evaporator necessitated longer capillaries to maintain the lower NARM refrigerant entering temperatures needed in the freezer, which in tum raised the pressure ratio and power use of the compressor while decreasing the amount of refrigerant flow.

In consultation with Ray Bohman, who was hired as a consultant for RF work at ORNL, the following corrective actions were recommended:

1. Install a time-delay-on-start relay on the freezer evaporator fan that would delay its operation until the freezer evaporator was cooled to the proper operating temperature.

2. Redesign the intercoolers to minimize intemal volume and cut down on the mass of refrigerant circulated in the system.

3. Install a low volume, low pressure drop, fan forced evaporator in the fresh food compartment that uses a low wattage, low volume fan (not time-delayed). This would further decrease charge inventory and reduce low-side pressure drop.

The limited time and budget remaining for EPA's support of this phase of the project permitted implementation of only the first corrective action proposed above.

\subsubsection{Steady-State Results}

We contrasted steady state efficiencies by looking at measured wattages for RF operation at similar compartment air temperatures and refrigerant entering and leaving temperatures near the end of a compressor on cycle with R-12 in the unmodified RF and with the R-32/R-124 NARM in the L-M RF cycle. Table 4.5 summarizes this comparison.

These steady-state operating data support the compressor calorimeter EER data described earlier and modeled L-M results using CYCLE-Z with the R-32/R-124 NARM. We think the relatively poor performance of the $L-M$ design with the mixed refrigerant (Tables 4.4 and 4.6 ) is attributable to cycling and heat exchanger inefficiencies.

\subsection{Time-Delay-On-Start Modification}

We installed a time-delay-on-start relay on the L-M RF freezer evaporator fan to delay air circulation until cold refrigerant was present in the coil, and then retested the unit. Test results did show lower average freezer temperatures, but long compressor run times (duty cycles) wiped out any energy savings (Tables 4.4 and 4.6 ). 

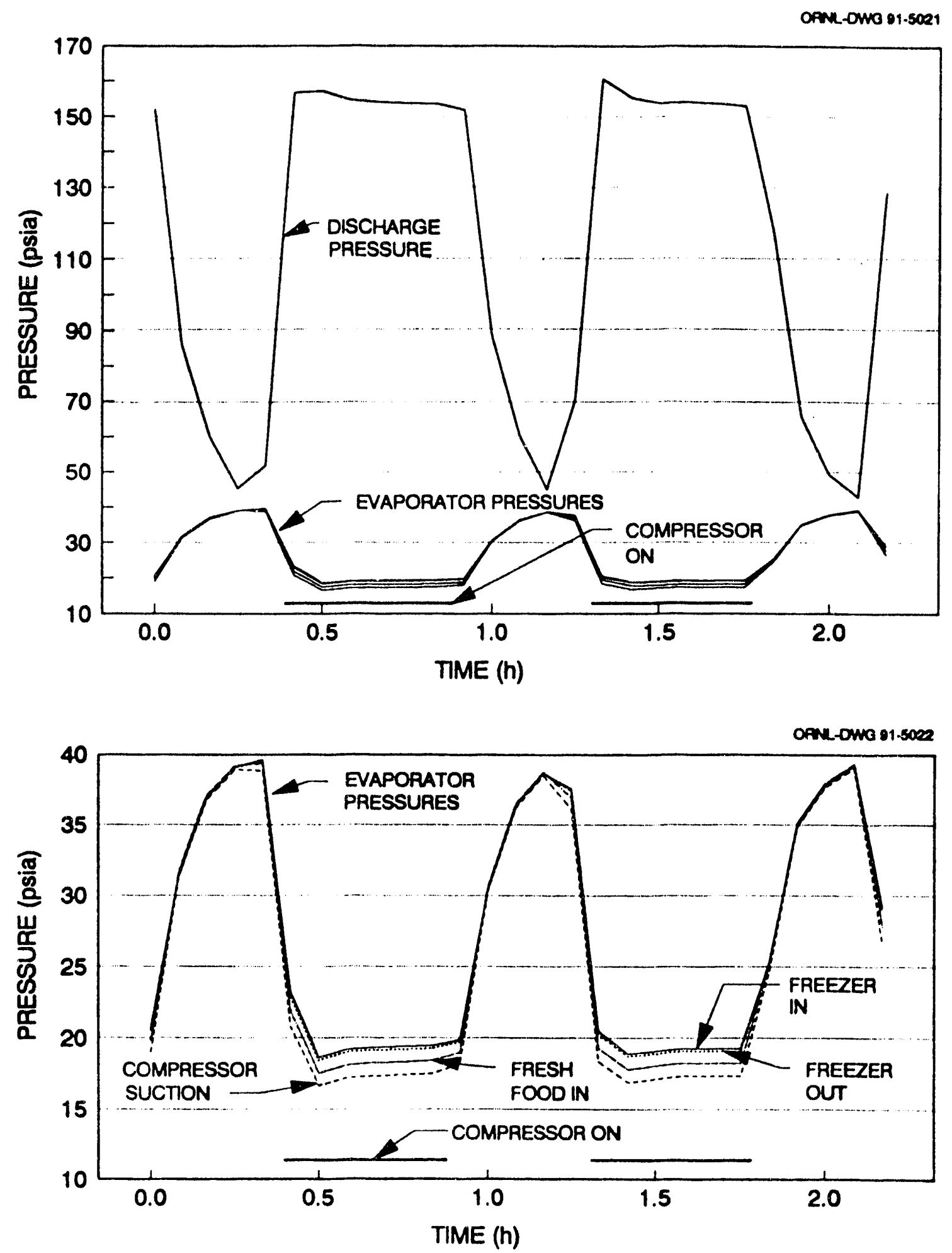

Fig. 4.7. System pressures for two compressor cycies of a Lorenz-Meutzner refrigerator freezer operating with an R-32/R-124 nonazeotropic refrigerant mixture. Large, 8 square foot, static, fresh food evaporator. 
Table 4.5. Refrigerator-freezer steady state energy use

\begin{tabular}{lccc}
\hline & $\begin{array}{c}\text { R-12 } \\
\text { (W) }\end{array}$ & $\begin{array}{c}\text { R-32 NARM } \\
\text { (W) }\end{array}$ & $\begin{array}{c}\text { Reduction } \\
\text { with NARM (\%) }\end{array}$ \\
\hline $\begin{array}{l}\text { Compressor + fans + parasitics } \\
+ \text { mullion heaters } \\
\text { (Mid/mid/on) }\end{array}$ & 235 & 187 & -20.4 \\
$\begin{array}{c}\text { Compressor + fans + parasitics } \\
\text { (Mid/mid/off) }\end{array}$ & 207 & 163 & -21.3 \\
\hline
\end{tabular}

Table 4.6. Lorenz-Meutzner refrigerator-freezer testing with $15 \%$ R-32/R-124 American Home Appliance Manufacturers four-point, $90^{\circ} \mathrm{F}$, closed-door test procedure after time-delay-on-start relay installation

\begin{tabular}{lccccc}
\hline $\begin{array}{c}\text { Tempernture } \\
\text { control } \\
\text { setting }\end{array}$ & $\begin{array}{c}\text { Power } \\
\text { consumption } \\
(\mathbf{k W h} / \mathbf{d})\end{array}$ & $\begin{array}{c}\text { Compressor } \\
\text { run time } \\
(\%)\end{array}$ & $\begin{array}{c}\text { Average } \\
\text { freezer } \\
\text { temperature } \\
\left({ }^{\circ} \mathbf{F}\right)\end{array}$ & $\begin{array}{c}\text { Average } \\
\text { fresh food } \\
\text { temperature } \\
\left({ }^{\circ} \mathbf{F}\right)\end{array}$ & $\begin{array}{c}\text { Freezer defrost } \\
\text { cycle time } \\
(\mathbf{h})\end{array}$ \\
\hline Mid/mid/off & 3.211 & 77.87 & 3.30 & 37.55 & 60.41 \\
Mid/mid/on & 4.268 & 94.26 & 1.34 & 37.89 & 50.98 \\
Warm/warm/off & 3.004 & 69.67 & 4.92 & 41.10 & 66.92 \\
Warm/warm/on & 4.015 & 88.82 & 3.26 & 41.69 & 53.52 \\
\hline
\end{tabular}

Overall power consumption rating: $3.48 \mathrm{kWh} / \mathrm{d}$.

These longer compressor run times are primarily due to the relative ineffectiveness of the freezer evaporator with the R-32/R-124 NARM. With refrigerant entering and leaving temperatures of $-20^{\circ} \mathrm{F}$ and $-6^{\circ} \mathrm{F}$, respectively, the lowest leaving air temperature that could be obtained from this coil was only about $-3^{\circ} \mathrm{F}$, as Fig. 4.8 shows. The combination of cross-flow operation and continuous fins made the freezer evaporator inefficient at transferring energy from an air strean with progressively decreasing temperature to a refrigerant stream with progressively increasing temperature.

Switching to a more restrictive capillary to decrease the freezer evaporator temperature only increased the pressure ratio, decreasing refrigerant tlow rate and further limiting refrigeration capacity during a compressor run. More effective use of refrigerant temperatures in the freezer evaporator is clearly required.

It is apparent from comparisons of the calorimeter work with NARMs and the corresponding L-M RF work that the dynamics of the heat exchange process in the eventual compressor application will have a significant effect on the capacities and EER values actually realized in an operating system. Calorimeter results indicated that the $15 \%$ by mass $R-32 / R-124$ NARM would have ample capacity to handle the same RF loads as $R-12$ with a $5 \%$ increase in operating efficiency. However, actual RF tests with this NARM in the L-M RF with an 


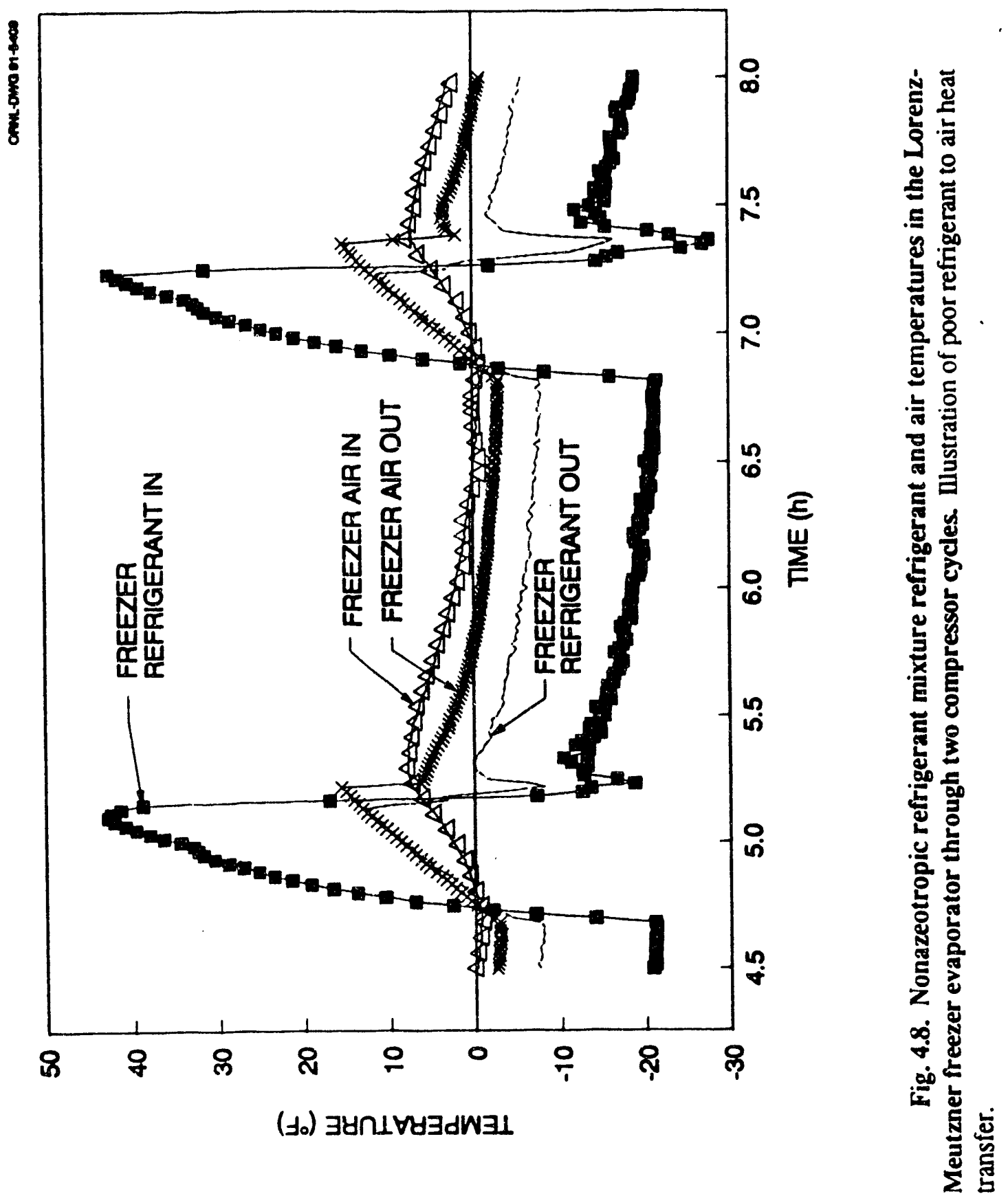


ineffective freezer evaporator suffered from long compressor "on" cycles which indicated insufficient capacity. We must add that additional heat exchanger surface area and thermal mass $(\approx+50 \%)$ and a larger refrigerant charge were required for the L-M RF tested. Both of these changes would also contribute to longer compressor nun times.

Because of the sensitivity of this L-M design to the amount of charge and because of the difficulties involved in putting a sampling part on this small refrigerant circuit without disturbing system performance, we took no refrigerant samples from this RF to confirm the circulating NARM composition. Because charging was always performed using the liquid phase, very litule variation in charge composition would be expected.

\subsection{CONCLUSIONS AND DISCUSSION}

Steady state operation results and compressor calorimeter data support the energy saving potential of NARM refrigerants in an L-M cycle. Steady-state energy use based on compressor power consumption during on cycles was about $20 \%$ less than similar data for the same compressor operating with $\mathrm{R}-12$ at similar compartment and refrigerant temperatures.

We saw a poor correlation between NARM compressor calorimeter, steady state, and modeled performance results and integrated L-M RF power consumption tests. System performance with the NARM is dependent on the efficiencies and design of other system components. Specifically, effective counterflow heat exchangers, an understanding of unique cycling losses, and an awareness of the effects of changing ambient and operating temperatures are needed to realize the efficiency potential of NARM refrigerants in the L-M system.

Counter-flow, refrigerant-to-air heat exchangers are important for this Lorenz-Meutzner design, because they are the only way to achieve coil leaving-air temperatures intermediate between the entering and leaving refrigerant temperatures. The absence of an effective counterflow freezer evaporator showed up in our test results as an inability to rapidly "pull down" compartment temperatures despite favorable compressor and steady-state test results.

The two stages of liquid line subcooling in the L-M circuit design cause warm refrigerant to back-up into the evaporators during the compressor off cycles. In these experiments forced convection was delayed until this situation was reversed.

The L-M RF design appears to be much more sensitive to ambient temperature variation than is the conventional single-evaporator RF. Balancing temperatures in the freezer and fresh food sections with a static charge and fixed circuit for a variety of ambient temperatures will be a formidable challenge.

\section{DUAL-LOOP REFRIGERATOR-FREEZER TESTING}

\section{S.1 INTRODUCTION}

Conventionally designed American RFs use only one evaporator in the freezer compartment. Frigid air from the freezer is passed through a controlled leak into the fresh food compartment to keep this section at the required temperature. Thermodynamically speaking, this arrangement means that the refrigeration system always works at pumping heat out of the colder freezer section and rejecting it to ambient temperatures. At the $90^{\circ} \mathrm{F}$ rating point, the heat load of the fresh food section in a conventional American, top-mount refrigerator is estimated to range from about the same size to roughly $20 \%$ luiger than that of the freezer. Therefore, a large 
percentage of the work load for a RF could be more efficiently cooled if the refrigerator had a scparate refrigeration loop for the fresh food compartment that could pump heat from these wammer temperatures to room temperature.

European manufacturers have introduced and sold RFs with two completely separate refrigeration systems (compressors, condensers, capillary lubes, and evaporators) that are dedicated to cooling only the freezer or fresh food section of the appliance. Naturally, these units have higher manufactured costs than the conventional one-circuit refrigerators, but they do take advantage of the themodynamically more favorable concept of pumping heat out of the fresh food section over a lower temperature lift. ${ }^{20}$

Some of the other advantages of the two-circuit dual-loop approach are: separate thermostats can be used to control the temperatures in each compartment, which usually results in more uniform average temperatures; relatively moist air from the food stored in the fresh food area is cooled by a heat exchanger at more moderate temperatures and does not contribute to frost on the colder freezer evaporator, separating the freezer and the refrigerator sections allows longer time periods between freezer defrosts and helps prevent drying out of vegetables and fruits stored in the refrigerator: and defrosting of the fresh food evaporator can be performed by allowing it to warm up to normal compartment temperatures between compressor "on" cycles or by shutting the fresh food circuit off for an extended time with or without running a fresh food evaporator fan.

Other RF circuits have been designed to try and exploit the advantages of a fresh food section isolated from the freezer. Many of these have used a "refrigerant tailing" effect in which the refrigerant loop was a series circuit containing separate evaporators for the freezer and fresh food sections. Enough refrigerant is circulated so that two-phase refrigerant, which is left over after the freezer is sufficiently cold, can spill over to and cool the fresh food section. ${ }^{19}$ Controlling and maintaining balanced compartment temperatures in these designs is more challenging.

Other innovative ideas for dual-loop RF designs involve either using air dampers to switch a single evaporator between cooling the freezer and cooling the fresh food compartments depending on demand. ${ }^{22}$ or utilizing a 3-way valve that can switch liquid refrigerant flow from a single compressor and condenser to capillary tubes and evaporator coils appropriate for freezer or fresh food cooling. ${ }^{23}$

As part of this project, ORNL was asked to design, build, and test the energy consumption of two dual-loop RF concepts. A dual-circuit dual-loop design with two completely separate refrigerant circuits for the freezer and fresh food comparments was designed by Arthur D. Little (ADL) and built by Amana for testing at ORNL. A refrigerant-switching dual-loop refrigerator built around a 3-way solenoid valve was designed by a consultant (Ray Bohman) according to specifications laid out by ORNL and was built by a local subcontractor for testing at ORNL.

\subsection{DUAL-CIRCUIT, DUAL-LOOP DESIGN AND TESTING}

\subsubsection{Dual-Circuit, Dual-Loop Design}

ORNL, EPA, and ADL arranged a July 13,1990, meeting at Amana to discuss details of ADL's design for a dual-circuit dual-loop RF that was to be built by Amana for this project. At this meeting the design options for the prototype two-circuit RF were worked out. The main features of this design are summarized as follows:

- Star with an existing Amana TM $18 \mathrm{~N} 17.7 \mathrm{ft}^{3}$ refrigerator. 
- Use the existing freezer evaporator and condenser for the freezer circuit.

- Mount a static condenser and a smaller, $2 \times 8 \times 24$-in., fan-forced evaporator in the fresh food compirtment for the fresh food loop.

- Use an Embraco EM 20 NR compressor for the iresh lood circuit (205 Btu/h, 3.10 EER at $-10^{\circ} \mathrm{F}$ evaporating and $130^{\circ} \mathrm{F}$ condensing rating point).

- Use an Embraco EM 40 SC compressor for the freczer circuit (415 Btu/h, 4.20 EER at $-10^{\circ} \mathrm{F}$ evaporating and $130^{\circ} \mathrm{F}$ condensing rating point).

- $\quad$ Provide a manifold of appropriately sized capillarics for both circuits.

- Route fan and heater power leads to the outside of the cabinet for monitoring and control.

- Use a normal, commercially available, thernostat for fresh food section.

- Use chest freezer thermostat for freezer section.

- $\quad$ Provide electrical connections to bypass the fresh food defrost.

- Block off the air passage between the freezer and refrigerator compartments.

- Mount thermocouples and pressure transducers according to the plan shown in Fig. 5.1.

Actual construction was stanted in August, and the completed unit was shipped to ORNL in early October. 1990.

\subsubsection{Dual-Circuit Dual-Loop Modeling}

Dick Merriam at ADL modeled the performance of a dual-circuit dual-loop refrigerator using a simple steady-state model and freezer cabinet loads, fan powers, compressor capacities. and component efficiencies he obtained from Amana. For a typical 18- $\mathrm{ft}^{3}$, top-mount RF operating with R-i2 in an 824-Btu/h compressor, Merrian used the compressor capacity and EER rating at the $130^{\circ} \mathrm{F}$ condensing condition and $-10^{\circ} \mathrm{F}$ evaporating condition to estimate the daily energy consumption for a conventionally designed unit as $2.290 \mathrm{kWh} / \mathrm{d}$. Amana had experimentally measured $2.293 \mathrm{kWh} / \mathrm{d}$ for the same unit. Values of $0.17 \mathrm{kWh} / \mathrm{d}$ and $0.07 \mathrm{kWh} / \mathrm{d}$ were used for the mullion heater and defrost energy use, respectively.

For a dual-circuit system with:

- fan-forced evaporators in both compartments.

- no air leakage between the freezer and fresh food sections.

- a 3.4-EER, 200-Btu/h compressor for the fresh food circuit,

- a 4.6-EER, 400-Btu/h compressor for the freezer circuit,

- oversized (normal freezer) evaporators in both compartunents.

- a back-mounted static condenser for the fresh food section.

- a normal fan-forced condenser for the freezer, and

- some standard compartment temperatures and parasitic power use.

Merriam used a similar technique to calculate that this dual-circuit dual-loop RF system would require $2.21 \mathrm{kWh} / \mathrm{d}$ if $R-12$ were used in both circuits and $2.13 \mathrm{kWh} / \mathrm{d}$ if $\mathrm{R}-142 \mathrm{~b}$ were used in the refrigerator circuit with $\mathrm{R}-12$ in the freezer. The compressor capacities and EERs used in this latter calculation were increased to allow for operation at more favorable condensing and ?pprating conditions, however. Modeling calculations were also performed simulating operation of the freezer with R-152a or R-134a and use of a natural convection fresh food evaporator, as shown in Appendix A. 

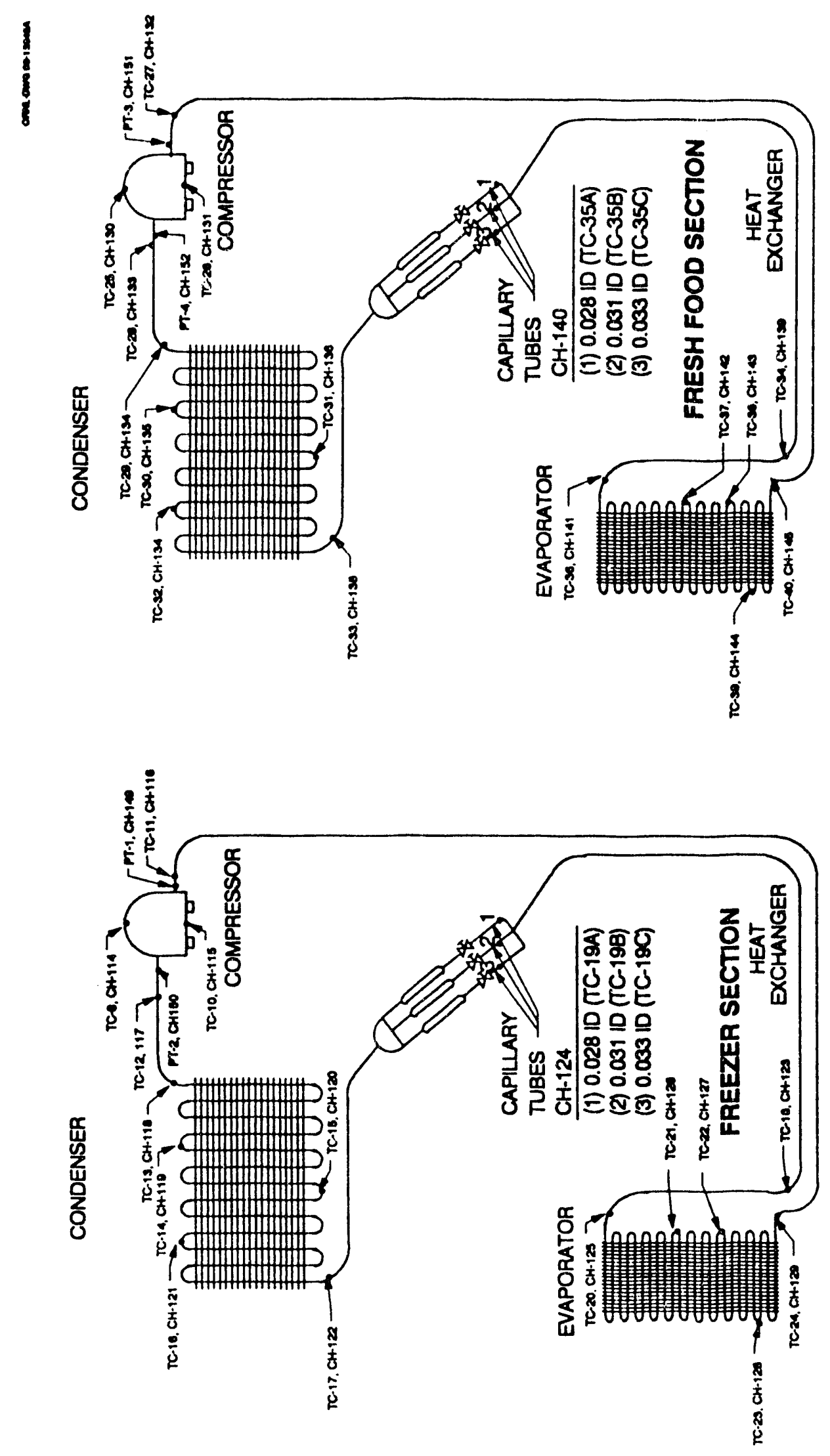

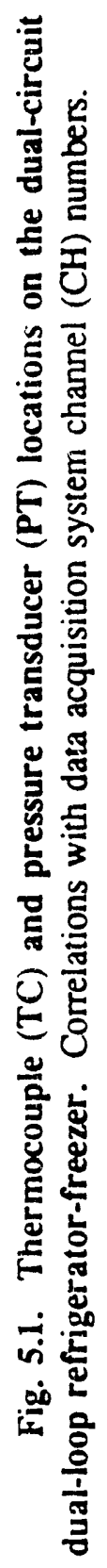




\subsubsection{Initial Modifications}

The dual-loop RF built for ORNL by Amana was received in October. Bruce Kopf, a design engineer in charge of construction of this unit. prepared a brief report describing the construction details, schematics of the wiring, electrical circuit modifications, and sensor locations on this test unit. ${ }^{24}$ Contact relays were installed on this RF so that a clear "on" and "off indication could be sensed by the data acquisition system for compressor run times and defrost periods. Charging valves and high- and low-side access points were installed on bol. refrigeration circuits so that refrigerant charges could te conveniently changed and adjusted. A long-term defrost timer ( $48 \mathrm{~h}$ of compressor run time) was substituted for the 12-h timer that originally came on the freezer circuit of the unit.

\subsubsection{Testing and Performance Rating}

We initially tested the unit with $R-12$. We compared its reconfigured performance with the DOE energy-efficiency information posted on the $R F$ door $(2.35 \mathrm{kWh} / \mathrm{d})$. We used the DOE/AHAM procedure for testing dual compressor systems with dual automatic defrost to calculate daily energy consumption. ${ }^{25}$ We used a shortened two-part test procedure that incorporates a defrost period and a period of steady-state compressor operation between defrosts. The steady-state operation data from the freezer and refrigerator loops is added to power consumed during the defrost in proportion to the remaining cycle time on the defrost timer(s) to obtain the total energy use for one defrost cycle.

This dual-loop RF was quite easy to charge. We selected capillary tubes that gave 0-5 psig and $18-20 \mathrm{psig}$ suction pressiris: $\left(-21^{\circ} \mathrm{F}\right.$ to $-9^{\circ} \mathrm{F}$ and $+17^{\circ} \mathrm{F}$ to $+20^{\circ} \mathrm{F}$ saturation temperatures for R-12) in the freezer and fresh foot circuits, respectively. Enough refrigerant was charged into each circuit to give an indication of saturated refrigerant temperatures across each evaporator while maintaining a comfortable amount of superheat (a refrigerant temperature of $-90^{\circ} \mathrm{F}$ ) at the compressor suction. The extent of refrigerant subcooling at the condenser outlets was also checked to be sure the circuits were not overcharged. The 0.033 -in. ID capillary tubes on each manifold seemed to produce the best operating conditions for both refrigeration loops on the test unit.

We completes baseline RF performance tests with R-12 in both the freezer and refrigerator circuits of this test unit were completed in January 1991. Table 5.1 is a summary of the test results. We chose compartment temperatures that closely bracketed temperatures used by ADL and ORNL for the dual-loop modeling studies. The overall power consumption of this test unit $(3.37 \mathrm{kWh} / \mathrm{d})$ is quite disappointing when compared with the $2.35-\mathrm{kWh} / \mathrm{d}$ rating listed by Amana for the unmodified, conventional circuit system.

A comparison between experimental data obtained during the $90^{\circ} \mathrm{F}$ closed-door test and $r$ : - deled energy consumption estimates provided by ADL for R-12 operation explains the additional energy being by the test unit.

ADL's original estimate of energy consumption (see Appendix A), assuming a 5.1 EER compressor for the freezer and a 4.8 EER compressor for the fresh food circuit, was as follows:

\begin{tabular}{lll} 
& $\begin{array}{l}\text { On } \\
\text { time }\end{array}$ & \\
Freezer compressor + fans & $\frac{\mathrm{kWh} / \mathrm{d}}{41.8}$ & 1.25 \\
Fresh food compressor & 50.0 & 0.72 \\
$\quad$ (Static evap. assumed) & & \\
$\begin{array}{l}\text { Defrost + parasitic } \\
\text { Total: }\end{array}$ & - & $\underline{0.24}$ \\
\hline
\end{tabular}


Table 5.1. Amana dual-loop, two-circuit baseline R-12 testing-American Home Appliarc: Manufacturers four-point, $90^{\circ} \mathrm{F}$, clused-door test procedure (unmodified refrigerator-freezer as received from supplier)

\begin{tabular}{|c|c|c|c|c|c|}
\hline $\begin{array}{c}\text { Temperalure } \\
\text { contrul } \\
\text { selting }\end{array}$ & $\begin{array}{c}\text { Puwer } \\
\text { consumption } \\
(\mathrm{kWh} / \mathrm{d})\end{array}$ & $\begin{array}{l}\text { Cornpressor } \\
\text { run liine } \\
(\%)\end{array}$ & $\begin{array}{l}\text { Average freezer } \\
\text { temperature } \\
\left({ }^{\circ} \mathrm{F}\right)\end{array}$ & $\begin{array}{c}\text { Average } \\
\text { fresh food } \\
\text { lemperature } \\
\left({ }^{\circ} \mathrm{F}\right)\end{array}$ & $\begin{array}{l}\text { Freezer defrost } \\
\text { cycle lime } \\
\text { (h) }\end{array}$ \\
\hline \multicolumn{6}{|l|}{$\overline{M i d} / \overline{m i d} /$ off } \\
\hline Freezer & 1.641 & 50.08 & 4.44 & 36.08 & 94.70 \\
\hline Fresh food & $\frac{1.657}{2300}$ & 39.95 & - & & \\
\hline Total & 3.298 & & & & \\
\hline \multicolumn{6}{|l|}{ Mid/mid/on } \\
\hline Frreezer & 2.006 & 51.73 & 4.41 & - & 91.68 \\
\hline Fresh food & 1.689 & 41.44 & - & 36.01 & \\
\hline Total & 3.695 & & & & \\
\hline \multicolumn{6}{|l|}{ Warmiwarm/off } \\
\hline Freezer & 1.568 & 47.12 & 5.34 & - & 101.76 \\
\hline Fresh food & 1.426 & 32.27 & - & 40.19 & \\
\hline Total & 2.994 & & & & \\
\hline \multicolumn{6}{|l|}{ Warm/warm/on } \\
\hline Freezer & 1.896 & 48.20 & 5.69 & 39.47 & 98.20 \\
\hline Fresh food & 1.658 & 34.49 & - & & \\
\hline Total & 3.554 & & & & \\
\hline
\end{tabular}

Overall power consumption rating: $3.37 \mathrm{kWh} / \mathrm{d}$.

Actual EERs for the freezer and fiesh food compressors were 4.8 and 4.1 , respectively. Additionally, a fan forced fresh food evaporator was used rather than static, and as a result the following results should have been predicted:

\begin{tabular}{|c|c|c|}
\hline & $\begin{array}{l}\text { On } \\
\text { lime }(\%)\end{array}$ & $\mathrm{kWh} / \mathrm{d}$ \\
\hline Freezer compressor + fans & 41.8 & 1.53 \\
\hline $\begin{array}{l}\text { Fresh food compressor }+ \text { fans } \\
\text { (Forced evap. }+50 \% \text { cond. fan on) }\end{array}$ & 50.0 & 1.11 \\
\hline $\begin{array}{l}\text { Defrost }+ \text { parasitic } \\
\text { Total: }\end{array}$ & - & $\frac{0.24}{2.88}$ \\
\hline
\end{tabular}

Estimates based on rated compressor performance, actual compressor run times (averaged from Table 5.1), longer defrost cycle times, and actual power consumption of mullion heaters and fans are as follows: 


\begin{tabular}{|c|c|c|}
\hline & $\begin{array}{l}\text { On } \\
\text { lime }(\%)\end{array}$ & $\mathrm{kWh} / \mathrm{d}$ \\
\hline Freezer compressor + fans & 50.3 & 1.85 \\
\hline Fresh food compressor + fans & 37.2 & 0.73 \\
\hline Actual defrost + parasitic & - & $\frac{0.38}{206}$ \\
\hline
\end{tabular}

The fresh food power consumption listed in Table 5.1 does not correspond with those listed above because the condenser fan motor (which runs when either compressor runs) is included in the fresh food portion of the Table 5.1 value. The last summation indicates $20 \%$ more on time for the freezer compressor and 58\% more parasitic load than modeled in the ADL study. A $26 \%$ decrease in fresh-food compressor "on" time and a $43 \%$ decrease in defrost energy were not enough to compensate for the additional power utilization. Clearly the freezer circuit draws much more energy than the modeling studies predicted.

These estimates can be compared to the $2.88 \mathrm{kWh} / \mathrm{d}$ power consumption measured for this $\mathrm{RF}$ by Amana in preliminary shakedown tests before it was shipped to ORNL. ${ }^{24}$ This value does not include the power consumption of the condenser fan that ran in conjunction with either compressor on cycle.

\subsubsection{Second Phase of Modifications}

We replaced the thermostat in the fresh food compartment of this dual-loop RF after these initial tests with one that permitted operation at higher fresh food temperatures without short cycling of the compressor. The disappointing energy consumption results for this unit also prompted the following modifications:

- We modified the electrical circuitry to prevent the freezer circuit condenser fan from running when the fresh food circuit was active. Previously the fan ran when either circuit was on.

- We replaced the 15- to 17-W fresh food evaporator fan with a smaller 5- to 6-W fan. The smaller fan results in less parasitic electrical load and less heat added to the fresh food compartment during the fresh food run cycle. Air-side heat transfer may be less efficient, however, and the short run times of the fresh food loop will minimize the energy savings from this change.

- We arranged the control circuitry for the mullion heaters to allow power to the heaters only when both the freezer compressor relay and the mullion heater switch are engaged. This arrangement is used on the Amana ESTR 18D RFs, and it simulates RF design in which hot condenser gas is used to accomplish the anti-sweat function.

Table 5.2 summarizes the test results with the modifications outlined above. While these results indicate a $10 \%$ decrease in energy consumption compared with those given in Table 5.1, they are still $28 \%$ greater than the energy use rating for this refrigerator in the conventionally operated, one-circuit, one-evaporator mode. 
Table 5.2. Amana dual-loop, two-circuit, baseline R-12 testing-

American Home Appliance Manufacturers four-point, $90^{\circ} \mathrm{F}$, closeddoor test procedure (after energy.saving modifications)

\begin{tabular}{|c|c|c|c|c|c|}
\hline $\begin{array}{l}\text { control } \\
\text { setting }\end{array}$ & $\begin{array}{c}\text { Power } \\
\text { consumption } \\
(\mathrm{kWh} / \mathrm{d})\end{array}$ & $\begin{array}{l}\text { Compressur } \\
\text { run lime } \\
(\%)\end{array}$ & $\begin{array}{l}\text { Average freezer } \\
\text { lemperature } \\
\left({ }^{\circ} \mathrm{F}\right)\end{array}$ & $\begin{array}{c}\text { Average } \\
\text { fresh food } \\
\text { teinperature } \\
\left({ }^{\circ} \mathrm{F}\right)\end{array}$ & $\begin{array}{l}\text { Freezer defrost } \\
\text { cycle time } \\
\text { (h) }\end{array}$ \\
\hline \multicolumn{6}{|l|}{ Mid/mid/off } \\
\hline Freezer & 1.599 & 48.12 & 3.83 & 37.93 & 98.37 \\
\hline $\begin{array}{l}\text { Fresh food } \\
\text { Total }\end{array}$ & $\frac{1.441}{3.040}$ & 33.62 & - & & \\
\hline \multicolumn{6}{|l|}{ Mid/ınid/on } \\
\hline Freezer & 1.782 & 49.07 & 3.94 & - & 96.52 \\
\hline Fresh food & 1.501 & 34.48 & - & 38.00 & \\
\hline Total & $\overline{3.283}$ & & & & \\
\hline \multicolumn{6}{|l|}{ Warm/warm/off } \\
\hline Freezer & 1.562 & 46.53 & 4.90 & - & 101.74 \\
\hline Fresh food & 1.293 & 31.61 & - & 42.26 & \\
\hline Total & 2.855 & & & & \\
\hline \multicolumn{6}{|c|}{ Warın/warm/on } \\
\hline Freezer & 1.757 & 48.04 & 5.08 & 42.26 & 98.44 \\
\hline Fresh food & 1.466 & 30.48 & - & & \\
\hline Total & $\overline{3.223}$ & & & & \\
\hline
\end{tabular}

Overall power consumption rating: $3.03 \mathrm{kWh} / \mathrm{d}$.

\subsubsection{Energy Consumption Analysis}

\subsubsection{ORNL's analysis}

In an attempt to carefully analyze the poor energy consumption results from this test unit, the two Embraco compressors used for the freczer and fresh food loops were calorimeter-rated with R-12, and reverse heat loss measurements were performed on the two chambers of the RF cabinet.

We performed calorimeter ratings (1) at the $-10 / 130^{\circ} \mathrm{F}$ standard rating condition so that a comparison could be made with the literature value for these two compressors. (2) at six conditions bracketing the nomal operating condition. and (3) at the normal operating condition. Tables 5.3 and 5.4 provided tabulated results from these calorimeter tests. Reverse heat loss measurements were performed by cooling the environmental chamber to about $50^{\circ} \mathrm{F}$ and operating measured heat loads and small fans in the two RF companments until thermal equilibrium was obtained. We attempted to obtain temperature differences across the cabinet walls that are approximately the same as when the RF is run as a refrigerator in the $90^{\circ} \mathrm{F}$, closed-door test. A 


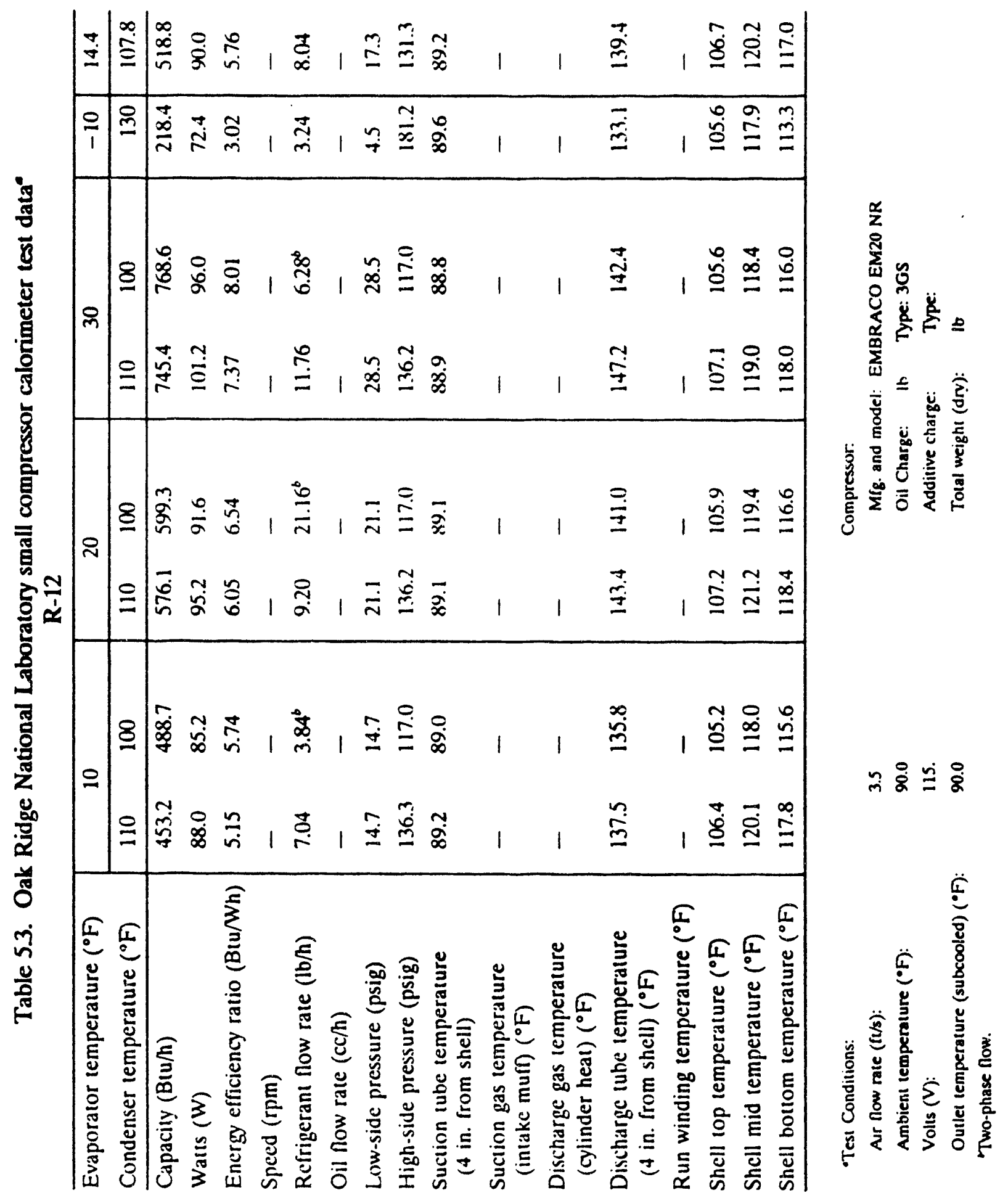


freezer UA value of $1.590 \mathrm{Btw} / \mathrm{h}^{\circ} \mathrm{F}$ and a fresh food $\mathrm{UA}$ value of $2.827 \mathrm{Btu} / \mathrm{h}^{\circ} \mathrm{F}$ were calculated from these measurements.

Using experimentally measured compressor EERs and compartment loadings calculated from reverse heat loss results together with the experimentally measured wattage of fans and other $\mathrm{RF}$ parasitics, the anticipated energy consumption of the dual-circuit, dual-loop RF at $90^{\circ} \mathrm{F}$ ambient conditions was calculated to be about $1.95 \mathrm{kWh} / \mathrm{d}$ rather than the $3.00 \mathrm{kWh} / \mathrm{d}$ value measured in our $90^{\circ} \mathrm{F}$ closed-door tests. This value is lower than previous model predictions, primarily because of the use of the higher compressor EERs and capacities measured for the Embraco compressors at actual operating conditions rather than at the $-10 / 130^{\circ} \mathrm{F}$ rating values used for earlier estimates. This calculated energy consumption would be a $15 \%$ improvement over Amana's stated energy use for the unmodified $18-\mathrm{ft}^{3}$ top mount $(2.35 \mathrm{kWh} / \mathrm{d})$.

To help clarify the discrepancy between modeled and actual RF energy consumption data, we repeated the original model verification calculation performed by $A D L$ on a conventional $R F$ (Appendix A) using values for the compressor EER and capacity that are more indicative of the operating environment in the $90^{\circ} \mathrm{F}$ closed-door test $\left(110^{\circ} /-10^{\circ} \mathrm{F}\right)$.

$\begin{array}{lll} & \begin{array}{l}\text { On } \\ \text { time }(\%)\end{array} & \frac{\mathrm{kWh} / \mathrm{d}}{1.666} \\ \begin{array}{l}\text { Freezer compressor + fans } \\ \text { (Forced cond.) }\end{array} & 34.7 & \underline{0.24} \\ \begin{array}{l}\text { Defrost + parasitic } \\ \text { Total: }\end{array} & & 1.91\end{array}$

This calculation based on actual compressor operating conditions is $16.7 \%$ more optimistic than the previous estimate $(2.290 \mathrm{kWh} / \mathrm{d})$ and does not compare well with Amana's measured system performance $(2.293 \mathrm{kWh} / \mathrm{d})$, suggesting a flaw in the original validation work. This lack of agreement suggests that this scheme of estimating the daily energy consumption of RFs by matching heat loads to compressor performance works best if the rated performance of compressors at the $130 \%-10^{\circ} \mathrm{F}$ calorimeter point is used.

When the dual-circuit, dual-loop RF is modeled using measured cabinet heat loads, actual fan and heater energy consumption, present operating configuration, and compressor ratings at the $130 \%-10^{\circ} \mathrm{F}$ condition, the predicted energy use is $2.621 \mathrm{kWh} / \mathrm{d}$, which is still $15.6 \%$ better than what has been achieved experimentally.

\subsubsection{Amana's analysis}

The ORNL RF performance data and calorimeter data was sent to Bruce Kopf at Amana for his opinion on why the test unit performed so poorly relative to the projections. After a cursory analysis, Kopf suggested installing the compressors that were actually tested on the calorimeter in une RF, charging each circuit scparately while the other circuit remains off, and checking to be sure no air leaks are present between the freezer and fresh food sections.

In a simplified analysis based only on compressor EERs and capacities, Eivind Sallo from Amana concluded that no efficiency gain can be expected by going to the dual-circuit approach with these compressors. His analysis indicated that, at the actual operating conditions, Embraco's estimates for the EER of an EM 40 SC compressor (used for the freezer circuit) was about 5.6 (5.02 experimentally; see Table 5.4) and an EER of 6.1 was predicted for the fresh food compressor (5.76 experimentally; see Table 5.3). The Matsushita compressor used in the conventional RF design had an EER of 5.72 at the freezer compartment operating conditions 


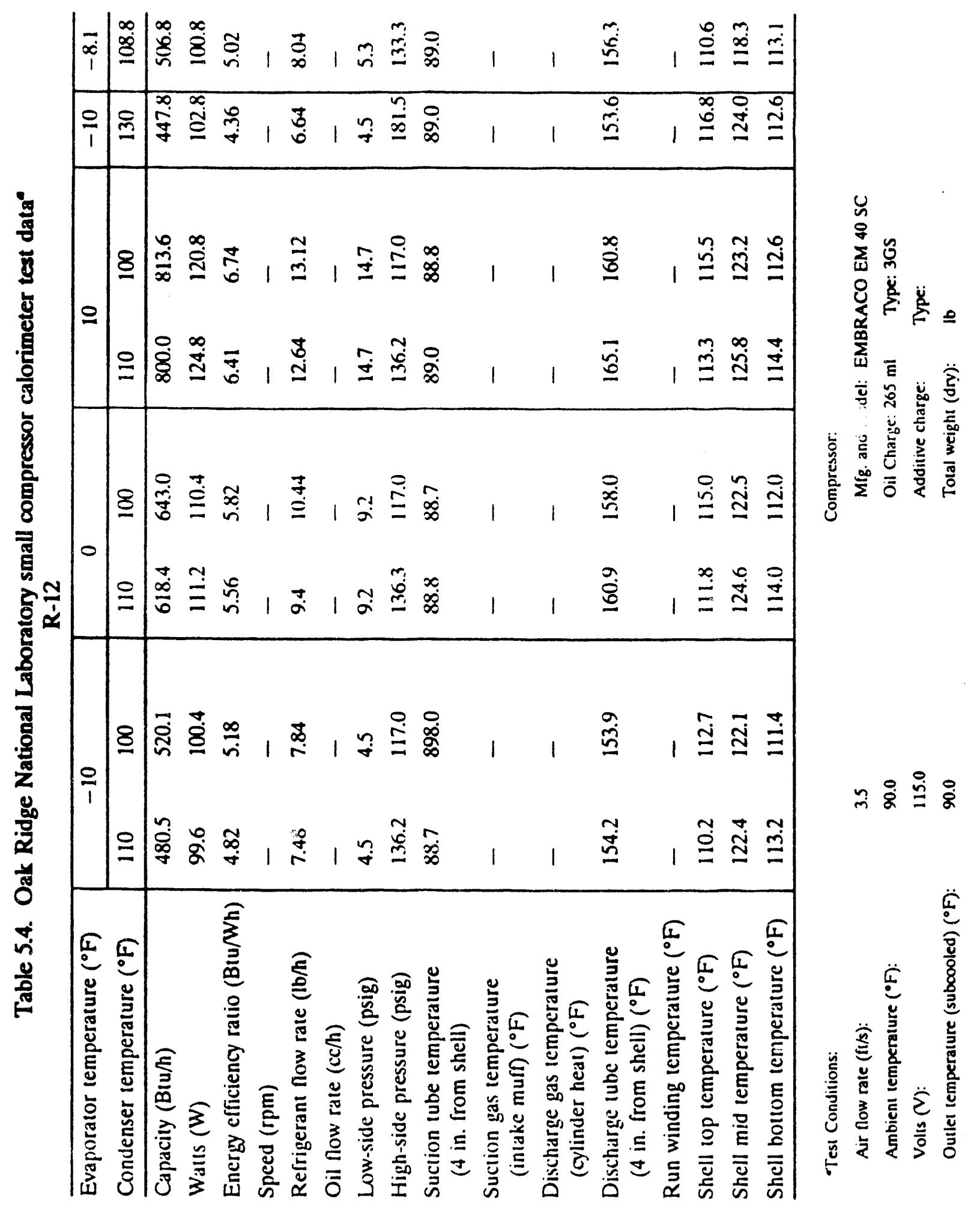


Table 5.5. Amana dual-loop, two-circuit, baseline R-12 testing-American

Home Appliance Manufacturers four-point, $90^{\circ} \mathrm{F}$, closed-door test procedure after energy-saving modifications (after compressor substitution and detailed charging)

\begin{tabular}{|c|c|c|c|c|c|}
\hline $\begin{array}{l}\text { Control } \\
\text { selling }\end{array}$ & $\begin{array}{c}\text { Power } \\
\text { consuinplion } \\
(\mathrm{kWh} / \mathrm{d})\end{array}$ & $\begin{array}{l}\text { Compressor } \\
\text { run lime } \\
(\%)\end{array}$ & $\begin{array}{c}\text { Average freezer } \\
\text { lemperature } \\
\left({ }^{\circ} \mathrm{F}\right)\end{array}$ & $\begin{array}{c}\text { Average } \\
\text { fresh food } \\
\text { teinperature } \\
\left({ }^{\circ} \mathrm{F}\right)\end{array}$ & $\begin{array}{c}\text { Freezer defros } \\
\text { cycle time } \\
\text { (h) }\end{array}$ \\
\hline \multicolumn{6}{|l|}{ Mid/mid/off } \\
\hline Freezer & 1.691 & 46.07 & 3.81 & 38.36 & 101.83 \\
\hline $\begin{array}{l}\text { Fresh food } \\
\text { Total }\end{array}$ & $\frac{1.261}{2.952}$ & 30.93 & - & & \\
\hline \multicolumn{6}{|l|}{ Mid/mid/on } \\
\hline Freezer & 1.835 & 46.09 & 3.44 & - & 101.72 \\
\hline Fresh food & 1.322 & 31.50 & - & 38.16 & \\
\hline Total & $\overline{3.157}$ & & & & \\
\hline \multicolumn{6}{|l|}{ Warın/warm/off } \\
\hline Freezer & 1.673 & 43.35 & 5.89 & - & 108.34 \\
\hline Fresh food & 1.200 & 29.38 & - & 40.34 & \\
\hline Total & 2.873 & & & & \\
\hline \multicolumn{6}{|l|}{ Warm/warm/on } \\
\hline Freezer & 1.76 .5 & 43.02 & 6.06 & 40.42 & 109.11 \\
\hline Fresh food & 1.240 & 28.90 & - & & \\
\hline Total & 3.005 & & & & \\
\hline
\end{tabular}

Overall power consumption rating: $2.98 \mathrm{kWh} / \mathrm{d}$.

Almost all of the additional energy use seen in the experimental results is due to longer compressor run times for the freezer circuit. Based on the measured compressor EER and the freezer cabinet heat load calculated using the UA value from reverse heat loss measurements, the freezer duty cycle should be about $30 \%$ to $32 \%$. Experimental duty cycles of $48 \%$ to $50 \%$ are being observed for the test unit. With two refrigeration circuits, cycling losses (even if they are quite small) are doubled.

Modeled results of RF system performance obtained by matching cabinet heat loads to compressor capacity and efficiency appear to be more valid if compressor performance ratings are taken from an operating condition more severe than the actual system environment.

This dual-circuit, dual-loop design did show superior compartment temperature control and pull down rates.

Other suggestions for improving the perfonnance of this dual-circuit. dual-loop design are building it in a cabinet designed specifically for separate insulated compartments, use fans and heat exchangers explicitly designed for the smaller loads, and charge the circuits with altemative refrigerants more suited for freezer and fresh food operation. 
indicative of the $90^{\circ} \mathrm{F}$ closed door test. Using cabinet UA values reported previously to calculate fractional cabinet heat loads $[135.13 \mathrm{Btu} / \mathrm{h}(0.48$ of the total) for the frcezer and $147.00 \mathrm{Btu} / \mathrm{h}$ ( 0.52 of the total) for the fresh food] at a $90^{\circ} \mathrm{F}$ ambient temperature, the weighted compressor EER based on fractional heat loads for the dual-circuit unit can be calculated as follows:

$$
(0.48 \times 5.6)+(0.52 \times 6.1)=5.86
$$

This combined compressor value is only $2.4 \%$ better than the 5.72 EER for the Matsushita compressor operating alone. When actually measured compressor EERs are used for the combined compressor calculation, the EER value for the dual-circuit RF is 5.7\% worse than the Masushita alone.

\subsubsection{Third Phase Modifications}

Analysis of the test control apparatus indicated that 7-8 W of energy was required by the variac being used to reduce laboratory line voltage to the $115 \mathrm{VAC}$ prescribed in test procedures. Elimination of this load would lower the per day energy consumption of this RF by about 0.18 to $2.85 \mathrm{kWh} / \mathrm{d}$.

The Embraco EM 20 NR and EM 40 SC compressors that were tested on the small compressor calnrimeter and whose performance is summarized in Tables 5.3 and 5.4, respectively, were installed on the prototype refrigerator. A capillary selection procedure and charging procedure recommended by Bruce Kopf at Amana was used to set up this dual-loop unit for additional testing. Basically, this procedure calls for adding or subtracting small amounts of charge from a continuously running system with the other circuit turned off. At the point where the refrigerant temperature difference across the evaporator is minimized with the least amount of compressor power consumption, the charge is optimized. At this point the capillary should give the desired suction pressure or saturated-evaporator temperature and there should be less than $2^{\circ} \mathrm{F}$ of subcooling in the condenser.

Table 5.5 gives results from this last series of tests with this unit. Some improvement is seen mainly due to the elimination of the 7-8 $\mathrm{W}$ load previously mentioned from the fresh food circuit. Comparisons between Tables 5.2 and 5.5 indicate that the new Embraco $40 \mathrm{SC}$ compressor being used for the freezer circuit is not performing as well as the previous one. The $2.98 \mathrm{kWh} / \mathrm{d}$ results from this laboratory test match the more realistic estimates tabulated near the end of Sect. 5.2.4.

\subsubsection{Conclusions and Discussion}

The main problem with the two-circuit design is that it uses small compressors that have very poor EERs when compared with the larger-capacity compressors used in conventional RFs. The EERs for the freezer and fresh food compressors on this unit are listed at $4.20 \mathrm{Btu} / \mathrm{W} \cdot \mathrm{h}$ and 3.10 Btu/W.h, respectively. Newer, 800-1000-Btu/h compressors used in conventionally designed RFs have EERs greater than 5.00 at the $-10^{\circ} / 130^{\circ} \mathrm{F}$ rating condition. 


\subsection{REFRIGERANT-SWITCHING, DUAL-LOOP REFRIGERATOR DESIGN AND TESTING}

\subsubsection{Refrigerant-Switching, Dual-Loop Design}

Ray Boluman was asked to design ORNL's alternate concept, dual-loop RF. Lennis Thomas, the local subcontractor who built the L-M RF for ORNL, indicated that he would be interested in constructing a test unit based on Bohman's design. The basic plan involved modifying an existing RF that had been well characterized using R-12 to a design provided by Ray. The switched-refrigerant concept, illustrated in Fig. 5.2(a), was favored over an air-switching idea, illustrated in Fig. 5.2(b), for several reasons:

- Simpler hardware and fluid circuiting requirements were needed to redirect liquid refrigerant as opposed to air.

- Commercial 3-way solenoid valves for liquid-refrigerant lines were available, whereas air duct baffling would have to be uniquely designed and fabricated for the air-switching system.

- Anticipated frost formation in the air-switching design would interfere with damper operation.

- Separated freezer and fresh food evaporators would ininimize defrosting requirements.

Bohman visited ORNL on October 25 and 26, 1990 to discuss altemative dual-loop RF concepts. Decisions made as a result of this visit are summarized briefly below:

- A dual-loop design that takes advantage of the lower temperature lift in the fresh-food compartment to decrease the compressor energy needed to satisfy the fresh-food cooling load was specified. Realistically this could only be accomplished with a two-circuit (previously described) or an air- or refrigerant-switching dual-loop concept.

- A preference for the refrigerant-switching concept was stated for many of the reasons outlined above and because it would be easier for the subcontractor to build from a conventional RF. A brief description of the operation and performance of a European dual-evaporator RF that utilized a 3-way, liquid-line valve was available.

- A conventional 18- $\mathrm{ft}^{3} \mathrm{RF}$ was to be used as a starting point for this work. This unit's performance with R-12 had been thoroughly characterized in previous testing and it was equipped with fittings and sensors needed for the dual-loop tests.

- Modeling results simulating refrigerant- and air-switching dual-loop RF operation with R-12 and altemative refrigerants were reviewed. A fan-forced fresh food evaporator and provisions for fresh food defrost were suggested as concessions to creating a viable RF rather than one built for all-out energy efficiency.

- The consultant agreed to work up a design that he could review with our local contractor who would build the test unit.

In December of 1990, a design was presented for review. The following design features were recommended:

- Separate evaporators and capillary tubes for the freezer and fresh food chambers.

- Use of a Danfoss valve to switch refrigerant flow to the freezer evaporator through the normally open port or to the fresh food evaporator through the normally closed port. 

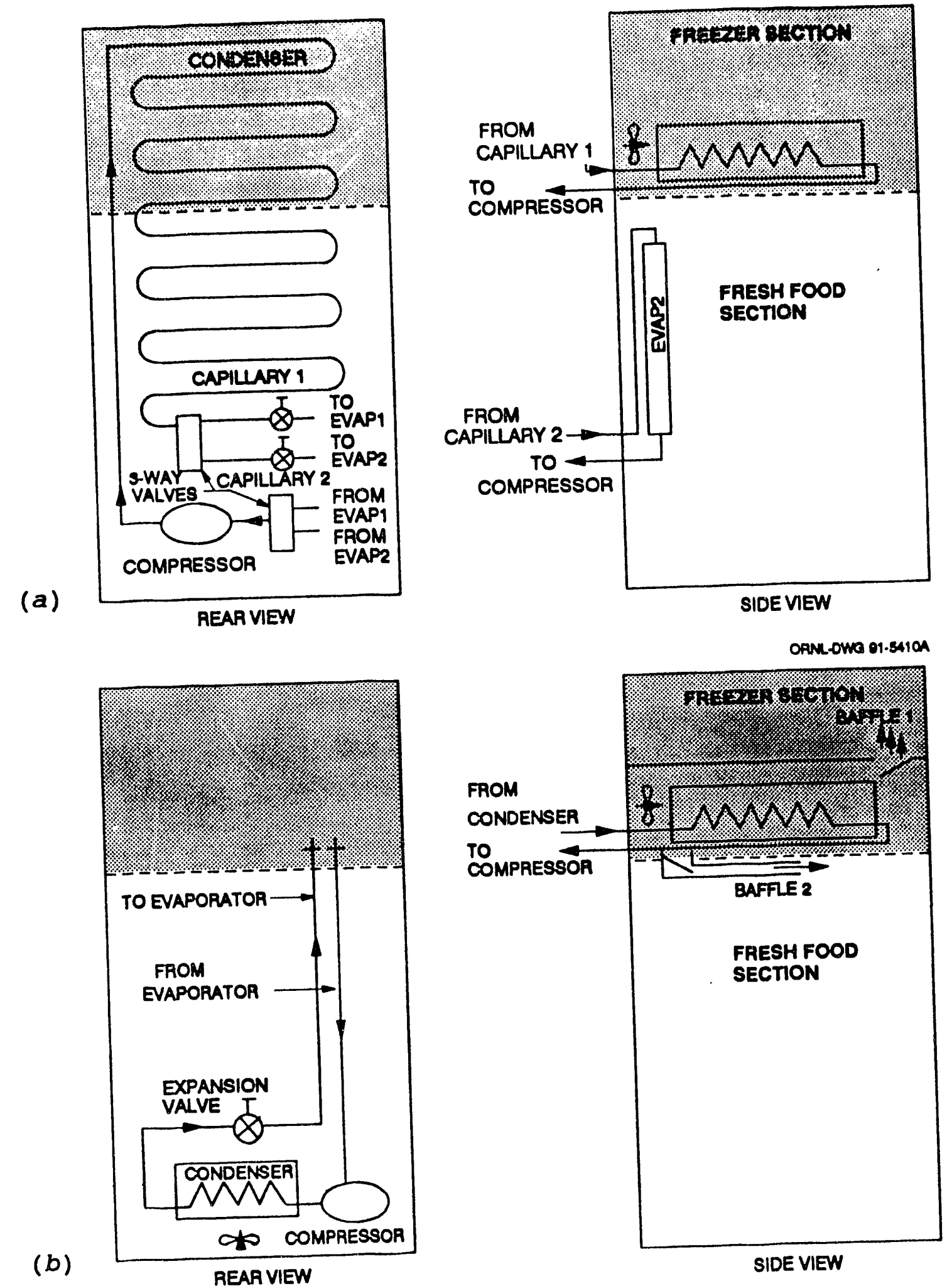

(b)

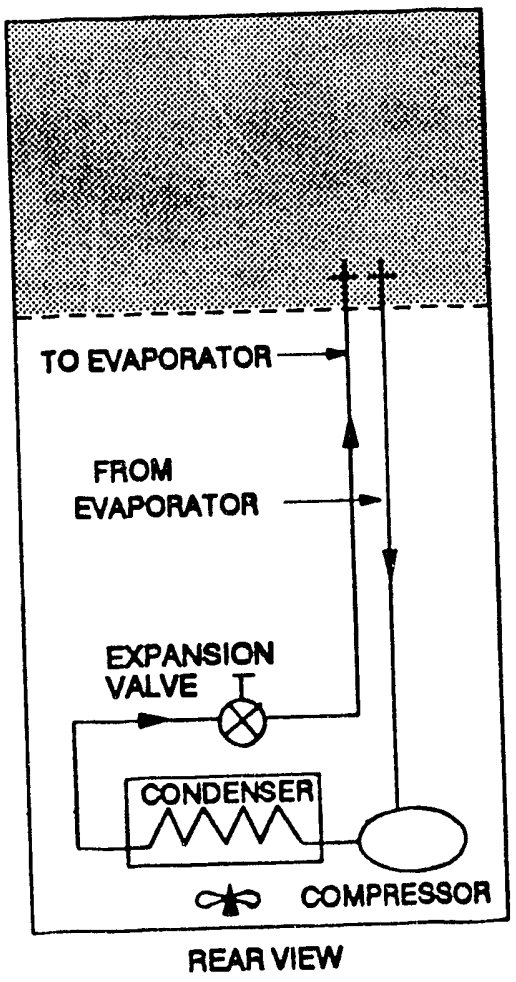

Fig. 5.2. Schematics of single-compressor dual-loop refrigerator-freezers. (a) Refrigerant switching, (b) air switching. 
- A fan-forced fresh food evaporator with approximately one-half to one-third the intemal volume of the freezer evaporator. Brazeway. Inc.. in Adrian, Michigan, was suggested as a possible vendor for fabrication of some test samples of this evaporator.

- A simplified thermostat control strategy in which the freezer thermostat establishes the compressor cycling pattern for the unit, but the fresh food thermostat takes precedence for refrigerant demand. Rationale for this prioritization is that the freezer usually has a larger thermal mass and requires longer run times, whereas the fresh food cooling should be accomplished more quickly.

- Incorporation of a mechanical check valve in the freezer suction line to prevent back-flow of warm refrigerant into the freezer evaporator during fresh food operation.

- An option to run the fresh food evaporator fan continuously or only in conjunction with compressor runs.

- Use of a larger (approximately $800 \mathrm{Btu} / \mathrm{h}$ ) compressor than that used in the dual-circuit unit to assure adequate pull-down performance and to take advantage of the better EERs associated with larger compressor sizes.

An initial "sketch" of the cycling performance and the electrical control circuit for this dual-loop design were prepared by the consultant (Appendix C). The smaller fresh food evaporator proposed in the initial design meant that this system would have to operate with freshfood evaporator temperatures below $10^{\circ} \mathrm{F}$ in order to adequately cool the unit in a $90^{\circ} \mathrm{F}$ cycling test. These fresh-food evaporator temperatures would necessitate periodic defrost.

On January 28th, 1991. Bohman met with Lennis Thomas al the laboratory to discuss the design and construction of this test unit. Finalized plans were presented, which included a detailed bill of materials needed for construction and some step-by-step instructions outlining the proper sequencing of tasks, as shown in Appendix C.

The RF that was to be used as the base unit was inspected, along with the additional parts needed to complete the design. ORNL provided a detailed sketch of locations for thermocouples and pressure transducers.

The base RF and the hardware required for its conversion to this dual-loop design were sent to Thomas in March 1991. Shakedown tests of the reconfigured unit using R-12 were performed in May, and the rebuilt refrigerator was delivered to ORNL in June 1991.

\subsubsection{Air-or Refrigerant-Switching Dual-Loop Modeling Analysis}

Using the same cabinet loadings, comparment temperatures, rating conditions, and component efficiencies outlined in Merriam's analysis of the dual-circuit, dual-loop design (Appendix A), an analysis of two dual-loop RF concepts (the "one-evaporator air-switching" and the "one-compressor, one-condenser, two-evaporator refrigerant-switching" designs) was performed using the CYCLE- $Z$ model and the $130^{\circ} /-10^{\circ} \mathrm{F}$ compressor rating data.

The modeling assumptions for the dual-loop analysis were as follows.

- Cabinet load assumptions
Fresh food compartment: $40^{\circ} \mathrm{F}$

Freezer compartment: $5^{\circ} \mathrm{F}$

Freczer load: 184.9 Btum

Fresh food load: $128.1 \mathrm{Btu} / \mathrm{h}$

Auxiliary heaters: $5 \mathrm{~W}$

Heater on time: $50 \%$

Defrost: $570 \mathrm{~W} / 10 \mathrm{~min} / 10 \mathrm{~h}$ 
Rating condition: $90^{\circ} \mathrm{F}$

Doors: closed

- Cycle model assumptions

- Compressor
Condenser fan: $15 \mathrm{~W}$

Evaporator fan: $13 \mathrm{~W}$

Evaporator UA: $100 \mathrm{Blu} /\left(\mathrm{h} / \mathrm{Sf} \cdot{ }^{\circ} \mathrm{F}\right)$

Condenser UA: $50 \mathrm{Btu} /\left(\mathrm{h} / \mathrm{Sf} \cdot{ }^{\circ} \mathrm{F}\right)$

Rated capacity: $896 \mathrm{Btu} / \mathrm{h}$

EER: 4.58

The work sheet displayed as Table 5.6 indicates that the best energy savings predicted for either design is 15 to $16 \%$ over that of a conventional R-12 system. Assumptions present in the original analysis and the present work would favor inflated efficiency predictions.

An 800-900 Btu/h compressor, like the Panasonic used in this analysis, was recommended for either the air- or refrigerant-switching designs to ensure adequate pull-down performance. Larger-capacity compressors generally have better efficiency ratings, also.

$\mathrm{R}-152 \mathrm{a}$ appeared to be a logical choice for an alternative dual-loop refrigerant because of its thernophysical similarities to R-12 and its comparable performance in R-12 compressors. The air- or refrigerant-switching designs do not permit using a different refrigerant in the freezer and fresh food loop as was possible in the dual-circuit, dual-loop design.

\subsubsection{Refrigerant-Switching Construction}

A circuit schematic and transducer map for this refrigerant-switching, dual-loop RF design is shown in Fig. 5.3. The subcontractor chosen to build this prototype had two main problems in the construction and shakedown tests of this unit. He could not get adequate refrigerant flow through the Danfoss 3-way valve we supplied him, and the thennostat we provided with the RF hardware supplies could not be adjusted to effectively control the temperature of the fresh food compartment.

After the subcontractor tried unsuccessfully to use Sporlan No. 180 pilot control valves as replacements for the refrigerant-switching device, he eventually reinstalled the Danfoss 3-way valve originally supplied. This valve has small tubing connections and orifices sized for refrigerant flow rates typical in European refrigerators.

A versatile Ranco No. 016-104 thermostat was ordered by ORNL on the advice of Bohman for use in the fresh food compartment. The cut-in temperature for this control could be adjusted to any temperature between $0^{\circ} \mathrm{F}$ and $55^{\circ} \mathrm{F}$ with an adjustable dead band of $3^{\circ} \mathrm{F}$ to $20^{\circ} \mathrm{F}$.

Run-in tests at the subcontractor's shop after installation of this equipment indicated that the combined restrictions of the Danfoss valve and the originally selected capillary lengths were too great to permit sufficient refrigerant flow rates. The unit was shipped back to ORNL for more thorough testing and modification. Bohman suggested that these problens can be solved by shortening capillary tubes. 


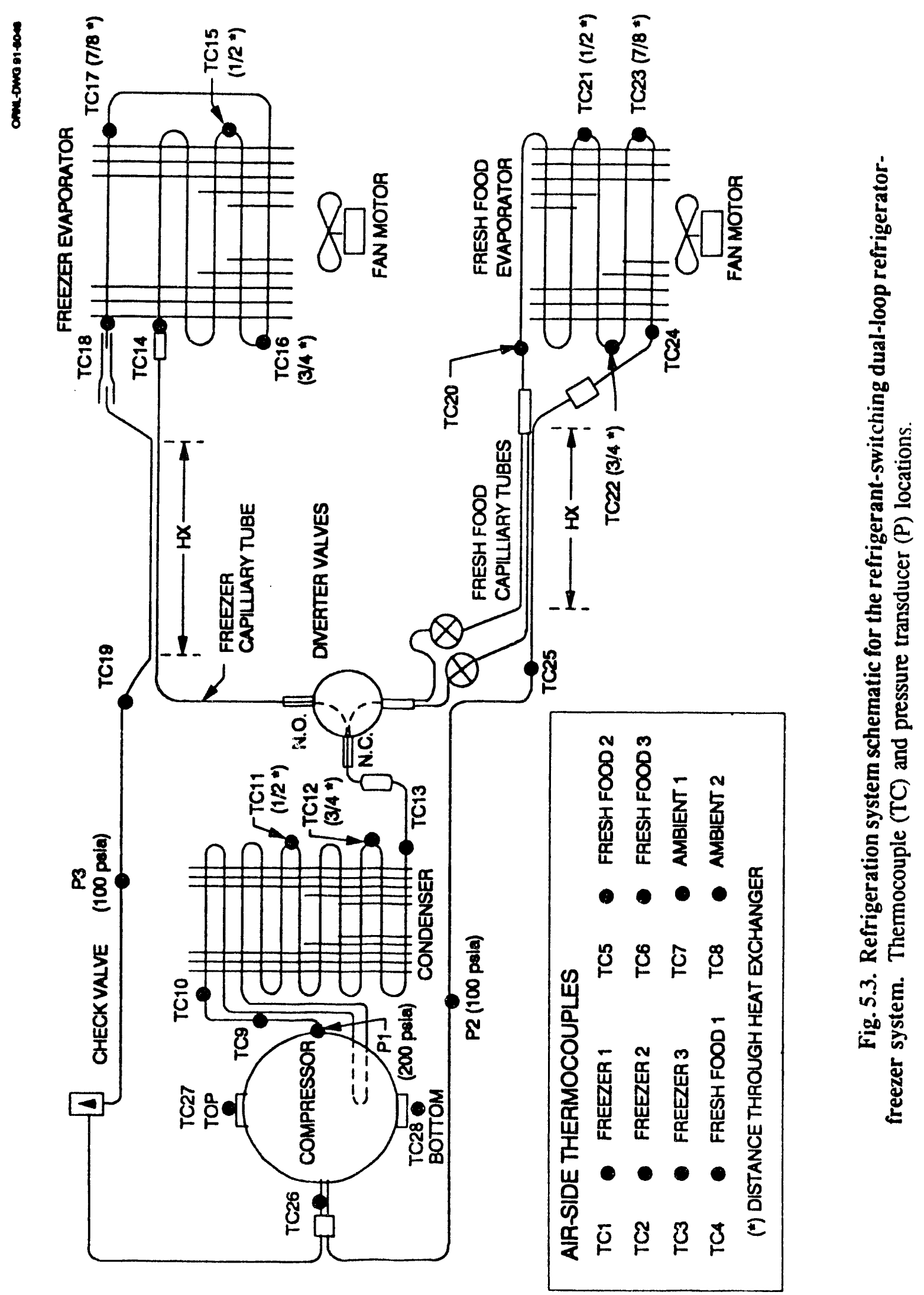




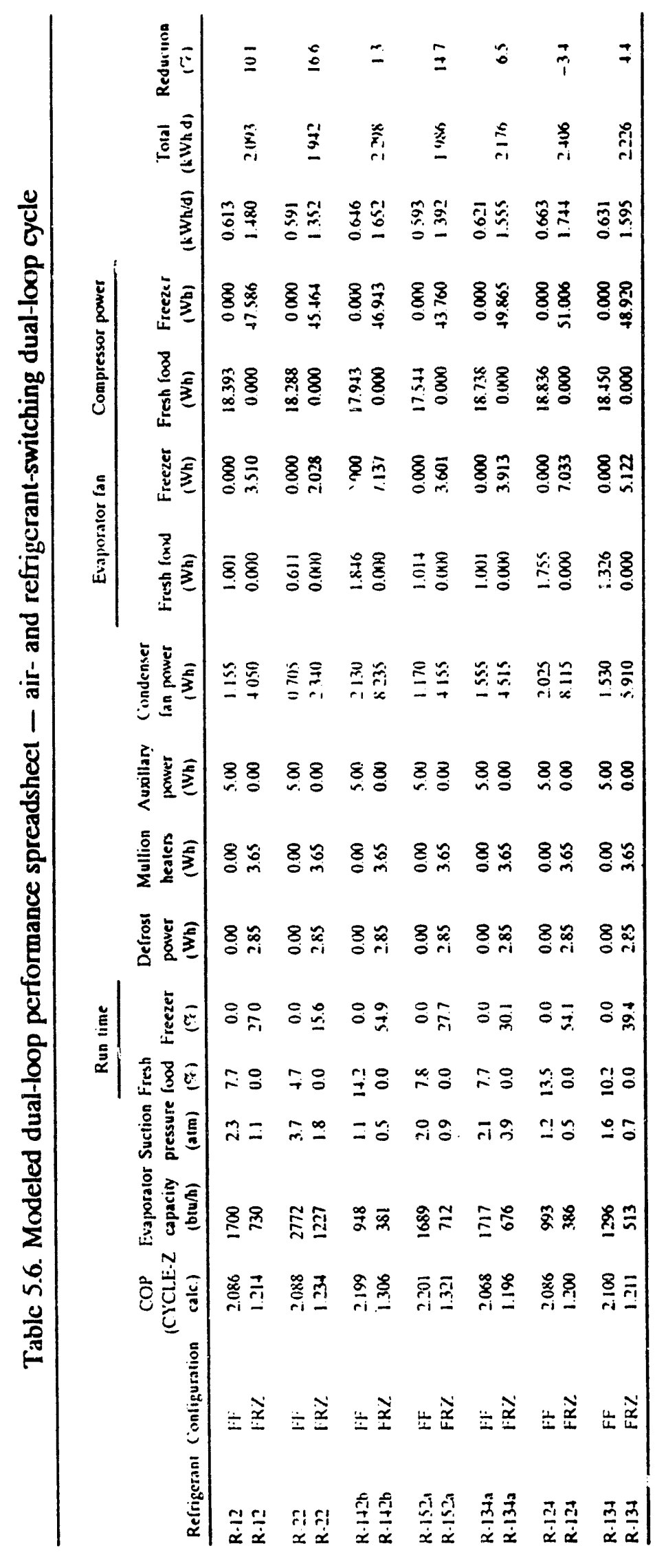




\subsubsection{Initial Test Results with R-12}

We fitted the built-up refrigerant-switching dual-loop $R F$ received from the local subcontractor with the required transducers and circuit relays to make it compatible with ORNL's data acquisition system and started with R-12 refrigerant and bascline testing. A set of $\mathrm{mid} / \mathrm{mid} / \mathrm{ON}$ and $\mathrm{mid} / \mathrm{mid} / \mathrm{OFF} 90^{\circ} \mathrm{F}$ closed door tests were perfomed with the long and short capillary tubes for fresh food operation (Table 5.7).

We discovered that one reason the compressor run times were so long and energy consumption was so high for these tests was because the freezer evaporator fan ran whenever the compressor ran, even when refrigerant was being diverted to the fresh food circuit. This fan added to the parasitic electrical load and also contributed an unnecessary heat load to the freezer compartment.

Another system problem experienced after about 4-5 days of operation was that the check valve in the freczer suction line began to leak and allowed warmer refrigerant to back up into the freezer evaporator during the fresh food portion of the compressor on cycle.

The test unit was modified by:

- re-circuiting the reezer fan so that it runs only when liquid refrigerant is flowing to the freezer evaporator, and

- installing a new magnetic check valve in the freezer suction line at an orientation that should help prevent leaks.

Results from this incomplete series of runs were sent to Bohman to get his opinion on circuit and operating modifications that may improve energy efficiency.

\subsubsection{Refrigerant-Switching Dual-Loop RF Performance after Initial Modifications}

Tables 5.8 and 5.9 summarize some "before" and "after" performance results on the diverter-valve dual-loop RF. Table 5.8 contains the AHAM $90^{\circ} \mathrm{F}$ ciosed-door results on this unit before it was modified into a two-evaporator RF with a liquid-line diverter valve. Table 5.9 is complete set of $90^{\circ} \mathrm{F}$, closed-door runs obtained on the test unit after control problems with the freezer fan and a faulty check valve were corrected. The overall test rating of $2.90 \mathrm{kWh} / \mathrm{d}$ obtained in Table 5.9 is $15 \%$ higher than that of the unmodified unit.

As a result of his analysis of this data. Bohman suggested the following circuit modifications:

- replace the 7-8 $\mathrm{ft}$ length of $0.028 \mathrm{in}$. ID capillary in the freezer circuit with $10 \mathrm{ft}$ of 0.031 in. capillary to allow more refrigerant circulation, and

- double the size of the fresh food evaporator to help balance the charge size required for efficient freezer and fresh food operation.

\subsubsection{Refrigerant-Switching Dual-Loop RF Performance after Second Phase Modifications}

After the fresh food evaporator in this refrigerant-switching (diverter-valve), dual-loop RF was enlarged to accommodate approximatcly the same charge size as the freezer circuit and the 0.028 in. ID capillary on the freezer circuit was replaced with the recommended length of 0.031 in. ID capillary, R-12 and R-152a were tested at the AHAM $90^{\circ} \mathrm{F}$, closed-door test conditions. Results from these tests are given in Tables 5.10 and 5.11 . 
Table 5.7. Refrigerant-switching, dual-loop baseline $\mathrm{R} \cdot 12$ testing, $90^{\circ} \mathrm{F}$ ambient closed-door procedure-refrigerator-freezer as received from Tillery Mechanical

\begin{tabular}{|c|c|c|c|c|c|c|c|}
\hline Control/Setting & $\begin{array}{c}\text { Power } \\
\text { consumption } \\
(\mathrm{kWh} / \mathrm{d})\end{array}$ & $\begin{array}{l}\text { Compressor } \\
\text { run liune } \\
(\%)\end{array}$ & $\begin{array}{l}\text { Run time on } \\
\text { fresh food } \\
\text { load }(\%)\end{array}$ & $\begin{array}{l}\text { Average freezer } \\
\text { lemperalure } \\
\left({ }^{\circ} \mathrm{F}\right)\end{array}$ & $\begin{array}{c}\text { Average } \\
\text { fresh food } \\
\text { temperature } \\
\left({ }^{\circ} \mathrm{F}\right)\end{array}$ & $\begin{array}{l}\text { Average fresh } \\
\text { food humid. } \\
\text { (Rel. \%) }\end{array}$ & $\begin{array}{l}\text { Freezer defrost } \\
\text { cycle time } \\
\text { (h) }\end{array}$ \\
\hline $\begin{array}{l}\text { Mid/mid/on } \\
\text { (longer fresh } \\
\text { food capillary) }\end{array}$ & 3.327 & 60.10 & 38.98 & 3.76 & 36.18 & 30.37 & 78.603 \\
\hline $\begin{array}{l}\text { Mid/mid/on } \\
\text { (shorter fresh } \\
\text { food capillary) }\end{array}$ & 3.328 & 61.08 & 39.11 & 3.43 & 35.44 & 30.20 & 77.668 \\
\hline $\begin{array}{l}\text { Mid/mid/off } \\
\text { (longer fresh } \\
\text { food capillary) }\end{array}$ & 3.010 & 59.28 & 36.75 & 4.10 & 36.98 & 32.39 & 79.697 \\
\hline
\end{tabular}

1. The "Mid//mid" condition indicates that themostats are adjusted to give freezer temperature $<5.00^{\circ} \mathrm{F}$ : "on" and "off" refer to the mullion heater switch position.

2. is inch. 0.036 " 1. D. fresh food capillary

3. 72 inch. $0.031 "$ I. D. fresh food capillary

Table 5.8. Refrigerant-switching dual-loop R-12 baseline data-before modification

\begin{tabular}{|c|c|c|c|c|c|}
\hline Control/setting & $\begin{array}{c}\text { Power } \\
\text { consumption } \\
\text { (kWh/d) }\end{array}$ & $\begin{array}{l}\text { Compressor } \\
\text { run tiine } \\
(\%)\end{array}$ & $\begin{array}{l}\text { Average freezer } \\
\text { lemperalure } \\
\left({ }^{\circ} \mathrm{F}\right)\end{array}$ & $\begin{array}{c}\text { Average } \\
\text { fresh food } \\
\text { leinperature } \\
\left({ }^{\circ} \mathrm{F}\right)\end{array}$ & $\begin{array}{l}\text { Freezer defrost } \\
\text { cycle time } \\
\text { (h) }\end{array}$ \\
\hline Mid/mid/on & 2.86 & 53.3 & 1.8 & 37.0 & 14.48 \\
\hline $\mathrm{Mid} / \mathrm{mid} / \mathrm{off}$ & 2.49 & 51.1 & 2.1 & 37.2 & 14.96 \\
\hline Warm/warm/on & 2.45 & 42.0 & 10.0 & 44.6 & 18.07 \\
\hline Warm/warm/on & 2.05 & 40.5 & 10.0 & 44.5 & 18.83 \\
\hline
\end{tabular}

Overall American Home Appliance Manufacturers test rating: $2.52 \mathrm{kWh} / \mathrm{d}$.

The "Mid/mid" condition indicates that thernostats are adjusted to give average freezer temperatures $<5.0^{\circ} \mathrm{F}$ and fresh food temperatures of about $38.0^{\circ} \mathrm{F}$. "Warm/warm thermostat sellings give freezer temperatures $>5.0^{\circ}$ and fresh food temperatures of about $40.0^{\circ} \mathrm{F}$. "On" and "off" refer to the anusweat heater swilch position. 
Table 5.9. Refrigerant-switching dual-loop $R-12$ baseline data after freezer fan and check valve modifications-longer fresh food capillary ${ }^{1}$

\begin{tabular}{|c|c|c|c|c|c|c|c|}
\hline Control setring ${ }^{2}$ & $\begin{array}{c}\text { Power } \\
\text { consumption } \\
(\mathrm{kWh} / \mathrm{d})\end{array}$ & $\begin{array}{l}\text { Compressor } \\
\text { run tume } \\
(\%)\end{array}$ & $\begin{array}{l}\text { Run time on } \\
\text { fresh food } \\
\text { load ( } \%)\end{array}$ & $\begin{array}{l}\text { Average freezer } \\
\text { lemperalure } \\
\left({ }^{\circ} \mathrm{F}\right)\end{array}$ & $\begin{array}{c}\text { Average } \\
\text { fresh lood } \\
\text { lemperalure } \\
\left.\text { ( }{ }^{\circ} \mathrm{F}\right)\end{array}$ & $\begin{array}{c}\text { Relative } \\
\text { huınidity } \\
(\%)\end{array}$ & $\begin{array}{l}\text { Freezer defrost } \\
\text { cycle time } \\
\text { (h) }\end{array}$ \\
\hline Mid/mid/on & 3.037 & 64.73 & 38.28 & 4.61 & 40.02 & 32.5 & 73.094 \\
\hline Mid/mid/off & 2.755 & 65.36 & 35.06 & 4.50 & 40.04 & 39.42 & 72.398 \\
\hline Warm/warm/on & 3.067 & 65.99 & 42.00 & 6.96 & 40.24 & 30.73 & 71.777 \\
\hline Warm/warm/off & 2.749 & 64.77 & 41.51 & 6.66 & 40.58 & 31.80 & 73.055 \\
\hline
\end{tabular}

Overall American Home Appliance Manufacturers lest rating: $2.90 \mathrm{kWh} / \mathrm{d}$.

1. The "Mid/mid" condition indicales that thenmostats are adjusted to give average freezer temperatures $<5.0^{\circ} \mathrm{F}$ and fresh food temperatures of about $38.0^{\circ} \mathrm{F}$. "Wanm/uami" thenmostal sellings give frezer temperatures $>5.0^{\circ} \mathrm{F}$ and fresli foud lemperatures of aboul $40.0^{\circ} \mathrm{F}$. "On" and "off" refer to the antisweat heater switch position.

2. 95 inches of 0.036 in. ID fresh food capillary.

Increasing the size of the fresh food evaporator permitted its operation at $+20^{\circ} \mathrm{F}$ rather than $+10^{\circ} \mathrm{F}$ as initially proposed. This change decreased the compressor power required during fresh food operation and obviated the necessity for defrosting the fresh food evaporator.

The $R-12$ results in Table 5.10 give a $2.55 \mathrm{kWh} / \mathrm{d}$ overall rating that is roughly equivalent to the $2.52 \mathrm{kWh} / \mathrm{d}$ obtained with $\mathrm{R}-12$ in the unmodified RF (Table 5.8). There is no improvement in energy consumption due to the more complex refrigerant-switching cycle unless the parasitic loads for added electrical components and the added cabinet heat loads resulting from these additions are subtracted from the $2.55 \mathrm{kWh} / \mathrm{d}$ value. Using averages for the compressor run times and the percentages of time satisfying the fresh food load listed in Table 5.7 together with rated wattages for the diverter valve and fresh food evaporator fan, a daily energy consumption value of $2.47 \mathrm{kWh} / \mathrm{d}$ can be computed for this R-12 data. This would suggest a $2.3 \%$ savings in energy due to the more complex, refrigerant-switching cycle operating with $\mathrm{R}-12$.

Comparing compressor run times in Tables 5.8 and 5.10 indicate they went from $40-54 \%$ in the unmodified RF to $52-57 \%$ in the diverter-valve design. This increase in run time may be due to the additional thennal inertia associated with added heat exchangers. tubing, and valving in the diverter-valve design. Very litule difference is seen between compressor run times in going from the R-12 mid/mid to warm/wam conditions in Table 5.7, suggesting a threshold inefficiency.

Table 5.11, which summarizes the R-152a results from the diventer-valve, dLal-loop RF design, shows an overall $2.37 \mathrm{kWh} / \mathrm{d}$ rating. This was a $7.1 \%$ improvement over $\mathrm{R}-12$ in the same circuit and a $6.0 \%$ improvement over baseline R-12 in the unmodified RF. Almost all of this improvement is due to the refrigerant because of the minimal cycle improvements discussed above in connection with the $R-12$ results.

The longer compressor run times seen for $\mathrm{R}-152 \mathrm{a}$ at the $\mathrm{mid} / \mathrm{min}$ conditions are explainable in terns of the decreased volumetric capacity of R-152a as compared to R-12. 
Table 5.10. Refrigerant-switching dual-Ioop R-12 baseline data after fresh food evaporator enlargement-longer fresh food capillary'

\begin{tabular}{|c|c|c|c|c|c|c|c|}
\hline Control selling ${ }^{2}$ & $\begin{array}{c}\text { Puwer } \\
\text { consumption } \\
(k W h / d)\end{array}$ & $\begin{array}{l}\text { Compressor } \\
\text { run time } \\
(\%)\end{array}$ & $\begin{array}{l}\text { Run lime on } \\
\text { fresh lood } \\
\text { load }(\%)\end{array}$ & $\begin{array}{l}\text { Average freczer } \\
\text { leinperature } \\
\left({ }^{\circ} \mathrm{F}\right)\end{array}$ & $\begin{array}{c}\text { Average } \\
\text { fresh food } \\
\text { lemperalure } \\
\left({ }^{\circ} \mathrm{F}\right)\end{array}$ & $\begin{array}{c}\text { Relative } \\
\text { huinidity } \\
(\%)\end{array}$ & $\begin{array}{l}\text { Freezer defrost } \\
\text { cycle tume } \\
\text { (h) }\end{array}$ \\
\hline & & & & & & & $\therefore$ \\
\hline Mid/mid/on & 2.765 & 56.52 & 31.57 & 2.27 & 37.53 & 37.53 & 83.00 \\
\hline Mid/mid/off & 2.499 & 56.71 & 30.20 & 2.03 & 39.64 & 38.06 & 82.68 \\
\hline Warm/warm/on & 2.653 & 53.28 & 32.65 & 6.16 & 42.43 & 35.38 & 88.14 \\
\hline Warm/warm/off & 2.386 & 52.32 & 32.53 & 5.81 & 42.14 & 33.39 & 88.68 \\
\hline
\end{tabular}

Overall American Home Appliance Manufacturers test rating: $2.55 \mathrm{kWh} / \mathrm{d}$.

1. 95 inches of $0.036 "$ I.D. fresh lood capillary.

2. The "Mid/mid" condition indicates that thermustats are adjusted to give average freezer temperatures $<5.0^{\circ} \mathrm{F}$ and fresh food temperatures of about $38.0^{\circ} \mathrm{F}$.

"Warm/warm" thermostat sellings give freeger kemperatures $>5.0^{\circ}$ and fresh food lemperatures of about to. $0^{\circ} \mathrm{F}$. "On" and "off" refer to the antisweat heater switch position.

Table 5.11. Refrigerant-switching dual-loop R-152a data after fresh food enlargement-longer fresh food capillary

\begin{tabular}{|c|c|c|c|c|c|c|c|}
\hline Control setting ${ }^{2}$ & $\begin{array}{l}\text { Power } \\
\text { consumplion } \\
\text { (kWh/d) }\end{array}$ & $\begin{array}{l}\text { Compressor } \\
\text { run lime } \\
(y /)\end{array}$ & $\begin{array}{l}\text { Run lime on } \\
\text { fresh food } \\
\text { loidd }(\%)\end{array}$ & $\begin{array}{c}\text { Average freezer } \\
\text { lemperature } \\
\left({ }^{\circ} \mathrm{F}\right)\end{array}$ & $\begin{array}{c}\text { Average } \\
\text { fresh food } \\
\text { temperature } \\
\left({ }^{\circ} \mathrm{F}\right)\end{array}$ & $\begin{array}{c}\text { Relative } \\
\text { humidity } \\
(\%)\end{array}$ & $\begin{array}{l}\text { Freezer defrosi } \\
\text { cycle time } \\
\text { (h) }\end{array}$ \\
\hline Mid/Inid/on & 2.811 & 63.85 & 27.06 & -0.85 & 40.80 & 24.73 & 73.51 \\
\hline Mid/mid/off & 2.554 & 64.46 & 27.63 & -0.92 & 39.97 & 34.65 & 72.90 \\
\hline Warm/warm/on & 2.537 & 53.24 & 34.16 & 5.40 & 40.87 & 37.66 & 88.15 \\
\hline Warm/warm/off & 2.183 & 52.10 & 34.09 & 5.09 & 40.82 & 38.02 & 89.88 \\
\hline
\end{tabular}

Overall American Home Appliance Manulacturers lest miling: $2.37 \mathrm{kWh} / \mathrm{d}$.

1. 95 inches of $0.0 .36 *$ I.D. fresh foud capillary.

2. The "Mid/mid" condition indicales that thermosials are adjusted io give average frecoer teinperatures $<5.0^{\circ} \mathrm{F}$ and fresh food temperatures of about $38.0^{\circ} \mathrm{F}$.

"Warm/warm" thermostat settings give freezer teinperatures $>5.0^{\circ}$ and fresh food temperatures of about $40.0^{\circ} \mathrm{F}$. "On" and "off" refer to the antisweat heater switch position. 
Surprisingly, very similar $R-152 a$ and $R-12$ compressor run times are seen at the warm/warm rating points, also suggesting some detcrminate inefficiency in the $R-12$ results.

On reviewing these dita. Bohman suggested that perfomance may be further improved by using a iarger displacement compressor for the R-152a tests and blocking off the retum bends on the freezer evaporator to improve air distribution across the coil.

\subsubsection{Final Laboratory Tests on Refrigerant-Switching Dual-Loop Refrigerator Freezer}

We installed a new themostat and freezer loop check valve on this RF to replace damaged and inoperative components. We also blocked the retum wends on the ends of the freezer evaporator with styrofoam wedges to force more air flow through the heat exchanger fins. A larger displacement compressor was not installed on the RF because any additional capillary or heat exchanger modifications necessitated by this change would have further extended the project.

The $90^{\circ} \mathrm{F}$, closed-door tests were repeated with R-12 and R-152a. We saw no improvement in the overall RF encrgy consumption rating for either refrigerant as a result of these modifications. Slight improvements were seen in the warm/warm test results for $R-12$ (Table 5.12) but the overall rating was $5.1 \%$ poorer than the previous test with this refrigerant. Testing with R-152a (Table 5.13) gave essentially the sime rating obtained for data in Table 5.11.

\subsubsection{Conclusions and Discussion}

Once appropriately sized capillary tubes have been selected for the compressor, heat exchangers, and compartment temperature conditions of this refrigerant-switching dual-loop $\mathrm{RF}$, the most important design consideration is to balance the charge size required for the freezer and fresh food circuits. Obviously, performance and efficiency were degraded when the refrigerant charge was a compromise between a starved freezer circuit and a flooded fresh food circuit (Table 5.9). In this prototype unit, the initially installed fresh food evaporator had to be doubled in size to match the internal volume of the freezer evaporator.

Ten to thirty percent longer compressor run times were required for the refrigerantswitching dual-loop RF to handle the same loads with the same refrigerant (Table 5.8 versus Table 5.10). Other than the larger thermal masses associated with additional tubing and heat exchanger surface in the dual-loop design, we can cite no good reasons for this inconsistency.

The magnetic check valves used to prevent wanmer refrigerant from backing up into the freezer loop during fresh food operation were a weak point in this design. Three of these valves failed during the testing perfonmed at ORNL, but we performed no additional analyses on the valves to further define the mode of failure.

Surprisingly good compartment temperature regulation was obtained with the simple compressor/diverter-valve control algorithm described in the refrigerant-switching dual-loop design section. Maximum range of the freezer and fresh food temperatures as measured by an average of the three weighted thermocouples required for the DOE $90^{\circ} \mathrm{F}$ closed-door test was less than $2^{\circ} \mathrm{F}$ and $4^{\circ} \mathrm{F}$, respectively, over a compressor on cycle. A small amount of compressor run time at the start of every on cycle was needed to satisfy the fresh food load. Usually, after switching to freezer operation, the freezcr thermostat was satisfied before the fresh food compartment reached the cut in tempcrature of the fresh food thermostat, so only one fresh food segment and freezer segment was needed for each compressor on cycle. This would change if door openings and changing comparument contents were factored into the testing. 
Table 5.12. Refrigerant-switching dual-loop R-12 data after fresh food evaporator enlargement-longer fresh food capillary', better air distribution in freezer evaporator

\begin{tabular}{|c|c|c|c|c|c|c|c|}
\hline Control setting ${ }^{2}$ & $\begin{array}{l}\text { Power } \\
\text { consumption } \\
\text { (kWh/d) }\end{array}$ & $\begin{array}{l}\text { Coinpressior } \\
\text { run lime } \\
\text { ("\%) }\end{array}$ & $\begin{array}{l}\text { Run lime on } \\
\text { fresh food } \\
\text { load }(\%)\end{array}$ & $\begin{array}{l}\text { Average freezer } \\
\text { lemperature } \\
\left.\text { ( }{ }^{\circ} \mathrm{F}\right)\end{array}$ & $\begin{array}{c}\text { Average } \\
\text { fresh food } \\
\text { lemperalure } \\
\left({ }^{\circ} \mathrm{F}\right)\end{array}$ & $\begin{array}{l}\text { Relative } \\
\text { humidity } \\
(\%)\end{array}$ & $\begin{array}{l}\text { Freezer defrost } \\
\text { cycle time } \\
\text { (h) }\end{array}$ \\
\hline Mid/mic in & 3.507 & 72.59 & 28.88 & -1.29 & 37.42 & 20.21 & 64.62 \\
\hline Mid/mid/off & 3.188 & 71.05 & 27.50 & -1.57 & 37.40 & 19.44 & 65.82 \\
\hline Warm/warm/on & 2.572 & 48.81 & 35.86 & 8.82 & 43.08 & 23.52 & 96.67 \\
\hline Warm/warm/off & 2.187 & 46.63 & 30.20 & 7.18 & 43.48 & 23.92 & 101.04 \\
\hline
\end{tabular}

Overall American Hense Appliance Manufacturers test maing: $2.68 \mathrm{kWh} / \mathrm{d}$

1. 95 inches of 0.036 in. ID fresh foxid capillan:

2. The $\mathrm{mid} / \mathrm{mid}$ condition indicales that thermostats are adjusted 10 give average freezer temperatures $<5.0^{\circ} \mathrm{F}$ and fresh food temperatures of atwout $38.0^{\circ} \mathrm{F}$. "Warm/warın" therınostat sellings give freceer temperatures $>5.0^{\circ}$ and fresh food temperatures of about $40.0^{\circ} \mathrm{F}$. "On" and "off" refer to the antisweil heater swilch position.

Table 5.13. Refrigerant-switching dual-loop R-152a data after fresh food enlargement-longer fresh food capillary', better air distribution in freezer evaporator

\begin{tabular}{|c|c|c|c|c|c|c|c|}
\hline Control setting? & $\begin{array}{c}\text { Power } \\
\text { consumption } \\
(\mathrm{kWh} / \mathrm{d})\end{array}$ & $\begin{array}{l}\text { Compressor } \\
\text { run liine } \\
(\%)\end{array}$ & $\begin{array}{l}\text { Run lime on } \\
\text { fresh lood } \\
\text { load }(\%)\end{array}$ & $\begin{array}{l}\text { Average freczer } \\
\text { lemperalure } \\
\left({ }^{\circ} \mathrm{F}\right)\end{array}$ & $\begin{array}{c}\text { Average } \\
\text { fresh food } \\
\text { temperature } \\
\left({ }^{\circ} \mathrm{F}\right)\end{array}$ & $\begin{array}{c}\text { Relative } \\
\text { humidity } \\
\text { (\%) }\end{array}$ & $\begin{array}{l}\text { Freezer defrost } \\
\text { cycle time } \\
\text { (h) }\end{array}$ \\
\hline $\mathrm{Mid} / \mathrm{mid} / \mathrm{on}^{3}$ & - & - & - & - & - & - & - \\
\hline $\mathrm{Mid} / \mathrm{mid} / \mathrm{off}^{3}$ & - & - & - & - & - & - & - \\
\hline Warm/warm/on & 2.534 & 54.22 & 31.78 & 4.16 & 43.64 & 20.61 & 86.65 \\
\hline Warm/warm/off & 2.192 & 52.70 & 30.70 & 3.90 & 43.84 & 22.08 & 89.09 \\
\hline
\end{tabular}

Overall American Home Appliance Manufacturers lest rating: $2.36 \mathrm{kWh} / \mathrm{d}$.

1. 95 inches of $0.0^{\prime} \mathrm{S}$ in. ID fresh food capillary.

2. The $\mathrm{mid} / \mathrm{n}$ id condition indicates that the mostats are adjusted to give average frezer temperatures $<5.0^{\circ} \mathrm{F}$ and fresh food temperatures of atout $38.0^{\circ} \mathrm{F}$. "Warm/warm" thermostat settings give freezer temperatures $>5.0^{\circ} \mathrm{F}$ and fresh food temperatures of about $40.0^{\circ} \mathrm{F}$. "On" and "off" refer to the antisweat heater switch position.

3. Because the warm-warm seltings resulted in freezer teinperatures less than $5^{\circ} \mathrm{F}$. the mid-mid data is not required to caicislate an overall rating. 
Small increases in the cycle efficiency of this dual-loop design were obtained when the parasitic and heat loads of the diverter valve and fresh food evaporator fan were subtracted for the kilowatt hour per day rating. Real energy savings of approximately $6.0 \%$ over $R-12$ in the conventional RF design were obtained when R-152a was used as a refrigerant in this unit. This represents an "apples-to-apples" comparison of R-152a to R-12 in an actual refrigerator. Using a larger (higher displaccment) compressor and/or a more restrictive capillary tube for the $\mathrm{R}-152 \mathrm{a}$ lesting have been suggested as methods to further improve perfomance.

Realistically, domestic RF manufacturers would be reluctant to market a product that incorporates so much additional cost and complexity for such marginal increases in efficiency. Increased evaporator surface area and enhanced heat transfer surfaces are other familiar areas where energy efficiency improvements can be made using the conventional design. ${ }^{26}$ The refinement and component balancing that has gone into mass production of millions of conventional single-evaporator RFs has resulted in a high degree of reliability over broad operating ranges. Any new design would have to overcome a tremendous backlog of confidence and operating experience.

\section{CLOSING OBSERVATIONS}

In retrospect, the goal of this project may have been overly ambitious. We attempted to go from several different energy saving concepts to a working prototype with very little product development. Many of the refinements and innovations in the current RF design were arrived at after many years of production and field experience. Anyone attempting to build and demonstrate a RF embodying "new" features and energy saving innovations has to take advantage of this large database of information and experience, most of which is proprietary or undocumented.

The chronology of the L-M RF provides a sharp contrast to the work done on the refrigerant-switching dual-loop design. With the L-M refrigerator, the refrigeration circuit schematic and some preliminary results and hardware development done by Lorenz et. al. and Dr. Kruse in Hannover were all that was available at the stan of the project. Additional development work on small intersystem heat exchangers, a modulating expansion valve, counter-flow refrigerant-to-air heat exchangers and more sophisticated compartment and charge management controls is needed to adequately demonstrate this RF concept under the variety of operating conditions typically seen.

Committed involvement by the system and component manufacturers in the RF industry is needed to efficiently and satisfactorily accomplish this L-M development work. Using a breadboard RF approach would have been a more productive method of researching the $L-M$ design, because the perfornance of individual components could have been more carefully documented rather than total system performance.

Early in the project we hired a consultant with 30 ycars of experience in the RF industry for the refrigerant-swilching dual-loop RF work to design and critique laboratory data obtained from this test unit. This prototype RF used pure refrigc rsts, conventional heat exchangers, commercially available controls, and a valve that a major refrigeration components manufacturer designed for use with refrigerants. As a result, more predictable laboratory results were obtained initially with this design, and, ultimately, a test unit that showed modest energy saving capabilities over the nomal range of operating conditions was built and tested.

It is important to note, as Bohman has suggested, that the RF systems researched in this report are noi likely to be readily accepted by refrigerator manufacturers despite a squeeze being created by the CFC phaseout and tightening anpliance efficiency standards. Increased 
system costs, added complexity, and reduced reliability all have to be weighed against relatively small improvements in efficiency that may be achievable in conventional systems with familiar modifications. Nevertheless. Bohman agrees that side-by-side comparisons of novel and conventional systems on a fair and equal basis are necessan' for industry to make informed business decisions.

Finally, the AHAM/DOE $90^{\circ} \mathrm{F}$ closed-door test employed exclusively in this report to rate RFs is probably the one best test method to us for comparing the performance of test units, but many other important criteria are needed for a commercially successful RF. Some of these are mentioned above. In addition, pull down performance, stability in a broad range of operating environments, and good compartment temperature control are other generally accepted and expected features for this appliance. 


\section{REFERENCES}

1. A. Lorenz and K. Mcutzner, "On Application of Non-Azeotropic Two-Component Refrigerants in Domestic Refrigcrators and Home Frcezers," presented at the Intemational Congress of Refrigeration, Moscow, 1975.

2. United Nations Environmental Programme (UNEP), Montreal Protocol on Substances That Deplete the Ozone Layer, Final Act. 1987.

3. Analysis and Technology Transfer Report 1988-Buildings and Community Systems, DOE/CH/00016-H2, U.S. DOE, May 1989.

4. E. A. Vincyard, J. R. Sand, and W. A. Miller, "Refrigerator-Freezer Testing with Alternative Refrigerants." ASHRAE Trans. 95(2), $295-99$ (1989).

5. W. Stoccker, Improving the Energy Effectiveness of Domestic Refrigerators by the Application of Refrigerant Mixtures. ORNL/Sub/78-5463/1. Martin Marietta Energy Systems, Inc.. Oak Ridge Natl. Lab., 1978.

6. Arthur D. Little. Inc., An Evaluation of a Tw'o-Evaporator Refrigerator-Freezer Using NonAzeotropic Mixtures, ORNL/Sub/82-47952/1. Martin Mariella Energy Systems, Inc., Oak Ridge Nat. Lab., 1984.

7. H. Kruse, Presentation at ASHRAE Meeting, Chicago, January 1989.

8. M. McLinden and R. Radermacher. "Methods for Comparing the Performance of Pure and Mixed Refrigerants in the Vapor Compression Cycle," Int. J. Refrig. 10(6), 318-325 (1987).

9. P. Domanski and M. McLinden, "A Simplified Cycle Simulation Model for the Performance Rating of Refrigerants and Refrigerant Mixtures." Int. J. Refrig. 15(2), $81-88$ (1992).

10. E. Vineyard, J. Sand, and T. Statt, "Selection of Ozone-Safe Nonazeotropic Refrigerant Mixtures for Capacity Modulation in Heat Pumps," ASHRAE Trans. 95(1), 34-46 (1989).

11. M. McLinden. "Thermodynamic Evaluation of Refrigerants in the Vapor Compression Cycle Using Reduced Properties," Int. J. Refrig. 11(3), 134-143 (1988).

12. M. McLinden, "Optimum Refrigerants for Non-Ideal Cycles: An Analysis Using Corresponding Stales." pp. 69-79 in Procesdings of the 1990 USNCIIIR-Purdue Refirigeration Conference and the 1990 ASHRAE-Purdue CFC Conference. July 17-20, 1990, Purdue Universiry, West Lafayette, Indiana, ed. David R. Tree, Purdue University, West Lafayette, Indiana, 1990.

13. C. K. Rice and J. R. Sand, "Initial Parametric Results Using CYCLE-Z-An LMTD. Specified, Lorenz-Meutzner Cycle Refrigerator Freezer Model." pp. 448-58 in Proceedings of the 1990 USNCIIIR-Purdue Refrigeration Conference and the 1990 ASHRAE-Purdue CFC 
Conference, July 17-20, 1990. Purdue Universiry. West Lafavette, Indiana, ed. David R. Trec. Purdue University. West Lafayellc. Indiana, 1990.

14. H. Vakil. "Themodynamics of Heat Exchange in Refrigeration Cycles with Non-Azeotropic Mixtures," presented at the OVI Congress of Refrigeration, Paris, 1988.

15. ASHRAE, ASHRAE Handbook, 1988 Equipment. Chap. 37. American Society of Heating, Refrigerating, and Air Conditioning Engineers, Inc.. Allanta, 1988.

16. ASHRAE, Methods of Testing for Rating Positive Displacement Refrigerant Compressors, American Society of Heating, Refrigerating and Air-Conditioning Engineers. Inc., Atlanta. 1978.

17. R. L. Merriam, Arthur D. Little, Inc., personal communication with J. R. Sand, Oak Ridge Naul. Lab., March 1990.

18. J. L. Boot, "Overview of Altematives to CFCs in Domestic Refrigerators and Freezers," Int. J. Refrig 13(2), 100-105 (1990).

19. R.F. Topping, Development of a High-Efficiency Automatic-Defrosting Refrigerator Freezer, ORNL/Sub/77-7255/3. Martin Marietta Energy Systems. Inc., Oak Ridge Na!' Lab., December 1982.

20. Energy Policy and Conservation Act, Pub. L. 94-163 (as amended by National Energy Conservation Policy Act 9 Pub. L. 95-619) and National Appliance Energy Conservation Act (Pub. L. 100-12)], Part B-Energy Conservation Program for Consumer Products Other than Automobiles (1990).

21. P. H. Pedersen, G. Galster, T. Guldbrandsen, and J. S. Norgard, "Design and Construction of an Efficient US-Type Combined Refrigerator/Freezer," pp. 547-54 in Proceedings of the 17th. International Congress of Refrigeration, Vol. B. Paris, 1987.

22. U.S. patent \#4,481,787, Neil Lynch, Assignee: Whirlpool Corporation, 1984.

23. The Danfoss Journal, 4, 2-3, 1985.

24. Amana Refrigeration. "Arthur D. Little Dual Loop System: Built by Amana Refrigeration, Inc.," Amana, lowa, October 1990.

25. Federal Register, Sect. 10, Pan 430, 49-54, 1990.

26. R. Bohman, "Enhancing the Efficiency of Refrigerator/Freezers," First National Conference on Appliance Efficiency. Arlington, Va., October 26-28, 1987. 


\section{APPENDIX A: ADL's Dual-Loop Modeling Work}

We have been carrying out analyses in support of developing specific recommen ?ations to Amana for an experimental design involving a dual loop system. To baseline the system, we have performed a cabinet loads analysis and cycle analysis for both the current design (Model TX-18M) and alternative designs. As background, a brief summary of the study results and assumptions is provided here. Our recommendations for a viable experiment are then developed for your consideration.

Cabinet loads model inputs were developed from physical measurements we made on a model TX-18M refrigerator in our lab, from the service manual, and from data supplied by Amana. The following table summarizes this information and the results of the analysis:

Cabinet Loads Assumptions

Cycle Model Assumptions

Compressor
Fresh Food Compartment: $40 \mathrm{~F}$

Freezer Compartment: 5 F

Door Gasket Heater: 7.3 w

Auxiliary Energy: 5 w

Average on-time for heaters: $50 \%$

Defrost: 570 w, 3 min per 10 hours

Rating Conditions: $90 \mathrm{~F}$

Doors: Closed

Compressor Fan: $15 \mathrm{w}$

Evaporator Fan: 13 w

Evaporator Air Flow: $44 \mathrm{cfm}$

Condenser Air Flow: $150 \mathrm{cfm}$

Evaporator UA: 100 Btuh/Sf-F

Condenser UA: 50 Btuh/Sf-F

Panasonic DA 103FR

Rated Capacity: 869 Biuh

Rated EER: 4.58 
We obtained the following results from the models for the loads and energy consumption:

Loads

Cycle

Amana Test Results
Fresh Food: 128.1 Btuh

Freezer: 184.9 Btuh

Capacity: 824 Btuh, before fan

Capacity: 780 Btuh, net fan heat

Evap Temp: $-9.7 \mathrm{~F}$

Cond Temp: $114.3 \mathrm{~F}$

COP: 1.30 (Compressor Only)

Duty Cycle: 0.40

Daily Compressor Energy: $1.781 \mathrm{kwh}$

Daily Total Energy: $2.290 \mathrm{kwh}$

Evap Temp: $-7.6 \mathrm{~F}$ (average of tests)

Cond Temp: 114.0 (average of tests)

Daily Energy: $2.293 \mathrm{kwh}$

Duty Cycle: approx 0.4 (depending on test condition)

The agreement between the predicted and measured data provides a good starting point for evaluating the design tradeoffs.

The following pages summarize the trade-off analyses we have done. We looked at: refrigerants, forced vs free convection (fresh food section only), fan powers vs cfm's änd UA's, effects of cfm's and UA's on energy requirements, and compressor models.

The studies provide a partial basis for the recommended system. Other factors taken into account were:

- The experimental design should be relatively close to a configuration likely to be accepted in the market place, and should enabie good performance, not only according to the DOE $90 \mathrm{~F}$ closed door test, but also according to the AHAM RF-1 test;

- Temperature and humidity control of the unit should be viable;

- Delivery of cooling to the fresh foods section should be in such a manner as to maintain desired conditions in the door compartments;

- Required defrost of the fresh food evaporator should be minimized;

- Loss of storage volume in the fresh food section should be minimized;

- The design should show promise for a significant energy efficiency improvement over the current design under the standard test conditions;

- The experimental design should facilitate control of fan speed, refrigerant charge, evaporator superheat, and compressor operation. 
The system we recommend is a dual loop cycle, with forced fan evaporators in both compartments. For the purposes of the experiment, the freezer compartment would not be changed from the current design, other than to block off the air passages between the freezer and fresh food sections (changes in the design would doubtless results from an detailed development program aimed at producing a marketable product). A small air flow passage would be added to the fresh food compartment, at the top of the cabinet, to house a small fan and an evaporator. Air flow would be directed at the door. Variable fan speed operation would be available (through the use of a shaded pole fan, and voltage control during the experiment using a rheostat) in both compartments. Manually controlled expansion devices would be used for the experiment. High efficiency Embraco compressors would be used in the two loops. (The specific units, which are not yet commercially available, are being provided to us by Embraco.)

With the reduced load on the freezer evaporator, it might be somewhat oversized. If so, ORNL could either block off part of the evaporator, or pull some of the fins, during the test.

We recommend a forced fan evaporator, rather than a free convective design, in the fresh food section to provide better evaporator performance with less evaporator surface needed and with installation simplified over that needed for the static design. In addition, it should provide better temperature control. The cycle analyses, shown on the following pages, indicated that, even taking into account the fan heat and additional electrical energy required to operate the fan, the forced fan configuration can compete with a static evaporator design with up to 6 square feet of available surface area. With improved fans in the future, it could provide similar performance expected with larger static evaporators. Our thinking was that it may be hard to get 6 to 8 square feet of unobstructed evaporator surface in the cabinet without a major redesign of the fresh food compartment.

For the purposes of the experiment, we suggest using the same evaporator in both the fresh food and freezer compartments. A more desirable arrangement for the fresh food section might be a single row finned tube evaporator if one is available. However to investigate the concept, the current evaporator should be sufficient.

To date, our analysis assumed the use of, and accounted for the energy from, a fan forced condenser for both loops. This would require additional fan power and require additional considerations relative to the location of the condenser. For the experiment, we recommend the use of a static condenser for the fresh food loop, mounted on the back of the cabinet. It could be the same as Amana has used on other units in the past. The specific size would be roughly $60 \%$ that normally associated with an $18 \mathrm{cu}-\mathrm{ft}$ refrigerator.

We are presently upgrading our model now to deal with static condensers. So, at this point, I don't really know how the system performance would be affected by this type of condenser. On the other hand, it would seem simpler to use this type of condenser for the experiment than to worry about how to configure a forced fan design into the current design.

We are obtaining some (relatively) high ERR small compressors from Embraco in the 200 and 400 Btuh range. They will be provided to you for the experiment.

These experiment design recommendations are offered in general terms for your consideration. I would like to call you (with Jane Bare) this afternoon to discuss this further with you. (We will try you about 4:00 pm your time.) If you think that the approach has merit, then we can discuss what additional specific information you need. The detailed experimental hardware design specification function will then shift to ORNL, with help provided by ADL as need and as we are capable.

If a static condenser can be used, the theoreticai energy savings obtained in the DOE closed door test is abcut $13 \%$. We note that this is relatively modest, given the additional hardware. Ho: 'er, two faciors tend to make this a conservative figure: 
- The closed door test does not account for humidity and frosting loads. With the two compartments completely separated, the defrost energy requirements should be lower under normal operating conditions;

- These savings are achieved using current technology compressors. Even the stateof-the-art Embraco compressors have a low EER relative to the larger compressor used in the current unit (3.4 EER for the fresh food loop compressor vs 4.6EER in the current unit). As more design attention is paid in the future to the smaller compressors, the performance potential of the dual-loop system should improve relative to the standard design. For example, if the EERs of the two smaller compressors improved by $10 \%$ (to 3.7 for the fresh food loop compressor and to 4.8 for the freezer compressor), the net energy reduction over the current unit would be $18 \%$.

Given these two considerations, there should be considerable future interest in this type of system. The performance potential should be at least as favorable as other system concepts now being investigated either theoretically or in the laboratory. 
Summary of Analyses for Freezer Compartment

Compressor: Embraco EM-SC Series

420 Btuh Capacity. 4.35 EER at Rated Conditions

Displacement: $0.23 \mathrm{cu}$-in

Fans: $\quad$ Freezer Evap: $0.3 \mathrm{w} / \mathrm{cfm}$ (13 w for baseline)

Condenser: $0.1 \mathrm{w} / \mathrm{cfm}$ ( $15 \mathrm{w}$ for baseline)

\begin{tabular}{|c|c|c|c|c|c|c|c|c|}
\hline Ref & $\begin{array}{l}\text { Evap } \\
\text { cfm }\end{array}$ & $\begin{array}{l}\text { Evap UA } \\
(\text { Btuh/F) }\end{array}$ & $\begin{array}{l}\text { Cond } \\
\text { cfm }\end{array}$ & $\begin{array}{l}\text { Cond UA } \\
\text { (Btuh/F) }\end{array}$ & $\begin{array}{l}\text { Cap } \\
\text { (Btuh) }\end{array}$ & $\begin{array}{l}\text { Pwr } \\
\text { (Btuh) }\end{array}$ & Duty & $\begin{array}{l}\text { Compr + Fan } \\
\text { Energy } \\
\text { (kWh/day) }\end{array}$ \\
\hline $\mathbf{R} 12$ & 44 & 100 & 150 & 50 & 487 & 330 & .418 & 1.25 \\
\hline & 35 & 90 & ." & $"$ & 460 & 323 & .436 & 1.26 \\
\hline & 26 & 80 & $"$ & $"$ & 460 & 310 & .469 & 1.28 \\
\hline & 44 & 100 & 100 & 40 & 481 & 334 & .423 & 1.23 \\
\hline $\mathrm{R} 152 \mathrm{a}$ & 44 & 100 & 100 & 40 & 430 & 286 & .479 & 1.23 \\
\hline R134a & 44 & 100 & 100 & 40 & 440 & 297 & .467 & 1.23 \\
\hline
\end{tabular}




\section{Summary of Analyses for Fresh Food Compartment}

Compressor: Embraco EM-20 Series

202 Btuh Capacity. 3.4 EER

Displacement: $0.138 \mathrm{cu}$-in

Fans: $\quad$ Freezer Evap: None if Natural Convection

0.2 watts/cfm if forced fan

Condenser: $10 \mathrm{w}$

$100 \mathrm{cfm}$

$\mathrm{UA}=40$

\begin{tabular}{|c|c|c|c|c|c|c|c|c|}
\hline Refrigerant & Evap Type & $\begin{array}{l}\text { Area } \\
\text { (Sf) }\end{array}$ & $\begin{array}{c}\text { UA } \\
(\text { Btuh/F) }\end{array}$ & $\mathrm{Cfm}$ & $\begin{array}{l}\text { Cap } \\
\text { (Btuh) }\end{array}$ & $\begin{array}{l}\text { Pwr } \\
\text { (Btuh) }\end{array}$ & Duty & $\begin{array}{l}\text { Compr/Fan } \\
\text { Energy } \\
\text { (kWh/day) }\end{array}$ \\
\hline \multirow[t]{4}{*}{$\mathrm{R}-12$} & Natural Conv & 4 & & & 256 & 209 & .500 & .86 \\
\hline & & 6 & & & 320 & 241 & .400 & .77 \\
\hline & & 8 & & & 369 & 262 & .347 & .72 \\
\hline & & 10 & & & 407 & 279 & .315 & .69 \\
\hline \multirow[t]{4}{*}{ R-142b } & Natural Conv & 4 & & & 188 & 116 & .681 & .72 \\
\hline & & 6 & & & 228 & 130 & .562 & .65 \\
\hline & & 8 & & & 258 & 139 & .497 & .61 \\
\hline & & 10 & & & 281 & 146 & .456 & .58 \\
\hline \multirow[t]{4}{*}{$R-142 b$} & Forced & & 100 & 44 & 388 & 146 & .358 & .64 \\
\hline & & & 90 & 35 & 370 & 172 & .370 & .64 \\
\hline & & & 80 & 26 & 345 & 169 & .391 & .65 \\
\hline & & & 70 & 17 & 304 & 165 & .438 & .70 \\
\hline
\end{tabular}




\section{Final Experiment Design Recommendation}

\section{Hardware Implementation}

Freezer Section:

Mullion:

Fresh Food Section:

Controls:

\section{Predicted Performance Data}

Retain current heat exchanger and fan. Replace compressor with Embraco $0.23 \mathrm{cu}$-in model (high efficiency unit). Resize cap-tube as required and add manual expansion valve for experimental purposes. $R 12$ can be used as the refrigerant.

Remove damper and air passages to the fresh food section. Provide air tight separation of the compartments. Reduce thickness to partially accommodate space requirements for the fresh food section fan and air flow passage.

Install horizontal evaporator at top of cabinet with a flow passage. Direct air towards door. Use current freezer section evaporator or a 1 row type finned tube evaporator of similar area if available. Cut small area in the mullion to partly accommodated fan and motor. Replace compressor with Embraco $0.138 \mathrm{cu}$-in model (high efficiency unit). Size cap-tube with manual expansion valve for experimental purposes. $\mathrm{R} 142 \mathrm{~b}$ is preferred refrigerant.

Provide seperate temperature sensing control module for the freezer section. Control operates in same manner as in the fresh food section. Oak Ridge may choose to provide its own control to investigate advantages of fan operation after compressor shut off. To be determined.

$\begin{array}{lllll}\text { Section } & \text { Compressor } & \text { Refrigerant } & \text { Duty } & \begin{array}{l}\text { Energy } \\ \text { (kWh/day) }\end{array} \\ \text { Freezer } & \begin{array}{l}\text { Embraco } \\ 0.23 \mathrm{Cu} \text {-in }\end{array} & \text { R-12 } & .418 & 1.25 \\ \text { Fresh Food } & \begin{array}{l}\text { Embraco } \\ 0.138 \mathrm{Cu}-\mathrm{in}\end{array} & \mathrm{R}-142 \mathrm{~b} & .370 & .64 \\ \text { Heaters } & & & .17 \\ \text { Defrost } & & & .07 \\ \text { Total Energy } & & & 2.13 \mathrm{kWh} / \text { day } \\ \text { If Static Condenser, } \\ \text { Total Energy }\end{array}$




\section{APPENDIX B: ADL's Duel-Loop Design Specifications}

Per our phone conversation today, we are providing additional design information lus the dual-loop breadboard refrigerator. This information should facilitate your costing for breadboard fabrication, due in mid-May.

\section{Compressors}

The compressors, supplied by Arthur D. Little, are:

Fresh Food Compartment:

Embraco Model EM 20NR-200 (0.138 cu. in.)

Freezer Compartment:

Embraco Model EM 40SC-420 (0.23 cu. in.)

We have requested physical dimensions of the compressors. We expect these data by May 10, and we will forward as soon as possible.

\section{Expansion Device}

Amana should install capillary tubes on both the freezer compartment and fresh-food-compartment loops. Do only a first-cut sizing of the capillary tubes. Do not fine tune the cap tubes experimentally. It is likely that ORNL will modify the expansion device during their testing.

\section{Condenser}

\section{Fresh Food Compartment:}

Use Amana static condenser, mounted on the back of the refrigerator cabinet. 


\section{Freezer Compartment:}

Use the existing condenser in the Top Mount 18 unit.

\section{Evaporator}

\section{Fresh Food Compartment:}

The attached sketches (Figures 1 - 3) show the design and installation of the fresh-food evaporator, fan, drain pan and defrost heater. The evaporator is 2 " $\times 8$ " $x$ 21", and will be supplied by Arthur D. Little. (Peerless of America is sending us the evaporator.) The fan and fan motor are the same as currently used for the Top Mount 18 evaporator. The defrost heater will be controlled by a Variac or rheostat provided by ORNL. The defrost heater is (TBD).

\section{Freezer Compartment:}

Use the existing evaporator, defrost heater, fan and fan motor as installed in the Top Mount 18. Plug the existing air supply duct to the fresh-food compartment.

Allowances should be made to permit rheostat control of both evaporator fan motors. ORNL will provide rheostats.

\section{Contro's}

\section{Fresh Food Compartment:}

Use the existing controller in the Top Mount 18.

\section{Freezer Compartment:}

Install in the freezer compartment a controller of the same design as used in the fresh food compartment.

\section{Charging}

Both refrigeration loops should be delivered charged with R-12. 
Fig. 1: Fresh Fod Evapor Tor =n-1:on

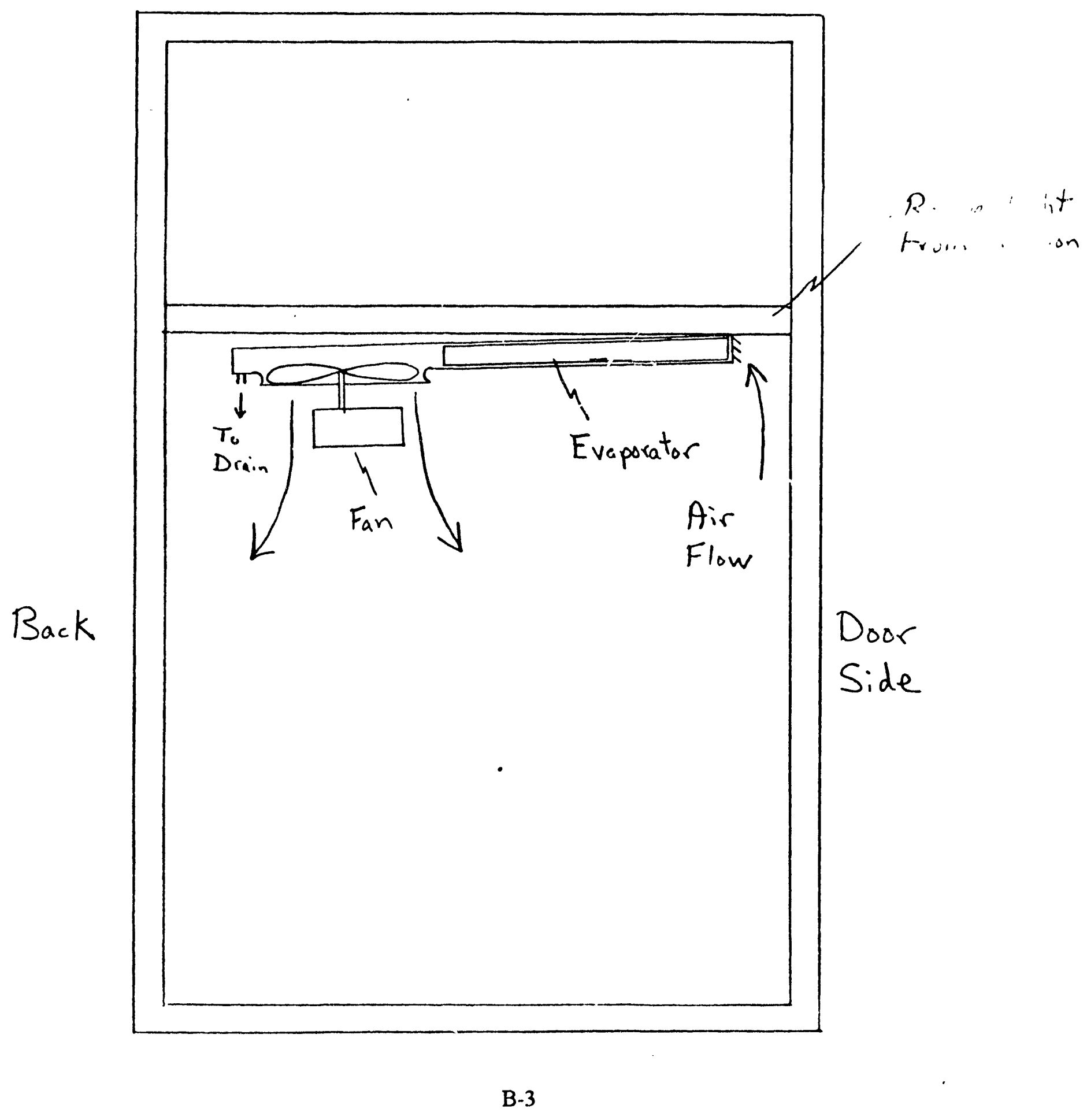




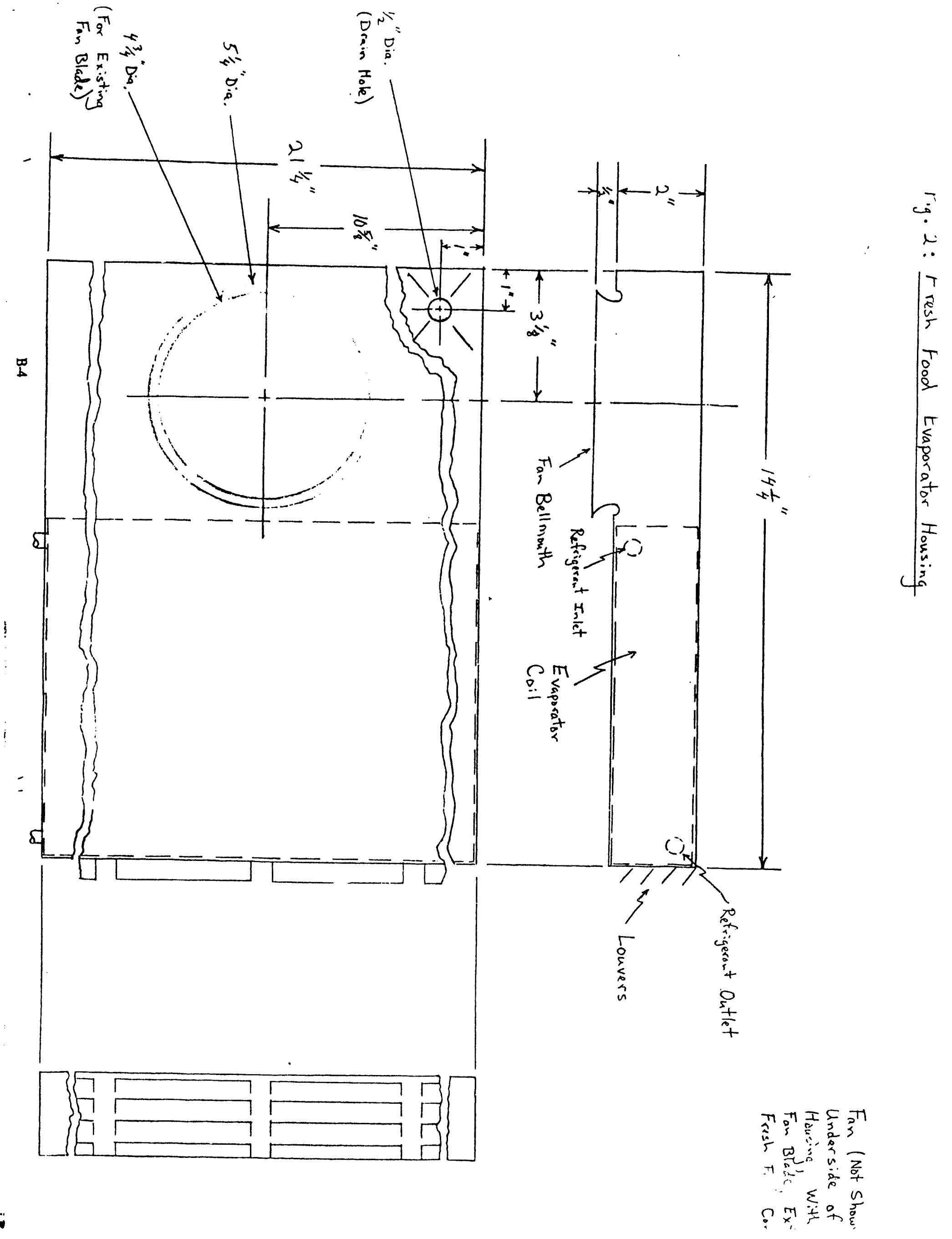


Fig. 3: Fresh Fost Evaporator Desin

(Eviporitor is 21 "long)

Refrig.
Out
个

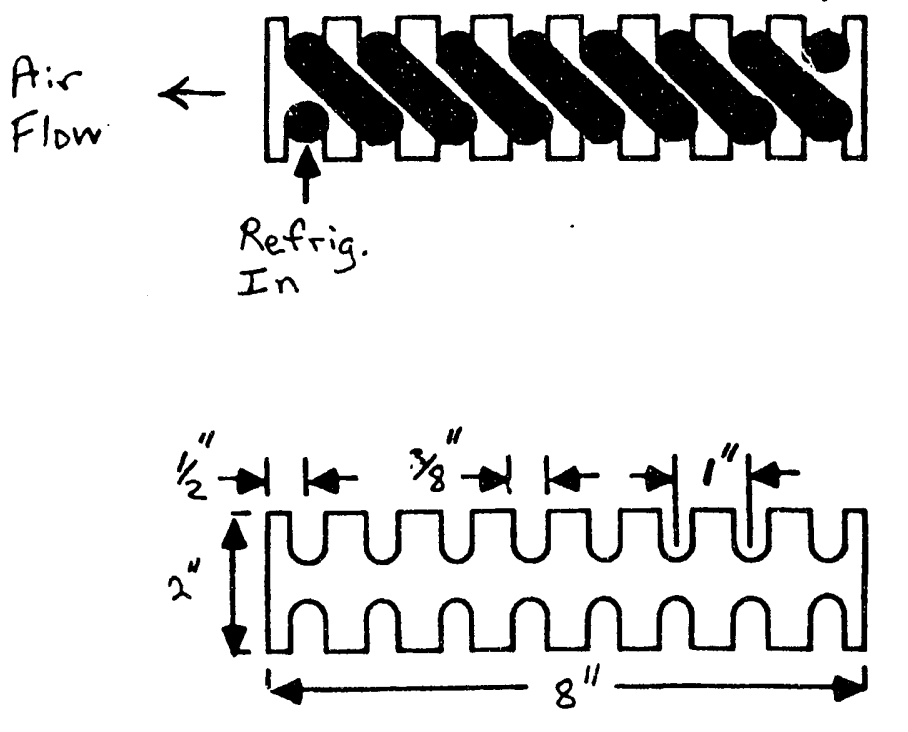

B-5 


\title{
APPENDIX C: Refrigerant-Switching Dual-Loop Design
}

\author{
SUBCONTRACTOR REPORT \\ ENGINEERING AND DESIGN OF AN EXPERIMENTAL \\ REFR IGERATOR/FREEZER \\ USING A
}

DUAL LOOP, SWITCHED REFRIGERANT TWO EVAPORATOR SYSTEM

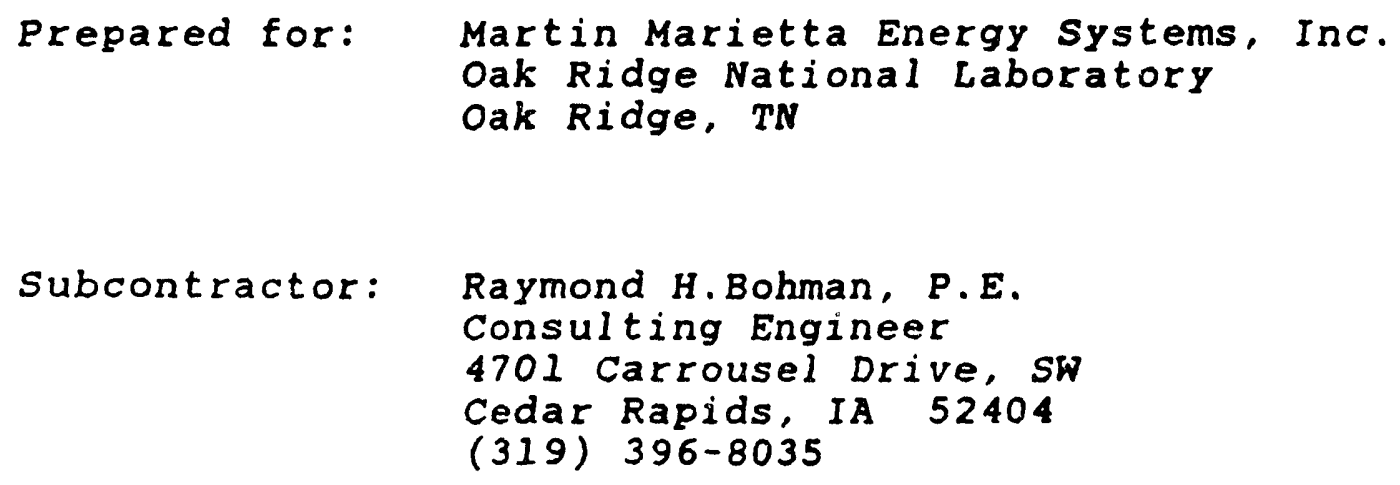

Subcontract No. $80 \mathrm{X}-S G 282 \mathrm{~V}$

Period of Performance: $10-25-90$ to $9-21-91$ 


\section{TABLE OF CONTENTS}

I. Background and Work statement

II. System Description
A - General Background
B - Dual Loop Concept
C - Specifics of the Dual Loop system
D - Control system
E - Fresh Food Evaporator Coil and Coil Housing Design
$F$ - Valve and Tubing specifications
G - Compressor, Condenser and Freezer Evaporator

II System Assembly steps a.7d Bills of Material

IV. Sketches and Drawings

V. Photographs 


\section{BACRGROUND AND WORK STATEMENT}

This project was undertaken by the Oak Ridge National

Laboratory (operated by Martin Marietta Energy Systems, Ins.) under a contract with the Environmental Protection Agency. EPA's objective in sponsoring this project was to determine the viability of, and practical application of novel dual loop, switched refrigerant refrigerator systems. This report deals exclusively with a switched refrigerant system which utilizes a 3-way refrigerant valve and two evaporators.

ORNL issued subcontract No. $80 \mathrm{X}-S G 282 \mathrm{~V}$ to the writer for the development of this system. The test vehicle selected for this feasibility study and actual application was a Whirlpool model ETI8NKXSNO2 Top Mount Automatic Defrosting

Refrigerator/Freezer. It had been previously tested by ORNL as manufactured, thus had an excellent data base which could be used for performance comparison. In addition, the cabinet structure and the method of assembly used for this model made for easy and straight-forward rework, always a plus in any engineering research project of this nature.

The work statement issued with this subcontract is quoted below:

\section{STATEMENT OF WORK}

Mr. Bohman shall provide personal services to develop designs for one or two dual circuit refrigerator-freezer (RF) systems. One design shall be for a switched refrigerant concept (Fig.1). This concept has one compressor with separate evaporators for freezer and fresh food compartments. The second design shall be for an air-switching concept (Fig. 2). This concept has one compressor and one evaporator which communicates alternately with the two compartments via a system of air dampers.

The designs shall provide sufficient detail such that ORNL can have existing RFs modified to incorporate the concepts for lab testing. Mr. Bohman will make at least one trip to ORNL to review the designs prior to modification of the RFs. In addition, Mr. Bohman shall provide a suggested control logic to be implemented for the tests of the modified RFs.

Note: Development of the air-switched concept described above was later dropped from this work statement with the agreement of Mr. Van Baxter. The consensus of all involved in this project: this concept had a very low probability of successfully reducing energy usage for a refrigerator-freezer. 


\section{SYSTEM DESCRIPTION}

\section{A - GENERAL BACKGROUND}

Historically, two evaporator refrigeration systems have used the evaporators in a series arrangement. Generally the freezer evaporator is first in the low side circuit and after the refrigerant has flowed through this evaporator, it enters the fresh food compartment evaporator (usually a cold plate design). There it cools the fresh food compartment and returns to the compressor. Evaporation of the single refrigerant (universally CFC-12) takes place at substantially one evaporating pressure and temperature, regardless of the ambient temperature surcounding the coil. since the evaporators are assembled in series in the system, and since the fresh food compartment cooling comes after the freezer cooling, this type of system has become known as a "tail-off system". It has been, and still is, widely used in partial automatic defrosting refrigerator-freezers. Industry experience, however, has proven that "cold plate" type refrigerators do not perform as well as the single evaporator auto-defrost models in the largc: sizes. For this reason, partial automatic defrost models are generally limited to models that have 15 cubic feet or less storage volume.

\section{B - DUAL LOOP CONCEPT}

To achieve an energy efficiency improvement in a two evaporator system, another approach is needed. In its most direct form a system concept as outlined on ORNL drawing 89154070 offers the potential for increasing the efficiency of a two evaporator refrigeration system. In this system concept, the refrigerant flow is switched alternately between evaporators in the freezer and fresh food compartments. With this arrangement, it should be possible to effect a higher refrigerant evaporating temperature in the fresh food evaporator where the compartment temperature is 35 to $40 \mathrm{~F}$, than in the freezer evaporator which needs to maintain a 0 to +5 F compartment temperature.

The energy required for the cycle is directly related to the "thermal lift" (the temperature difference between evaporating and condensing temperatures). It follows then, that an improvement in total unit energy efficiency should be possible if cooling of the individual compartments can be accomplished at a refrigerant evaporating temperature that is "more appropriate" for that compartment. Thus, if cooling of the fresh food compartment can be done at an evaporating temperature of +10 to $+15 \mathrm{~F}$, less energy will be required than cooling it using a $-15 \mathrm{~F}$ evaporating temperature. The dual 
loop refrigerant circuit designed for this project attempts to achieve this potential gain. Simulation modeling results by Dr. James sand indicated that an energy usage reduction of approximately 108 may be possible using CFC-12 as the refrigerant. Other refrigerants modeled also indicated energy use reductions, but at different levels.

\section{C - SPECIFICS OF THE DUAL LOOP SYSTEM}

Following the general outline of the dual loop concept disclosed on ORNL drawing 89-15407D, a system schematic diagram was developed. A sketch of this system and the basic elements of a control circuit are included on sketch \#01. (Copies of all sketches are included elsewhere in this report.) Further estimates of how the unit might function using the control logic indicated on sketch \#01 were diagrammed (sketches \#02 and \#03). While the graphs are only estimates of a cycling situation, the general data, shapes of the curves and response times can be considered typical for automatic defrosting refrigerators. When a final prototype is tested, the nuances of operation of this type of system can be confirmed by actual test data.

The refrigerant system for this unit utilizes a 3-way diverter valve, two evaporators, each with its own capillary and heat exchanger/suction tube, and a check valve located in the freezer evaporator suction tube. The check valve serves to prevent the re-pressurization of the freezer evaporator (with a loss of cooling effect) during that part of the cycle when refrigerant flow is directed to the fresh food evaporator.

\section{D - CONTROL SYSTEM}

The electro-mechanical control system devised uses two thermostats to control the refrigerator. In operation, the freezer thermostat serves to establish the cycling pattern for the unit by controlling the compressor. It also enables the fresh food thermostat to energize the diverter valve and fresh food evaporator tan. Using a SPDT switch in the fan motor circuit will allow selection of fresh food fan operation either cycling with cooling or on a continuous basis. Final testing will determine the best mode of operation.

When the diverter valve is energized, refrigerant flow is directed to the fresh food evaporator to accomplish cooling cor this compartment. When the thermostat for this compartment is satisfied, it opens the diverter valve circuit and refrigerant is now directed to the freezer evaporator. When its thermostat is satisfied, it opens the compressor circuit and the unit shuts off. Sketches 02 and 03 outline 
the probable sequence of events using this control logic.

sketch \#01 depicts the basic control wiring diagram for refrigerant system operation only. Sketch \#05 is a final schematic wiring diagram for the complete unit. It includes the accessory electrical components needed for the unit such as the defrost timer, anti-sweat heaters and cabinet door switch and lighting. Sketch \#09 presents a "point to point" wiring diagram which was developed to achieve the desired electro-mechanical control system using as much of the existing wiring in the whirlpool test unit as possible.

\section{E - FRESH FOOD EVAPORATOR COIL AND COIL HOUSING DESIGII}

In order to achieve the type of cooling performance which is typical for 18 cubic feet top mount refrigerator-freezers, a decision was made to design a forced air, fin and tube evaporator for this unit. Brazeway, Inc. of Adrian, MI agreed to provide sample coils if the design conformed to their existing fin tooling. With these parameters, a coil was designed. In order to keep the added low side volume to a minimum, 5/16 diameter tubing was selected for this coil. The final design is outlined on sketch \#04.

To appropriately mount this coil in the fresh food compartment of the test unit, a coil housing was needed. This was designed to allow mounting of the evaporator coil and the fresh food evaporator ian and fan motor. The housing was mounted to the ceiling of the fresh food compartment, with a planned air flow pattern that would tend to enhance the natural convection air currents within that compartment. sketch \#07 outlines the required configuration.

\section{F - VALVE AND TUBING SPECIFICATIONS}

The diverter valve used for this test unit was placed at the outlet of the condenser, with the object of feeding seperate capillary tubes to each of the evaporators alternately. As first assembled, a Bosch-siemens 3-way diverter valve was lised. Later, this valve was replaced with a Danfoss valve of similar design. The Danfoss valve exhibited better diverting characteristics with no unwanted leakage to the circuit being diverted.

Each of the two evaporators had its own suction tube with capillary tube(s) soldered to it in a heat exchange relationship. As noted above, a check valve was installed in the freezer evaporator suction tube to prevent undesired repressurization of that evaporator. As a starting point, the existing capillary tube for the freezer section ( 72 inches $x$ 
.026 I.D.) was specified. In order to evaporate at a higher pressure and temperature in the fresh food evaporator, a higher refrigerant flow rate was needed. This required a less restrictive capillary tube. In order to have the capability to change capillary restriction easily, two tubes were specified for the initial construction, assembled with shutoff valves, so that change could be accomplished during test runs. The capillary sizes selected were:

$$
\begin{array}{llll}
71 & \text { inches } x & .031 & \text { I.D. } \\
96 & \text { inches } x & .036 & \text { I.D. }
\end{array}
$$

The longer, larger bore tube was estimated to allow a refrigerant flow rate that is approximately $1.5 \mathrm{x}$ that of the smaller bore tube.

G - COMPRESSOR, CONDENSER AND FREEZER EVAPORATOR

For the test unit, the originally installed compressor, condenser, and freezer evaporator were not changed. This strategy will allow direct comparison of the test results from this system with those that were obtained using a conventional single coil. 
INSTRUCTIONS AND CHECK: LIST

FOR

ASSEMBL, Y OF 2-EVAFORATDR, DIVERTEF VALVE TEST IUNIT

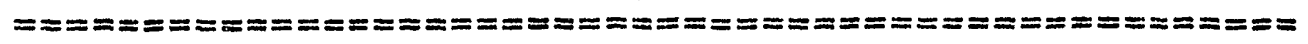

FRESH FOOD EVAPORATOR COIL HOUSING

(1) FAERICATE EVAFORATOR COIL HOUSING PER SKETCH \#OT.

(2) FAERICATE AIR ELOCKING WEDGE FER SKETCH \#07.

(3) INSTALL F. FOOD EVAP. FAN MOTOF INTO HOUSING.

(4) FREPARE MOUNTING MEANS FOR F. FOOD EVAF. COIL.

(5) INSTALL OFF-CYCLE EVAFORATOR HEATERS ON RETUFN EENDS AT LOWER SIDE OF COIL WHEN ASSEMBLED.

(6) WHEN HOUSING IS COMPLETE AND REFRIGERANT CONNECTIONS ARE MADE, ASSEMBLE INTO TEST UNIT. (USE SELF THREADING SCREWS TO ATTACH.)

CONTROL BOX ASS'Y

(1) DISMOUNT ASS'Y FROM CENTER DIVIDEK FANEL.

(2) REPLACE COLD CONTROL WITH THE G.E. SPDT SAMPLE THERMDSTAT OETAINED FOR THIS FROJECT.

(3) INSTALL SPDT SELECTOR SWITCH THFOUGH EOTTOM PANEL.

(4) REVISE WIRING AS SHOWN ON SKETCH \#09. 
INSTEUCTIONS AND CHECK LIST (CONT'D.)

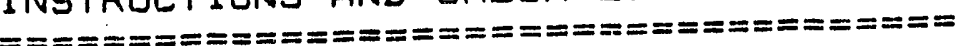

(1) PREPARE SUCTION LINE HEAT EXCHANGER PER SKETCH \#10.

(2) IF DIVIDER PANEL MUST BE INSTALLED EEFORE COIL HOUSING ASSEMBLY, FORM HX, THEN BRING EVAPORATOR END THROUGH DIVIDER PANEL AND ADJUST FOR HOOK-UP TO F. FOOD EVAPDRATOR COIL.

(3) BRAZE SUCTION LINE AND CAP TUEES TO COIL EXTENSION TUBES. FABRICATE CONNECTOR TO RECEIVE CAF TUEES AS NEEDED.

(4) ATTACH DIVERTER VALVE TO CAEINET IN CONVENIENT LOCATION ON LOWER BACK.

(5) PURGE EXISTING SYSTEM CHARGE.

(6) MAKE HOOK-UP OF DIVEFTER VALVE. (REFER TO SKETCHES \#08 AND \#10.)

(7) INSTALL CHECK VALVE INTO FREEZER SUCTION LINE. (MAKE CERTAIN FLOW AND ORIENTATION ARE CORRECT.)

(8) ROUTE BOTH SUCTION LINES TO A SUCTION TEE. (FAERICATE FROM A 1 TO $2 "$ LENGTH OF $5 / 8$ 0.D. COPPER TUBING.)

(9) MAKE ALL TUEING HOOK-UPS AND BRAZE IN PLACE.

(10) INSTALL SHUT-OFF VALVE AT ENTRY OF EACH F. FOOD HX CAP TUAE. MAKE CONNECTIONS AS NEEDED.

(11) WHEN ALL CONNECTIONS ARE COMPLETE, CHARGE SYSTEM WITH A TEST CHARGE TO LEAK TEST ALL NEW JOINTS.

(12) WHEN SYSTEM FROOVES TO BE LEAK FREE, IT IS READY FOR FINAL EVACUATION AND CHARGING. 
INSTFIUCTIONS AND CHECK LIST (CONT'D.)

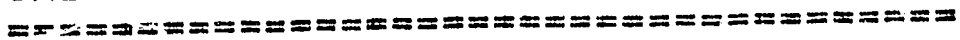

CAEINET

(1) DISASSEMBLE REFRIGERATOR AS NEEDED TO MAKE REVISIONS. a. REMOVE DOORS

b. " "CENTER MULLION AND DIVIDER PANEL

c. " FREEZER COMPARTMENT REAR FANEL

c. " BACK COVER FOR TUBE AND WIRING ENTRY

e. DFEN ENTRY AREA FOR ACCESS TO CAEINET INTEFIIOR.

(2) REMQVE GAFFLE CONTROL MECHANISM FROM DIVIDER FANEL.

(3) FILL AIR PASSAGES IN CENTER DIVIDER PANEL WITH INSULATION AND SEAL WITH TAPE.

(4) DETERMINE ROUTING REQUIREMENTS OF F. FOOD SUCTION LINE HX THROUGH CENTER DIVIDER FANEL. PREPARE PANEL AS NEEDED. (MAY USE AIR PASSAGE OR FORM NOTCH IN PANEL.)

(5) MOUNT FREEZER THERMOSTAT BRACKET, THERMOSTAT AND HOUSING IN UFPER LEFT CORNER OF FREEZER. (USE SELFTHREADING SCREWS TO ATTACH TO LINER.)

(6) PREPARE ADDITIONAL HARNESS WIRES NEEDED TO REVISE EXISTING HARNESS. MAKE REVISIONS TO HARNESS. (REFER TO SK.ETCH \#09.)

(7) WHEN ALL REVISIONS ARE COMPLETE, REASSEMBLE CABINET WITH NEW COMPONENTS INSTALLED. 


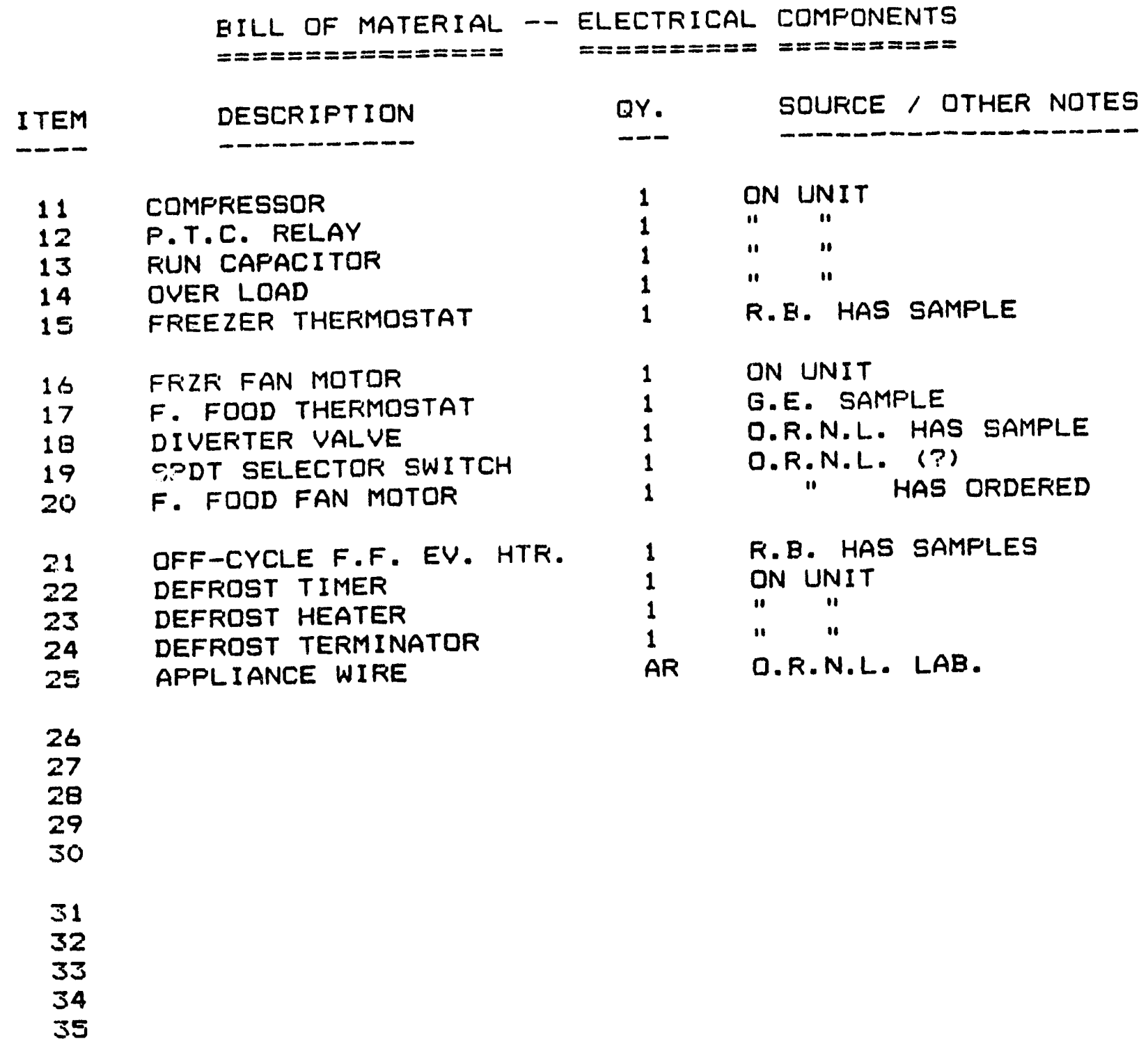




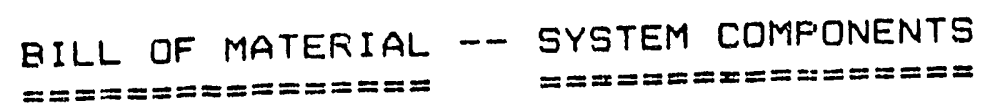

\begin{tabular}{|c|c|c|c|}
\hline ITEM & DESCRIPTION & QY. & SOURCE / OTHER NOTES \\
\hline $\begin{array}{l}(11) \\
(18) \\
41 \\
42 \\
43\end{array}$ & $\begin{array}{l}\text { COMPRESSOR } \\
\text { DIVERTER VALVE } \\
\text { CONDENSER } \\
\text { SUCTION LINE - FRZR } \\
\text { CAF TUEE - FRZR EVAF. }\end{array}$ & $\begin{array}{l}1 \\
1 \\
1 \\
1 \\
1\end{array}$ & 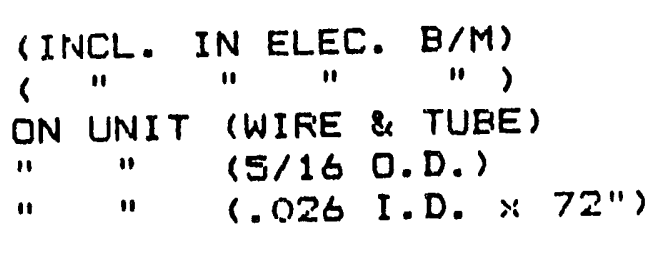 \\
\hline $\begin{array}{l}44 \\
45 \\
46 \\
47 \\
48\end{array}$ & $\begin{array}{l}\text { EVAP. - FREEZER } \\
\text { SUCT. LINE - F.F. EVAP } \\
\text { CAF TUEE "A" " } \\
\text { CAP TUEE "E" " } \\
\text { SHUT-OFF VALVES - C.T. }\end{array}$ & $\begin{array}{l}1 \\
1 \\
1 \\
1 \\
2\end{array}$ & $\begin{array}{l}\text { ON UNIT } \\
5 / 160 . D . \text { CU. } \\
71 \% \times .0311 .0 \\
96 \times .0361 .0 . \\
\text { O.R.N.L. LAB }\end{array}$ \\
\hline $\begin{array}{l}49 \\
50 \\
51 \\
52 \\
53\end{array}$ & $\begin{array}{l}\text { F. FOOD EVAFORATOR } \\
\text { SUCTION LINE TEE } \\
\text { CHECK VALVE } \\
\text { STRAINER }\end{array}$ & $\begin{array}{l}1 \\
1 \\
1 \\
1\end{array}$ & $\begin{array}{l}\text { BRAZEWAY SAMPLE } \\
\text { FAE. FROM } 5 / 8 \text { CU. TUEE } \\
\text { R.B. HAS SAMPLE } \\
\text { ON UNIT }\end{array}$ \\
\hline $\begin{array}{l}54 \\
55 \\
56 \\
57 \\
58\end{array}$ & & & \\
\hline $\begin{array}{l}59 \\
60 \\
61 \\
62 \\
63\end{array}$ & & & \\
\hline
\end{tabular}




$$
\begin{aligned}
& \text { BILL OF MATERIAL }- \text { OTHER COMPONENTS } \\
& ===============0========0
\end{aligned}
$$

ITEM
---
71
72
73
74
75
76
77
78
79
80
81
82
83
84
85

QY. SOURCE / OTHER. NOTES

1 FAB. PER SKETCH \#07

1 R.B. HAS SAMPLE

1 FAR. FER SKETCH \$O7 
SKETCH InDEX SHEET

oral 2 -evaporator. Diverter Valve Project

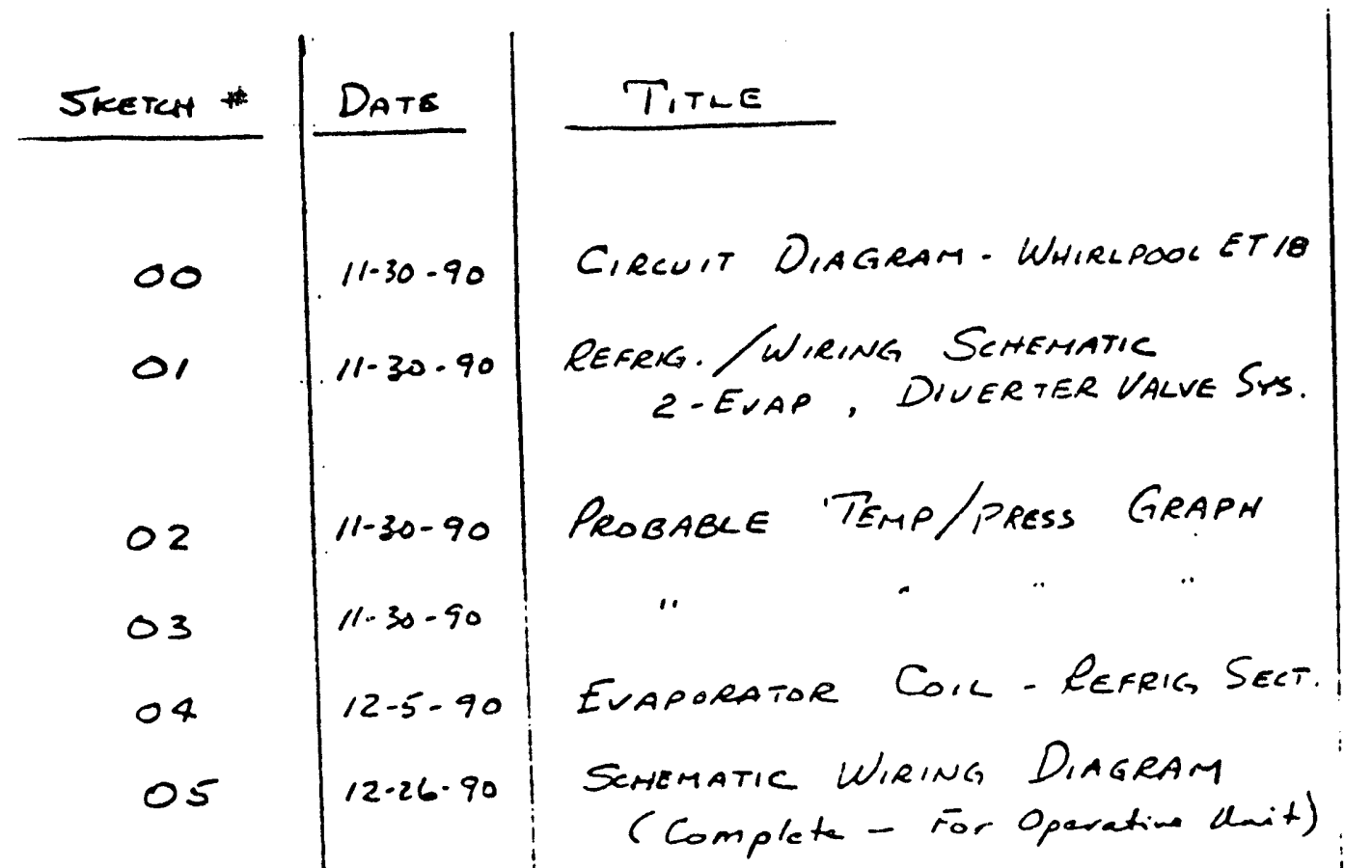

Notes

ladder Diagram for Existing U.

Concept sketch with Possible Control Scheme

Probable operating characters: for system - $90^{\circ}$ Mid/ric Probable operating characteristic. for System. H. freezer load

Sketch made for Brazeary Say LADOER Diagram for Test U.

Copied from Whirlpool Serum literature

Assay layout and detail. drawing of housing.

Schematic of system w/ BIM Listing included.

For final wiring revisions specs for assay

C-14 
Sketer "oo

$11-30-90$

CIRCUIT DIAGIAM - WMIRLPOOL ET $18 N K \times S N$

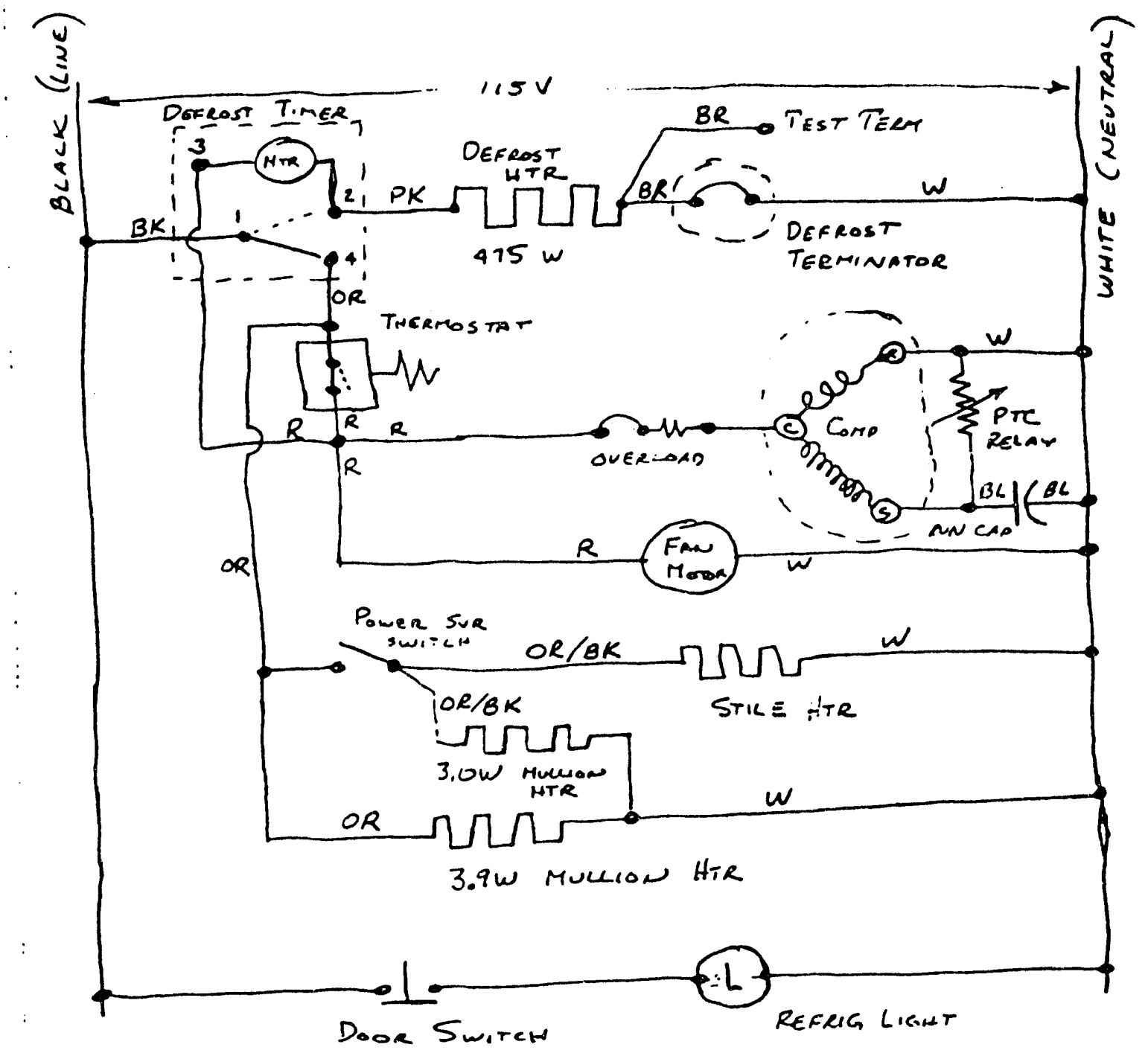

C-15 
Sketer

or

11-30-90 Rerricagran/WIrIng - 2 Evap. Valved Systert
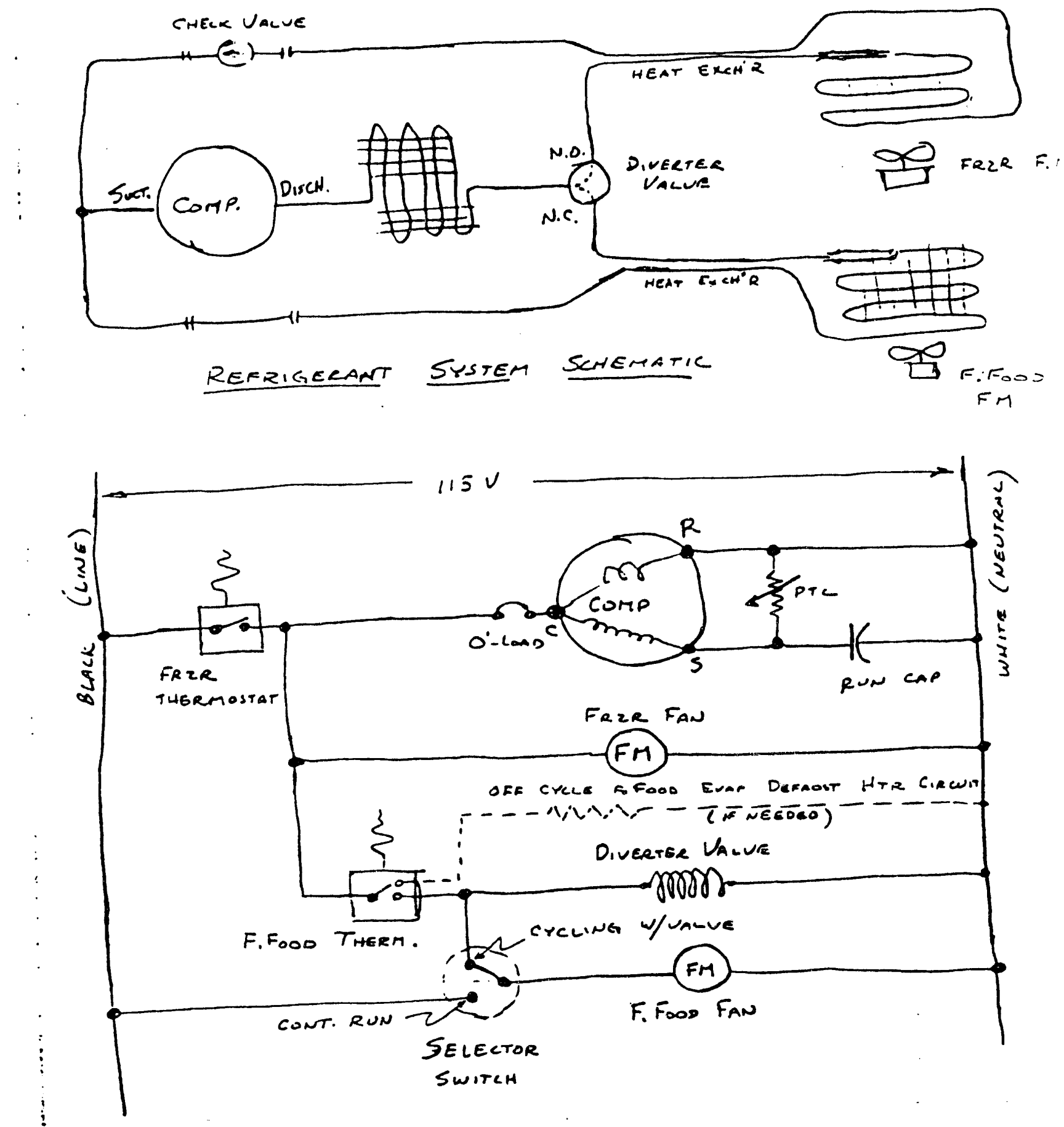

Simplified wiring Diagram (for System Only)

C-16 
Probate Temp./press Graph

2-Evap. Diverter Valve System

Conditions: Cycling - $90^{\circ}$ Arb. WITH HI FREEZER LOAD (ICE FREEZE)
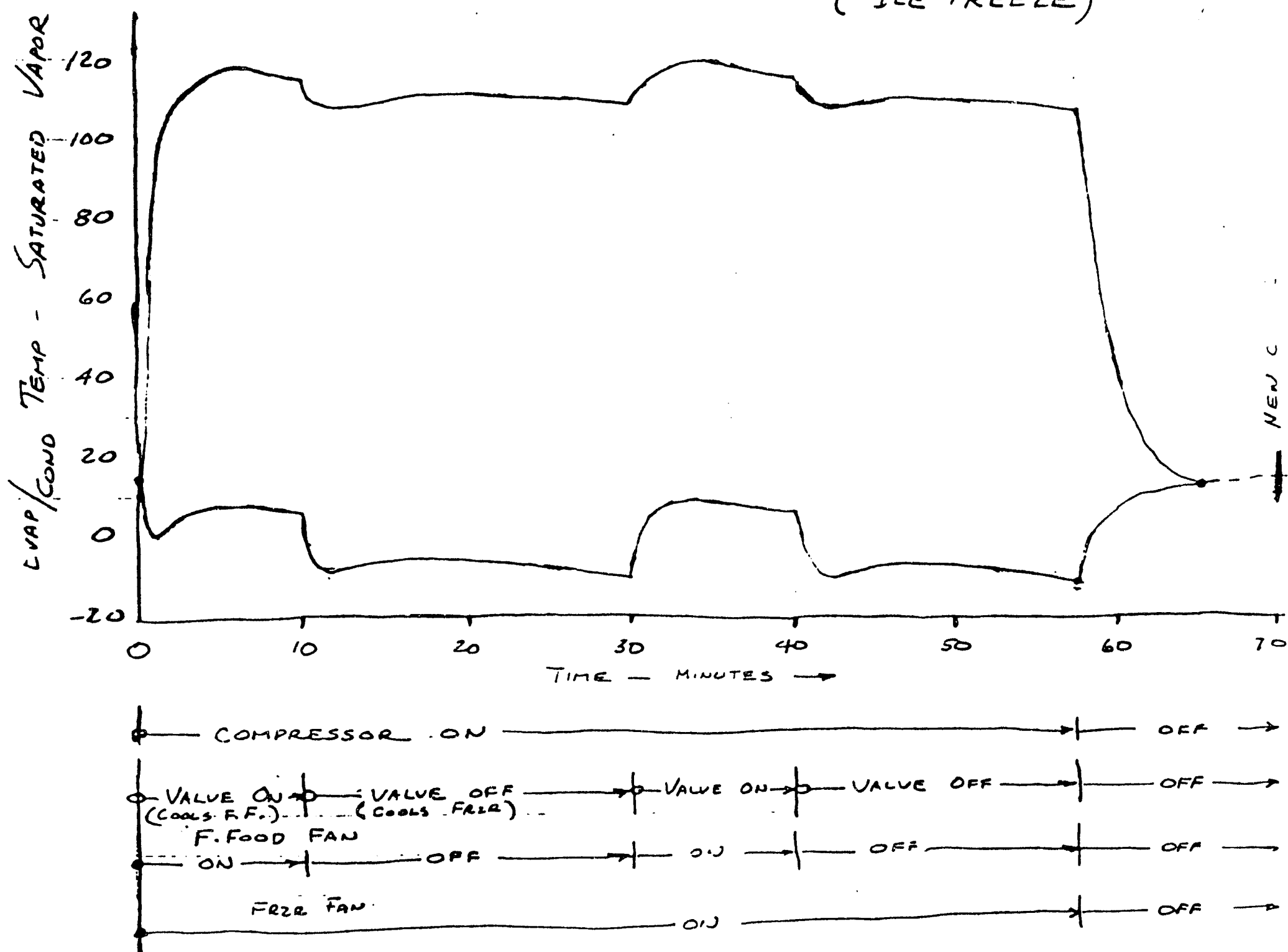

C-17 
Probable Temp./Press Graph

2 Eva. Diverter Valve 'System

Conditions: Normal Cycling- $90^{\circ}$ Amp. For $5 / 38$ CaST TEMPS.
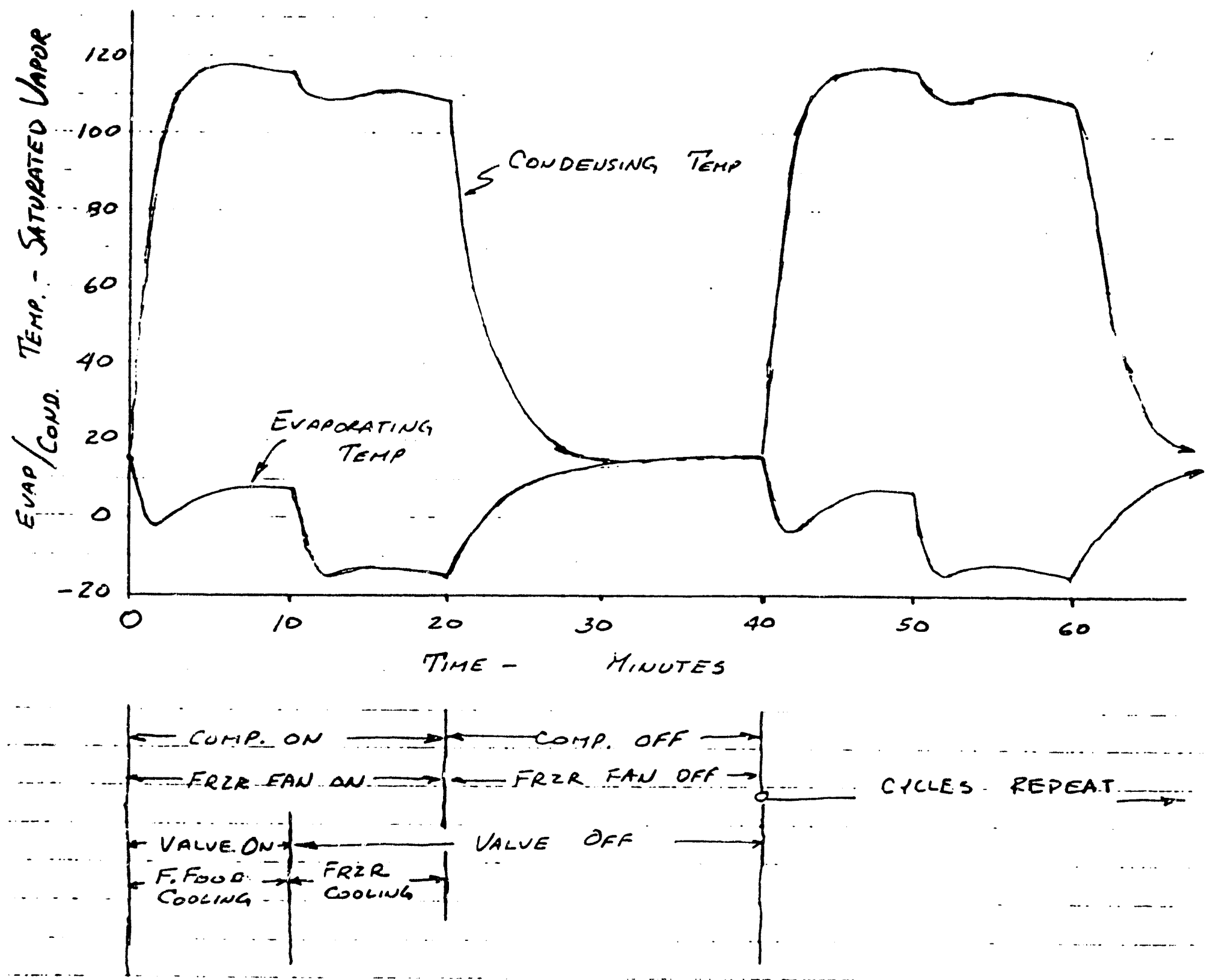

C. 18 
Evapuratur Coic - Refrig Section $18 F^{3}$ FEASIBILITY MOOEL (ORNL)

Siesren $=0$ -

$12-5 \cdot 90$

SLze to Receive $\$ / 16$ oD Sustion Line

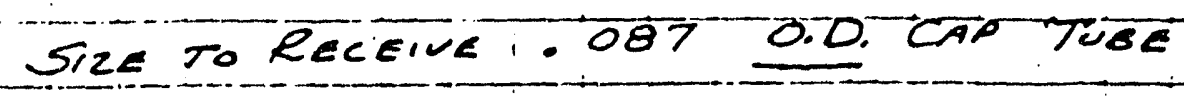

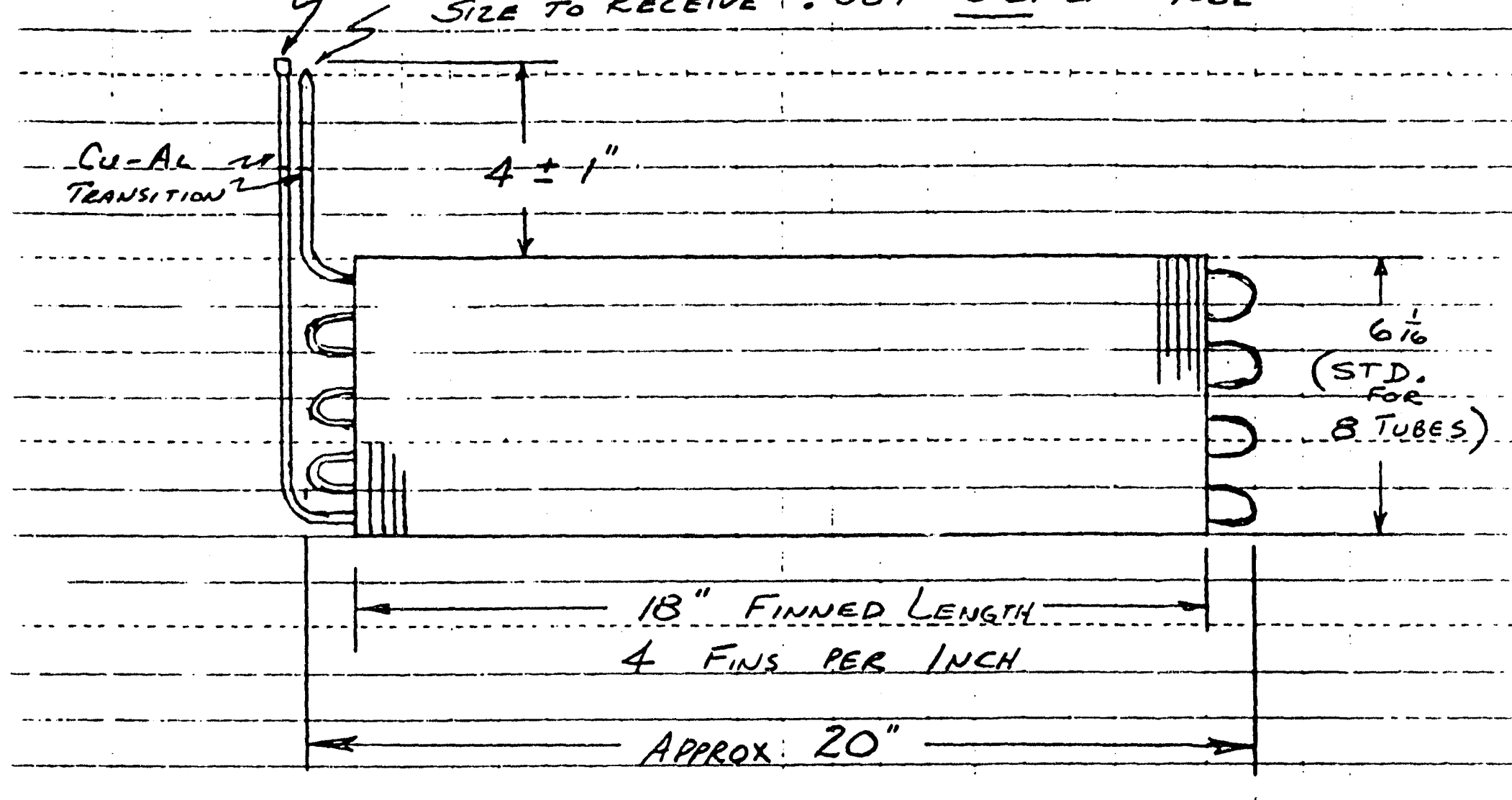

GENERAL SPELIEICATIONS

I-Row, 8 Tubes, istagger Patterw

$5 / 16$ OD $\times .025$ WALL TUBING

Fin Size E THAKUESS PER BRAzEWAY STO.

Desirei Internal Voume Range:: $9:-10 \mathrm{in}^{3}$ (Estimateo For ABove Colk : 9.4 in ${ }^{3}$ )

C.19 
Schematic Wiring Diagram (Complete -- For Opsrative Unit)

$$
\text { SKETCH }=05
$$$$
12-26-90
$$

Rs

orel 2-Evaporator Diverter Valve System

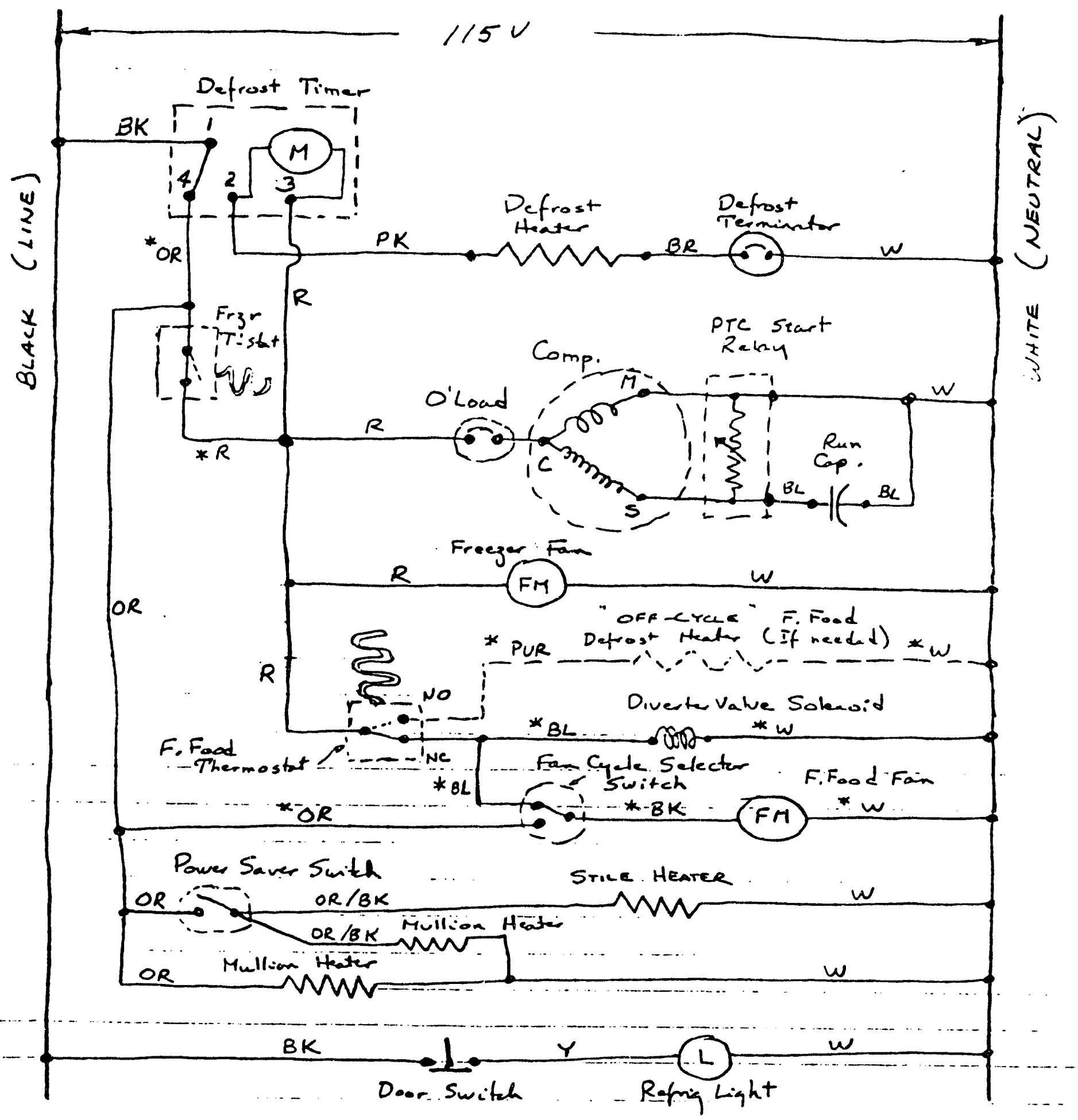

C-20 


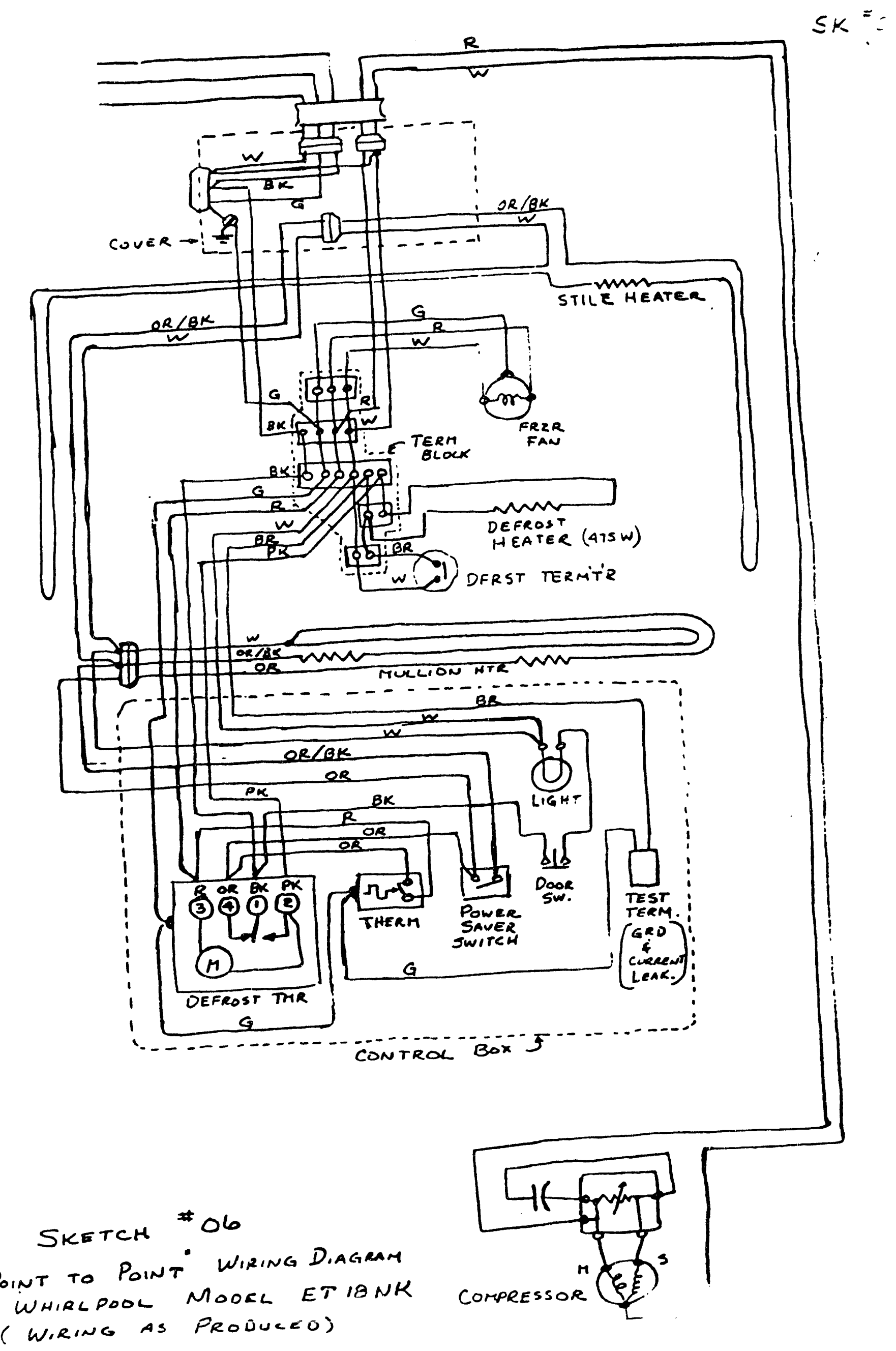




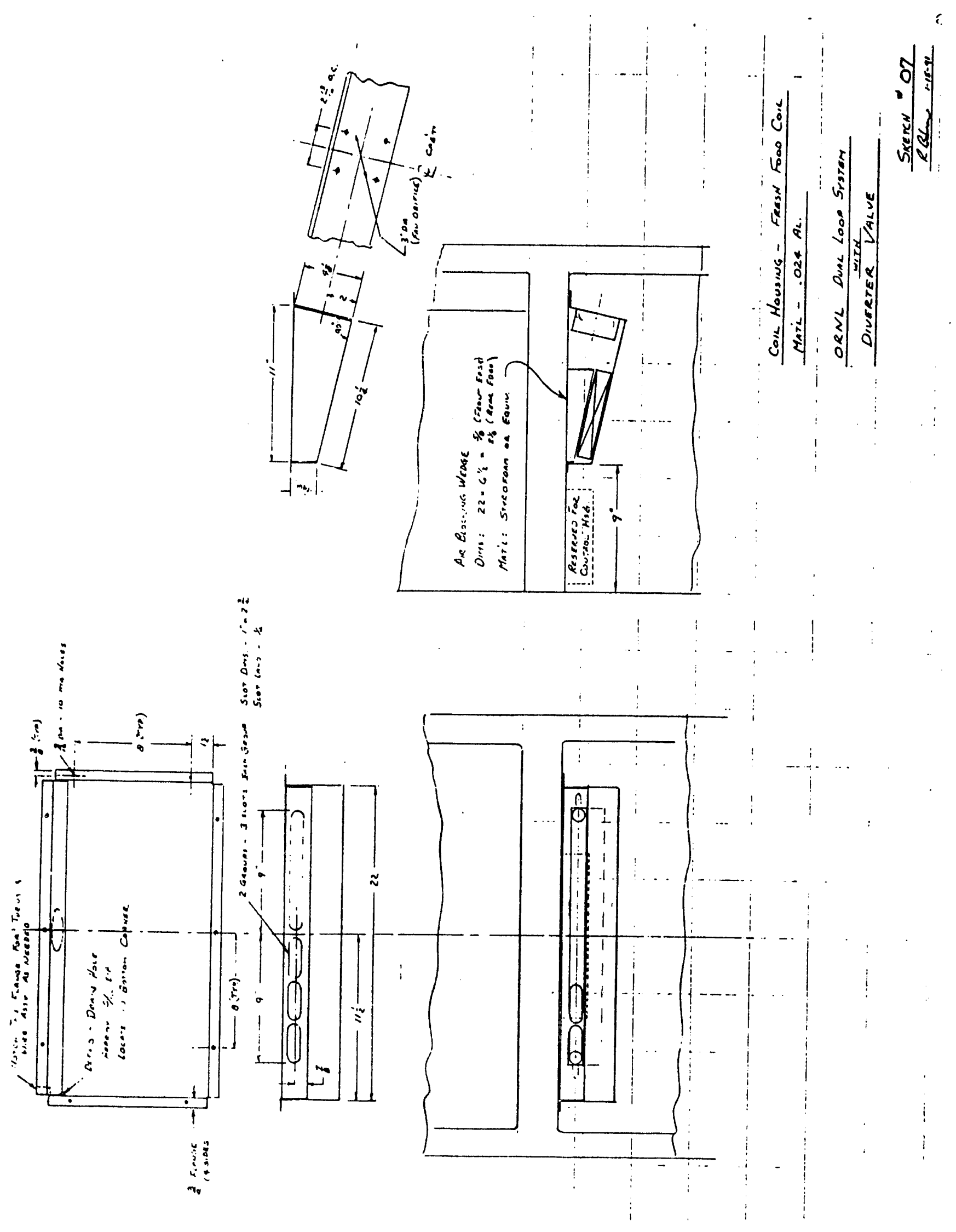


aymond $H$. Bohman P.E. CONSULTING ENGIMEER

4701 CARROUSEL DRIVE SW CEDAR RAPIOS. IOWA 52404
Refrigeration Systeid Semematic 2. Evap. Diverter Valve SYSTEM

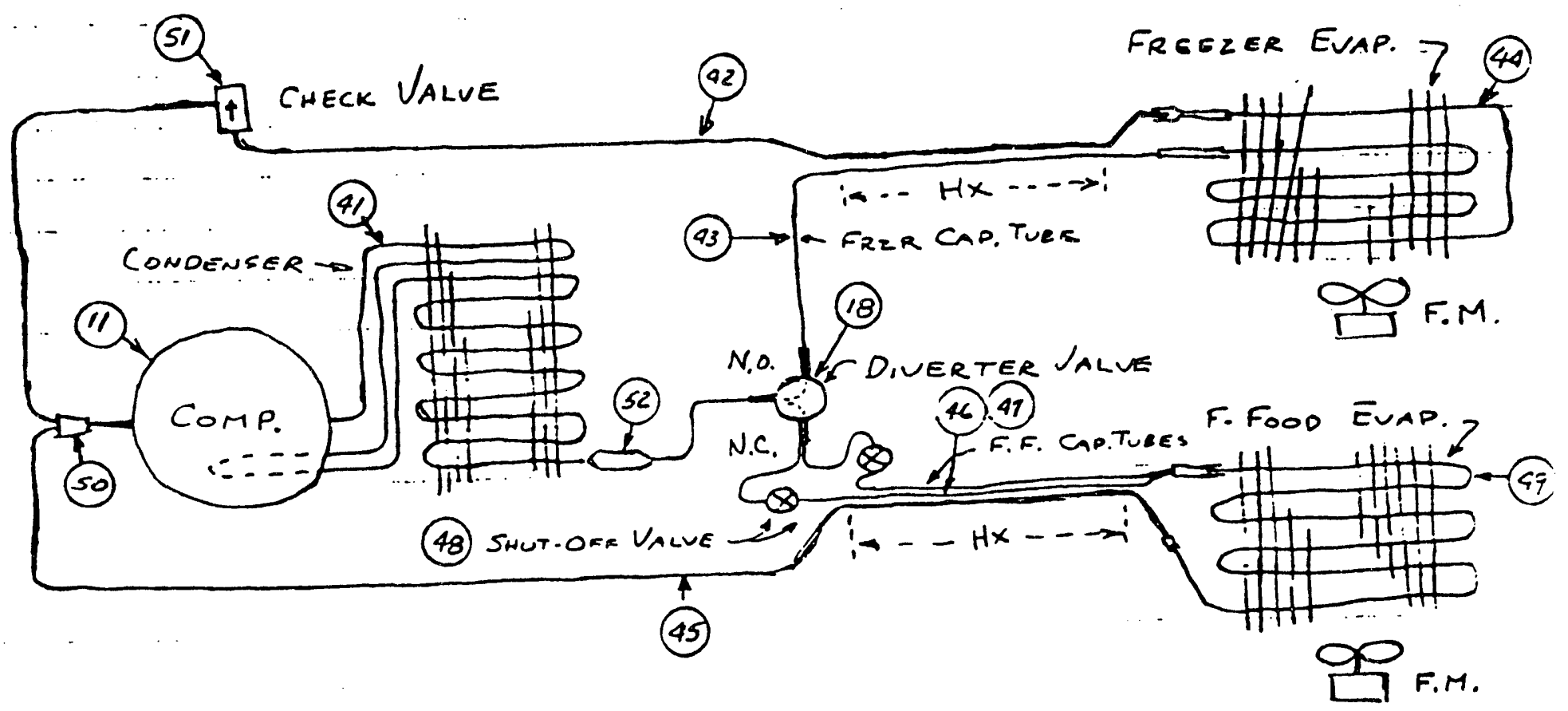

BILL OF MATERIAL - SYSTEM COMFONENTS

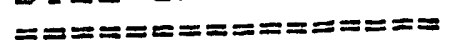

ITEM

- -

(11)

(18)

41

42

43

44

45

46

47

48

49

50

51

52

53
QY. SOURCE / OTHER NOTES

(INCL. IN ELEC. B/M)

\section{COMPRESSOR \\ DIVERTER VALVE}

CONDENSER

SUCTION LINE - FRZR

CAP TUBE - FRZR EVAP.

-

1

1

1

1

EVAP. - FREEZER

SUCT. LINE - F.F. EVAP

CAP TUBE "A" " "

CAP TUBE "B" "

"

SHUT-OFF VALVES - C.T.

F. FOOD EVAPORATOR

SUCTION L.INE TEE

CHECK, VALVE

STRAINER
ON UNIT (WIRE \& TUBE)

" " (5/16 O.D.)

" " (.026 I.D. x $72 ")$

ON UNIT

S/16 G.D. CU.

$711 \times .0311 .0$.

$96^{\circ \times} \times .036 \quad 1.0$.

Q.R.N.L. LAB

BRAZEWAY SAMPLE

FAB. FROM $5 / 8$ CU. TUEE

R.B. HAS SAMPLE

ON UNIT 
R.

Point-to-Point WIRING DIAGRAM (ORuL 2-EVAP. Div. Valve SYSTEM) (Modifications Required for et 18 NK) INIEING HARNESS 
Suction Line HX F.F. Eva

$R B$

Diverter Valve Tube IDEnTIFICATION

$1-23-9$

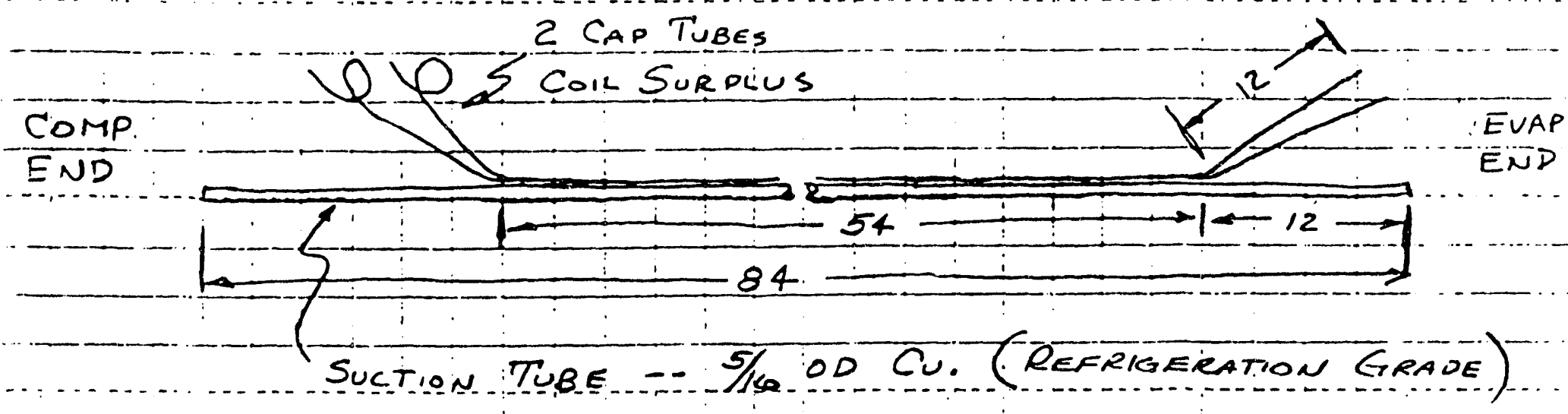

Note: Suction Tube LenGTH MaY bE ADJusted to Fit. HX LENGTH SHOULD bE MaInTAINED

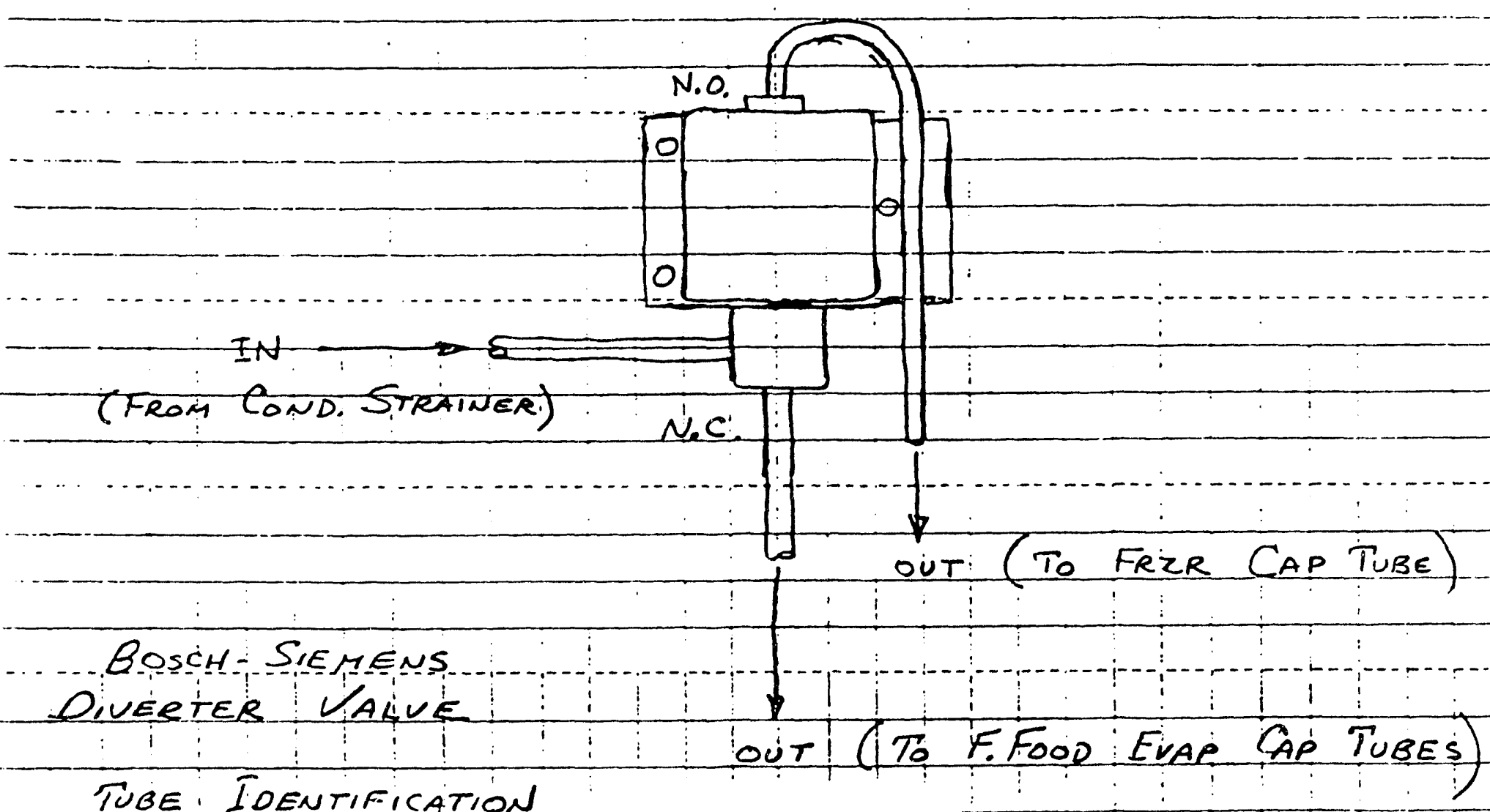

Tube IDentification

C. 25 


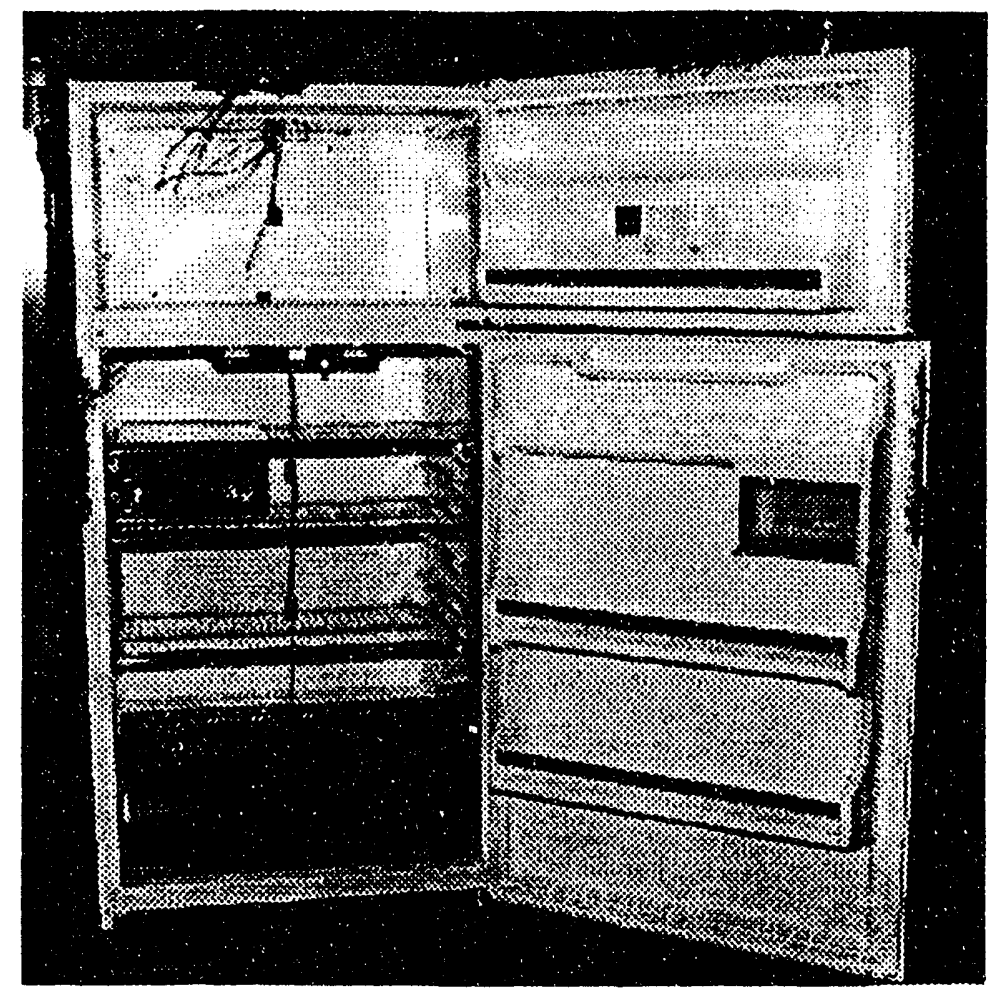

Fig. C.1. Test unit - Whirlpool top mount model ET18NKXSNO2. Front view. 


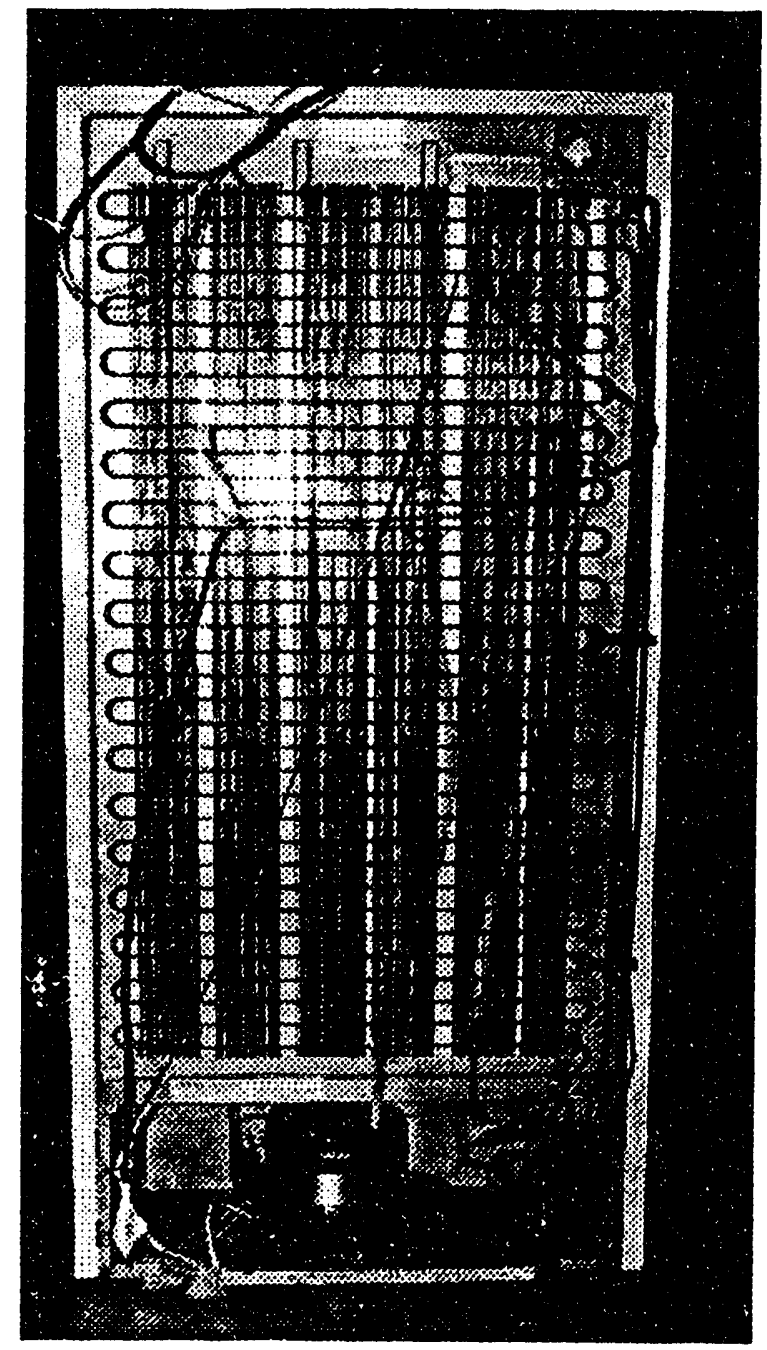

Fig. C.2. Test unit - Whirlpool top mount model ET18NKXSN02 Back view. 


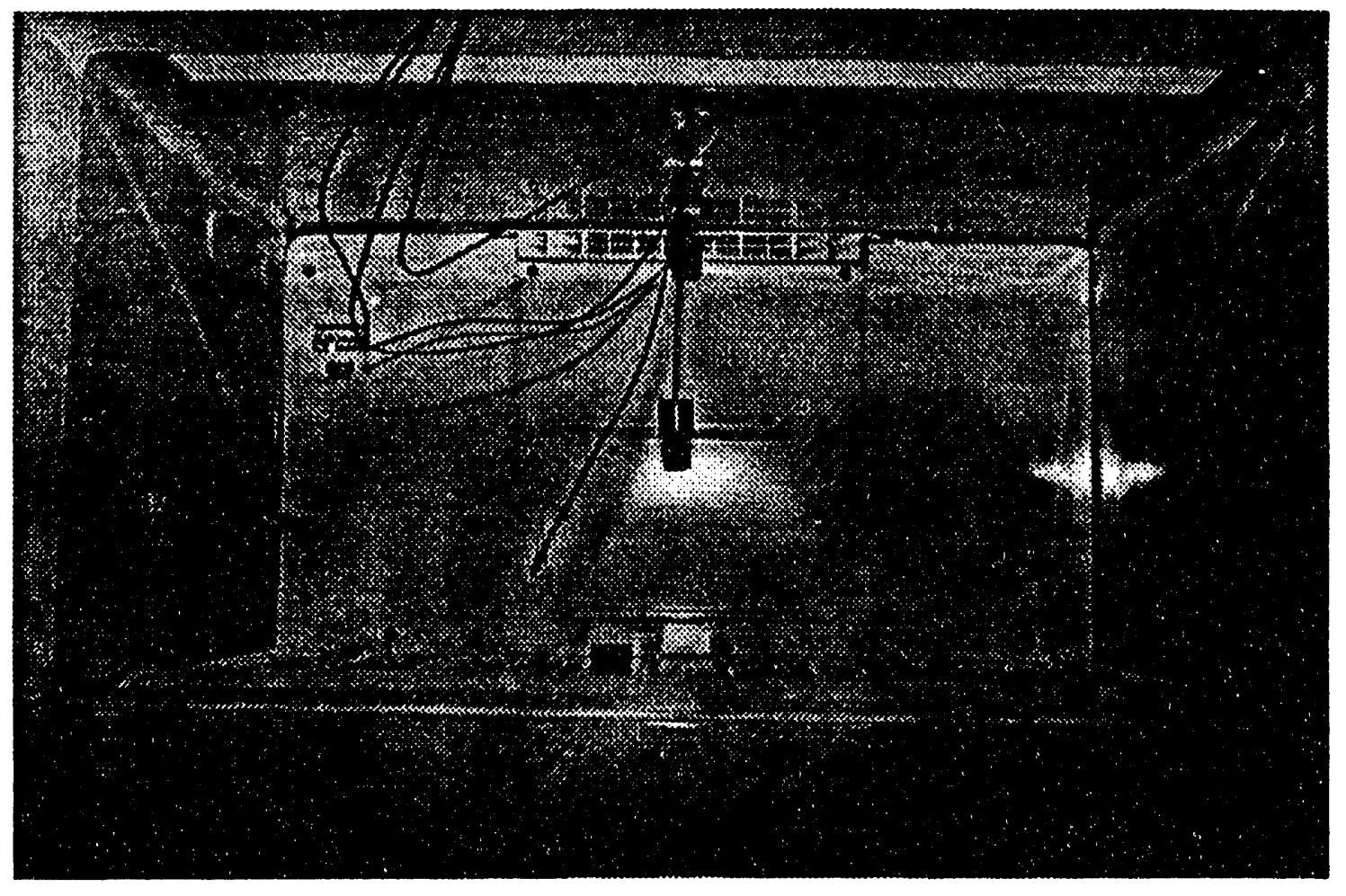

Fig. C.3. Freczer compartment. 


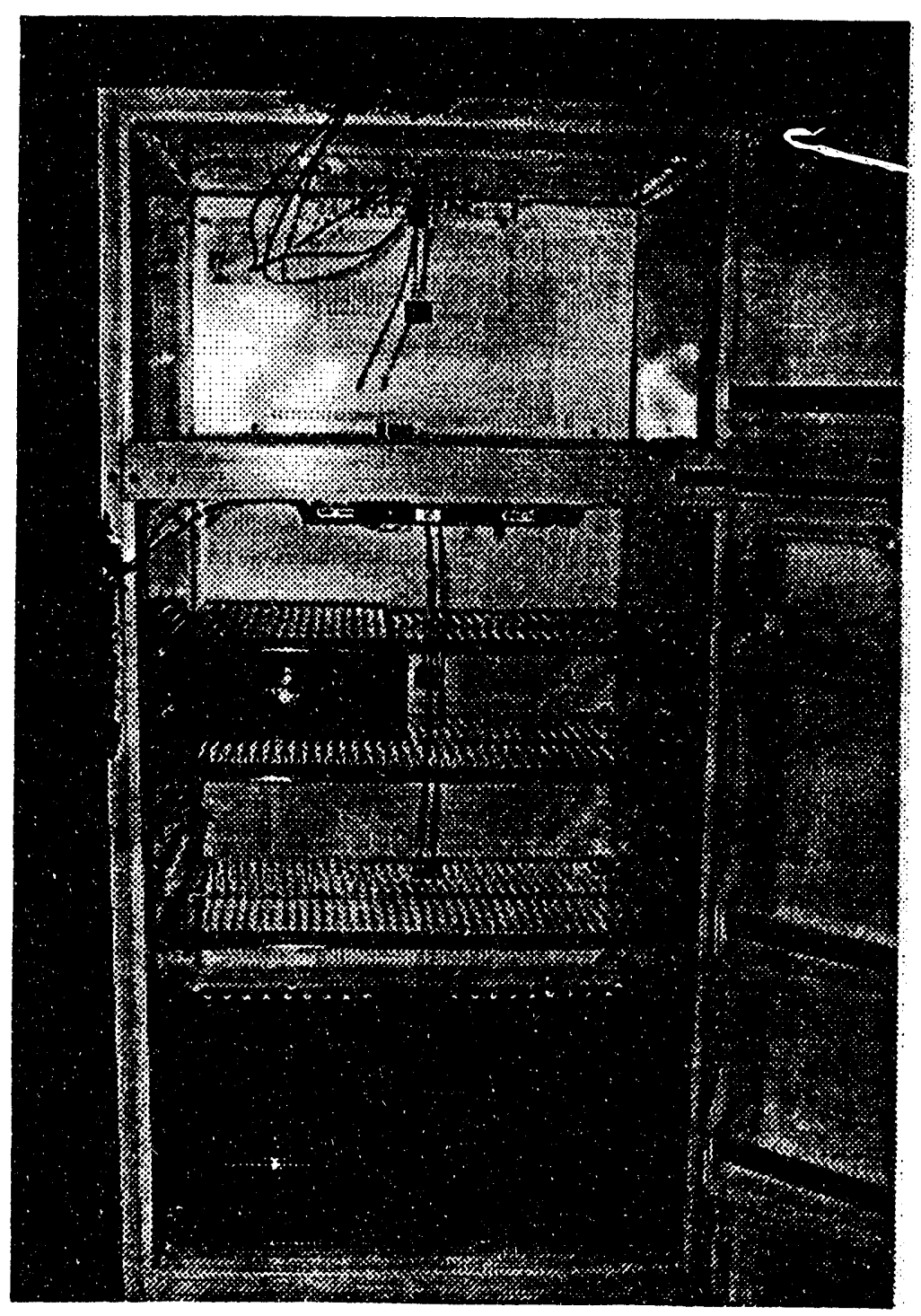

Fig. C.4. Refrigcrator interior. 


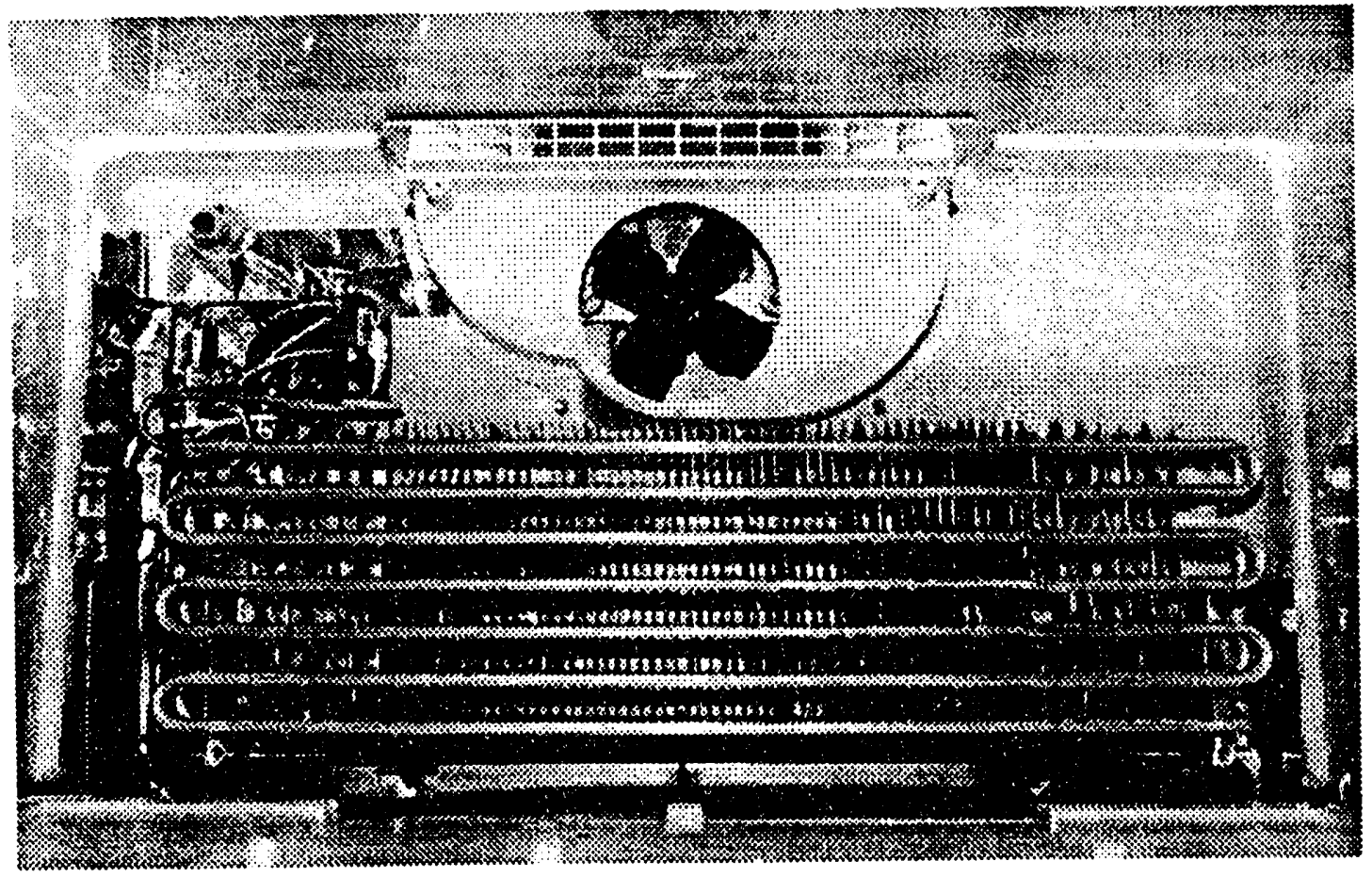

Fig. C.5. Freezer evaporator. 


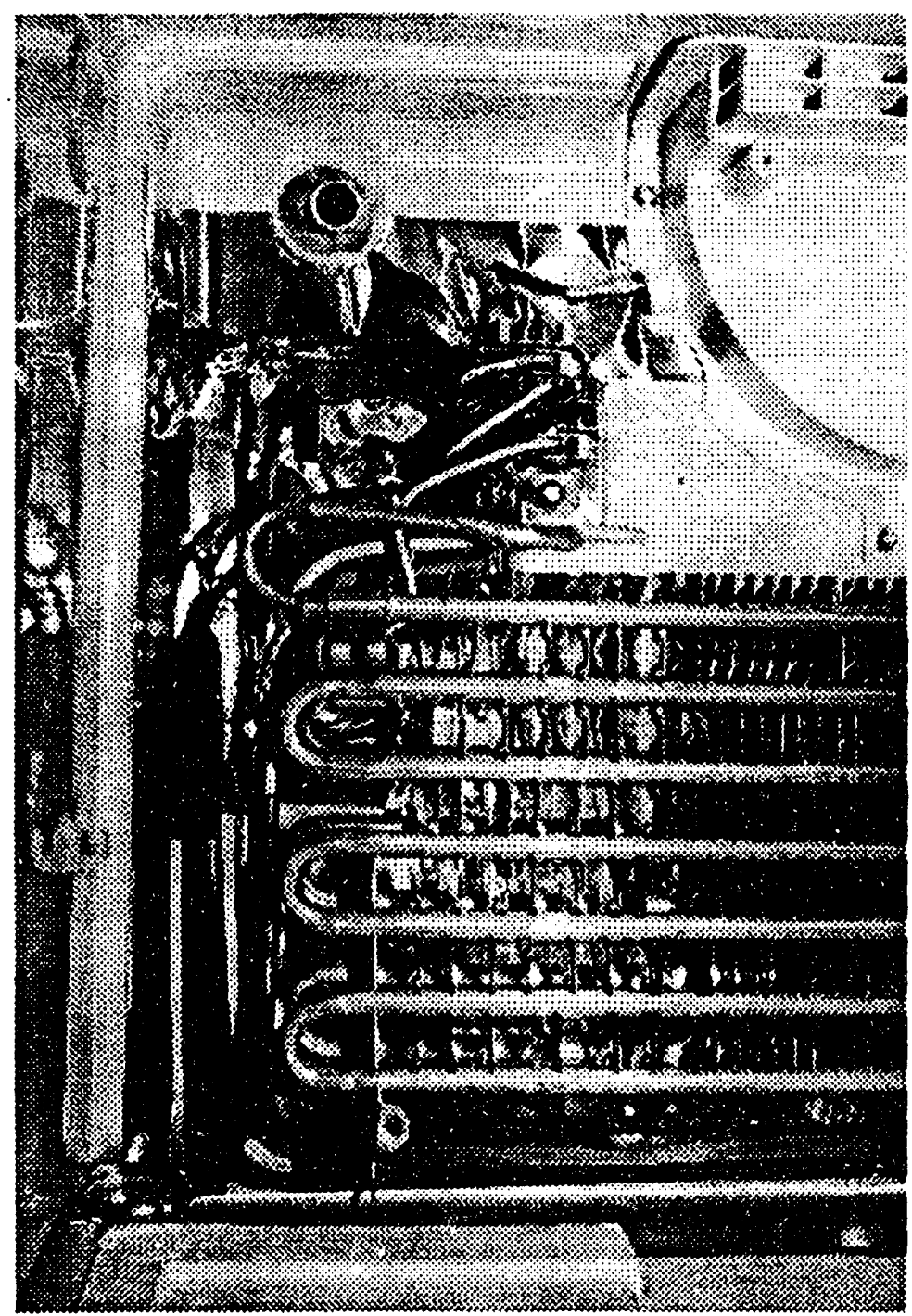

Fig. C.6. Wiring and tubing entry, left end of freezer evaporator. 


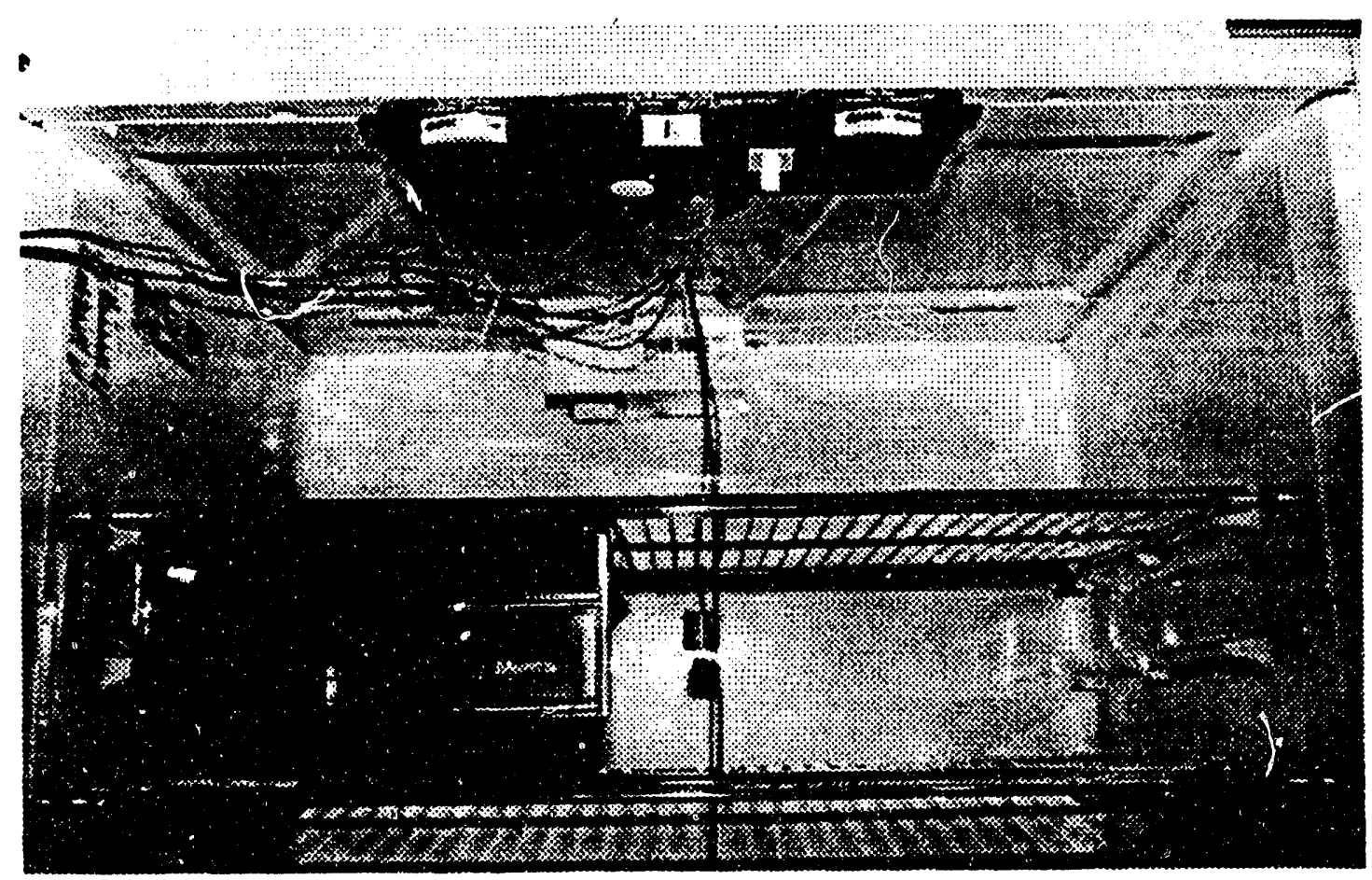

Fig. C.7. Fresh food compartment ceiling. 


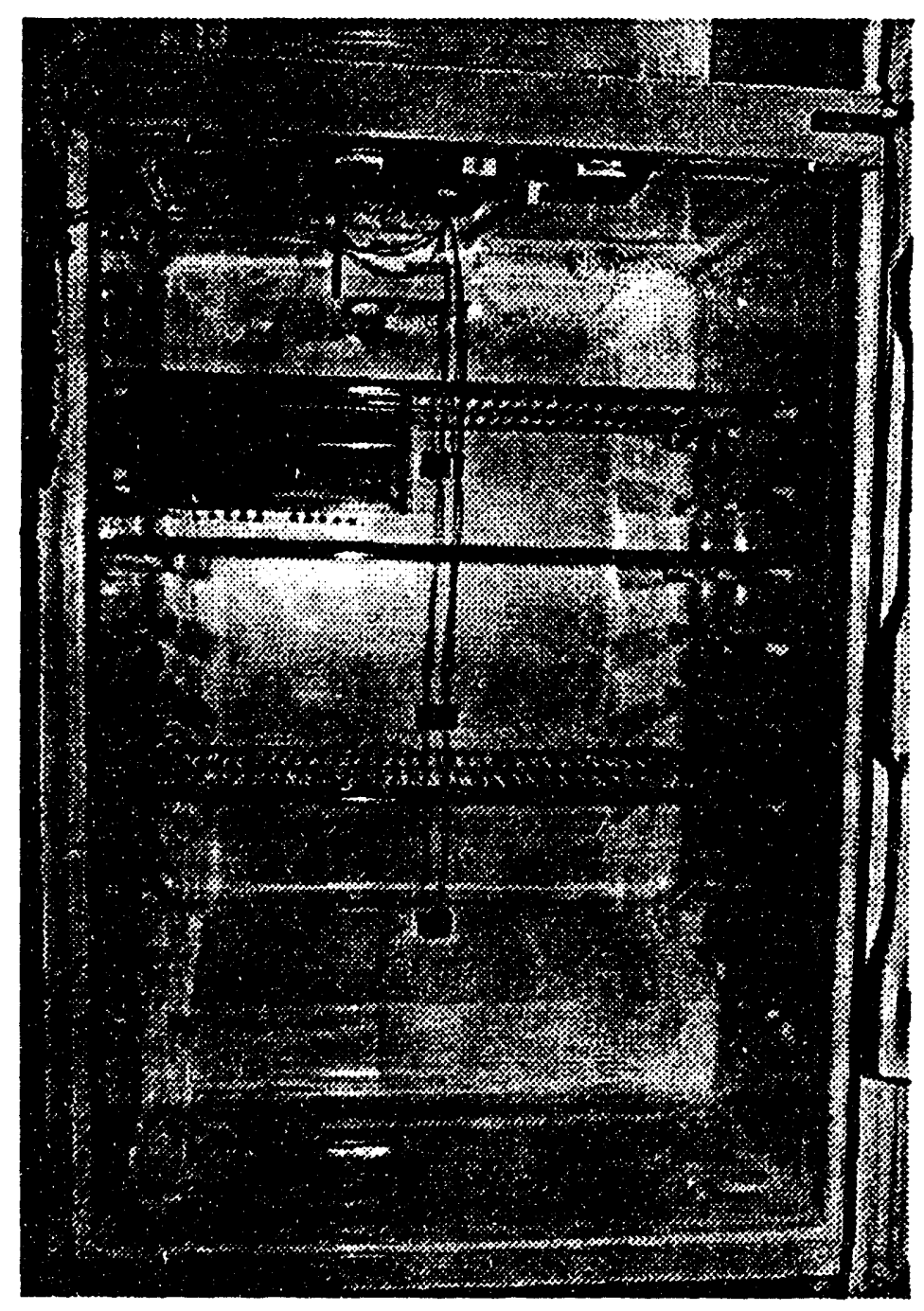

Fig. C.8. Fresh food compartment. 


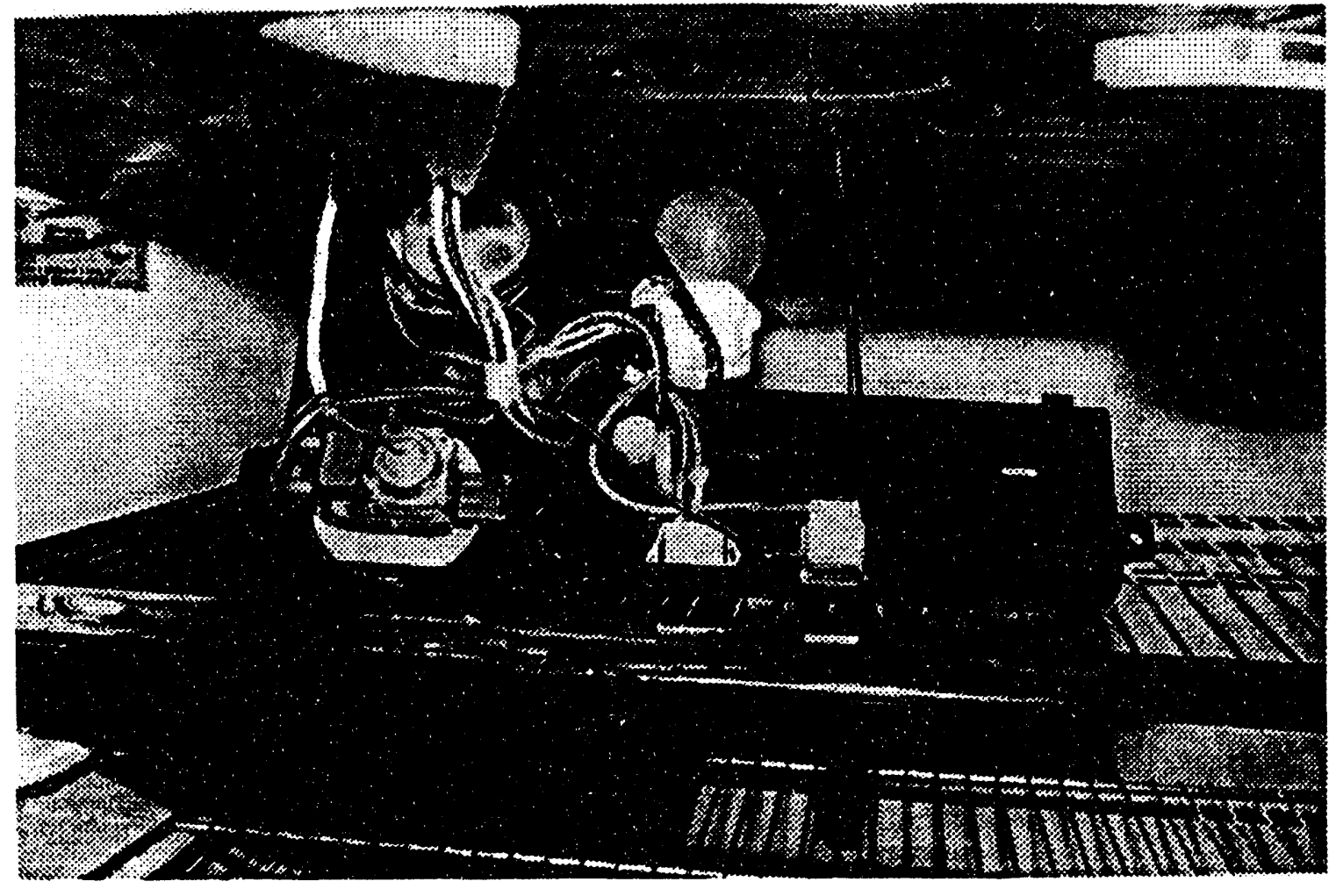

Fig. C.9. Controls and control housing (dismounted). 


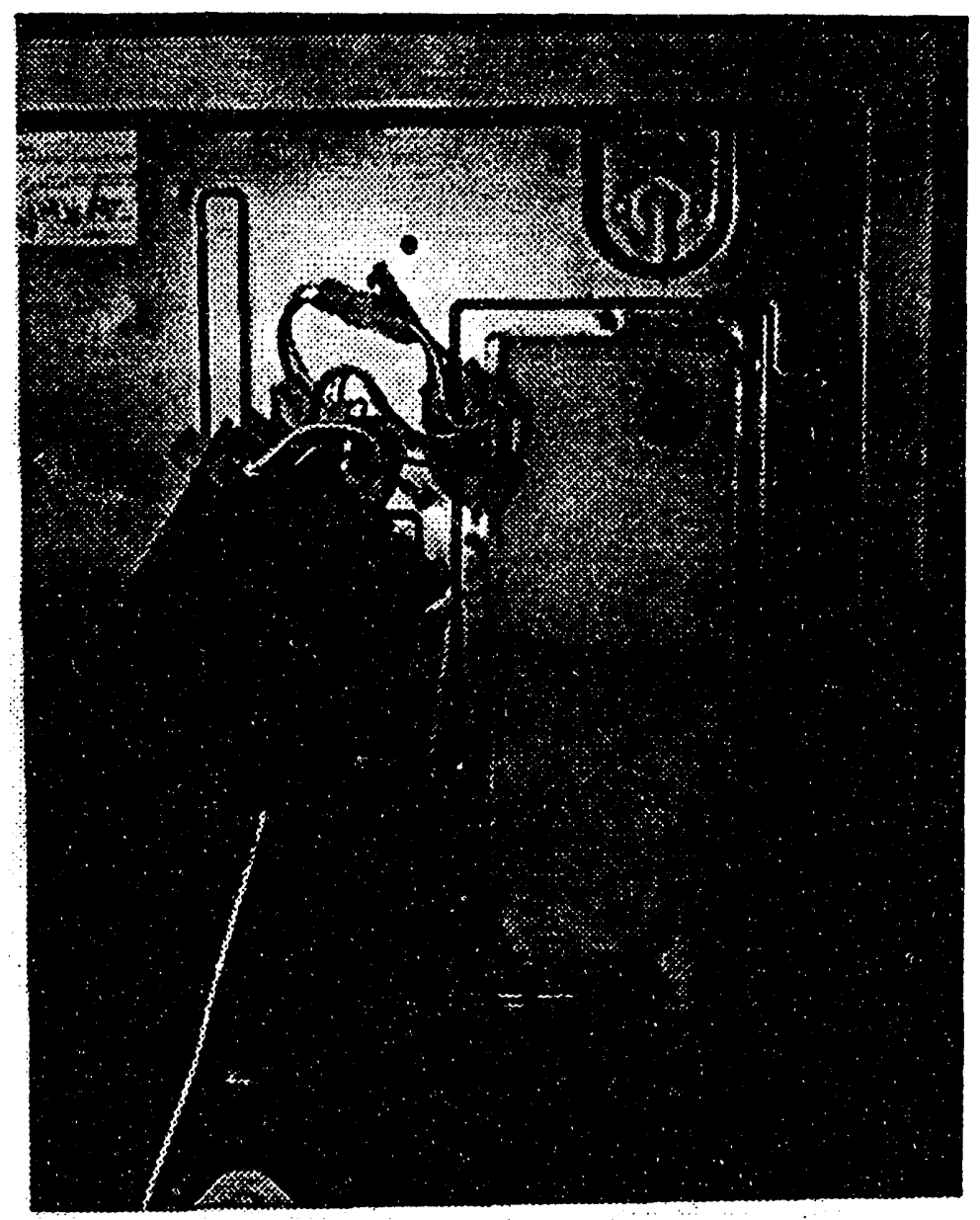

Fig. C.10. Access port to interior (cover removed). Rear view. 


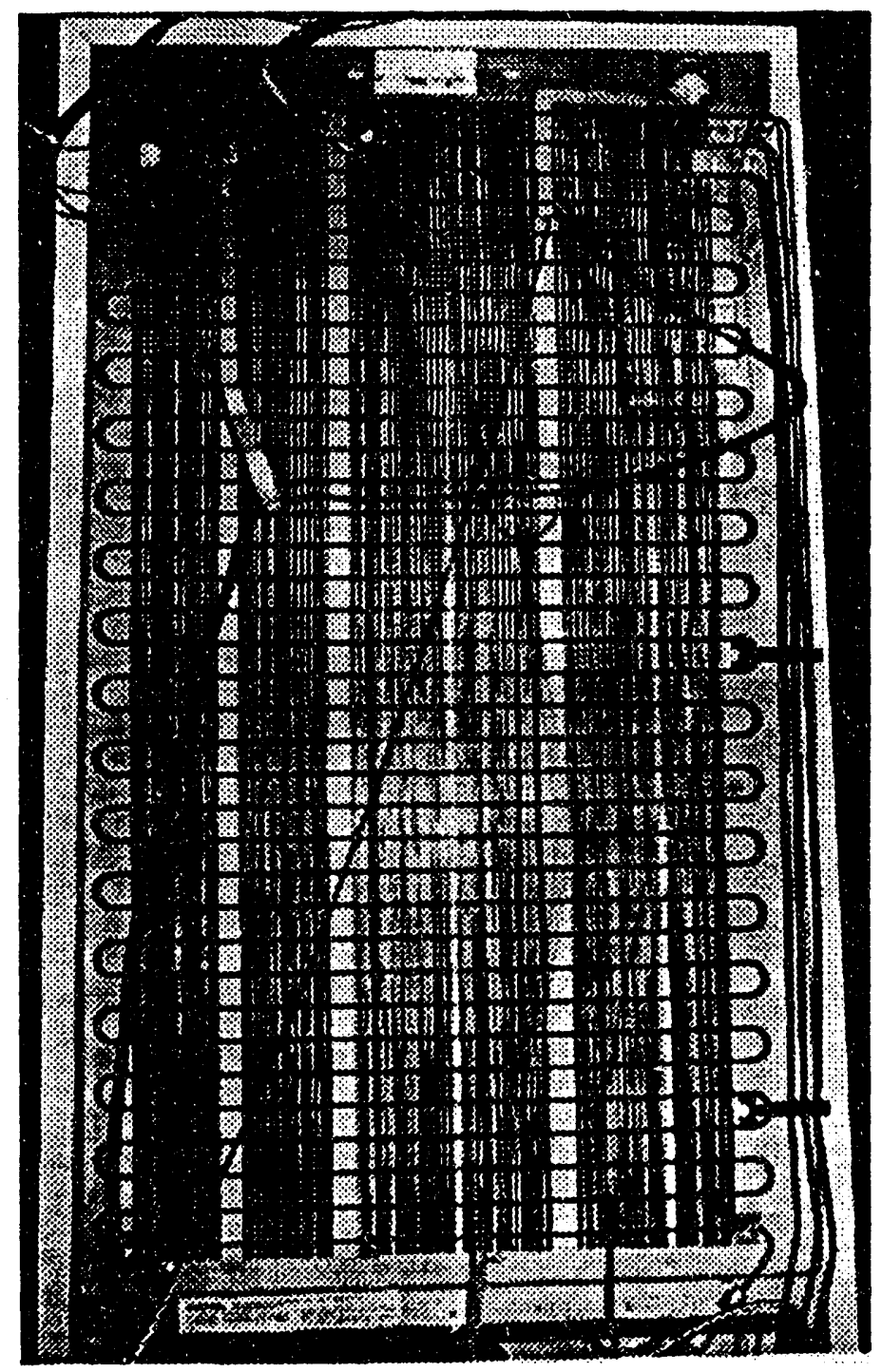

Fig. C.11. Cabinet rear view; static condenser (wire and tube). 


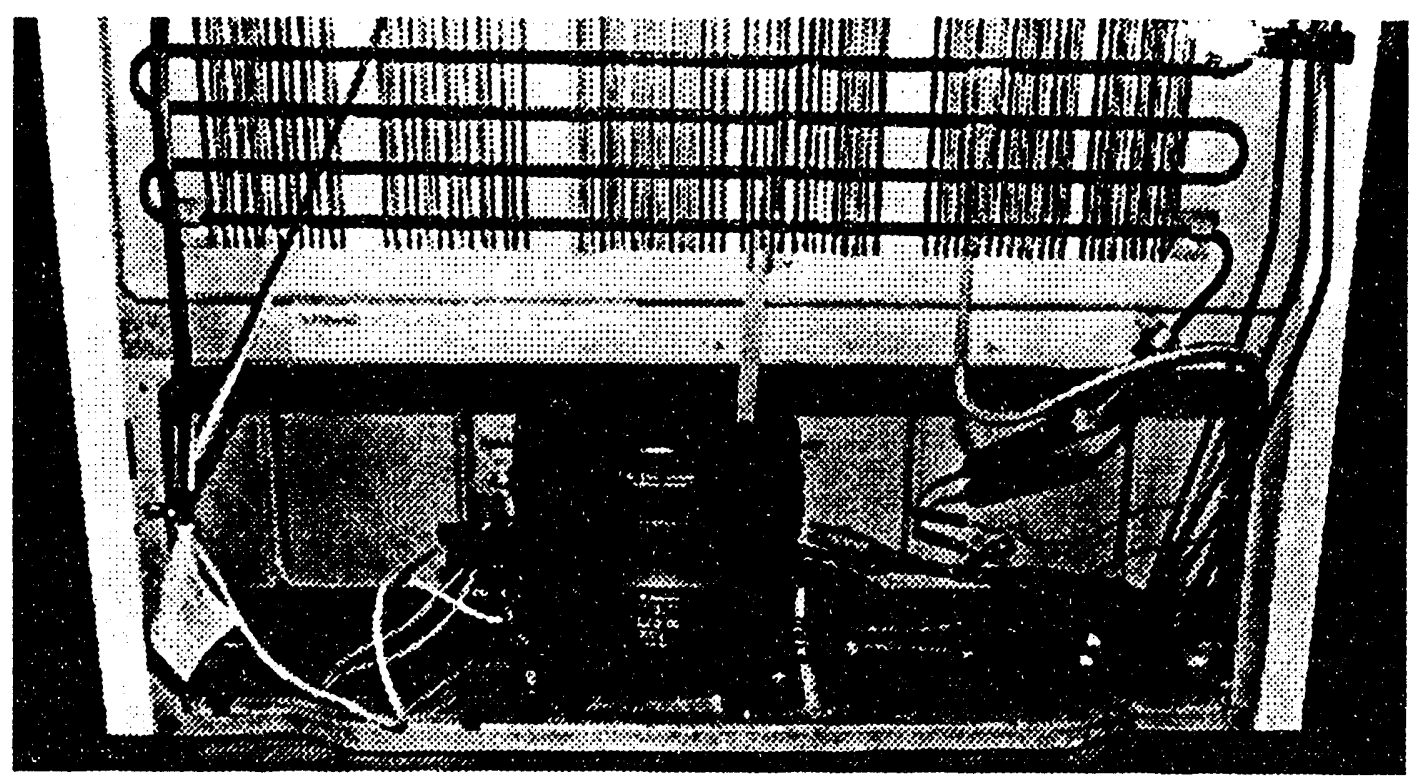

Fig. C.12 Machine compartment. 

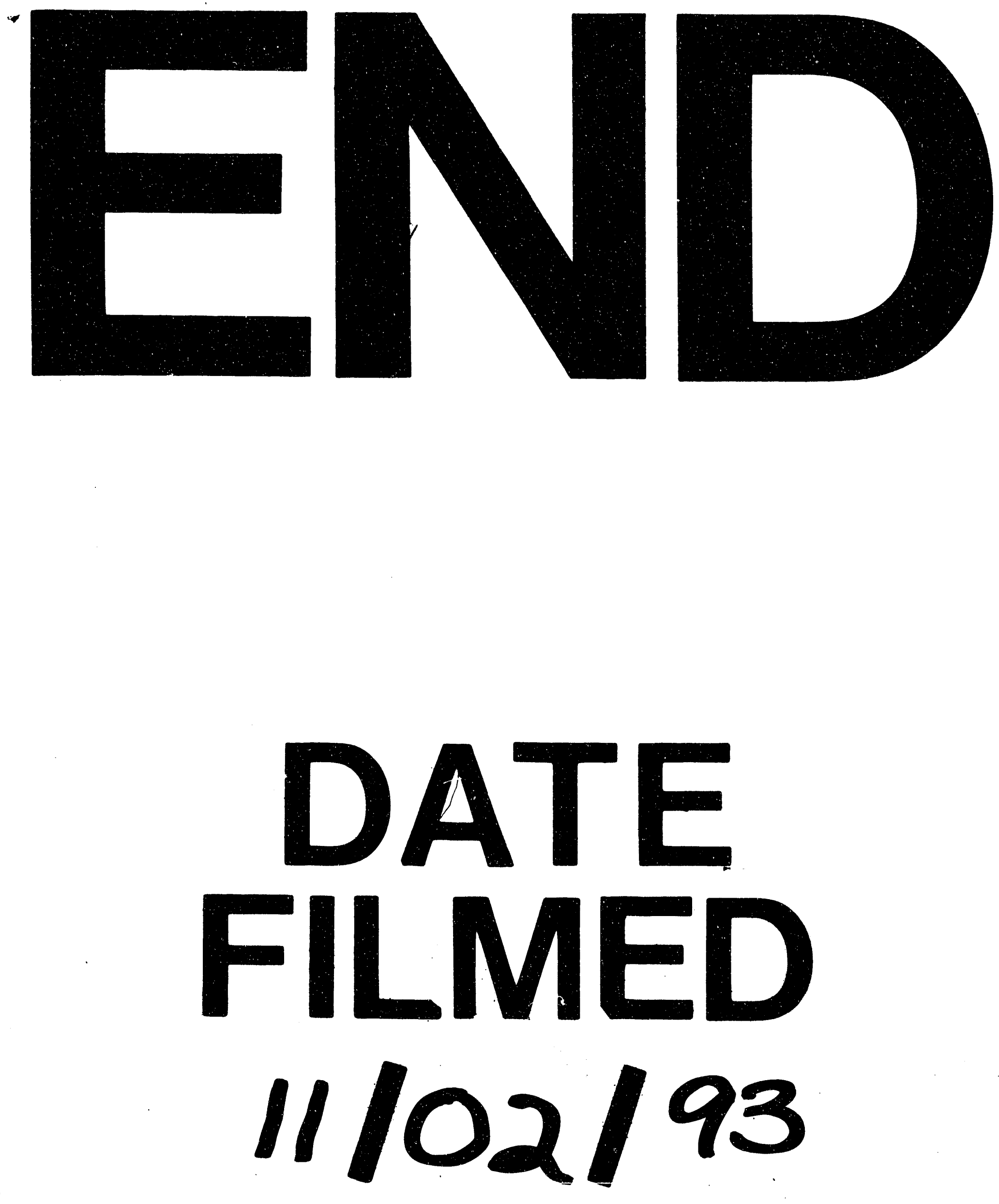
